



\section{The Economics of Dryland Management}





\title{
The Economics of Dryland Management
}

\author{
John A. Dixon East-West Center \\ David E. James Macquarie University \\ Paul B. Sherman East-West Center
}


First published in 1989 by

Earthscan Publications Ltd

3 Endsleigh Street, London WC1H ODD

Copyright (C) 1989 by United Nations Environment Programme - The Australian Government - East-West Center

All rights reserved

British Library Cataloguing in Publication Data

Dixon, John A. (John Alexander), 1946-

The economics of dryland management.

1. Arid regions. Natural resources. Management

I. Title Il. James, David E. III. Sherman, Paul B.

333. 73

ISBN 1-85383-052-6

Production by David Williams Associates 01-521 4130

Typeset by TJB Photosetting Ltd, Grantham, Lincolnshire Printed by WBC Ltd, Bristol

Earthscan Publications Limited is an editorially independent and wholly owned subsidiary of the International Institute for Environment and Development. 


\section{Contents}

Foreword $\quad$ xi

Preface $\quad$ xv

1. The Dryland Problem 1

Dimensions of the problem. 5

History and background of dryland usage; Current

conditions in the drylands; The future of the drylands

References

2. Dryland Characteristics and the Degradation:Process 15

Physical and biological characteristics

Climate; Surface water and groundwater resources;

Topography and soils; Vegetation; Animal populations

Degradation and land use

Degradation processes; Livestock production; Rainfed crop production; Irrigated agriculture; Forestry and agroforestry; Other land uses

Social and institutional factors .

Human factors; Institutional and political factors

References

3. The Role of Public Policy in Dryland Development and Management

Policies towards the drylands

Diversity of dryland problems; The case for public

assistance; General policy issues in development planning;

Formulation of policies, programmes and projects;

Economics and the policy process

Designing appropriate policies

Economic issues in designing remedial action; Determining the appropriate level of protection; Desirable characteristics of policies, programmes and projects 
vi The Economics of Dryland Management

Social, cultural and institutional factors

Human factors; Institutional factors

References

4. General Economic Principles and Techniques of Analysis

Concepts of economic welfare

Measurement of benefits and costs

Price distortions; Economic externalities; Use rights and resource management systems; The effect of time;

Breakdown of resource management systems; Renewable and non-renewable resources; Irreversible damage to resources; Risk and uncertainty

Design of an economic analysis

Techniques of economic analysis

References

5. Managing Drylands as Renewable Economic Resources

Renewable production systems in dryland areas

Sustainable production from dryland ecosystems; Products of dryland areas; Economic management objectives

Degradation: causes and corrective actions

Perspective of the land user; Externalities and open-access common property resource effects; Corrective policies and strategies

Dryland agriculture and forestry

Rainfed crop management; Dryland forestry; Appropriate farm technology; Soil and water conservation

Grazing systems

Key variables in grazing management; Handling stochastic conditions; Computer simulation modelling of dryland grazing systems

References

6. Economic Appraisal of Investments in Dryland

Programmes and Projects

Financial analysis

Social benefit-cost analysis

Project costs; Physical boundaries of analysis; Shadow prices; Dealing with inflation; Secondary impacts; 
Calculation of net social benefits; Income distribution

Decision criteria

Choosing a decision criterion

Cost-effectiveness analysis

References

7. Valuation of On-Site and Off-Site Effects

Valuation of productivity changes

On-site productivity changes; Off-site productivity

changes; Effects of production changes on prices, factor

markets and consumer's and producer's surplus

Valuation of other effects

Damage to property and materials; Human life and health;

Population dislocation; Dealing with intangibles and non-quantifiables

Cost analysis techniques

Preventive expenditures; Replacement cost;

Opportunity-cost approach; Travel-cost approach

References

8. Risk and Uncertainty in Dryland Development and Management

Handling risk and uncertainty

Sources of risk and uncertainty in dryland decision-making;

Definitions of risk and uncertainty

Risk analysis

Applications of risk analysis; A framework for risk analysis;

Interpretation of results of risk analysis

Decision-making under conditions of uncertainty

Decisions based on available information; Sensitivity analysis; Decision analysis techniques; Uncertainty associated with irreversible damage to resources

Defensive strategies to cope with risk and uncertainty

Overcoming the effects of risk; Investment in information;

Use of expert systems; Adaptive environmental assessment and management; Critical zones and safe minimum standards

References 
9. Models for Dryland Development Planning 193

General policy issues in dryland development planning $\quad 193$

Linear programming models

General properties and applications of linear programming models; Setting up a linear programming model; Finding the optimum solution; Introducing an environmental externality; Limitations of the linear programming approach

Sectoral planning models General properties of input-output models; Solving an input-output system; Simulating the effects of new production; Incorporating consumption expenditure; Data sources and construction of input-output models;

Application of multipliers to dryland development planning Natural-resource accounts Approaches to NRA

Global models

References

10.Implementation of Policies, Programmes and Projects

Presenting results to decision-makers

Characteristics of a useful economic analysis; Important elements of an economic analysis

Creation of implementation incentives

Direct government expenditure; Influencing private behaviour; Characteristics of efficient incentives

Selecting the appropriate incentives

Constraints on the use of economic incentives; A checklist of incentive characteristics

Social and cultural constraints to implementation

Policies on land tenure and use rights

Systems and incentives; Accommodation and change

Management of programmes and projects

Technical management; Financial management; Social management; Administrative management

References 
11. Case Study: Benefit-Cost Analysis of Soil Conservation in Maphutseng, Lesotho by Jan Bojö

Background

The FISC project and the Maphutseng area

The economic analysis

254

Choice of evaluation criteria; Quantification of costs;

Quantification of benefits; Valuation of costs and benefits in economic prices; Discounting; Time horizon; Results;

Distributional effects; Uncertainty and sensitivity

analysis; Summary of sensitivity analysis; Policy

implications of the economic analysis

The financial analysis

275

The farmer's viewpoint; The long-run perspective; Policy implications of the financial analysis

Acknowledgements

List of persons contacted in Lesotho

Annex: cost calculations

280

References

286

Index 



\section{Foreword}

Since its inception in 1972, and particularly since the United Nations Conference on Desertification in 1977, the United Nations Environment Programme has worked to assess the nature, extent and significance of desertification; to identify and promote effective technological, policy and organizational means of combating desertification. In addition, UNEP has worked to make available (in co-operation with concerned institutions) training, technical cooperation and information on desertification control. It has been UNEP's belief that a major factor in the failure of governments to give adequate policy attention and funds for desertification control is that the economic significance of dryland degradation, as well as of its rehabilitation, has not been clearly understood by them.

The Drylands Project began in 1985 following a major review of the UN Plan of Action to Combat Desertification (PACD), initially formulated by the UN Conference on Desertification in 1977. The 1985 review revealed that limited progress had been made in implementing the Plan. Adverse pressures of economic development had continued to outstrip the benefits of remedial actions being taken in dryland areas.

Dryland degradation and rehabilitation is a public policy area of vital significance, to which environmental assessment, economicdevelopment planning techniques and social benefit-cost analysis can be applied. By 1985, a significant body of economic analysis had been developed that could be applied, in general, to deal with environmental and natural resource problems. It was then that UNEP, the Government of Australia and the East - West Center came together to initiate the process of evolving a systematic approach to analysing dryland degradation and rehabilitation issues within the framework of economic analysis. The present volume is a product of that collaborative effort.

The Drylands Project, with its focus on the role of economics in dryland management, is seeking to develop a systematic approach 
to dealing with the challenge of improved dryland management.

To date, this work has been guided by a global conference and three regional workshops involving over 300 participants from 45 countries, and generously supported by 14 international and national agencies between March 1986 and January 1987. The resulting objectives formulated for the Drylands Project are as follows:

- to focus attention on the need for better economic assessment of dryland degradation and rehabilitation and its role in decision-making;

- to pursue the problem within the context of overall development planning; and

- to demonstrate how the techniques of economic analysis can be used to guide the design and implementation of policies, programmes, projects and land management practices to prevent, arrest or reverse the processes of dryland degradation.

The conference and workshops established a working strategy to achieve these objectives which included the preparation of the following documents:

- an Executive Report, Drylands Dilemma, aimed at senior level officials in governments, aid agencies and non-governmental organizations, to heighten their awareness of the severity of dryland degradation problems and show the role economics can play in resolving them.

- this volume, The Economics of Dryland Management, aimed at project analysts, economists, planners and programme development officers. It provides the information necessary for an understanding of the complex problems of drylands and explains how economic analysis can help resolve them.

- a second volume, Dryland Management: Economic Case Studies, designed to complement the first volume by illustrating the application of economic principles and techniques. The case studies suggest solutions to various dryland management problems throughout the world.

Drylands Dilemma was released at the Governing Council of UNEP in June 1987. 
Over 40 specialists from 12 countries have been actively involved in producing these documents. Technical leadership has been shared by Dr David James, a consultant to the Australian Government, who received a UNEP Global 500 award in 1988 for his work in environmental economics, and Dr John Dixon, a well-known environmental economist who is a Research Associate at the East West Center, Hawaii. Paul Sherman, a project fellow at the East West Center, was also involved throughout the production of these documents.

Summary proceedings of the conferences and workshops listed below were documented in a series of reports published by the Australian Government Publishing Service:

- International Conference on the Economics of Dryland Degradation and Rehabilitation, Canberra, March 1986.

- South and South-East Asian Regional Workshop on the Economics of Dryland Degradation and Rehabilitation, New Delhi, August 1986.

- Chinese Regional Workshop on the Economics of Dryland Degradation and Rehabilitation, Beijing, September 1986.

- African Regional Workshop on the Economics of Dryland Degradation and Rehabilitation, Nairobi, January 1987.

The main co-ordinating and sponsoring agencies for the Drylands Project are:

Australian Government

United Nations Environment Programme

East - West Center

Other project sponsors include:

African Development Bank

Australian International Development Assistance Bureau

Canadian International Development Agency

Commission of the European Communities

Commonwealth Secretariat

Economic and Social Commission for Asia and the Pacific

International Institute for Environment and Development

Norwegian Agency for International Development

United Kingdom Overseas Development Administration

United Nations Educational, Scientific and Cultural Organization

United States Agency for International Development 
xiv The Economics of Dryland Management

Proposals are currently under consideration for an ongoing commitment to the objectives of the Drylands Project.

Dr Don MacRae, Co-ordinator, Drylands Project, Australian Government

Dr Mostafa K Tolba, Executive Director,

United Nations Environment Programme

Dr Victor Hao Li, President,

East - West Center, Hawaii 


\section{Preface}

The problem of dryland degradation - also known as desertification - is one of the most serious resource management problems facing the world today. Occupying about one-third of the world's land surface area, and supporting a population of 850 million, the drylands are rapidly being degraded through population growth, overgrazing, cropping in marginal lands, inappropriate irrigation and deforestation. Already, the lives of more than $\mathbf{2 0 0}$ million people are at risk because of severe resource degradation, and all available evidence indicates that the problem is becoming worse.

Concerted efforts have been made by the UN, other international agencies and national governments to arrest and reverse current trends. Their efforts have largely failed.

Until now, the problem has been seen as an ecological and social one - which it undoubtedly is. The basic symptoms of dryland degradation are a reflection of imbalance in the relationship between human beings and the natural environment on which they depend. Action plans to combat the problem have emphasized the need for ecologically sustainable use of the natural resource base.

Such recommendations are correct, but they are clearly not sufficient to achieve success. The thrust of the latest attempt to address the problem is based on the belief that an economic approach will facilitate the translation of action plans into policies, programmes and projects that will win the support of national governments and funding agencies, and provide the incentive to deal more effectively with the problem.

There is a widespread view that economic development and resource conservation are conflicting goals. We strongly reject this view. Using the concepts and techniques of natural resource economics, we have tried to demonstrate that long-run, sustainable development demands the conservation and proper management of resource stocks. The natural resources of any country are an important component of that country's capital stock. Once destroyed, the replacement or rehabilitation costs may be 
prohibitive. If the capital cannot be renewed, future income and possibilities will be severely affected, with consequent human suffering.

The applications of economics presented here show how resources can be managed so that economic gains - without destruction of the resource base - can be achieved. Policymakers, planners, developers and resource managers need guidance on how to allocate scarce resources, including human skills and investment funds, in order to maximize human welfare. A major aim of this book is to demonstrate, in practical terms, how alternatives can be evaluated.

Decision-making in the dryland context takes place at various levels from that of the individual farmer or grazier to the national development planning level. Dryland degradation also has international dimensions. The economic assessment and planning techniques described in this book address all levels of application. The familiar economic principles of project and programme evaluation are discussed as are various approaches to regional, national and global decision-making. The conceptual framework and decision support systems for land management practices are also dealt with in detail. Methods of implementation, based on economic principles and policy instruments, are outlined.

As authors, our task has been largely one of synthesis. This book represents the work of numerous researchers over a period of almost three years who have contributed to the International Project on the Economics of Dryland Degradation and Rehabilitation. The foundations of the book owe much to the research programme on Natural Systems Assessment for Development undertaken by the Environment and Policy Institute at the East - West Center. In addition, without the help of many technical experts, policymakers and support staff, it would not have been possible to produce the present work. We express our deep appreciation to everyone who has assisted us and, in particular, to those who have helped us to understand - in scientific, behavioural, political and economic terms - the special characteristics of dryland resources and their management. The responsibility for any omissions, errors or misconceptions is our own.

Various experts provided material for inclusion in the book and reviewed selected chapters; these contributors include Leon Braat, Alison Gilbert, John Girt, Catrinus Jepma, Jack Knetsch, Hans Opschoor, Ray Perry, Brian Spooner, Vic Squires and Tim Yapp. These individuals will see their contributions reworked and 
integrated into this book. Special note should be made of the important contributions to Chapter 2 by Perry and Squires. Knetsch provided most of the material on land tenure and use rights in Chapter 10. Detailed reviews of earlier drafts greatly assisted us in revising and improving the book; reviews of all or major parts of the manuscript were provided by Jan Bojö, Uttam Dabholkar, Samir El-Swaify, Huib Jansen, Jack Knetsch, Jack Mabbutt, Geoff Norton and Hans Opschoor. We also owe a debt to the many resource managers, researchers and government officials who attended the series of conferences and workshops held during the course of the project. We hope that they will see some of their ideas and concerns reflected in this book.

Research assistance was provided by Jane Fowler, Sherrie Cross and Regina Gregory; word-processing by Mieke James and Mary Ruddle; editorial support by Helen Takeuchi and artwork by Laurel Lynn Indalecio. We also acknowledge computer hardware provided by Rotating Memory Group (the Netherlands) and communications facilities from Narhex Ltd, Australia.

Neil Middleton and his staff at Earthscan Publications, London, have helped greatly in the complex technical and administrative task of converting a manuscript into a book. It is a pleasure working with this group of talented professionals. Earthscan will also shortly publish the companion volume, Dryland Management: Economic Case Studies.

We are each grateful to our home institution or firm, and to the principal co-sponsors - the United Nations Environment Programme, the Australian Government, and the East - West Center. In this regard, we note the special contribution of Don MacRae of Australia and Yusuf Ahmad of the United Nations Environment Programme for initiating the Drylands Project and generating much of the interest in and financial support for it. The energy and commitment of these individuals and co-sponsors, along with the many other agencies that supported the project that are listed in the Foreword, made this book possible.

John A. Dixon, East-West Center

David E. James, Ecoservices Pty Ltd (formerly at Macquarie University, Australia)

Paul B. Sherman, East-West Center 



\section{The Dryland Problem}

Over the past two decades it has become increasingly clear that many dryland areas (those areas in which productivity is limited by available moisture) are exhibiting symptoms of widespread overuse and inappropriate management. Though these problems are not new, greater attention has been turned to the ongoing degradation of the world's drylands since the Sahelian drought of the late 1960 s and early 1970 s. Dryland degradation involves a progressive destruction of the biological and physical resources of the land which results in a reduced usefulness of these areas to humanity. In the extreme situation, land is rendered unfit for any productive use (desertification), and rehabilitation may not be feasible given economic constraints or a reasonable time horizon.

There is no universally accepted criterion to determine which lands belong to the category "drylands" or the more restrictive category of "arid lands". Past attempts to define these areas have been based on a variety of parameters such as precipitation, evaporation, precipitation - temperature relationships, soils and plant communities (Heathcote, 1983). As Gilbert White (1960) has said: "There are no clear boundaries of arid lands; there are as many lines on maps as there are measures of aridity in climate, plants, landforms and soils." In addition, climatically defined boundaries shift from year to year.

In general, the category of arid lands contains the hyper-arid, arid and semi-arid zones. The broader term "drylands" includes all these zones plus the tropical sub-humid zone, which is prone to the same degradation processes that occur on arid lands. For practical purposes in this book, "drylands" refers to this latter, broader category of lands vulnerable to the process of land degradation. Table 1.1 shows the attributes of these zones, described by UNESCO (1979). Figure 1.1 shows the distribution of dryland areas around the world.

In a recent paper, Nelson (1988 p.2) critically examined a number of the estimates made of the extent of dryland degradation or 
desertification. He found considerable confusion over definitions and cause-and-effect relationships. Nelson offers the following definition:

Desertification is a process of sustained land (soil and vegetation) degradation in arid, semi-arid and dry sub-humid areas, caused at least partly by man. It reduces productive potential to an extent which can neither be readily reversed by removing the cause nor easily reclaimed without substantial investment.

We accept this definition as a useful one for some of the more extreme forms of dryland degradation. It acknowledges the human element, the change in productivity of the land and the difficulty and costs of finding solutions.

Dryland degradation occurs in various degrees. It is the result of complex interacting factors of physical, social, economic and political origin. Among the most important are excessive land-use pressure, seasonal dryness and drought stress, periods of increasing aridity and the natural vulnerability of drylands. Though the seasonal variations and natural vulnerability have always been present, the additional burdens of increased populations and more intensive land use in recent decades, when combined with periods of increasing aridity, have resulted in an accelerating pace of degradation. (Glantz, 1977; United Nations, 1977).

Degradation of the drylands is not a recent phenomenon. The extent of the degradation, however, in terms of both area already affected and area at risk, has increased to the point where concerted action is necessary just to control the problem, let alone reverse past degradation. Given the large numbers of people dependent on drylands for their livelihood, the need for sound management and the costs of continued neglect grow ever larger.

This book is about economic analysis of management options and alternatives for dryland areas. The assessment of any option must consider the physical and social dimensions of land use, and their effects on each other. As economists, however, our primary focus is on people, how they use their land resource and the economic returns that they receive from their resource management decisions. Nevertheless, an understanding of the extent of dryland degradation, of the basic physical processes involved and of common patterns of land use is an essential element of the economic analysis. 
In the following sections, the historical background of land use and degradation in the drylands is briefly reviewed. This is followed by a summary of their current conditions and some qualitative projections of future dimensions of the problem. These subjects are only briefly discussed, to provide the reader with a context for the rest of this book, those interested in a fuller

\section{Table 1.1: Characteristics of dryland zones}

\begin{tabular}{|c|c|c|c|c|c|}
\hline Zone & $P / E T P^{1}$ & Vegetation & $\begin{array}{l}\text { Potential } \\
\text { land uses }\end{array}$ & $\begin{array}{l}\text { Annual } \\
\text { precipitation } \\
\text { range }(\mathrm{mm})\end{array}$ & $\begin{array}{c}\text { Interannua } \\
\text { rainfall } \\
\text { variability }\end{array}$ \\
\hline $\begin{array}{l}\text { Hyper- } \\
\text { arid }\end{array}$ & $<0.03$ & $\begin{array}{l}\text { Little perennial } \\
\text { vegetation except } \\
\text { some bushes in } \\
\text { river beds; annual } \\
\text { plants can grow in } \\
\text { good areas }\end{array}$ & $\begin{array}{l}\text { Agriculture } \\
\text { and grazing } \\
\text { generally } \\
\text { impossible } \\
\text { except in } \\
\text { isolated } \\
\text { cases }\end{array}$ & $<100$ & Up to $100 \%$ \\
\hline Arid & $\begin{array}{c}0.03- \\
0.20\end{array}$ & $\begin{array}{l}\text { Scattered vegeta- } \\
\text { tion may include } \\
\text { bushes and small } \\
\text { woody succulent, } \\
\text { thorny or leafless } \\
\text { shrubs }\end{array}$ & $\begin{array}{l}\text { Light } \\
\text { pastoral use } \\
\text { possible; no } \\
\text { rainfed. } \\
\text { agriculture }\end{array}$ & $-100-300$ & $50-100 \%$ \\
\hline Semi-arid & $\begin{array}{c}0.20- \\
0.50\end{array}$ & $\begin{array}{l}\text { Includes steppes, } \\
\text { some savannahs } \\
\text { and tropical scrub }\end{array}$ & $\begin{array}{l}\text { Grazing } \\
\text { areas; rain- } \\
\text { fed } \\
\text { agriculture } \\
\text { possible but } \\
\text { hazardous }\end{array}$ & $\begin{array}{l}\text { Summer rainfall } \\
\text { areas } 300-800 \text {; } \\
\text { winter rainfall } \\
\text { areas } 200-500\end{array}$ & $25-50 \%$ \\
\hline Sub-humid & $\begin{array}{c}0.50- \\
0.75\end{array}$ & $\begin{array}{l}\text { Includes tropical } \\
\text { savannahs, } \\
\text { maquis, } \\
\text { chaparral and } \\
\text { some steppes }\end{array}$ & $\begin{array}{l}\text { Suitable for } \\
\text { rainfed } \\
\text { agriculture }\end{array}$ & $500-800$ & $<25 \%$ \\
\hline
\end{tabular}

Source: adapted from UNESCO, 1977.

1 Mean annual precipitation divided by mean annual potential evapotranspiration. 
Figure 1.1: Distribution of dryland areas around the world

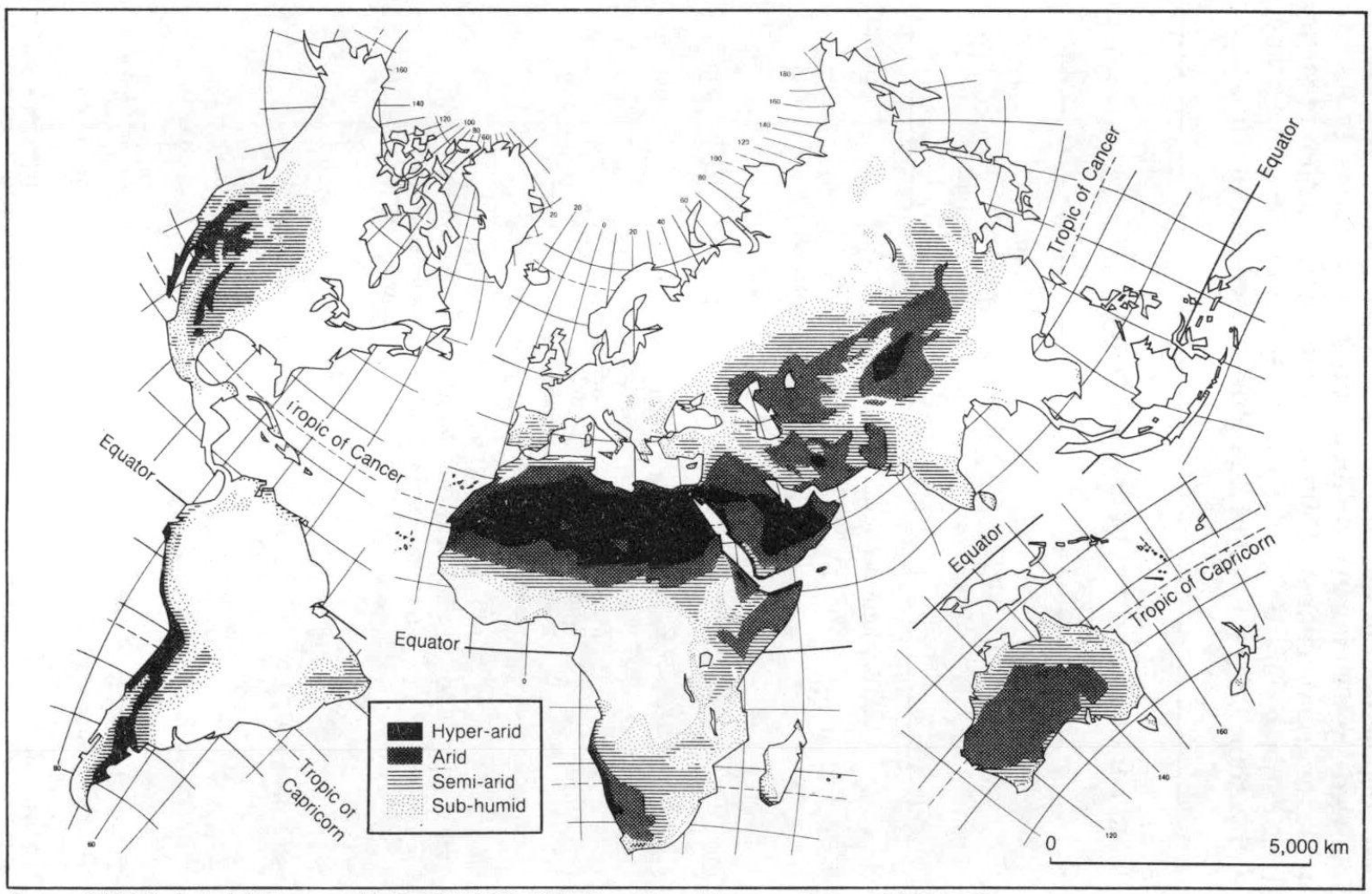

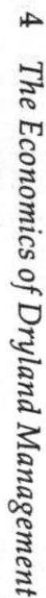

Source: MAB Technical Notes, no. 7, (C) UNESCO 1977. Reproduced by permission of UNESCO. 
account should check the sources listed at the end of this chapter. (Where possible, the statistics in this chapter refer to what we have defined as "drylands"; however, some statistics are available only for the narrower category of arid lands.)

\section{Dimensions of the problem}

History and background of dryland usage

Until the beginning of the Middle Stone Age, around 10,000 BC, the effects of human beings on the environment were very limited. The small number of humans, combined with their lack of technology, made them more the passive subjects of the environment rather than its rulers. As hunter-gatherers, people were subject to the vagaries of climate and followed the animals necessary for their existence.

The most significant early effect of people on the environment was through the use of fire. It is believed that extensive areas of both the New World and the Old World were bumed more than 10,000 years ago. Fire provided security from night predators and could also be used as a hunting aid to drive game. It was the first significant means of manipulating the environment to the advantage of people; for example, thick forest and brush were changed into more favourable grassy plains. In later periods after the domestication of animals, fires were used to burn forests and grasslands to reduce scrub and to promote new growth that was used as fodder.

During the rise of agriculture, fire was also used as a tool. In the earliest days of agriculture, broadcast fires may have been used to increase seed yields of grains and herbs. Shifting cultivation employing slash-and-burn techniques became a dominant form of agriculture in many areas.

Deforestation, either directly by fire as a deliberate means of changing the landscape or for fuel needs, was probably the earliest major cause of dryland degradation when the cleared land was not converted to another sustainable land use such as pasture. As populations and the size of settlements grew, the need for fuels also grew. Advances in technology, such as the development of pottery fired in kilns and later the smelting of metals, also increased demands for fuel. Use of timber for construction of buildings and ships was yet another factor contributing to deforestation.

With the beginning of agriculture and animal domestication about eight to ten thousand years ago, people began to be more 
active agents with respect to their environment. Though the reasons for the adoption of agriculture are still disputed, many believe that it arose out of necessity, as populations began to expand beyond the point where a hunter-gatherer's lifestyle could sustain them. Regardless of the reason why it happened, with the development of agriculture came the ability to produce and store food rather than just depending on natural supplies. A gradual increase in the importance of wild grains in the diet probably helped to fuel the transition from gathering wild grains to sowing and harvesting.

A number of references detail the history of agriculture in dry regions (see, for example, Stamp, 1961; Lawton and Wilke, 1979). The earliest means of agriculture in semi-arid areas was probably dry farming in the Near East; in this area, agriculture evolved into a pattern of shifting cultivation as yields declined. Following this was a slow shift to a cereal - fallow system on a more permanent basis which allowed the land to recuperate. Simple water harvesting and runoff systems were then developed, finally followed by increasingly complex irrigation systems.

In the early days of agriculture, it is doubtful that overcultivation resulted in serious, long-term environmental effects. As yields declined, it was usually possible to move to a new site and start again - scarcity of land was not yet a problem. However, as time passed and communities became larger, it became increasingly difficult just to move on; larger populations required more food, and localized land-quality problems began to develop.

With the advent of irrigation and the so-called "hydraulic" civilizations, dryland degradation and its effects suddenly became more important. It is believed that soil salinization was an important cause of the northward movement of the centres of political power from southern to central Iraq four thousand years ago (Jacobsen and Adams, 1958). This was the earliest of three major occurrences of salinity in Mesopotamia. These findings are based on evidence pieced together from historical records and archaeological finds. The declines in yields from salinization due to improper irrigation have not completely disappeared from this region even today. North Africa and the eastern Mediterranean region also show signs of past salinization problems.

The domestication of animals brought many advantages but also meant new environmental problems. For sedentary agriculturists, care had to be taken to provide adequate feed for domesticated animals and to prevent overgrazing, especially in the vicinity of 
watering areas. At the other end of the spectrum, pure nomads in arid areas had to be constantly moving, following the rains which provided both water and new fodder. However, the small numbers of people and livestock relative to the amount of land available made overgrazing a much less important problem than it is today. As time passed and settlements and agricultural areas grew, the ratio of animals to pasture land grew also, providing the beginnings of the serious overgrazing problems of today. The history of agriculture has been one of human - environment interactions: changing agricultural practices in response to growing human needs (Grigg, 1974).

In addition to the influence of people on the environment, changing climate also has had its effects (Bryson and Murray, 1977). Though worldwide climate has not varied significantly in geologic terms in the past ten to fifteen thousand years, even small variations have had large environmental and human impacts in certain areas. Evidence indicates that there was a period of greater humidity and rainfall in the arid zones of Africa and Western Asia about eight thousand years ago and that many plants and animals no longer present were once able to thrive in these areas. Following this period was a substantially drier period, resulting in conditions even less favourable to plant growth than current conditions. This, in turn, was followed by more favourable conditions again, beginning about $1000 \mathrm{BC}$.

In the last three thousand years, moisture and temperature conditions have been somewhat constant, subject to only minor and short-term variations. However, the size of populations and the increasing dependence on cultivated crops have caused these "minor" climatic fluctuations to have increasingly major effects on people.

\section{Current conditions in the drylands}

During the last century, and particularly the past few decades, the drylands have been subjected to increasing pressure. Increased populations and more intensive land use have combined to place unprecedented demands on dryland resources, resulting in a threat to their future productivity. Many dryland ecosystems are fragile; and once begun, the degradation process is often selfaccelerating, eventually resulting in desert-like conditions.

A major assessment of the status of arid areas was undertaken for the United Nations Conference on Desertification (UNCOD) held in Nairobi in 1977. This assessment was not a global survey, but a 
by-product of the mapping of desertification hazards around the world. Four classes of desertification were defined, ranging from slight (land with little or no deterioration of plant cover or soil) to very severe (extremely poor conditions where large sand dunes, numerous gullies or salt crusts dominate the land). It was estimated that more than 80 per cent of rangelands were at least moderately desertified. In addition, 77 per cent of rainfed cropland and 21 per cent of irrigated lands also fell into this category. In human terms, about 700 million people were estimated to have lived in arid areas, and as many as 400 million of these people were already adversely affected by degradation (Dregne, 1983).

As a follow-up to UNCOD, the United Nations Environment Programme (UNEP) sponsored an update in 1983 on the status and trends of desertification. This report was published in 1984 by UNEP. Though this update still suffered from inadequate information from many countries, it is probably the best assessment of the current dimensions of the problem.

Among the results of this 1983 assessment was a recognition that parts of the sub-humid tropics were also subject to desertification. This increased the threatened area to 4,500 million hectares, or about 35 per cent of the Earth's land surface. In addition, these lands held almost 20 per cent of the world's population - in excess of 850 million people.

The assessment indicated that 75 per cent of the productive land in the drylands was already at least moderately desertified (that is, it showed losses of up to 25 per cent of its original productivity). By land-use category, rangelands suffered most, with 80 per cent at least moderately desertified, followed by rainfed croplands with 60 per cent and irrigated lands with 30 per cent. The rural population directly affected by at least moderate desertification was estimated to be 280 million, while the addition of urban residents would increase this figure to 470 million people, about 10 per cent of the world's population (Mabbutt, 1984).

Another estimate of dryland areas is provided by El-Swaify et al. (1985). Defining the semi-arid tropics (SAT) as tropical areas where the mean monthly rainfall exceeds mean potential evapotranspiration for only two to seven months of the year, they estimate that some 1,960 million hectares in forty-eight countries on four continents are included in this category. The estimated population in the SAT areas was over 700 million in the 1970s. The SAT definition relies more on seasonality of rainfall, rather than total amount, as a defining characteristic. In both cases, agricultural production is 
limited by moisture availability.

A 1987 UN Food and Agriculture Organization (FAO) report, Improving Productivity in Dryland Areas, estimated that drylands, defined as areas with less than 119 growing days per year, covered almost 19 per cent of the land area in developing countries. The proportion of drylands varied from 25 per cent in Africa, 28 per cent in Central America and 20 per cent in South-west Asia to less than 11 per cent in East and South-east Asia. A total of over $\mathbf{3 0 0}$ million people lived in these areas in 1975, of which 38 per cent lived in very dry areas with less than 75 growing days per year (FAO, 1987; WRV IIED, 1988).

Dollar figures of the costs of degradation are few and far between. Dryland Management: Economic Case Studies (Dixon, James and Sherman, 1990) contains studies undertaken in Canada and Australia as well as a global study (Gigengack et al., 1990) which discusses the widely quoted UNEP estimate of $\$ 26$ billion a year in lost agricultural and livestock productivity due to dryland degradation. In Canada, the annual cost of degradation in the prairie region is estimated at $\$ 622$ million in 1984 . The Australian study reports on a number of research projects undertaken in Australia, showing that annual overall costs of degradation in Australia are also in the hundreds of millions of dollars. The social costs of severe land degradation are also large. Although these costs - famine, population dislocation, disease and civil unrest - initially affect the rural poor, the spill-over effects will eventually have an impact on other economic classes (WRI/IIED, 1988). Displaced dryland residents move into cities or other rural areas as "environmental refugees".

The extent of degradation varies widely around the globe. Figure 1.2 shows the degree of degradation for arid areas. In general, the problems in developing countries are much more serious than in the developed regions, both in the extent of damages to the land and in their effects on people. For example, 25 to 35 per cent of rainfed croplands in developed temperate areas showing signs of degradation fall under the severely degraded category, while the comparable figure in developing regions is 50 per cent overall and up to 65 per cent in the worst areas. Though they comprise only 15 per cent of the total dryland area, croplands contain 85 per cent of the dryland rural population. The pressures on these lands continue to grow.

In many regions, large areas of land that once supported agriculture or intensive grazing are no longer productive. To the south of the Sahara, millions of hectares of once productive land have 
Figure 1.2: Degree of desertification around the world

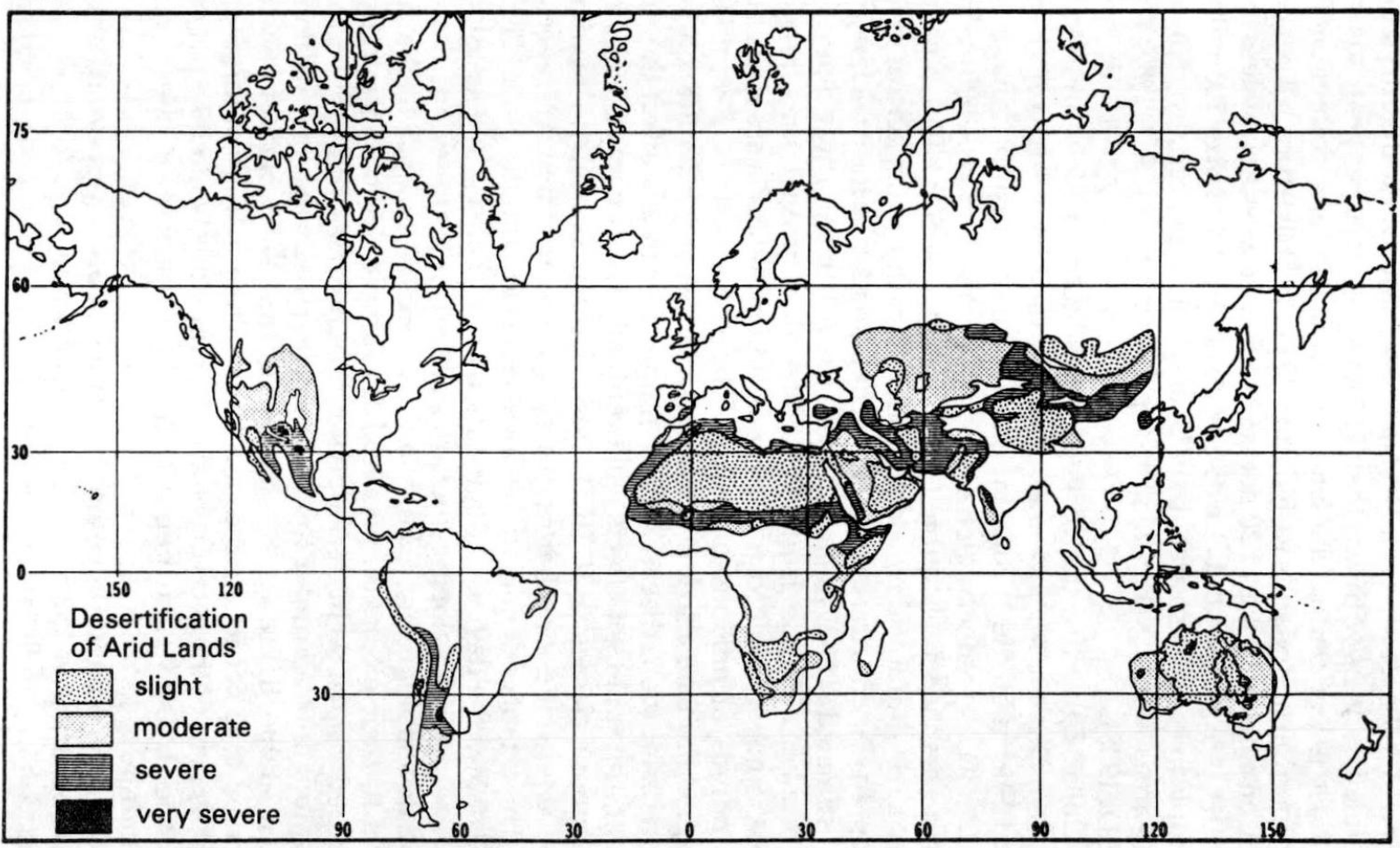


become desert in the past fifty years. Uncertainty exists as to the exact extent and pace of desertification. In the Sudan, for example, the widely quoted statement that the Sahara is advancing south at $5.5 \mathrm{~km}$ per year may not be true. Nelson (1988) discusses the available evidence that suggests a more complicated set of landdegradation and land-recovery changes dependent on rainfall. A more serious problem may be the replacement of palatable grass and perennials by less palatable species and annuals, thereby reducing both forage and fuelwood. Nevertheless, the dry spells of the last two decades have contributed to this phenomenon, exacerbating the problems of over-use and mismanagement.

The most productive desert areas - irrigated croplands - are also showing signs of damage. Each year, hundreds of thousands of hectares of irrigated croplands are lost to salinity (Kovda, 1983). Though some of these areas have been successfully irrigated for thousands of years, many schemes, both new and old, are showing signs of rapidly declining yields. Recent efforts at reclamation, however, have been at least partially successful in reducing salinity problems in some areas. Even so, competing demands for limited groundwater supplies are increasing in many areas.

Deforestation continues to be a major cause of dryland degradation in many regions. In much of Africa south of the Sahara, Latin America and South Asia, the destruction of woody vegetation for fuel and other needs far outstrips the replanting and regrowth of forests.

\section{The future of the drylands}

The 1977 UN Conference on Desertification (UNCOD) established an ambitious Plan of Action to Combat Desertification (PACD; United Nations, 1978), which was reassessed in 1983 (UNEP, 1984; Mabbutt, 1985). It was hoped at the time that the design and implementation of the PACD would halt the continuing dryland degradation and begin to reverse past damages. The recent assessment showed that, in general, the Plan of Action had been quite unsuccessful, and degradation was not just continuing but even accelerating in some areas.

The assessment found the situation worsening in developing regions. In much of Africa south of the Sahara, and in parts of Asia and South America, rangelands continue to deteriorate. Areas adjacent to the borders of semi-arid rainfed farming areas exhibit the strongest trends of increased deterioration.

In the rainfed croplands, degradation is increasing most rapidly 
in tropical areas of Africa, South Asia and South America and in subtropical Mexico. The combination of increasing populations, intensive and often inappropriate land use and inherently vulnerable land has caused a growing problem in these areas. Increasing mechanization and the extension of cropping on unsuitable land have resulted in continuing problems in Mediterranean Africa and West Asia.

The situation in irrigated lands is somewhat better. Though waterlogging, salinization and problems with water supplies continue to cause difficulties in some areas, the overall situation is somewhat static. In general, gains from reclamation and the development of new schemes are offsetting the losses in older schemes.

Overall, therefore, though the apparent trends are mostly discouraging, there are some bright spots. Major irrigation reclamation schemes have significantly reduced the salinization problems in some parts of Western and South Asia. The Soviet Union and China have introduced major efforts to prevent and reverse dryland degradation. Problems in the temperate rainfed croplands in the United States, Australia and Europe appear to be decreasing.

The future of drylands will depend on the efforts made in the next few decades (Whitehead et al, 1988). Unless preventive action is increased, we can expect significant deterioration of both rangelands and rainfed croplands, especially in the developing countries, by the year 2000 . Economic factors will clearly play a crucial role in future policies and actions. The importance of financial support has been explicitly recognized (Ahmad and Kassas, 1987). With increased attention from governments and aid agencies, it is still possible to slow and even arrest the degradation of drylands. Proper planning and development can reverse past problems and provide better opportunities for dryland residents. The main focus of this book is to help achieve these goals.

\section{References}

Ahmad, Y. J. and M. Kassas (1987),

Desertification: Financial Support for the Biosphere (London: Hodder \& Stoughton).

Bryson, R. A. and T. J. Murray (1977),

Climates of Hunger: Mankind and the World's Changing Weather (Canberra: Australian National University Press).

Dixon, J. A., D. E. James and P. B. Sherman (eds) (1990),

Dryland Management: Economic Case Studies (London: Earthscan 
Publications).

Dregne, H. E. (1983),

Desertification of Arid Lands, Vol. 3: Advances in Desert and Arid Land Technology and Development (New York: Harwood).

El-Swaify, S. A., P. Pathak, T. J. Rego and S. Singh (1985),

"Soil management for optimized productivity under rainfed conditions in the semi-arid tropics", Advances in Soil Science, vol.1, pp.1-64.

Gigengack, A. R., et al. (1990),

"Global modelling of dryland degradation", in Dixon, James and Sherman op. cit.

Glantz, M. H., (ed.) (1977),

Desertification: Environmental Degradation in and around Arid Lands (Boulder, Colo: Westview Press).

Grigg, D. B., (1974),

The Agricultural Systems of the World: An Evolutionary Approach (Cambridge: Cambridge University Press).

Heathcote, R. L., (1983),

The Arid Lands: Their Use and Abuse. (London: Longman).

Jacobson, T. and R. M. Adams (1958),

"Salt and silt in ancient Mesopotamian agriculture", Science, vol.128, no.3334, pp.1251 -8.

Kovda, V. A. (1983),

"Loss of productive land due to salinization", Ambio, vol.12 no.2, pp. $91-3$.

Lawton, H. W. and P. J. Wilke (1979),

"Ancient agricultural systems in dry regions" in A. E. Hall, G. H. Cannell and H. W. Lawton (eds), Agriculture in Semi-Arid Environments (Berlin: Springer Verlag).

Mabbutt J. A. (1984)

"A new global assessment of the status and trends of desertification", Environmental Conservation, vol.11, no.2, pp.103-13.

Mabbutt, J. A. (1985),

"Desertification of the world's rangelands", Desertification Control Bulletin, No.12, pp.1- 11 .

Nelson, R. (1988),

Dryland Management: The "Desertification Problem", Environment Department Working Paper No. 8 (Washington, DC: World Bank).

Stamp, L. D. (ed.), (1961),

A History of Land Use in Arid Regions (Paris: UNESCO).

United Nations, (1977),

Desertification: Its Causes and Consequences (Oxford: Pergamon Press).

United Nations, (1978),

United Nations Conference on Desertification-Round-Up, Plan of Action and Resolutions, (New York: United Nations).

UN Environment Programme (UNEP), (1984),

General Assessment of Progress in the Implementation of the Plan of Action 
to Combat Desertification 1978-1984, UNEP/GC.12/9, (Nairobi: UNEP). UNESCO, (1977),

MAB Technical Notes, no.7 (Paris: UNESCO).

UNESCO, (1979),

Map of the World Distribution of Arid Regions, Explanatory Note, MAB Technical Notes no.7 (Paris: UNESCO).

UN Food and Agriculture Organization (FAO), (1987),

Improving Productivity in Dryland Areas (Rome: FAO).

White, G. W., (1960),

Science and the Future of Arid Lands, (Paris: UNESCO).

Whitehead, E. E., C. F. Hutchinson, B. M. Timmerman and R. G. Vanady (eds) (1988),

Arid Lands: Today and Tomorrow (Boulder, Colo: Westview Press).

WRI/IIED (World Resources Institute/International Institute for Environment and Development) with UNEP (1988),

World Resources, 1988 - 89, (New York: Basic Books). 


\section{Dryland Characteristics and the Degradation Process}

Drylands are as diverse as the people using them. The great variability in the physical and climatic dimensions of drylands, both in location and over time, means that the information presented here is generalized and may not be true in all locations. Since the focus of this book is on economic analysis, however, this brief survey is designed to introduce the major physical and biological characteristics of drylands.

The human dimension, how people use dryland resources and how better management strategies can be developed, is the underlying starting-point of any economic analysis. Therefore, the description of major land uses in dryland areas is presented to illustrate how people interact with the land and water resources. The fragility and climatic variability of drylands increase the management challenge, and the remaining chapters discuss how these challenges are handled in economic analyses of management options.

The interrelationship of people, physical resources, institutions and policies determines how drylands are managed. If there are problems, the search for solutions must also begin with an understanding of these interactions. This chapter examines these interactions as part of the search for improved management options.

\section{Physical and biological characteristics}

\section{Climate}

One method of characterizing drylands is as areas where average rainfall is less than the potential moisture losses through evaporation and transpiration. The primary factor affecting precipitation is global atmospheric circulation, with subsiding dry air masses about the tropics and dominant westerly winds towards the poles. A secondary factor is remoteness from oceanic sources of rainfall as determined by the dimensions of the continents and by mountain barriers. 
As such, drylands can be viewed as areas where the growing season is limited by a lack of moisture. This latter classification results in a broader definition of drylands, since other site factors such as steep slopes and shallow or stony soils also result in limited moisture availability. Box 2.1 describes the factors that affect soil moisture and thus affect plant growth.

\section{Box 2.1: Soil moisture and plant growth}

Given temperature conditions suitable for plant growth, a growing season is a period when water is available to plants from moisture stored in the soil. Soil provides storage for water from which plants can extract it through their roots. The availability of water in the soil depends on the balance between water inputs and water outputs and the water-holding capacity of the soil root zone. Each of these depends on a number of factors.

Water inputs are from rainfall (or snow), not all of which enters the soil. As it falls, rain is partitioned into interception, infiltration and runoff. Interception is that part which is evaporated directly from wetted soil or vegetation surfaces. It accounts for all, or a large part of, small falls and a significant part of large falls. The amount of interception increases with temperature and with wind speed.

That part of rainfall left after interception losses is partitioned at the soil surface into infiltration and runoff. The partitioning is controlled by the nature (permeability) of the soil surface, its slope, the ability of the soil column to allow water to drain away from the surface into the soil and the intensity and duration of the rainfall. In general, coarse-textured soils absorb water at a higher rate than fine-textured soils. Some soils develop surface crusts which are only slowly permeable.

All soils have some upper limit to the rate of infiltration, and this rate decreases as the soil becomes wet, that is, with the duration of rainfall. Infiltration increases with the residence time of rain water on the surface and so is higher on flat surfaces than on sloping ones where water runs off. When rainfall intensity exceeds the infiltration rate, the excess runs off and is lost to that particular site.

Water outputs from the soil moisture store are evapotranspiration and deep drainage. Evapotranspiration includes evaporation from soil surfaces and transpiration from plants. Once the soil surface has dried, evaporation is small and is normally unimportant in comparison with transpiration. Plant leaves transpire water at a rate related to, but somewhat lower than, evaporation from a standard pan. Transpiration from a crop with leaves covering 100 per cent of the soil surface is approximately 0.8 times measured evaporation. It is lower if leaf cover is not complete, as is the case with most arid rangelands. 
Deep drainage is that part of the water which has infiltrated into the soil but which exceeds the water-holding capacity of the root zone of the soil. It drains below the root zone and is lost to plants, but can be important in other ways by contributing to groundwater supplies.

All soils have a water-holding capacity which is the maximum amount of water the soil can hold after it has been allowed to drain freely. The water-holding capacity depends on the nature of the soil materials and the depth of soil. Sandy soils have a lower water-holding capacity than clayey soils, and organic matter increases the capacity. As plants extract water from the soil, the remaining water progressively becomes more difficult to extract until a point is reached below which plants cannot extract further water. This is called the wilting point of the soil. Sandy soils have lower wilting points than clayey soils. Thus, the amount of water available to plants is the difference between water-holding capacity and wilting point. This can be as low as 2 or 3 per cent by volume for sandy soils and as high as 15 to 20 per cent for clays. Soils containing gravel or stones have a lower volume of soil material for storing water. It should be clear from this that soil properties affecting available moisture have an important bearing on length of growing season.

In symbolic form the amount of water in the soil at any time can be expressed as follows:

$W=P-I-R-D-E T$

where $W=$ amount of water in the soil (up to the maximum water-holding capacity);

$P=$ precipitation;

$I=$ interception;

$R=$ runoff;

$D=$ deep drainage;

$E T=$ evapotranspiration.

Starting from dry soil conditions, a growing season starts with inputs to the soil moisture store from rainfall minus interception, runoff and deep drainage. Plants then make daily extractions proportional to the amount of leaf area and the evaporation rate. If there is no further rain, the growing season ceases when plants have withdrawn all the available water. Further rains while the soil still holds water available to plants will add to the soil moisture store and prolong the growing season. Hence the importance recognized by farmers and graziers everywhere of follow-up rains.

The soil moisture can be considered as analogous to a bank account with an upper limit on the amount of money which it can hold. It receives deposits (from rainfall) at irregular intervals and, while the balance is greater than zero, it is subject to regular daily withdrawals (water used by plants). When the balance falls to zero the account has to be closed, and any further deposits have to start another account with the same upper limit. The period of time during which the account is above zero is equivalent to a growing season. 
Plants extract water from the soil more rapidly in summer growing seasons than in winter. The effect of this is that a given soil storage of water can be completely exhausted in a much shorter period of time in summer than under winter conditions. In winter-rainfall areas, soil water storage may last for several weeks without rain. Such a rainless period in summerrainfall areas would end a growing season, and any subsequent growing period would have to wait for another rainfall. To maintain a continuous growing season under summer-rainfall conditions requires a sequence of falls with intervals no longer than about a week between them. If any interval between falls is longer, what would have been a continuous growing season is broken into two short ones. This tendency for there to be two or more short growing seasons within a summer rainy season explains why non-irrigated cropping is not feasible under mean annual rainfalls as high as 700 or $800 \mathrm{~mm}$ in some areas.

For successful cropping, the growing season (soil water continuously available to plants) must equal or exceed a minimum length of time, for example, a period of about one hundred days or slightly more for wheat. Crops can tolerate short periods when water is not available, but yields will be reduced. Forage production by rangeland plants is less with short growing periods than with longer ones.

The main areas of arid lands extend from the western side of all continents to varying distances into the continental interiors as determined by topography; most occur between $20^{\circ}$ to $35^{\circ}$ latitude. They are areas with low rainfall, high temperatures and high evaporation potential. In hyper-arid areas rainfall is uncertain and, in any year, may fall in summer or winter, both or neither. Arid areas may have seasonal rainfall patterns, but precipitation is low, thus limiting production activities to grazing of animals. Productivity is generally low (Slatyer and Perry, 1969).

The main semi-arid areas occur on each side of the arid areas. They generally have seasonal rainfall - on the pole side in winter (Mediterranean-type climate) and on the equator side in summer (monsoonal and similar climates). Mediterranean-type climates have cool wet winters and hot dry summers; monsoonal and similar climates have hot wet summers and warm dry winters.

Another form of dryland is the cold desert which generally occurs in high-altitude continental areas. In these areas, all or most of the precipitation falls as snow. As temperatures rise in spring, the snow melts, water permeates into the soil, and the growing season begins. The commencement of the growing season is more reliable than where it depends on rainfall, but its length is determined by the amount of water permeating into the soil. In areas such as 
the steppes of Russia and prairies of Canada, cereals are grown in spring on soil water derived from winter snow.

Problems of deficient rainfall are compounded by its marked variability from year to year, which generally increases as a function of aridity. Mean interannual variability ranges from between 50 and 100 per cent in extreme arid areas to 25 per cent or less in sub-humid zones. This is associated with a skewed distribution of rainfall, in which most years will receive less than the average amount.

Accordingly, all dryland areas are subject to drought, which can be defined as a significant period in which there is not enough rain to support productive land use. In some parts of the drylands, notably in the Sudano-Sahelian region of Africa, droughts can extend over large regions and persist over runs of several years; elsewhere they tend to be more localized and of shorter duration (see Box 2.2). Nowhere at present can drought be predicted with sufficient certainty to alter land-use practices to deal with short-term conditions. Strategies only can be designed taking into account drought probabilities based on historical records. A conservative management policy provides a "buffer" against extreme climatic events. Pressing economic and social needs, however, may work against conservative management.

The nature of dryland rainfall varies widely with aridity and seasonal conditions. The less arid tropical drylands can receive heavy and general summer rains, particularly the monsoonal areas of Asia and East Africa. In drier parts, however, rainfall is localized in space as well as in time. The distribution of rainfall within the season can be as important for productivity as the amount of rainfall received.

\section{Box 2.2: Rainfall variability in four sub-Saharan zones}

Rainfall variability is a major and anticipated phenomenon in most semiarid areas. The general word for such change is variation. A climatic change is a variation that persists for at least several decades; a climatic fluctuation is said to occur when rainfall variation lasts several decades and then returns to its original value. Periodic wet and dry periods are examples of climatic fluctuations.

Although there may not be any measurable worldwide trends, Africa has recently experienced major climatic changes. These changes were initially observed along the southern edge of the Sahara (the Sahel and Sahelo-Sudanian belts). Figure 2.1 shows that, from high rainfall levels in 
20 The Economics of Dryland Management

Figure 2.1: Standard annual rainfall departures in four subSaharan zones
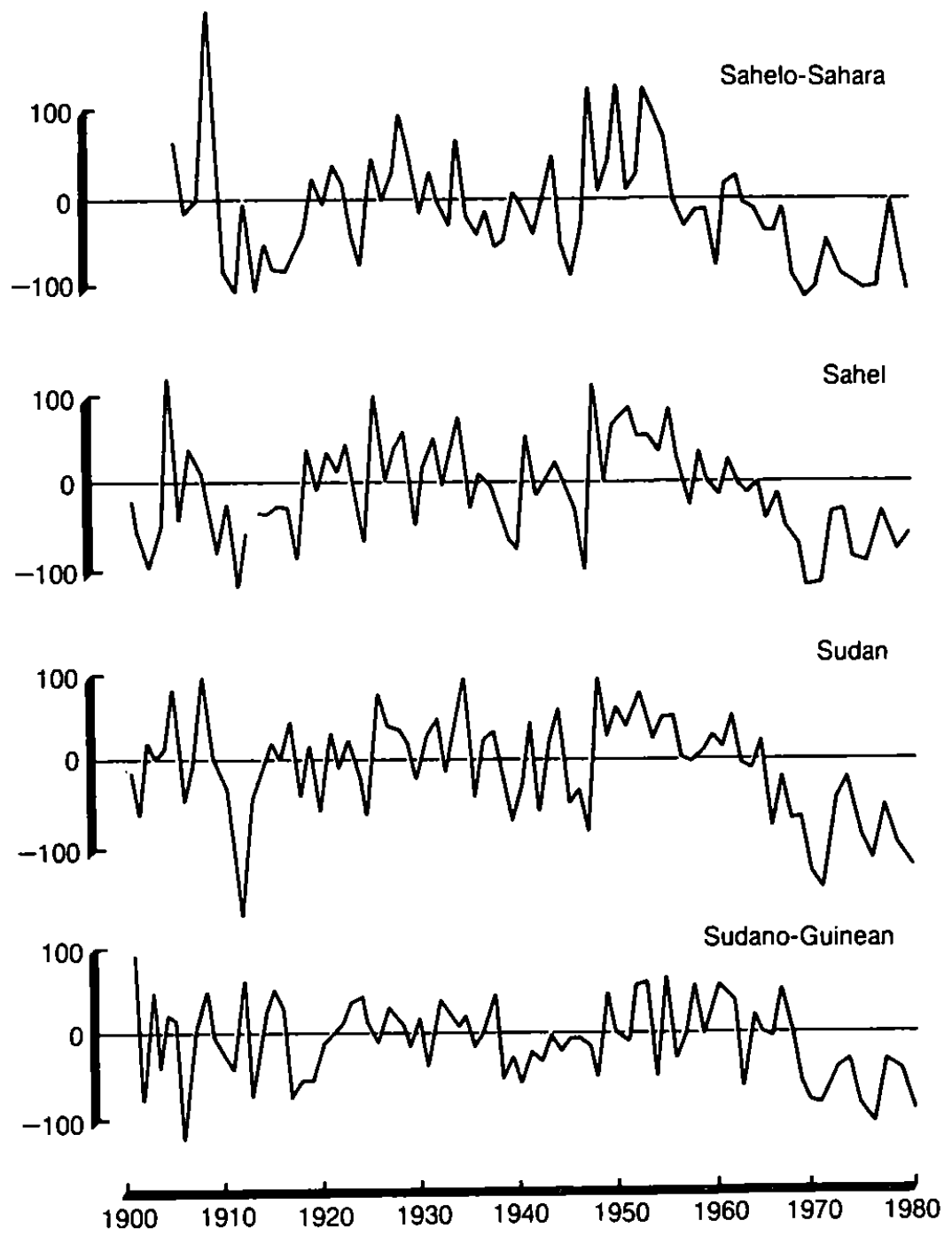

Source: after Nicholson, 1982. From Nature and Resources, vol. 20, no. 1, C UNESCO 1984. Reproduced by permission of UNESCO. 
the 1950s, rainfall has declined steadily to extreme lows in the early 1970 s. It has fluctuated since then but remains far below long-term mean values.

Whether this is a climatic change or a climatic fluctuation is not clear. Some observers believe that there are important human factors involved. First, overgrazing and other land-use practices have tended to make the surface more reflective to solar radiation. Second, in inland areas, much of rainfall occurs from re-evaporated soil moisture. If land-use patterns reduce soil storage capacity, evapotranspiration (and rainfall) may be affected.

Source: Nature and Resources, vol. XX, no.1 (Jan. - Mar. 1984), pp.2 - 8

All dryland areas are subject to occasional heavy rains. Such storms can produce devastating runoff from ground that is relatively unprotected by vegetation and can cause widespread flooding in normally dry river systems.

Cloudless skies and dry air allow intense heating of ground surfaces and lower atmosphere during the day, and rapid cooling after sunset. Most dryland climates have wide temperature ranges, stressful to plants and animals. Absolute temperatures vary with latitude and setting, but they include the highest recorded temperatures as well as low temperatures during the severe winters of Central Asia. Winter frost is commonplace. As a consequence of local heating and general treelessness, many dryland areas are characterized by strong seasonal or local winds.

\section{Surface water and groundwater resources}

Surface water is derived from runoff, which is affected by the amount, intensity and duration of rainfall, permeability of the soil and slope. In arid areas runoff is infrequent, but even here highintensity storms cause occasional flash floods in otherwise dry watercourses. Surface runoff can be channelled into dams, surface catchment tanks or cisterns and stored for future use. High rates of evaporation limit the duration of storage in surface tanks and dams, but cisterns can retain water for years. Surface water supplies may also be available from rivers originating in wetter regions or from snow or ice in mountain catchments.

Groundwater is derived from deep drainage past the root zone of the soil. In arid areas little or no deep drainage occurs over most of the landscape, and additions to groundwater are mainly from concentrations of surface water in watercourses or flooded areas. In higher-rainfall parts of the drylands, most of the landscape contributes deep drainage to groundwater. Groundwater can be used 
from natural springs (where they occur) but is normally exploited by wells, either dug or drilled.

Unconfined aquifers store water in near-surface coarse-textured materials without an upper aquitard. They are commonly alluvial materials near watercourses, colluvial materials at the foot of mountain ranges and, to a lesser extent, sandy plains. They provide important local sources of generally good-quality water at shallow depth, but supplies are generally limited.

Confined aquifers are porous rock strata between two strata of low permeability. Water in confined aquifers is generally under pressure; the pressure causes water to rise in wells tapping the aquifer. If it rises to the surface it is referred to as an artesian well, and if not it is called subartesian. The quality of water in confined aquifers depends on the chemical nature of the aquifer materials and can range from good in clean sandstones to highly saline in marine sediments. In some areas, deep confined aquifers may contain "fossil" water that receives no recharge. Use of such nonrenewable aquifers is similar to mining a mineral deposit.

Fractured rock aquifers store water in cracks or fissures in rocks which otherwise have a very low permeability. The quality of the water depends on the chemical nature of the rocks, and the yield of water depends on the size, frequency and interconnection of the fissures.

\section{Topography and soils}

Drylands range from sea level to high altitudes, from plains to steep slopes. Soils are even more diverse and include shallow to deep, sands to clays, acid to alkaline, infertile to fertile. The diversity of topography and soils is so great that it is impossible to generalize, although levels of organic matter range from only moderate in more mesic areas to very low under arid conditions.

Whatever the type of soil, it is the basic resource of the drylands. It provides the medium in which plants grow, and its properties, such as texture and moisture-holding capacity, determine the proportion of rainfall available for plant growth.

In many dryland regions surface layers are stripped away by wind and water, and the subsoil is exposed. The sub-surface layers are hard and impervious and can no longer absorb rain. Water flows over the surface carrying away soil (and nutrients) and cutting rills and gullies which become deeper and wider year by year. Land use can accelerate this process; this is discussed later. 


\section{Vegetation}

Plants provide the means by which energy from the sun is converted into the vegetable material which people and their animals depend on for food. Plants also protect the soil surface, reducing wind and water erosion. Removal of the vegetative cover results in a reduction in this protection and causes increased erosion which normally reduces future productivity.

The natural vegetation of drylands varies greatly and includes many different types of grassland, shrubland, woodland and forest. Perennial vegetation tends to be open and patchy, with significant potential for accelerated erosion. Annual productivity also varies greatly from very low in the driest situations to high in wetter locations.

Because of the low and uncertain precipitation and desiccating factors such as high temperature and constant dry winds, the vegetation is in a precarious balance with the available moisture. It is therefore particularly vulnerable to change caused by overgrazing and by cutting or burning of the vegetative cover. Once damaged, the land has a significantly lower carrying capacity for livestock and people, as well as being highly susceptible to further degradation.

Plants that live successfully in dryland regions have adapted to survive irregular rainfall, high solar radiation and periodic drought. For example, on many medium-textured soils, the main plant groups over extensive dryland regions are widely spaced, low, multiple-stemmed trees, low shrubs and sparse grasses. This structure seems to have independently evolved as an efficient mode for utilizing sparse water and for surviving erratic drought (Friedel and Squires, 1983). Any loss of a key component (such as trees) renders the system more vulnerable to stress.

Intact plant communities act to utilize the available sources of water and nutrients, with lichens, perennial grasses, and shrubs and trees each utilizing a different set of nutrients and either passing on or utilizing the detritus of others. The principal characteristics of dryland plant communities may be summarized as follows:

- Biological productivity, matching moisture supply, is highly variable over time. Only with irrigation can this characteristic be changed.

- Primary productivity (by plants) is very patchily distributed over the landscape, in response both to the spottiness of rainfall and to runoff characteristics of the land. Because of this, a very 
small proportion of the land may produce a very large proportion of the available biomass.

- Indigenous plants have evolved efficient mechanisms for resilience, both as individuals and as populations. These must not be degraded if the community is to survive.

- Recovery is much slower in dry ecosystems than in humid ones because of the generally lower species diversity of dryland communities and the rarity of seasons with sufficient moisture for recovery.

\section{Animal populations}

Dryland ecosystems support wildlife (both carnivores and herbivores) as well as domestic livestock. Animals in dryland ecosystems have to cope either physiologically, behaviourally or communally with the following environmental characteristics:

- low overall possibilities of production;

- temporarily very favourable conditions but with low predictability; and

- highly irregular spatial distribution of productive possibilities.

Like plants, herbivores and carnivores in dryland ecosystems evolve to fill certain niches. Among the herbivores, for example, some are grazers, some browsers, and many are even more specific in their diet. In this way they, as a community, can achieve a dynamic equilibrium with the vegetation (Coppock, Ellis and Swift, 1986).

One very characteristic adaptation of animals in dryland ecosystems is mobility. Among the grazing ungulates migration can be over hundreds of kilometres, making use of seasonal or more erratic patterns of rainfall and the complementary opportunities offered by different habitats.

\section{Degradation and land use}

The basic causes of dryland degradation are over-use or inappropriate use of land resources by people. Five types of action are particularly important in causing the degradation of drylands:

- overcultivation of the soil;

- cultivation of inappropriate lands; 
- overgrazing;

- deforestation; and

- inappropriate irrigation practices.

Land degradation is often blamed on droughts, an opinion lent some credence by signs of degradation that may first become obvious in conjunction with a drought. This occurs because land resources under stress from inappropriate use or over-use often suddenly collapse with the additional stress of a drought. In other cases, a rangeland may have an appropriate number of animals given normal rainfall. In periods of drought, however, the carrying capacity of the land falls markedly. Pasture deterioration (including that directly due to drought together with the grazing/trampling impact) will result, but may be short-lived or localized, depending on circumstances. Nevertheless, traditional grazing and cropping systems can coexist with an environment that experiences periodic drought.

Lower than normal (or previously normal) production is a common result of both land degradation and drought; and thus, from the viewpoint of resulting lower yields, the two are easily confused. In causing lower yields, land degradation has similar effects to a greatly increased frequency of drought, which leads to the suggestion, or even the belief, that climatic changes are the cause of land degradation. The real situation is that land degradation, in causing lower yields, has a similar effect to lower rainfall.

Although opinions of the experts (Hare, 1977; Grainger, 1985) on the effect of long-term climate change vary, an element of the degradation process in the world's dryland regions may be related to natural causes. Long-term changes in rainfall amount and distribution have important impacts on dryland productivity and rates of land degradation (Biswas, 1986; Farmer, 1986).

In the preface to his book Desertification of Arid Lands, Dregne (1983, p.ix) writes:

Desertification is a term that became widely known following the environmental destruction and human suffering caused by the 1969 - 1973 drought in sub-Saharan Sahel. Curiously enough, in view of the drought-inspired motivation for the 1977 United Nations Conference on Desertification, the consultants who prepared the background documents concluded that drought was not the cause of desertification, only a contributor to it; rather, unwise human activity was the culprit. 
Correctly identifying the causal agent is important in tackling the problem. If natural phenomena can be blamed, then decisionmakers can take a head-in-the-sand approach and do nothing. However, if people are in part the cause, then we should be able to prevent or reverse some forms of land degradation. We can also learn to respond to climate-induced dryland problems. Obviously people and drought are interactive elements in the degradation process.

Although not denying the important role that adverse rainfall trends can have in leading to environmental deterioration and to social and economic insecurity, we take the view that the essential dynamic trigger in dryland degradation is the pressure from the use of drylands by people. Thus, after a brief description of the degradation process, we examine the major land uses in dryland areas and how they set the degradation process in motion. Following this, the factors that determine the type and intensity of land use are discussed.

\section{Degradation processes}

Drylands are ecosystems in which, under normal conditions, the various processes interact together in a fluctuating, though more or less stable, state (sometimes called dynamic equilibrium) within a specific range of environmental conditions. People can manage or modify these ecosystems, within limits, to obtain a yield of products (water, food, fibre, fuel) without the system breaking down. If the limits are exceeded (inappropriate use, over-use or poor timing), the system becomes unstable (that is, land degradation begins).

From each ecosystem people may safely harvest a "maximum sustained yield" of products without stressing it to the point of instability and degradation. In the case of rangelands, different systems vary greatly in their ability to withstand pressure or stress. If the limits are very narrow, the maximum sustained yield will be very low or zero, and the systems are said to be fragile. Systems able to withstand heavy use (high maximum sustained yield) are said to be robust; those that rapidly recover from heavy use are called resilient.

All the components and processes of ecosystems are important, but two major components, soils and vegetation, and the processes concerned in partitioning incoming precipitation at the soil surface, are particularly significant to dryland degradation. Soils provide structural support for plants and store water and nutrients 
on which plants depend. Vegetation acts to protect the soil surface from the onslaughts of the elements. Vegetative cover greatly reduces the impact of wind and water at the soil surface and thus protects the soil from erosion. Removal of vegetation allows the full force of wind and rain to ravage and move the soil surface. Land management that destroys or significantly reduces vegetative cover is by far the most important cause of dryland degradation.

The division of rainfall into intercepted water, infiltrated water and surface runoff is important because relatively small changes have a considerable effect on the amount of water available for plant growth and on the erosive power of runoff. Reduced infiltration means less soil water for plant growth and more runoff (and erosion). The resulting poorer plant growth and soil disturbance make for even less infiltration and even more runoff, beginning a self-stimulating series which, unless checked in the early stages, can soon become too difficult and too expensive to reverse.

Inappropriate use or over-use of dryland resources not only causes degradation of resources at the site of misuse (on-site) but may. have more serious effects elsewhere (off-site). It is common throughout the world for misuse and degradation of resources in sparsely populated upper parts of catchments to be the cause of great suffering and economic losses in heavily populated and intensely developed lower parts of catchments.

On-site results of degradation can include lower soil fertility and productivity; accelerated soil erosion; reduction, loss or change of vegetation; reduced quantity and quality of water resources; and, in irrigated areas, waterlogging and salinization of soils. Off-site effects such as dust storms, sedimentation of rivers, lakes and dams, increased frequency and severity of flooding and increased salinity and turbidity of downstream water resources can affect areas and populations thousands of kilometres away and be very important in terms of human suffering and economic costs.

\section{Livestock production}

In areas where growing seasons are too short for cropping and no irrigation exists, livestock grazing is the main form of land use. Livestock production is not limited to these areas but is also important in areas suitable for cropping (Perry, 1978).

Livestock production varies greatly in type of animal (sheep, goats, cattle, camels), product (meat, fibre, milk, blood, skins), land tenure (nomadic, transhumant, village-based, individual 
property), stocking intensity and organizational structure (subsistence to market-oriented).

At the poorer end of the scale is the nomadic (or more usually transhumant) subsistence activity, with the human population living directly on milk, occasionally meat and in dry times blood, from mixed flocks and herds of animals. Each family unit requires a minimum number of animals, and so animal and human populations are linked. The number of animals per person is low, production per animal is low, and therefore production per person is very low. Infrastructure and market organization are usually poor, and livestock owners have no control over them. Drought causes famine and deaths among both animals and people, unless outside intervention occurs. Land or grazing rights are communally owned, but this ownership may not be respected beyond the community.

Nomadic graziers make the best use of the marginal arid lands where rains may or may not come, and where the vegetation is sparsely distributed and low in edible biomass. Herders have found many ways of coping with the climatic stress that typifies their arid landscapes. Ordinarily, they spread their stock thinly over large areas so that grazing pressure is lightened, and they can take advantage of the mosaic of ecosystems which are characteristic of drylands where topographic variety yields good forage only here and there. They are mobile, often travelling great distances to reach seasonal pastures. Keeping a diverse herd of animals is an important way of insuring against drought. Sheep and goats continue to lactate during dry periods and have high reproduction rates, while goats and camels will survive drought better than sheep and cattle.

Farmers and nomadic graziers in rainfed cropping areas have long had a symbiotic relationship. Meat and milk are exchanged for grains and legumes. Fallow lands are grazed by nomadic herds in exchange for the fertilizing value of the dung. In some cases nomads may take the villagers' animals off to seasonal pastures.

Farmers in the semi-arid areas will usually keep some livestock, grazing them on cereal fallow or on communal village grazing lands. The limited areas of such pastures within reach of villages mean that they are usually used quite intensively and suffer a considerable amount of degradation. As villages expand, agriculture expands into marginal lands previously used for grazing by livestock.

At the other extreme are large, market-oriented ranching 
operations generally grazing one type of animal on individually or company-owned land. Large ranches are the more typical kind of pastoral system in the dry areas of developed nations like the United States, Canada and Australia. '(See Squires, 1981, for a detailed account of livestock management in Australia.) Ranching also has developed in some regions in response to demand for meat in the lucrative markets in Nigeria, the lvory Coast, Libya and Saudi Arabia. Livestock on ranches are generally selected or bred for high production.

With fences and mechanization replacing human labour, the number of animals per unit of labour is high, so that animal production per person is very high. Markets and infrastructure are highly developed.

Land degradation due to overgrazing is widespread on grazing lands in both developed and developing countries around the world. It occurs when the livestock population per unit area of the ecosystem exceeds the safe stocking rate at that time. In developing countries it is usually associated with increased human and livestock populations or decreasing areas of pasture. In developed countries, land degradation is usually climate-induced. In both cases, a period of low rainfall reduces the carrying capacity; and if the number of livestock is not reduced quickly, land degradation can result.

In the early stages of stress, the more palatable plant species, annual or perennial, are reduced or eliminated and are replaced by less palatable species or invaders from other ecosystems. Because they bear most of the grazing pressure in low rainfall years, palatable perennial grasses tend to be replaced by annual grasses. Initially, in good rainfall years, these annuals may produce more forage than the original ecosystem, but in poor rainfall years they produce little or nothing.

The original situation where forage production fluctuated with good and bad years has changed to a feast or famine situation. In low rainfall years (and in the initial period of the following normal or high rainfall year), the soil surface, once protected by perennial grasses, is exposed to wind and water erosion. The process of degradation continues with less plant growth, increasing grazing pressure (unless animal populations are greatly decreased) and increasing erosion (as a result of decreased plant cover) until the surface is reduced to gullies, bare rock or sand dunes.

In many areas on the wetter margins of arid rangelands, unpalatable woody shrubs and small trees, originally suppressed by 
competitive perennial grasses and attendant periodic grass fires, increase as the more palatable plants are reduced. Once established and overtopping the ground vegetation, they become highly competitive and further reduce ground-storey cover and yield. They may protect the soil surface from wind erosion but are not very effective against water erosion and have little value for grazing.

Concentrations of livestock near watering points, supplementary feeding places and camp sites, for example, destroy ground vegetation cover and cause further soil degradation by severe trampling.

In arid grazing lands of developing countries, excessive cutting of woody shrubs or low trees mainly for fuel is another cause of land degradation. With increasing human populations, large areas have been virtually denuded of even the smallest woody shrubs. Wood is also used for livestock pens and construction, but by far the largest use is for fuel.

\section{Rainfed crop production}

Where the growing season is long enough, the drylands can be used for growing short-season crops. The vast majority of dryland area has only one rainy season; therefore, only one crop per year can be grown on the same piece of land. Small areas have two rainy seasons, each producing a growing season long enough for crops.

The drylands are responsible for much of the world's production of cereals (wheat, barley, sorghum, millet) and pulses (chickpeas, lentils, peas, groundnuts). Less important are oil crops (rape, linseed, groundnuts) and a wide range of fruits, vegetables, herbs and spices. The drylands are not limited to annual crops; perennials, which have a short growing season and are dormant for the remainder of the year, can also be grown. Prominent among such plants are vines (for fruit, dried fruit and wine), olives, fruit trees (peaches, plums, apricots, figs) and nut trees (almonds, pistachios). Many of these dryland crops are also grown in wetter environments.

Traditional systems of rainfed cropping have evolved over thousands of years to make the best use of whatever rain does fall. The basic elements of such systems involve five stabilizing characteristics:

- Rainfed agriculture has, until recently, taken place in areas where rain was most likely to fall in reasonable quantity and where 
soil depth was greatest. Drier regions were reserved for livestock grazing, which involved regular seasonal movements (transhumance).

- Flexibility was a key factor. Several different crops were sown to reduce the risk of complete crop failure.

- Drought-resistant food crops were emphasized to provide the basic source of food.

- Long fallows were used to prevent stress on the land. During the long fallow the soil would be protected by vegetative cover, vital nutrients would accumulate in the topsoil, and organic matter content would build up.

- The pastoralists and sedentary farmers co-operated by bartering cereals and meat. In Africa and South West Asia the pastoralists were able to graze their livestock on village fallow lands in the dry season.

As with livestock production, dryland crop production varies greatly from small subsistence peasant operations to large-scale market-oriented operations.

Subsistence peasant operations are labour intensive on small plots, often growing a mixture of crops including cereals, pulses, fruits, vegetables and spices. They have little capital or mechanization and use little fertilizer (except animal and human wastes) and few or no pesticides and herbicides. The educational level of the operators is low; they have limited access to technical advice and improved varieties, and have a low productivity per unit of area and per unit of labour. Post-harvest treatment and storage are poor, and considerable losses of the product are caused by fungi, insects and rodents. Infrastructure and market organization are poor. Subsistence farmers are little affected by local or international commodity markets, but are severely affected by droughts that cause famine and death.

In recent years, traditional rainfed cropping systems have been breaking down not only in Africa and India but elsewhere. Population growth and competition for land have resulted in the expansion of subsistence cropping into marginal lands at the expense of traditional livestock areas. The cultivation of these less productive and more drought-prone lands, together with diminishing returns from lands under shorter fallows, has resulted in a decrease in average crop yields per hectare. Overcultivation of marginal lands and the consequent crowding of increasing numbers of livestock into 
smaller areas of pasture have caused both crop and livestock productivity to fall and soil erosion to increase. In other areas, cash cropping has expanded at the expense of subsistence food crops, leading to low food availability during droughts as well as periodic overproduction and low prices.

At the other end of the spectrum are large, capital-intensive, highly mechanized operations, growing a limited range of crops for national or international markets. The operators are well educated and are able to take advantage of modern technology including superior varieties, fertilizers, herbicides, pesticides and modern harvesting and post-harvest storage techniques. Productivity per unit of area is moderate, but productivity per unit of labour is high, and storage losses are low. Droughts cause lower or negative financial returns, but well-managed operations would be planned to be profitable in the long term with a probability of crop failure of one in ten years or thereabouts. Commodity price variations are also a source of financial risk.

Cash cropping is on the increase in many developing countries. These crops, such as groundnuts and cotton, replaced traditional rainfed food crops or, in some instances, have been planted on new lands developed for the purpose. Development involves land clearing and levelling and irrigation. Cash crops which are principally grown for export are more demanding but more profitable.

The expansion of groundnut cropping in Africa has caused a large reduction in the amount of fallow land in the agricultural zone. Many of these fallows were traditionally used by nomads as dry-season grazing. However, evidence is now mounting that cash cropping in the Sahel, for example, is on the decline, because of peasants' concern with maintaining production of their subsistence food crops (Grainger, 1985).

Cropping results in land degradation mainly because of inappropriate use of arable land and use of inappropriate land. Inappropriate use of arable land includes excessive cultivation, cropping too frequently, inadequate fertilization or baring the soil through grazing or removal of crop residues. Excessive cultivation breaks down soil structure, may compact the soil below the plough layer and, with some soils, causes crusting or setting of the soil surface, thus reducing soil moisture and increasing runoff and erosion. Cropping too frequently has similar effects, but also depletes soil nutrients, resulting in poor plant cover and poor yields, especially if little or no fertilizer is used. Grazing or removing plant residues and stubbles leaves the soil surface exposed to wind and 
water erosion. In the absence of plant cover, runoff is higher and soil moisture lower, resulting in less plant growth and more soil erosion.

Cropping may also cause land degradation where inappropriate land is used. Where cropping is extended to areas that are too dry for it, frequent crop failures occur, leaving the soil surface exposed to erosion for long periods. A similar effect results from cultivating shallow soils, since the soil moisture-storage capacity is too low to maintain water available to plants for a long enough growing season. This also results in frequent crop failures. Clearing and cultivation of steeply sloping land also lead to severe soil erosion.

\section{Irrigated agriculture}

Where adequate supplies of suitable-quality groundwater or surface water are available and appropriate soils and terrain exist, crops and forage plants can be irrigated, reducing or eliminating the direct dependence on rainfall. This allows rainfed growing seasons to be extended, crops to be grown during dry seasons and year-long production of long-season crops or two or three shortseason crops on the same area. Irrigation can greatly increase production and reduce the effects of drought. It does not necessarily eliminate the threat of drought, however, because supplies of water from surface storage are also dependent on rainfall. Irrigation can also, in theory, help to stem the vicious cycle of land degradation, in which the area of (often marginal) land under cultivation is constantly increased to compensate for falling yields caused by poor farming practices (Worthington, 1977).

If not properly designed and maintained, however, irrigation schemes may have a relatively short life span. Many productive irrigation areas have failed, and many of those existing today are losing part of their productive land each year. Only with careful management can their life be prolonged.

In irrigated areas, sedimentation, poor-quality irrigation water, waterlogging and salinization are common concerns. Sedimentation occurs where irrigation water has a high sediment load derived from degradation and erosion of the upper parts of catchments. The sediment is deposited in dams and irrigation channels which can become completely filled or choked by silt. Sedimentation of irrigated areas is an off-site effect of poor land management and degradation of the upper parts of catchments and can be controlled by reducing erosion in those areas or by building expensive sediment-trapping structures. 
Use of poor-quality irrigation water causes salts to accumulate in the soil, resulting in salinization. Although this problem can be reduced by using excess water to leach the salts below the root zone, it may have adverse off-site effects via salt runoff into groundwater or surface waters.

Waterlogging develops where the water table rises due to excessive application of water. Where the rising water table also brings salts to the surface, as is commonly the case, the land also becomes salinized. The deleterious effects of using poor-quality water or of rising water tables can only be controlled by the installation of adequate drainage systems, an expensive but necessary adjunct of almost all irrigation areas. However, disposal of the drainage water may have undesirable off-site effects further downstream.

Where the source of water for irrigation is groundwater, excessive extraction will lower the water table, thus increasing costs of pumping, possibly to uneconomic levels. With some aquifers where good-quality water floats on salt water (generally unconfined aquifers on islands, near rivers and in coastal areas), extraction needs to be managed to prevent saltwater intrusion.

\section{Forestry and agroforestry}

Forestry and agroforestry are forms of agriculture in which the product is wood for various uses. The main difference is that the crop may take many years before it is harvested, particularly in areas where growing seasons are short and the trees are dormant for much of the year.

Three types of technique are common:

- agroforestry, in which forestry is blended with agriculture - tree crops are planted in such a way that crop and/or livestock production is enhanced rather than displaced;

- local or community forestry (also called social or mass forestry), which mobilizes large numbers of people to plant and protect trees, either on village-controlled or on private lands, with the aim of producing wood or other products mainly for village rather than industrial uses - foresters educate, supervise and assist rather than carry out such schemes themselves; and

- plantation forestry, where trees are grown commercially on large plantations, usually under the direction of foresters.

Agroforestry approaches tree planting with an understanding of 
the farmer's point of view, so it is also a form of social forestry. Social forestry and agroforestry often overlap. But while agroforestry is a set of techniques primarily for growing trees together with other crops and livestock, social forestry's primary objective is to get ordinary people to participate in tree planting and tree care in ways that will improve their lives. At the very heart of most dryland agroforestry schemes are the multi-purpose trees like Acacia, Leucaena and Prosopis. They can be grown quickly on poor soils to yield food, fodder, fuelwood, building timber and other products. In addition, they increase soil fertility and provide shade for livestock.

Shelterbelts and windbreaks are another popular form of afforestation, protecting soil, crops and livestock from hot desiccating winds such as those common in India, China and parts of Africa.

Tree crop plantations are not uncommon in some dryland regions. These may be for specific products like gum arabic or for fuelwood. For many years, foresters regarded plantations as places from which local people must be excluded. Their attitude is changing as mass afforestation campaigns (carried out largely by ordinary people) have become commonplace, especially in China and India. For most countries, village-based schemes may prove to be most successful and the only practical option.

Forestry and agroforestry occupy only a small proportion of the area of drylands but are particularly important for supplying fuel for heating and cooking in developing countries. This reduces indiscriminate cutting of trees and shrubs from places where they are needed to protect against soil erosion. Fuelwood crops commonly can be grown in areas unsuitable for other agricultural purposes (for example, waterlogged or saline areas, sand dunes, steep slopes and stony areas). They may serve a double purpose of stabilizing sand dunes or steep slopes, thus protecting productive agricultural land from sand encroachment or sedimentation.

\section{Other land uses}

Mining, tourism, communications and urban settlements occupy only a very small part of dryland areas but are important because they are highly intensive and financially valuable uses of land.

Mining is a temporary use of land (mines are abandoned when the ore has been extracted) but has the effect of completely changing the land. Deep mines use very little area, the main requirement being space for dumping waste rock and tailings on the surface. Open-cut or surface mining uses larger areas and can result in 
complete destruction of the productive capacity of the land for other purposes. However, it is possible to rehabilitate mined land so that it can be used for other purposes in the future.

Mining exploration, particularly seismic operations used for oil and gas exploration, normally affects much more land than the mines or wells themselves. Similarly, the infrastructure associated with mining (roads, railways, power lines and pipelines) occupies more land than the mines and processing works, though it may provide benefits to agricultural communities which they also serve.

Tourism has many forms. Different tourists are attracted to wilderness areas, national parks, game reserves, heritage areas, ancient ruins and modern constructions to watch or participate in sports and other activities. Development of tourism may provide an important source of local and national income.

Viewing wildlife in its natural setting has become an important tourist activity in some areas. Concentrations of people, however, can be as destructive of land resources as concentrations of livestock and need to be managed (Liddle, 1975). Often, game parks or wildlife reserves must be established, since maintaining wildlife herds is often incompatible with other forms of land use. Elephants damage trees, many wild herbivores harbour diseases, and birds damage crops. The problems wild animals can present, or are believed to present, to pastoralists and/or agriculturists mean there is usually a demand that they be confined to reserves. This is also necessary to protect game from indiscriminate hunting. At the same time, wildlife reserves usually take high-quality land away from farmers and herders, and so may not be popular with local inhabitants.

The growth of settlements in dryland regions is important and has positive as well as negative implications. The provision of services, communications, health, education and welfare is an obvious benefit. Often the level of these will be greater if the settlement services mining, tourism or regional bureaucracy. Settlements pose threats to the environment because of pollution, waste disposal and increased demand for water and fuelwood. In some regions the recreational demands on fragile drylands are too great. More affluent settlements (such as mining towns) may put pressure on the surrounding drylands via off-road vehicle use.

Transport and communications (roads, railways, pipelines, power lines, telegraph lines) use more land than most people would think but are important for any community. Apart from the land they actually occupy, they can, in difficult terrain, cause 
considerable off-site effects through erosion and diversion of water flows.

\section{Social and institutional factors}

People use resources to meet their needs for food, income or enjoyment; they rarely consciously degrade resources. If land or resource degradation occurs, the causes are usually complex and the answers frequently are not easy. A severe climatic event can lead to rapid degradation of a resource and may be very difficult to combat at short notice. Much more common, however, is the complex interaction of physical resources, population pressures and institutions that may result in sustainable resource use or, when one or more of the factors is in imbalance, may result in degradation of the resource.

Human and institutional factors, therefore, are key elements in understanding the sources of problems and designing appropriate responses.

\section{Human factors}

The specific human factors causing or affecting dryland degradation vary greatly from country to country, but they all have the common underlying feature of people attempting to get a greater yield from the land systems than these systems can bear without being degraded (Spooner and Mann, 1982). In developing countries, the main driving force is the need to support greatly increased rural populations; in the developed countries, it is the desire for higher profits:

In many countries in Asia and Africa, traditional subsistence grazing systems have been used for thousand of years, more or less in equilibrium with the environment. Human and livestock populations were controlled at low levels by deaths due to droughts, disease and tribal warfare. In the past fifty to one hundred years, the introduction of improved medical and veterinary services, the use of newer technologies to obtain or store water and famine relief during droughts have reduced deaths, and populations have grown. In many areas human and livestock populations have increased three or fourfold in the past fifty years to levels well above the capacity of the rangeland resources to support them, particularly in times of climatic stress. In such cases, it will be difficult or impossible for the traditional use of these resources to be developed to support the greatly increased populations - the only viable solutions 
involve finding other ways to support the excess population.

In the market economies of the developed countries, livestock populations on ranches are determined more by financial factors and the common belief that, within limits, more stock will produce more profit. Ranchers may stock heavily because of their need to pay interest and principal on loans, their desire to accumulate profits rapidly, or in expectation of continued favourable rainfall.

As rural populations grow, farmers are forced to cultivate less suitable lands. As a result, the plight of the traditional grazing communities of many developing countries has been exacerbated by the encroachment of dryland cropping into the wetter margins of the rangelands. In addition to reducing the area that the increased human and livestock populations of the rangelands can use, it removes the previously most productive part of the rangelands.

The greatly increased, and still increasing, population of most developing countries is the main cause of extending dryland cropping into unsuitable areas such as those with shallow or infertile soils, steep slopes or the wetter margins of rangelands. The consequences are disastrous, not only on-site but also off-site. On such lands yields are low and variable, and the soils are exposed to accelerated erosion leading to even lower yields and even more erosion. The products of erosion - wind-blown dust and sand and waterborne sediments - cause off-site losses over considerable distances. Cropping of the higher-rainfall parts of rangelands increases grazing pressure on the already overstocked remainder of the rangelands, as described earlier.

Most decisions on land use that lead to degradation are made because of short-term needs. For example, the immediate problem subsistence graziers face is a decreasing share of the rangeland because of increased population. To ensure survival of their families, they must overstock the rangeland in order to maintain the number of animals needed to provide for their families . Similarly, fuelwood collection for both rural and urban areas has led to rapid loss of forest cover in many locations, particularly near urban centres.

Whatever the main cause of degradation, ignorance and optimism are commonly involved. People involved in land-use decisions that lead to resource degradation may be ignorant of the inevitable long-term results of their decisions. Individuals do not consciously set out to destroy the resources on which they depend; normally they are simply unaware that the decisions they are 
making will overtax the resources and ultimately lead to degradation, especially for resources subject to highly variable rainfall. They are optimistic that the rangelands can support high livestock populations, that marginal lands are suitable for cultivation and cropping, that extreme climatic events will not happen and that degraded land will somehow repair itself.

\section{Institutional and political factors}

Land tenure. Land tenure systems vary greatly between and within countries with drylands and include individual ownership of specific areas, various forms of leasehold, collective farms and communal ownership. In some countries (for example, the United States), the operations of individual ranchers may include both privately owned lands and leased federal lands. In some parts of Africa and Asia, individual farmers may have the cropping rights to specific areas of land; but once the crop is harvested, the grazing rights may belong to traditional pastoralists. Generally in the Americas, Australia and most of Europe, grazing lands are controlled by individuals (or companies) who own or lease specific areas, whereas in much of Africa and Asia grazing lands are communally owned and managed under traditional grazing systems or, in the centrally planned economies, in collective farms.

Arguments abound as to the advantages and disadvantages of various forms of land tenure in relation to land degradation, and these arguments can be supported by selected examples. However, one fact that cannot be disputed is that grazing lands have been degraded under all forms of tenure, and no tenure system is immune from degradation. A larger proportion of communally owned, traditionally grazed lands has been more severely degraded, but this may be due more to factors such as greatly increased population and extension of cropping onto the higherrainfall margins than to the tenure system itself.

It is logical to think that private ownership or long-term secure leaseholds would encourage individuals to take a long-term view of the resources, whereas short-term leases and common ownership may encourage management for short-term gains. With regard to rehabilitation of degraded land, individuals with privately owned land or long-term secure leaseholds are more likely to invest in rehabilitation measures than those with short-term leases or common ownership.

Land tenure issues are discussed in detail in Chapter 10.

Commodity prices. Commodity prices have an important bearing 
on livestock population. In market economies, for example, farmers sell few cattle when beef prices are low, and therefore stocking rates rise. An extreme illustration of this is the situation in central Australia in the mid-1970s when beef prices were so low that costs of transport to market exceeded the price of the animals. For several years the graziers sold no cattle, and the livestock population rapidly increased to about double the safe carrying capacity of the region. Fortunately the period of low prices coincided with years of high rainfall; otherwise, there would have been widespread land degradation and stock losses.

It is a popular belief that pastoralists in many developing countries measure their wealth by the number of livestock they own, and therefore will not sell them. Some observers have disputed this, saying that pastoralists will sell if the market is right - the main reason they do not sell is low commodity prices.

In many developing countries, prices of rural commodities are set at artificially low levels to benefit urban populations on whom governments depend for their survival. Under such policies, pastoralists retain their livestock rather than sell them. Furthermore, returns to farmers for crop products are too low for them to afford good cropping practices. Low commodity prices and lack of access to adequate markets are major underlying factors contributing to dryland degradation.

Political aspects. In many Asian and African countries the pastoral communities are culturally, linguistically, tribally or even racially different from the majority of the population. They are minorities occupying regions distant from the seat of government. Their political voice is weak, and it is easy for governments to neglect them and their land. In such situations, the problems of dryland degradation are not high on the agendas of the national governments, if they are recognized at all. At the 1977 UN Conference on Desertification, many delegates felt that social and political inequities were at the heart of many land degradation problems. Both technical and political changes are necessary.

International aspects. Tariffs and trade barriers (sometimes disguised as quarantine restrictions or over-stringent quality standards) imposed by rich countries on imports of agricultural products adversely affect rural commodity prices in the poor countries; these restrictions have similar effects on land degradation as internally controlled low commodity prices. Some authors such as Westoby (1978) believe that dryland degradation in developing countries is not caused by lack of resources or overpopulation but 
is a consequence of the development of rich countries being founded on the underdevelopment of the poor countries. While this is an extreme viewpoint, policies such as subsidized agriculture and import restrictions in developed countries do have adverse effects on residents of developing countries.

The large external debt of many developing countries also affects dryland land use. To generate the foreign exchange needed for debt repayment, governments emphasize cash crops over food crops. The intensive farming practices used to grow such crops and the depleting nature of some of these crops on soils may result in degradation of croplands.

\section{References}

Biswas, A. K. (1986),

"Land use in Africa", Land Use Policy, vol.3, no.4, pp.247 - 59.

Coppock, D. L., J. E. Ellis and D. M. Swift (1986),

"Livestock feeding ecology and resource utilization in a nomadic pastoral ecosytem", Journal of Applied Ecology, vol.23, no.2, pp. 573 - 83.

Dregne, H. E. (1983),

Desertification of Arid Lands, Vol.3: Advances in Desert and Arid Land Technology and Development (New York: Harwood).

Farmer, G. (1986),

"Rainfall variability in tropical Africa: some implications for policy", Land Use Policy, vol.3, no.4, pp.336- 42.

Friedel, M. H., and V. R. Squires (1983),

"Plants as a resource", in G. Crook (ed.), Man in the Centre (Perth: CSIRO Division of Groundwater Resources).

Grainger, A. (1985),

Desertification, How People Make Deserts, How People Can Stop Them and Why They Wont (London: Earthscan/IED).

Hare, F. K. (1977),

"Climate and desertification", in Secretariat of the UN Conference on Desertification (ed.), Desertification: Its Causes and Consequences (New York: Pergamon Press).

Liddle, M. J. (1975),

"A selective review of the ecological effects of human trampling on natural ecosystems", Biological Conservation, vol.7, no.1, pp.17-36.

Nicholson, S. E. (1982),

"A note on sub-Saharan rainfall in the years $1976-80$ ", MS report (Worcester, Mass: Clark University).

Perry, R. A. (1978),

"Rangeland resources: worldwide opportunities and challenges", in 


\section{The Economics of Dryland Management}

Proceedings of the Intermational Rangelands Congress (Denver, Colo: Society for Range Management).

Slatyer, R. O., and R. A. Perry (eds) (1969)

Arid Lands of Australia (Canberra: Australian National University Press).

Spooner, B. and H. S. Mann (eds) (1982),

Desertification and Development: Dryland Ecology in Social Perspective (London: Academic Press).

Squires, V. R. (1981),

Livestock Management in the Arid Zone (Melbourne: Inkata Press).

Westoby, J. C. (1978),

"Forest industries for socio-economic development", guest speaker's address, Eighth World Forestry Conference, Jakarta.

Worthington, E. B. (ed.) (1977),

Arid Land Irrigation in Developing Countries: Environmental Problems and Effects (Oxford: Pergamon Press). 


\section{The Role of Public Policy in Dryland Development and Management}

\section{Policies towards the drylands}

Diversity of dryland problems

As shown in Chapter 2, dryland degradation is a complex phenomenon with many different causes. Drylands cover a wide variety of land types, including arid lands, semi-arid lands, irrigated lands and lands in the sub-humid tropics. These lands are put to many different uses, such as grazing, cropping, forestry, settlement, tourism and mining.

There is great variation in socioeconomic conditions in different dryland areas. Some countries have well-developed market economies, while in others barter and subsistence farming play a major role. Income levels vary significantly, both between and within countries. Social and cultural traditions often impose particular constraints /on land-use|rights, ranging from open-access grazing by nomads on common lands to commercial farming and pastoralism on privately owned lands. The intensity of land use also varies, from small-scale agriculture and animal husbandry to extensive cropping and grazing.

Political and administrative systems vary widely, as do the bodies and institutions involved in decisions concerning dryland resources. Institutions with an interest in dryland decision-making include international banks and donor agencies, national governments, state and provincial governments, local communities, co-operatives, voluntary assistance groups, non-government organizations, private corporations, families and individual farmers. Many different experts are also involved, such as planners, scientists, technologists, sociologists and economists.

Last, but by no means least, the urgency of the problem of dryland degradation varies enormously on a global scale, from acute crisis in some of the African countries, with their frequent famines, to the chronic subsistence conditions in Asia, and the risk of declining dryland productivity in affluent countries such as 
Canada, the United States and Australia.

In view of the diversity of all these factors, it is clear that there is no simple formula for the solution to the world's dryland problems. Corrective actions are nevertheless needed to overcome the adverse impacts of a diminishing resource base, declining incomes, loss of employment and deteriorating social conditions (UNESCO, 1977).

\section{The case for public assistance}

Public assistance is warranted when individuals themselves are unable, either collectively or on their own, to prevent or cope with the adverse impacts of land degradation on their welfare. International agencies, national and provincial governments, community groups and non-government organizations all face major responsibilities to help overcome existing problems (UNEP/ Commonwealth of Australia, 1987).

Difficulties experienced by individuals in using dryland resources have a number of different causes and explanations. Basically, the problem is caused by actions that may appear to be completely rational from the perspective of an individual, but which impose significant costs or welfare losses on society as a whole. Such costs may occur on-site, because land users have a very shortterm time perspective. Instead of planning for long-term sustained productivity, current land users may over-exploit the resource base, leaving it in a degraded condition for future users. The system of land-use rights may encourage this process. Lack of technical expertise or land management skills can contribute to the problem. Some effects, such as off-site damages caused by soil erosion, or resource degradation on a regional scale caused by salinization, may not be taken into account by individual land users. When these effects take place in communities dependent on market mechanisms, they are typically referred to as "failures of the market system", but they also have their counterparts in communities that rely on subsistence production and barter exchange (Chisholm and Dumsday, 1987).

\section{General policy issues in dryland development planning}

General policy options include actions aimed directly at land improvement or protection, birth control, education, projects that stimulate the processing of raw materials, migration programmes, infrastructure development and the establishment of new industries. Projects focusing only on soil and water conservation or 
prevention of salinization may turn out to be ineffective in the long run because they deal with symptoms and not underlying causes. Similarly, projects that encourage commercial cropping to raise rural incomes may intensify pressures on the land. In the long run, birth control programmes may be the most effective policy to halt land degradation.

Dryland degradation is largely the result of human decisionmaking. It often has indirect rather than direct causes. For example, if an expansion of commercial cropping adversely affects rural labour or nomadic groups, more intensive use may be made of marginal, non-commercial lands, leading to degradation that could spread on a regional or even a national scale. Given the central role of individual resource users in most decision-making on dryland management, these same people must be involved in the process of problem identification and in planning ways to overcome these problems.

Seemingly unrelated policy decisions such as a shift in the exchange rate also can have large effects on dryland use. A currency depreciation, leading to a large inflow of investment funds to the industrial sector, might create more jobs in urban areas, attracting labour from the rural sector and relieving pressure on the land. Other impacts may result from increased development assistance to the rural sector, changes in trade preferences, technology transfers or commercial investments. The interactions between the domestic and international economy point out that domestic policies may be swamped by the spill-over effects from such factors as foreign capital flows, a change in overseas agricultural marketing policies or a major shift in international exchange rates.

\section{Formulation of policies, programmes and projects}

Improved use of dryland resources can be promoted in a variety of ways. Once the problems and their underlying causes have been identified, the search for solutions can begin. Alternatives range from modifying national policies, such as agricultural and trade policies, to designing regional development programmes and implementing small-scale projects at the field level. For many countries, a combination of strategies at all levels of government will be necessary to mount an effective national programme against dryland degradation. Such strategies should be part of a wellthought-out, comprehensive plan for natural-resource utilization and economic development that includes measures specifically designed to deal with dryland areas. The general approach to 
planning, as conceived by Child et al (1987), is shown in Figure 3.1.

Public policy towards the drylands should focus on:

- methods of encouraging improved use of drylands as a renewable economic resource through the introduction of better land-use practices and production technologies;

- allocation of investment funds to specific dryland improvement programmes and projects; and

- general policy and planning initiatives aimed at promoting more rational use of dryland areas in the context of overall economic development planning (World Bank, 1985).

\section{Economics and the policy process}

In view of the general scarcity of resources, the number of feasible policy options will be limited, so priorities must be established. Economic analysis can usefully be applied to general planning problems and to the process of evaluating options, formulating policies and devising effective incentive schemes.

Several steps are involved in applying economic analysis to dryland policy problems.

The first step is identifying the causes of degradation in each situation. As discussed in Chapter 2, one set of causes clearly operates at the land user level, where degradation is directly induced by people's actions. As such, one cannot overstress the importance of consultation with people at this level to understand why the observed actions are being taken. On a more general level, other factors indirectly cause the problem, such as the economics of rural industries, the structure of commodity markets, land-use rights, population growth, income levels and distribution, and social and cultural values. To achieve effective results, the reasons for inappropriate development patterns and land-use practices must be clearly understood.

The second step involves the collection of information on the extent of degradation, productive potential and improvement options for the land resources under consideration. Environmental impact assessments are needed at this stage, with inputs by local resource users and non-economists such as ecologists, physical scientists and agricultural experts. Baseline indicators of environmental quality must be established and predictions made of physical changes in land productivity and of other effects resulting from different policy options. Such information must be assembled so 
that decision-makers can assess in economic terms the development opportunities and problems associated with the expected short- and long-term uses of the resource.

The next step is the evaluation of policy options and alternative courses of action to use drylands more effectively. Economics offers operational concepts for evaluating the changes in social welfare that can be expected to result from various policies. Various techniques of economic evaluation and decision-making are available for this task.

On the basis of policy evaluations, development strategies can be deoised that lead to long-run sustainable production from drylands. Guided by economic assessment and planning, the processes of degradation may be stopped or slowed, better use made of existing land and degraded land brought back to productive use. Broad policy initiatives must be translated into specific programmes and projects. Factors to be taken into account in choosing corrective actions include the views of those farmers or pastoralists who will be affected, available financial and physical resources, the legislative and political environment and feasible policy instruments. Co-ordination among various administrative agencies may be required to develop an integrated strategy to bring about desired changes.

Resources required to carry out assistance policies and programmes must be mobilized to achieve effective results. Necessary inputs will usually entail managerial expertise in both the public and private sectors, technical information, materials and labour supplies. Of particular importance is investment finance. Borrowing arrangements must be compatible with the needs of public agencies and, where relevant, with the needs of people on the land.

The next stage is the actual implementation of policies, programmes and projects. Measures to combat land degradation commonly involve a number of administrative sectors. Information and administrative functions need to be effectively co-ordinated. The adoption of economic guidelines for development planning and resource management should facilitate these procedures. Public participation should be encouraged; this aspect is discussed later.

Incentives must be created to encourage the acceptance of new policy initiatives. Among the various possibilities, changes in land tenure and user rights may be of paramount importance. Monetary and in-kind incentives can also play a valuable role. Generally, central governments should focus on providing a supportive technical, institutional and financial framework for the activities of local, community-based groups which are best equipped to relate to land 
The Economics of Dryland Management

Figure 3.1: Interrelationships among different kinds and levels of planning that are essential for development in arid and semi-arid rangelands

\section{PLANNING}

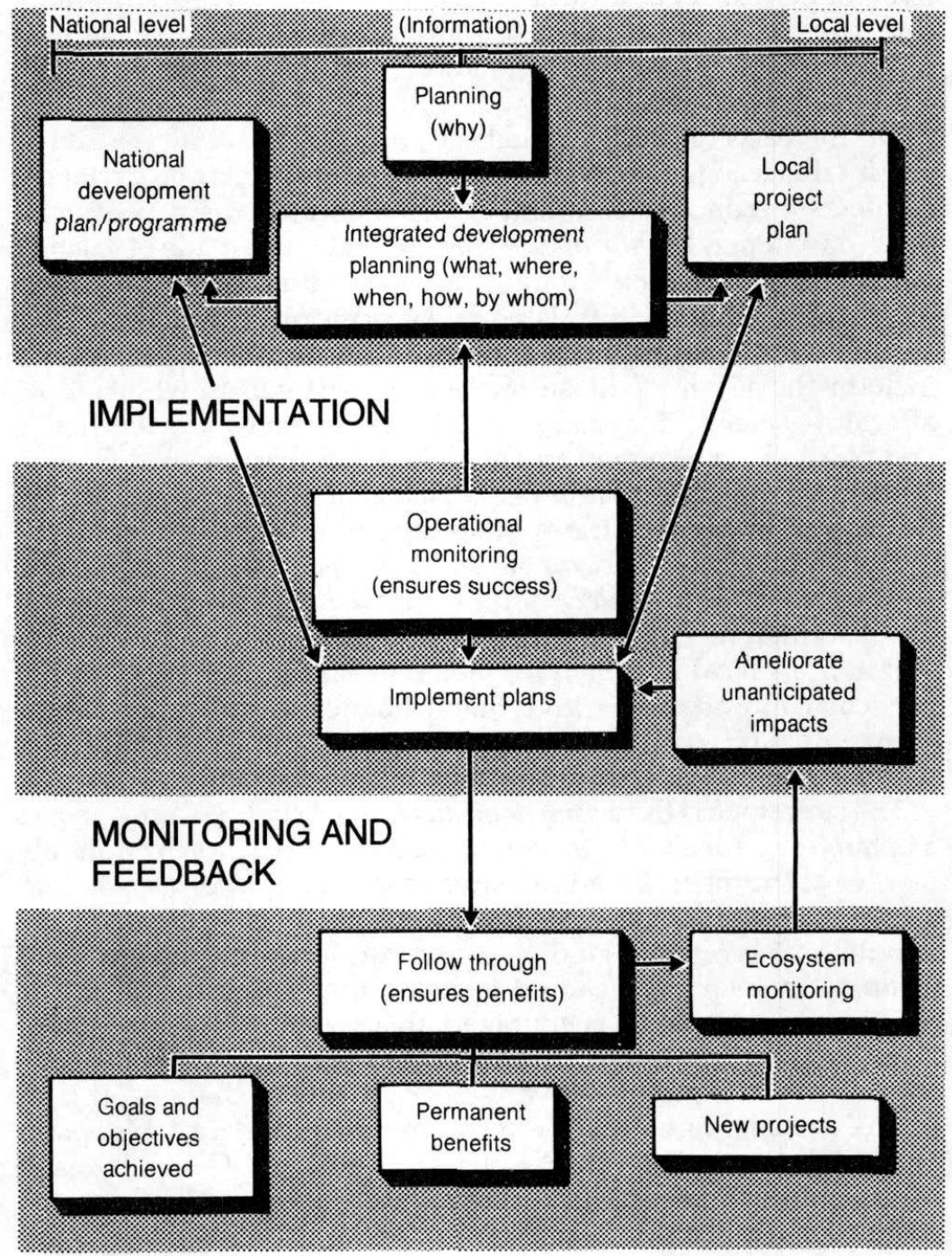

Source: Child et al, 1987. Reprinted by permission of the publisher. 
users and the physical, social and economic environment in which they operate.

Continuous monitoring and assessment of the social, economic and environmental effects of programmes and projects are required to ensure viability and success. This involves an ongoing political and economic commitment. The uncertainty associated with measures to combat dryland degradation, particularly in developing countries, calls for flexible and adaptive management.

A more detailed schedule of the steps in the planning and implementation of development is given in Table 3.1. The approach was developed for rangeland development but can also be applied to other dryland developments.

\section{Designing appropriate policies}

\section{Economic issues in designing remedial action}

Given the magnitude of dryland degradation problems and the limited funds available to deal with them, difficult public choices often must be made. For most countries, it is not possible to restore all lands to their original condition or, in many cases, even to maintain all land in its current state. One of the initial decisions policy-makers must face is choosing lands for which public-sector assistance can be given. A number of factors must be considered in this decision.

Effects on dryland residents. An important criterion is the effect of present and future degradation on the people who depend on a certain area. Areas with large populations currently experiencing severe impacts as a result of dryland degradation should be given high priority in government funding allocations. Areas with large populations at risk as a result of ongoing degradation must also be given high priority, and those affected must be included in the planning process. Though this may appear to be stating the obvious, an examination of current situations in many countries indicates that public assistance is often directed to areas other than those with populations in greatest need. As discussed in Chapter 2, the limited political influence of many dryland residents, combined with the restricted economic potential of dryland areas, often leaves those most in need with relatively small allocations when funding decisions are made.

Potential benefits. Another criterion for choosing the areas on which to focus attention is the potential for generating economic benefits. The measurement of benefits may vary from one country or region to another, depending on social, economic and cultural 


\section{0}

The Economics of Dryland Management

factors. In extreme situations, where people face starvation and death, the benefits to be aimed for are clearly the provision of food and saving of life. It is probably a waste of time even attempting to assess the economic benefits of remedial policies, programmes and projects in such circumstances. A more realistic approach is to define the object of policy as the relief of human suffering, and explore the most efficient and economic means of meeting this social goal.

In other contexts, the more familiar economic criterion of maximizing the net benefits of improvement measures may be applied. By devoting resources to the areas most likely to benefit from investment, governments can maximize the improvement in social welfare from a given level of expenditure. However, policies must also take into account the distribution of social benefits,

Table 3.1: The sequential steps in planning and implementing rangeland developments

Pre-planning

(1) Assemble and evaluate existing information.

(2) Encourage and advise host government in interventions only it can make:

- set policy guidelines for rangeland areas;

- set country goals and objectives for rangeland development;

- devise budgeting, procurement and accounting procedures suitable for rangeland areas;

- establish education, extension and research priorities for rangeland areas;

- assess and allocate available technical/professional human resources;

- project amount of host-government finance and capital expenditure available for rangeland development.

(3) Describe and analyse situation:

- physical;

- biological;

- socioanthropological;

- economic;

- political.

(4) Analyse national or regional problem:

- set broad programme goals and objectives; 
- identify candidate programmes/projects;

- set priorities;

- specify new information needs.

New information acquisition and evaluation

Action programme planning (for candidate area defined in preplanning)

(1) Local pre-planning:

- incorporate new information;

- refine situation statement and analysis;

- redefine problem statements;

- fine-tune problem definition;

- set area-specific goals and objectives;

- define strategies.

(2) Project planning:

- analyse problems and decisions;

- identify and design facilitating actions;

- identify and design direct actions;

- sequence and schedule;

- hire staff;

- work out logistics;

- establish budget.

Implementation of plan

(1) Check and confirm sequence of actions.

(2) Arrange logistical support.

(3) Recruit, assign and train personnel.

(4) Arrange co-operation.

(5) Execute plan (facilitate and direct action elements)..

(6) Monitor project management functions:

- logistical plan;

- co-operation;

- performance schedule;

- quality of performance;

- budget fiscal plan;

- unanticipated side-effects.

(7) Redesign or adjust plan and modify implementation. .

Follow-up

(1) Monitor impacts on resources, humans and animals.

(2) Assure goal and objective attainment.

(3) Assess effectiveness of project.

(4) Ensure continuity/transition to next programme phase. .

Source: Child et al, 1987. Reprinted by permission of the publisher. 
which is also an important consideration in many cases. Unless those responsible for land degradation both contribute to planning and see the benefits from public assistance programmes, they may not co-operate with the scheme. Planning should take place with, not for, the people.

There is a symmetry between benefits received and costs avoided. An economic analysis should include any new benefit (for example, an increase in crop yield) generated by a programme or project. The analysis should also include as a benefit a potential loss that has been avoided by the programme or project. Therefore, in addition to focusing on areas with the potential for generating significant benefits, areas vulnerable to significant losses from degradation must be carefully assessed. Such/areas can be defined as those currently or potentially highly productive but susceptible to degradation. By investing in actions that prevent degradation, potentially large future losses can be avoided. A good example of this is investment in proper drainage systems in irrigated areas prone to salinization or waterlogging.

Reducing off-site damage. A related category is lands where present or future degradation is predicted to result in large losses to nearby areas. Such off-site losses may include damage to crops downwind or damage from erosion and sedimentation downstream. Preventing degradation in these areas can result in indirect gains that justify the necessary expenditures. For example, an erosion control programme that reduces sedimentation in a downstream reservoir may increase the useful life of the dam, thereby producing added benefits.

Costs of rehabilitation. The relative costs and benefits of rehabilitation will depend on how far degradation has already progressed. By allowing degradation to proceed to the point where it is essentially irreversible, many options for the use of that land are foreclosed, thus constraining future possibilities. Rehabilitation costs escalate sharply as degradation continues, and delaying action may allow the damage quickly to reach an irreversible stage. (See Figure 3.2 and explanation in 'Box 3.1.)

In some cases, it will not be worthwhile to invest in rehabilitation or protection, even if the land subsequently does become irreversibly degraded. If the costs of protection outweigh the potential benefits, it may not pay to prevent further damage. Policies should not be based simply on reversing or arresting degradation itself, but rather on making the best economic use of the resources available. 
The Role of Public Policy in Dryland Development and Management

53

If possible, however, lands susceptible to irreversible damage in the short run should at least be evaluated before the damage is severe, allowing decisions to be made while options are still available. Evaluating areas before they move into rapid decline can provent poor decisions being made by default, and avert irreversible losses.

Figure 3.2: Progress of dryland degradation and associated costs of rehabilitation

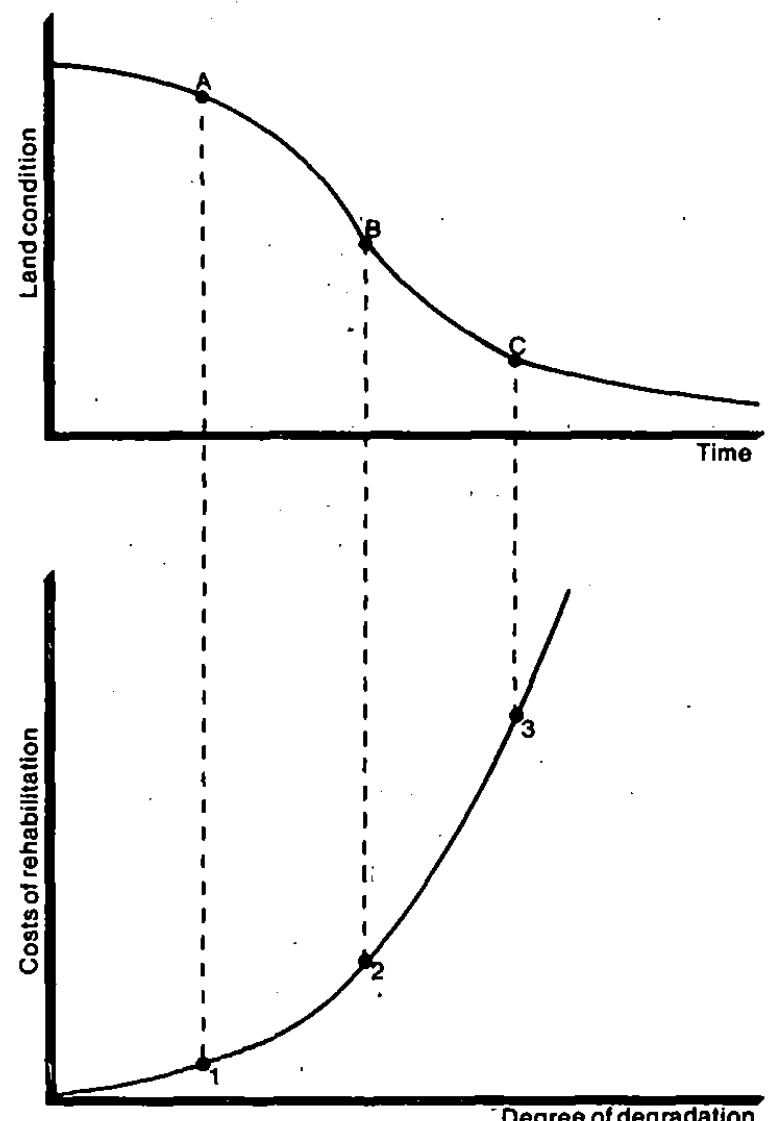

Degree of degradation

Determining the appropriate level of protection

In the ideal world, the only "acceptable" level of degradation might be no degradation. Given the reality of present problems, however, 
this is not a viable prospect for most countries. The choice of which lands to rehabilitate, which lands to protect from further degradation and which lands to allow to degrade is a key issue in the development and management of dryland areas.

\section{Box 3.1: Land degradation and costs of rehabilitation}

The upper panel of Figure 3.2 illustrates the effects of degradation on land condition as the degradation process continues. To the left of point $A$, the first stages of degradation have begun. If no action is taken, the pace of degradation continues to accelerate, and the land condition undergoes a rapid decline. At point $B$, the rate of degradation has reached a maximum. Beyond this point, the land condition continues to decline, though at a decreasing rate. By the time point $C$ has been reached, the land has undergone severe degradation and will be difficult, if not impossible, to restore to its original productive capacity.

In the lower panel of Figure 3.2, the costs of rehabilitation corresponding to the degree of degradation are shown. At point 1 (corresponding to point $A$ in the upper panel), costs of rehabilitation are still relatively low. By point 2 (corresponding to point $B$ above), costs have risen substantially. At high levels of degradation such as point 3 and beyond, the costs of rehabilitation are so high that it will raraly be worthwhile to proceed with the necessary investment. In these circumstances, other alternatives such as resettlement may have to be considered as a means of assisting affected residents.

In choosing the areas to receive attention and deciding which actions to take, various factors may override considerations of economic efficiency. Sometimes, for political, humanitarian or other reasons, public assistance may be restricted to a particular geographic region. The problem must then be addressed solely for that region. In other situations, the choice of areas on which to focus may be unconstrained, and economic evaluation criteria can be applied to policy options across all regions. An initial assessment will help identify opportunities and order priorities.

An apt analogy is the concept of triage in the medical field. During wartime or in emergency situations, a quick evaluation of each patient is performed, and the patients are divided into three groups. Those patients in the worst condition, with little chance of a successful recovery even with intense treatment, are simply made as comfortable as possible without expending scarce resources that 
will probably be ineffective anyway. A second group includes those who are in reasonably good condition and need little or no attention. The third group includes those who, with immediate help, can recover and survive; this group receives the most attention. In this manner, scarce resources are allocated to maximize overall benefits.

In the drylands, the scarce resources available must be allocated in à similar manner. Lands in good condition may need little or no attention. Lands already in very poor shape often must be left untreated even if that will mean further degradation. The bulk of resources should go to lands that have a good chance of recovery if they are treated in a timely fashion.

People may object to policies that consciously allow degradation to continue in particular areas. However undesirable such policies might appear, the alternatives are often no better. Saving one area may preclude rehabilitating other areas with higher potential returns.

In addition to the concept of triage, another medical analogy is relevant: the cost of preventive medicine is often far less than the cost of curing an illness. Triage may be necessary in emergency situations, but proper emphasis on prevention can ensure that an emergency situation does not evolve. Maximizing economic benefits necessarily entails making decisions on the allocation of support between preventive and rehabilitative measures.

\section{Desirable characteristics of policies, programmes and projects}

The likelihood of success in public policies, programmes and projects will be considerably enhanced if certain conditions are observed. Such prerequisites may appear to be self-evident, but in practice their absence has severely hindered the long-term success of public assistance schemes in the past. The following list is not meant to be comprehensive but only to provide a useful checklist to consider when formulating policies and designing specific programmes and projects.

Community participation. In the view of many people, neglecting to consider community concerns has doomed more public initiatives than any other single factor. Policies are often formulated at a great distance from where they are to be implemented without any input from those most affected. In some cases, programmes and projects are destined to failure from the start because they directly contradict accepted social or cultural practices of the people for whom they are designed. In other cases, communication with 
the intended recipients could have quickly revealed the deficiencies of a policy in a given situation. All too often, paternalistic attitudes of planners in government and aid agencies prevent the establishment of lines of communication which could mean the difference between success and failure.

Planners must ensure that the problems they believe are most important are also those perceived by the inhabitants to be the most critical ones. For example, promotion of plantation forestry in areas where arable land for food production is at a premium is bound to be met with resistance by those who believe their need for increased food production is more important than increased fuelwood production. Communities must see for themselves the benefits of assistance schemes to enlist their co-operation.

Programmes and projects initiated by communities themselves, with or without outside assistance, are much more likely to be effective. In India, forestry projects at the village level involving communities at an early stage have proved extremely successful. On the other hand, programmes and projects with centralized power held outside the community and controlling all the decisions often prove to be failures. A good example of this is the Rahad irrigation programme in eastern Sudan. A centralized bureaucratic corporation made all decisions, and the programme left many tenants worse off than before it began.

A related problem is the introduction of methods and technologies which are forced onto local people with inadequate field trials in the new locale. Ambitious planting of exotic crops or trees, initiation of mechanized farming, large irrigation schemes or large-scale soil conservation schemes can all be highly successful in one region, yet fail dismally in another. Even when well designed, such programmes are often perceived to be failures if local inhabitants are not convinced of the long-term benefits the projects are supposed to bring about. Programmes that build on local knowledge tend to be more successful.

Attractiveness to the user. New programmes and projects aimed at improving the welfare of land users may not succeed because the intended users do not see the benefits that they would receive. This can occur for a number of reasons.

If some aspect of the technology, technique or material involved is new to the intended users, they may not understand or believe that such a change will be beneficial. In some cases, they may have a strong argument and see some weaknesses that the designers of the programme or project have overlooked. When this occurs, the 
project team must work with the users to overcome the problem. If the obstacle is only lack of familiarity, the advantages can be shown via a demonstration scheme or some other means. If the users see for themselves that the project will work, they will be much more likely to accept it. It is also possible that the proposed technology is unsuitable for a particular locale, in which case the programme or project must be redesigned to avoid a costly failure.

Another reason many programmes and projects are not implemented to the degree expected is that analysts do not adequately consider constraints on the users. For example, an analysis of an agroforestry project may show large net benefits over the life of the project, but in early years the net benefits may be negative. Many dryland residents live at or barely above subsistence conditions. From their viewpoint, the costs to them now may outweigh any benefits that may (or may not) arise in the future.

Where these conditions hold true, successful implementation may require incentives which offset these early losses. Incentives may entail subsidies or outright provision of materials, low-cost or no-interest loans, changes in land tenure or user rights or a variety of other means depending on the situation. Through such efforts, adoption rates can be raised dramatically. There are some observers, however, who argue strongly against subsidies in any form as destroying community commitment and involvement. While selfreliance and self-financing of programmes are always desirable, this is not always possible.

Programmes and projects that are designed to reduce off-site environmental effects may also require incentives. These programmes and projects often have large net social benefits, but to the individual who must implement them the private costs can outweigh the benefits. In these cases, there is no incentive for an individual to participate in the project. The use of positive incentives is much more likely to encourage participation as compared to a regulatory approach.

Use of appropriate technology. The failure of many schemes can be traced to an unsuccessful attempt to transfer technology to a region where either environmental, social, technological or educational constraints limit its usefulness. With adequate planning in the design stage, many of these problems can be avoided or at least mitigated. One should, of course, review past experience from the area to see what has already been tried and whether it was successful. 
Small-scale field testing is often necessary to see whether a new technology is suitable. Such testing can show if the species chosen are appropriate and if the necessary technology will perform as expected.

In general, programmes and projects with the best chance of success will have the following characteristics:

- low initial costs;

- low maintenance;

- easily repaired, with locally produced materials if possible;

- easy to use;

- labour intensive rather than capital intensive, with less labour needed during periods when labour is scarce; and

- culturally appropriate.

Sustainability. Policies towards the drylands are frequently aimed at promoting sustainable production from the natural-resource base. Development projects introduced under such policies should be designed to cope with the special properties of dryland environments. Those responsible for the design of projects must be aware of several potential pitfalls. As already described in Chapter 2, the drylands are characterized by uncertain and fluctuating environmental conditions. Projects can fail because they are designed under optimistic assumptions that do not hold in the field. For long-term success, projects must be able to withstand the harshest conditions they will encounter. Designing and evaluating projects assuming they will only face normal conditions will rarely result in success in a dryland situation.

With many projects, especially those involving forestry and agriculture, trade-offs between productivity under normal conditions and the ability to survive under harsh conditions must be explicitly considered. The long-term benefits of a high-yielding tree are zero if it dies during the first year of below-normal rainfall. A conservative management policy may yield the highest returns over time.

Some projects often have an effect opposite to that intended, by increasing degradation rather than alleviating the problem. The extension of mechanized farming onto lands more suitable for grazing is a relevant example. The vegetative cover is removed to sow crops. In good years there may be a good harvest, but in other years crops fail and returns are minimal. In addition, the bare soil becomes more prone to erosion, and the productivity of the land 
decreases over time. To ensure long-term effectiveness, an adequate assessment and monitoring programme must be built into the project.

\section{Social, cultural and institutional factors}

In the previous section the discussion of desirable characteristics of policies, programmes and projects highlighted the importance of social and cultural factors. These factors, in combination with institutional arrangements, help determine whether or not new ideas or projects are acceptable to those who are supposed to adopt and implement them. The best-designed programme for dryland management is useless if it is not accepted and not implemented.

\section{Human factors}

Programme and project planning and management should be based on careful interpretation of the human factors that underlie the current situation (Spooner and Mann, 1982). Dryland degradation is, after all, the reduction of the primary productivity of the renewable natural resources of the world's drylands by people. Therefore, the crucial question at the policy level is: why do people do it? Or more specifically: why do they continue the activities which lead to degradation? This raises another question: if people were fully aware of the effects of their actions, would they still do it?

One of the problems is that people generally do not distinguish between ecological constraints and other types of constraint in the decisions they make on a day-to-day basis. They make the best accommodations they can to the whole range of constraints and incentives that they perceive. As a result, land degradation usually results from actions that, when viewed from the perspective of the individual resource user, are rational and socially and culturally acceptable, and make economic sense. It is essential to examine the pattern of resource use from the individual's point of view as well as from that of society or the government planner.

A number of social and cultural factors will affect the cohesion, self-sufficiency and autonomy of community life and thus affect resource use and management. For example, the availability of newly introduced technology, in the form of machinery, techniques, seed or fertilizer, invariably affects power relationships and makes it possible for entrepreneurs to exploit a new social niche. A second example is a change in the ratio of population to resources, which might be considered simply another form of 
perturbation, and may certainly have similar effects. A third factor concerns the nature of power relationships between the community and the outside world. A comparison of communities suffering the direct effects of degradation suggests that degradation occurs more often in communities that are in some sense marginal or peripheral to the main concerns of the society.

It is difficult to make general prescriptions about how to handle these social and cultural factors, because each situation is unique. Still, by being aware of these factors and realizing that land degradation is a common by-product of ordinary people doing the best they can under a given set of circumstances, it is more likely that successful public assistance programmes can be designed. Experience has shown that legal approaches and direct regulation have had only limited success. It is much more efficient to work within social and cultural constraints, rather than to ignore them and design elegant but non-implementable programmes or projects.

\section{Institutional factors}

The importance of institutional factors to successful programme implementation should be obvious from the preceding discussion. Since institutions reflect the existing patterns of social and governmental organization, they must be explicitly taken into account. This may mean that in some cases a "second-best" approach must be taken to dryland development and management. The preferred programme may not be implementable given existing institutional arrangements. A second-best solution that can actually be implemented is far superior to an "ideal" programme that fails.

\section{References}

Child, R. D., H. F. Heady, R. A. Peterson, R. D. Pieper and C. E. Poulton (1987),

Arid and Semi-Arid Rangelands: Guidelines for Development (Morrilton, Ark.: Winrock International).

Chisholm, A. and R. Dumsday (eds) (1987),

Land Degradation: Problems and Policies (Cambridge: Cambridge University Press).

Spooner, B. and H. S. Mann (eds) (1982),

Desertification and Development: Dryland Ecology in Social Perspective (London: Academic Press).

UNEP/Commonwealth of Australia (1987),

Drylands Dilemma: A Solution to the Problem (Canberra: Australian 
The Role of Public Policy in Dryland Development and Management 61 Government Publishing Service).

Unesco (1977),

Development of Arid and Semi-Arid Lands: Obstacles and Prospects, MAB Technical Notes No. 6 (Paris: UNESCO). World Bank (1985),

Desertification in the Sahelian and Sudanian Zones of West Africa (Washington, DC: World Bank). 


\section{General Economic Principles and Techniques of Analysis}

Economics deals with the allocation of scarce resources. It is concerned with the problem of decision-making under various constraints. An economist analysing a resource-using activity attempts to understand the reason decisions are made, the benefits and costs of those decisions and the likely impact of changes in policies, prices and management practices on those decisions. Economics deals with scarcity, with trade-offs between alternatives, with choices to make and options forgone.

As an applied social science, economic analysis can be used to:

(1) identify the benefits and costs of present patterns of resource use;

(2) analyse the benefits and costs of proposed management strategies;

(3) examine the distributional implications of proposed actions (for example, who benefits and who pays the costs);

(4) identify destructive behavioural patterns that lead to undesirable or unsustainable patterns of dryland resource management; and

(5) help formulate policies that can promote better, more sustainable resource use.

Economic analysis of dryland resource management options must consider several levels of analysis: the individual, public and private investment projects, and regional or national level programmes or policies. At the individual level the focus of the analysis may be the survival of a very poor subsistence farmer; the analysis may also examine a series of alternative management strategies being considered by a commercial farmer or pastoralist who is, in essence, a business person participating in a wider market economy. Although the needs, motivations, income levels and constraints faced by these two kinds of resource user are very different, the basic economic principles used to analyse each situation 
are the same. This book presents economic approaches and techniques that can be used in this process.

For example, the Weibei upland in Shaanxi province in China is a semi-arid area; future agricultural development is dependent on supplemental irrigation to ensure sustainable production. As described by Wang, Wu and Li (1990) in Dryland Management: Economic Case Studies (Dixon, James and Sherman, 1990), the local irrigation authority has experimented with various land-levelling techniques to maintain soil fertility while increasing the efficiency of use of available irrigation water. Economic analysis helped to clarify the benefits and costs of the various alternatives from the perspective of the individual farmer and the government planner. Sometimes the economic analysis will find that a proposed activity is profitable from both the individual and the social perspective. In other cases, this may not be true: an action may be socially beneficial (that is, total benefits exceed total costs) but unattractive to the individual farmer or herder. The economic analysis can then identify this divergence; this information, in turn, can be used to design an alternative approach that is attractive to the individual resource user and still has positive net social benefits.

\section{Concepts of economic welfare}

Scarcity is the simple notion that not enough resources are available to meet all possible desires of all potential users. Economics deals with the trade-offs and the choices between mutually exclusive alternatives that are necessary because of scarcity. As a social science, economics is meaningful only when people are involved in using the scarce resource. For instance, lack of rainfall or water in an arid area becomes important in economic terms only when it has an effect, either directly or indirectly, on people.

If resources were infinite, there would be little need for economic analysis. However, since most resources are scarce (compared with potential human demands), it makes sense to analyse alternative uses and decide which ones yield the greatest level of benefits. Individuals are concerned with increasing their income by making better use of the resources available. Governments seek to increase public welfare and have to make decisions on allocation of scarce investment funds. Not all good projects can be funded, however. Much of economics, therefore, deals with questions relating to the efficiency with which resources are allocated, and how that allocation is measured and evaluated. 
The equity implications of alternative resource allocations among individuals are also important in assessing benefits and costs. For example, a subsistence farmer will place greater value on an increase in sorghum production of $100 \mathrm{~kg}$ per hectare than another, better-off farmer will. This is due to the law of diminishing marginal utility; the gain in welfare from each additional unit (for example, $\mathrm{kg}$ of sorghum) is slightly less than for the preceding unit. Therefore, the welfare attributed to a given change in production (or a cost) may vary depending on who receives it.

Economic analysis has traditionally ignored this dimension and focused on the efficiency with which a project generated benefits regardless of who received them. In the dryland context, however, with its complex socioeconomic mix, it may be necessary to weigh benefits and costs differently depending on who receives them and relative scarcity values in different sectors of society (in effect, shadow pricing benefits and costs; see Chapter 6). Marginal utility or welfare is subjective and therefore difficult to measure. Nevertheless, when dealing with dryland areas that contain large numbers of very poor or disadvantaged inhabitants, it may be necessary to take distributional effects explicitly into account. To do this requires consideration of political, social and economic factors.

\section{Measurement of benefits and costs}

Benefits and costs are not absolute quantities. Their size and importance depend on the value system being used and the perspective from which they are measured. A key proposition in this book is that much of the degradation of drylands observed around the world is the result of individuals using dryland resources in a way that they perceive as optimal (that is, they are trying to maximize their welfare or net benefits). Few people would knowingly degrade a pasture or ruin an agricultural field, yet these results are commonly observed. This suggests that the benefits of improved dryland management may not, from the individual's perspective, match the associated costs. In some dryland situations, people are doing their best just to survive. In other situations, welfare may exceed this critical level.

Chapter 2 pointed out a number of the biological and physical effects of degradation commonly found in drylands. These effects can occur on-site, such as changed species composition in overgrazed rangelands or salinization from improper irrigation or 
drainage, or off-site, such as from wind or water erosion.

A clear understanding of the biological and physical cause-andeffect relationships is an essential first step in the economic analysis. The analysis must go beyond these changes, however, and consider the impacts of these changes on people. There can be direct impacts on human health (for example, from changes in the quantity and quality of water) or indirect impacts via changes in the productivity of various agricultural or pastoral systems.

Once the effects have been identified and quantified in physical terms, economic valuation techniques are used to assign monetary values to the various benefits and costs for use in the economic analysis. There is also a role for qualitative inputs into the analysis; not all environmental effects, for example, can be expressed in monetary terms. (For a fuller description of these points, see Hufschmidt et al., 1983; Dixon and Hufschmidt, 1986; Dixon et al., 1988.) Despite the availability of economic tools to assess policy alternatives, degradation appears to be increasing, seemingly "desirable" projects are not adopted or carried out, and financial resources are often put into projects that yield little in the way of benefits. One major reason for these failures is the divergence between public and private perspectives concerning the benefits and costs of activities. This divergence can be caused by price distortions, economic externalities, breakdown of resource management systems or time horizons and implicit discount rates. These effects are observed in both market economies (where they are commonly referred to as "market failures" or "market distortions") and in nonmarket economies (for example, over-use of open-access resources in subsistence economies).

\section{Price distortions}

Price distortions can cause misuse and degradation of resources. These distortions are found in both market and non-market economies and in both capitalist and socialist systems. In a conventional price-using economy, these distortions are a form of "market failure" and occur when the price charged for a good or service is too low, leading to wasteful use or degradation of the resource. (It has been argued that "political failures" are just as common and have equally devastating results. These are discussed in Chapter 10.)

For example, take an arid region where surface water is scarce and groundwater is tapped by a public well to water livestock. If the price charged for groundwater is determined solely by the cost of 
drilling the well and powering the pump, water used by individual livestock owners may then exceed the sustainable yield of groundwater. This leads to a fall in the level of water in the aquifer and the need for new, deeper wells or the use of other, more expensive water sources. In this case, the low cost initially charged for the groundwater has created a situation where supply and demand are not in balance and over-use occurs. A higher initial price for the water would have curbed demand and signalled to water users that water was scarce.

A key to understanding distortions in resource management is recognizing the divergence between the perceived welfare of individuals and the welfare of the wider community. Economists explain the problem in terms of (1) externalities or (2) use rights for natural resources.

\section{Economic externalities}

Economic externalities occur when the action of an individual (or group or community) has an effect on someone else who is not part of the decision-making process. Externalities can be positive and considered as benefits, but more often are negative and impose costs. The scale can be very local, such as cultivation practices in one field resulting in windborne deposits of soil in an adjacent field, or global, as with nuclear reactor accidents and the resultant spread of radiation. The distinguishing characteristic of an externality is the lack of accountability; the person using the resources and receiving the benefit of resource use pays only some of the associated costs. This leads to over-use and additional costs being imposed on others.

For example, if a mining company diverts water from a river, it only considers the costs of building a diversionary structure. Downstream residents will suffer welfare losses due to reduced water supply and/or water pollution. Even if these downstream users do not pay for the water, they will have lost part of the benefit that they originally received from its use. This unpaid-for benefit is technically referred to as consumer's surplus (see Box 4.1). The company could compensate the downstream residents, but it is unlikely that it would do this voluntarily. Unless the people complain or the government intervenes, the company will logically continue to divert and use the river water (without considering off-site costs), and downstream water users will suffer a reduction in their economic well-being.

Spatial externalities do not exist if all the effects of a decision fall 
within the area controlled by a decision-maker or are, in effect, "internalized". There may still be negative environmental effects, but the "costs" of these effects are borne by the same person who receives the "benefits" of the initial decision that led to the effects. For example, a farmer is concerned about water runoff from his or her fields into a small pond on his or her property. The benefits of a greater application of agricultural chemicals (for example, larger yields) have to be compared with the costs associated with water pollution of the pond (for example, reduced fish population, decreased water quality and decreased recreational use). The farmer can experiment with alternative ways to apply agricultural chemicals, control water runoff or use other technologies to increase yields. Rational management of such a confined system would lead to that combination of activities that maximized net benefits. If the pond was outside the farmer's property, however, the farmer would have little interest or incentive in controlling agricultural chemical runoff.

\section{Box 4.1: Consumer's and producer's surplus}

The net benefits of production and consumption of any good, $X$, consist of the sum of so-called consumer's and producer's surplus. To measure consumer's surplus the analysis begins with each individual's demand curve for good $X$, which shows how an individual would vary the quantity of $X$ consumed in response to changes in the price of $X$. It is assumed that the individual has a fixed money income and that there are constant market prices for all other commodities. Figure 4.1 shows a typical individual demand curve; it slopes downward to the right because quantity demanded increases as price goes down.

Calculation of consumer's surplus. Suppose that the individual were supplied the quantity $0 Q_{1}$ of $\operatorname{good} X$. The marginal valuation of $X$ would be $O P_{1}$. To buy $O Q_{1}$ of $X$, the monetary outlay would be price multiplied by quantity consumed, or the area of the rectangle $O P_{1} A Q_{1}$. Total willingness to pay, however, clearly exceeds this amount, for it comprises the sum of all of the marginal valuations of $X$ from 0 to $Q_{1}$ - that is, the area of the region $O D A Q_{1}$. This area is a representation of the total utility level and would appear as a gross or total benefit in a benefit - cost calculation. The area of the shaded region $D A P_{1}$ is known as (Marshallian) consumer's surplus and measures the maximum willingness to pay. over and above the actual cash cost of consumption. Consumer's surplus for society as a whole is measured from the market demand curve for good $X$, which consists of the horizontal aggregation of the demand curves of all individuals 
consuming $X$, as shown in Figure 4.2.

Consumer's surplus should always be added to the market value of goods and services consumed to obtain a proper estimate of total economic benefits. Consumer's surplus is particularly important (and large) for those goods and services that have a zero or very low price. Open-access grazing lands or public recreation areas are two examples.

Producer's surplus, or economic rent, is measured as the difference between the total revenue from production and sales, and the total costs of production. This can be measured for individual producers or for a whole industry. Where the fixed costs of production are zero, producer's surplus for an industry consists of the area above the market supply curve and below the price line, as shown in Figure 4.2.

Figure 4.1: Demand curve and consumer's surplus for individual

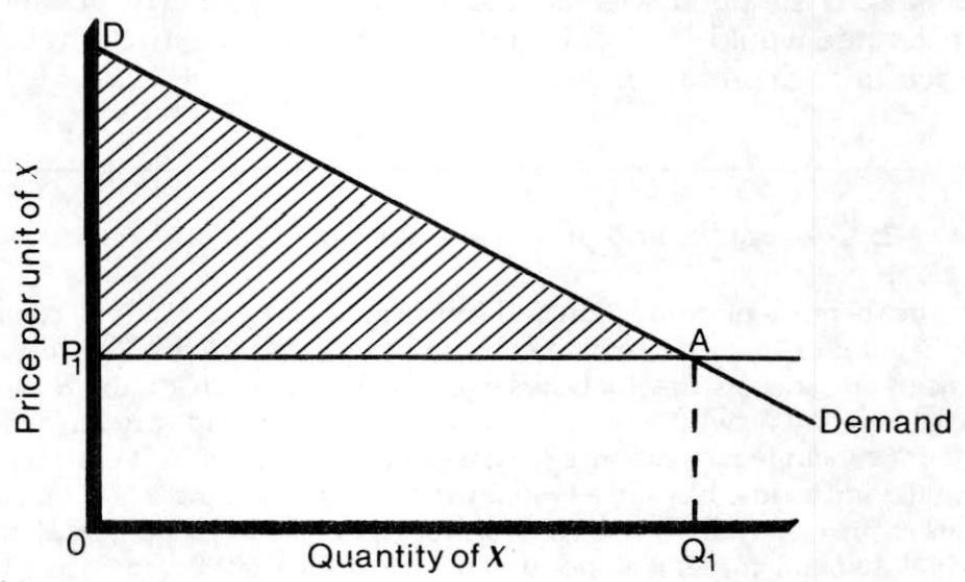

Use rights and resource management systems

Externalities arise in dryland areas for numerous reasons. One particular form of externality results in the collective over-use of openaccess and common property resources. The costs of using the resource seem small to the individual user because they are distributed among all the members of the group - or in the case of public lands, among all the members of society. The classic example is overgrazing: an individual will tend to put too many cattle in the common pasture because the benefits of an additional animal all accrue to the individual while the costs of reduced forage are borne by the entire group. Communal property may or may not be well 
Figure 4.2: Consumer's and producer's surplus for society

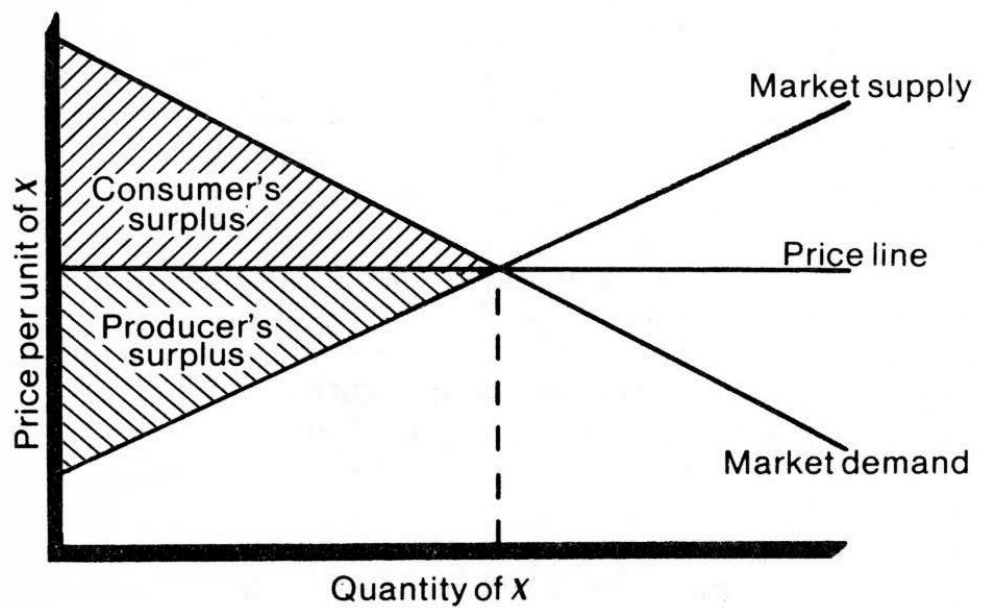

managed, depending on the institutional arrangements that have evolved to control use of such lands. Public lands, those owned by government, are most open to abuse, because a community's sense of obligation to manage the land wisely is lacking; some form of government protection is usually necessary. Abuse tends to be especially serious where private and communal resources are scarce.

\section{The effect of time}

Another aspect of market failure is related to time. There may be a long time lag between cause and effect, especially when land resources degrade very slowly. For instance, land degradation involves gradual physical phenomena such as soil erosion, changes in soil structure, salinization, changes in water quality and changes in pasture species composition. Just as with adverse effects which are physically distant, costs and benefits that occur far in the future may not fit into the individual's decision-making framework, and thus become externalities.

The time horizon defines the future period that is used for decision-making purposes. This will vary among individuals, as well as between individuals, corporations and government; it also depends on the type of project being considered. An individual, unless concerned with the quality of resources being left to offspring, will probably not look beyond his or her own lifetime. In 
situations of extreme scarcity and urgency, the individual may not even look beyond next year. Private corporations may also have short time horizons if the company's goal is to earn quick returns from resource exploitation. A government may have a longer time horizon, in part a reflection of concern with inter-generational equity (that is, leaving something for future generations).

Short time horizons inevitably lead to a lack of concern for the sustainable use of a resource. Sustainable use has both an ecological and an economic meaning. Ecological sustainability refers to the continued physical productivity of a resource over time. Economic sustainability may involve harvest and depletion of a physical resource, combined with reinvestment in another resource or sector. Conversion of land from one use (such as forests) to another (such as plantation crop) is an example of the latter concept.

With non-sustainable resource use, non-renewable resources are depleted too rapidly to maximize long-term benefits, and renewable resources are used faster than their natural rate of replenishment. This is especially likely in the case of fragile renewables such as dryland vegetation and groundwater - where over-use can threaten the replenishment process itself and change a renewable resource into a non-renewable one. The long-term benefits will not only be reduced, but may be eliminated entirely.

\section{Box 4.2: Discounting}

Discounting is the process of adjusting the value of some benefit or cost received at some point in the future to a current value.

Discounting allows the analyst to compare alternative projects by bringing the streams of benefits and costs over time to a single, present value. The formula to do this is quite simple:

$$
P V=\frac{B_{\mathrm{i}} \text { or } C_{\mathrm{i}}}{(1+r)^{\mathrm{i}}}
$$

where $P V=$ present value of a future benefit or cost;

$B_{\mathrm{i}}, C_{\mathrm{i}}=$ value of a benefit received or cost incurred in year $\mathrm{i}$;

$r=$ the discount rate.

Discount tables and discount factors (for example, Gittinger, 1982) are available to help with the required calculations. 
The phrase time preference is used to express the idea that people will value the same good or service differently depending on when they receive it. This idea is reflected in economic analysis by use of the discount rate. For example, the promise of a bowl of grain to be consumed ten years from now is usually less valuable to a person than the same bowl of grain consumed today. The discount rate is the percentage, usually defined as an annual rate, by which future values are reduced to determine their present equivalent. Discounting is performed by applying a simple formula (see Box 4.2).

Discounting has no connection with inflation. All future benefits or costs are specified in present or constant price values. Prices are adjusted only when there is a change in the relative prices between goods over time. (See Box 4.3 for more information on selecting discount rates.)

\section{Box 4.3: Selecting a discount rate}

Opportunity cost of capital. This approach is based on the forgone production that results when capital is invested in one project rather than another, or invested by government in a particular project rather than by the private sector. In this sense the opportunity cost of capital is directly related to the theory of capital productivity. Invested in plant or equipment, a dollar's worth of investment should yield net benefits over time. The discount rate is this rate of return.

This approach is also closely related to the financial (or nominal) interest rate, although the latter may include an upward adjustment for inflation. The real (inflation-adjusted) opportunity cost rate is affected by changes in real income, the distribution of wealth, taste and technology.

The opportunity cost approach appears to be used (implicitly) by the World Bank in requiring that, to be eligible for loans, proposed projects promise an annual rate of retum at least equal to a specified rate.

The cost of borrowing money. Governments frequently have to borrow money, either domestically or internationally, to finance development projects. (The financing mechanisms used include government debt from borrowing, inflation or taxation of private consumption - Haveman, 1969.) Especially when a country expects to borrow abroad, this approach may be used to set the discount rate.

A danger in this cost-of-borrowing-money criterion is that extremely favourable loans (at very low, subsidized interest rates) will favour the selection of projects with long-term net benefits; and vice versa, a high discount rate will favour the selection of projects with a rapid pay-off. To 
the extent that these extremes represent distortions of true scarcity in the economy, they will lead to misallocation of scarce resources.

The social rate of time preference. A third school of thought relies on the ability of society to reflect more accurately than the private market the trade-offs between present and future consumption. If from society's viewpoint individuals overconsume in the present rather than save for investment and future production, the social rate of time preference should be lower than that exhibited by individuals in private markets (the lifetime of an individual is much shorter than the relevant time horizon of society). How the social rate of time preference is actually set depends upon circumstances in the particular country involved. Many governments may not have an explicit, consistent social rate of time preference. (If the social rate is determined by the political process, this in turn is influenced by elected officials who may have a very short time horizon namely, until the next election.)

In summary, the actual rate to be used in economic analysis will be country-specific and will probably be established as a matter of government policy. Important factors governing the choice of rate will be the opportunity cost of capital, donor or lending agency requirements, the cost of money to the government and the government's current views of the private-sector consumption - investment mix in relation to its concerns for future generations.

Our position in this book is that project analysts should seek guidance from responsible government policy-making agencies on the discount rate to be used. In the absence of such guidance, analysts should undertake project economic analyses using a range of rates reflecting those recently or currently in use in the country for public and private investment projects. It is important to re-emphasize that these rates should be on a real-cost, inflation-adjusted basis.

A higher discount rate leads to lower present values of any given future benefit or cost. For example, at a 2 per cent discount rate, a benefit (or cost) of $\$ 100$ received twenty years in the future has a present value of $\$ 67.30$, but the same $\$ 100$ discounted for twenty years at a 10 per cent discount rate is worth only $\$ 14.86$ (see Table 4.1). As the length of time increases, the present value of any future benefit becomes smaller and smaller. At a 10 per cent discount rate. $\$ 100$ received one hundred years in the future is only "worth" 1 cent today.

Since discount rates reflect many factors, there is no single, unique rate in any setting. The implicit, or explicit, discount rate will vary depending on the perspective of different individuals or 
Table 4.1: The present value of $\$ 100$ received in future years at various discount rates

\begin{tabular}{|c|c|c|c|c|}
\hline \multirow{2}{*}{$\begin{array}{c}\text { Time } \\
\text { (year) }\end{array}$} & \multicolumn{4}{|c|}{ Discount Rate } \\
\hline & $2 \%$ & $5 \%$ & $8 \%$ & $10 \%$ \\
\hline 0 & $\$ 100.00$ & $\$ 100.00$ & $\$ 100.00$ & $\$ 100.00$ \\
\hline 10 & 82.03 & 61.39 & 46.32 & 38.55 \\
\hline 20 & 67.30 & 37.69 & 21.45 & 14.86 \\
\hline 25 & 60.95 & 29.53 & 14.60 & 9.23 \\
\hline 40 & 45.29 & 14.20 & 4.60 & 2.21 \\
\hline 60 & 30.48 & 5.35 & 0.99 & 0.33 \\
\hline 100 & 13.80 & 0.76 & 0.05 & 0.01 \\
\hline
\end{tabular}

Note: Different combinations of discount rates and time will yield the same present value of the same amount of money received in the future. For example, a present value of $\$ 14$ to $\$ 15$ is yielded by a $\$ 100$ benefit received 100 years in the future if the discount rate is 2 per cent; at a 5 per cent discount rate the present value of $\$ 100$ declines to $\$ 14$ in 40 years' time; for an 8 per cent discount rate the decline to $\$ 14$ occurs in only 25 years in the future, and with a 10 per cent discount rate it takes only 20 years (see the dotted line in the table).

groups. As a result, different discount rates often cause a divergence between public and private benefit - cost analyses. The government planner may use an explicit rate of 7 per cent, for example, while the farmer uses an implicit rate of 20 per cent. Thus, land management projects that the government sees as being clearly profitable in the long run may seem unprofitable to the farmer, the person expected to adopt and implement the project.

The time horizon and the discount rate are separate decision parameters. An individual may adopt a certain planning horizon; and because of his or her discount rate, the contribution of certain future benefits or costs to net present value (NPV) may be close to zero. On the other hand, an individual may adopt a very short planning horizon that ignores benefits and costs beyond that horizon.

Land tenure arrangements also affect time horizons. A farmer who owns his or her own land will tend to take a longer planning 


\section{The Economics of Dryland Management}

horizon than a tenant farmer or one who is illegally cultivating government land. This is mainly because of uncertainty about future access to the resource, which leads to lack of interest in long-term maintenance. In this case future benefits and costs are ignored, regardless of the discount rate.

Thus, land degradation can result from a series of different circumstances - long time horizon with high discount rates and short time horizon with either high or low discount rates. When government involvement is introduced, the situation is even more complicated. Governments tend to adopt longer time horizons (because of concerns with social well-being and resource sustainability) and use lower discount rates than private individuals. In effect, the farmer gives less consideration to long-term effects than the government and may ignore some effects included in the government analysis, although both are considering the same project. For example, many rehabilitation projects with very long-term benefits are considered economically unattractive by those directly affected, because, while present costs are included at full value, discounting reduces the long-term benefits to small or negligible amounts.

In situations like this, the answer is not to change the discount rate so that long-term benefits are given greater weight. Rather, the analysis shows why government and farmer view the project differently. The task will be to design a set of policies (taxes, subsidies or other incentives) to ensure that the farmer will also see the activity as profitable and therefore undertake it. This may be via regulations or enforcement (although coercion tends not to work well); more likely the best approach will be by use of a subsidy or some payment to decrease the apparent cost of initial investments. This will increase the profitability of the project to the farmer and make him or her more likely to undertake it.

In situations of severe distress (such as during a drought) the time horizon used by the individual may be measured in months, not years. Thus, the analyst needs to understand the perspective of the land user in order to design efficient and acceptable projects and programmes.

Many of the points raised here and in the following chapters can be found in the case study in Chapter 11, which concerns the analysis of a soil conservation project being implemented in Maphutseng, Lesotho. The project is designed to improve farm incomes by means of both infrastructure development (rehabilitating old terraces, constructing new ones, upgrading drains) and 
improved agronomic practices (introducing new seed varieties, reforestation, improved grazing systems). In this study both financial and economic analyses were carried out. As there was no clear policy from either the government or the donor as to what discount rate was acceptable, a 5 per cent rate was selected to represent the opportunity cost of capital. (The financial analysis, carried out from the perspective of the individual farmer, relied on a calculation of net return to labour on a yearly basis to measure profitability.) A twenty-year time horizon was selected for the conservation project, with sensitivity analysis carried out using ten- and fifty-year time horizons. Details are given in the study.

\section{Breakdown of resource management systems}

Common property is generally well managed where appropriate institutional arrangements control its use. In a traditional tribal situation, for example, the individual feels a strong tie to other tribal members and will regard costs imposed on them as being his or her own; or a community may have developed rules for resource use that ensure its sustainability. However, in many cases these systems break down when population growth creates increasing pressure. Other causes also can lead to breakdowns. For example, in Africa the advent of colonial rule in the nineteenth century led to the breakdown of traditional mechanisms (such as sharing of pasture, responses during drought) for ensuring sustainable use of resources.

Some people have suggested that privatization of all land is the only answer to these land resource management problems. This is not generally true. In many cases relatively small changes in the property rights regime may help. Access to resources can be restricted to a certain number of people, or limits can be placed on the quantity of the resource that each individual can take. Quotas on the use of irrigation water are one example. In the dryland context, stocking permits or control of access can provide a degree of control, if they are enforceable. Another alternative is regulating the period or season during which a pasture can be used. Enforcing such restrictions raises issues of programme implementation and political will. Some of these issues are discussed in Chapter 10.

\section{Renewable and non-renewable resources}

Most resources can be classified as non-renewable (coal, oil, most minerals) or renewable (wind, sun, rain, many rivers). Renewables range from those resources that are almost impossible to deplete or 
degrade (for example, sunlight, tides, wind) to those that need careful management in order to use them in a sustainable, renewable manner. The latter includes such resources as groundwater aquifers, wildlife and fishery stocks, agricultural and grazing lands. Economic theory also uses the terms "flow" and "stock" resources to refer to renewables (which produce a flow of goods and services over time) and non-renewables (a fixed stock to be depleted or consumed over time, although during depletion a flow of goods and services is produced).

Soils, and associated patterns of land use, fall somewhere in between. Soils may be treated as a non-renewable or exhaustible resource to be "used up" and degraded, or they can be maintained in a way that produces a sustainable level of output over time. Water resources, especially groundwater but also surface sources, can similarly be treated as either renewable or non-renewable resources.

In dryland areas, the vulnerability and fragility of the systems are such that many of the basic resources (largely land and water) fall in the transitional zone between being renewable and nonrenewable resources. Although the goal of "sustainable development" is laudatory, it is not always economically optimal to use resources in a sustainable manner, especially when viewed from a private perspective. As already pointed out in this chapter, people use resources in a way that maximizes net benefits given their own situation and perspective. This can result in sustainable development; in many cases, however, especially in many arid and semi-arid areas, this "rational use" can lead to degradation - the changing of land and water resources from renewable into non-renewable resources. The pressures on the poor to meet present-day needs conflict with the need to use resources at sustainable rates in the long term. This can result in irreversible changes. In some circumstances, it may be economically efficient, from both a private and a public perspective, to deplete a renewable resource. A fuller discussion on the management of drylands as a renewable resource follows in Chapter 5 .

\section{Irreversible damage to resources}

In the simplest sense, an irreversible change is one that is permanent and cannot be altered. Economists, however, tend to view irreversibility in a slightly different fashion. Some consider a decision irreversible if it significantly reduces future options for a long period of time (Henry, 1974) or if it limits the range of actions 
that can be taken subsequently (Miller and Lad, 1984). Others take a different view - a decision is rarely irreversible per se but may require such a large investment in time, resources or technology as to render it effectively irreversible. (Extinction of species is one type of irreversible change that, by definition, cannot be reversed.)

In reality, irreversibility is a matter of degree. The clear-cutting of a forest in a semi-arid area may mean that centuries are required before a similar ecosystem is re-established, if at all. Clearly, the time element plays a crucial role in the degree of irreversibility of an action. In addition, the extent to which the regenerated state replicates the original state is a factor in the degree of irreversibility.

Irreversible land degradation can be divided into two categories. In the first category, fallowing or "passive repair" can reverse past damages, but if the length of time necessary for rehabilitation exceeds the limits of an appropriate time horizon, the damage may be considered irreversible. This can occur if, for example, all topsoil is lost through erosion and must be reformed by natural processes over hundreds or thousands of years.

The second category of irreversible land degradation would encompass land that has been degraded and, even if left fallow, would not return to its original condition. For example, severe gully erosion will rarely reverse itself. In some cases, rehabilitation techniques can reverse this degradation, but if the cost and resources necessary for rehabilitation are too high, or the technology needed for reclamation is unavailable, the damage can again be considered irreversible.

Irreversibility and the drylands. The fragility of dryland environments makes them vulnerable to degradation if improperly used. Once this degradation begins, it is often self-accelerating and eventually may cause irreversible damage to the land. Irreversibility in this case can mean either that the costs of rehabilitation are so high as to make it unfeasible, or that no technology exists to reverse the degradation.

Many developing countries that have large proportions of drylands have few alternative means of production if these lands are lost. Foreign exchange is often scarce, and if food is not produced at home, shortages often occur. Since much of the land is used for subsistence purposes, it has a very high value to those who depend on it.

Concern about disappearing agricultural land is not new. Because these lands are in fixed supply (though this supply can be increased somewhat through clearing of forests, use of irrigation 
and other technologies), the relative value of agricultural land in the future may rise as populations increase and more food is needed. This will be offset somewhat by technological developments that allow more food to be grown on a given piece of land, but it may be difficult to predict which of the two effects will be dominant. It is possible that such lands will be worth more in the future than they are today. As a result, even when the costs of protection and rehabilitation are greater than the expected benefits based on the present value of the land, this is not always sufficient justification for avoiding action.

In the drylands, a delay in implementing protection or rehabilitation may result in irreversible damage. As a result of the uncertainty about the future value of the land, if the opportunity cost of preventing irreversible damage is low, then it should be prevented from occurring. Determining how much should be spent is a difficult question. Both the discount and the degree of uncertainty will affect this decision.

\section{Risk and uncertainty}

Complete knowledge or absolute certainty is rare in the real world. For most activities we can only roughly predict expected outcomes. In some settings the variability of outcomes is larger than others. Chapter 2 explained why dryland agriculture and grazing are usually more variable than in wetter locales. Economic evaluations of land-use alternatives for dryland resources, as well as of programmes and projects designed to combat degradation processes, must allow for risk and uncertainty.

The end results of the presence of risk and uncertainty are similar - a greater variability in expected outcomes. However, a technical distinction is usually drawn between risk and uncertainty (Howe, 1979; Pearce and Nash, 1981). Risk can be defined when the probability distribution of a stochastic (random) variable is known. In the dryland context, historical records can indicate the probability of drought or rainfall, even though these events cannot be predicted for a particular year. Agricultural crops may be planted with the expectation that every so many years a failure will occur. Extended drought may also be expected based on historical probabilities.

Uncertainty is associated with incomplete knowledge and may take several forms. The physical characteristics of dryland resources and the impacts of human activity may not be fully known. There may be gaps in information on socioeconomic values. Uncertainty may prevail also on the probability distributions 
of stochastic variables. Techniques based on decision theory can be used to deal with the problem of uncertainty.

Risk and uncertainty are discussed in considerable detail in Chapter 8.

\section{Design of an economic analysis}

The actual design of any economic analysis will, of course, depend on the particular problem being examined. Nevertheless, in evaluating policies, programmes and projects, some major tasks need to be performed, including the following:

- identification of the problem;

- prediction and quantification of the impacts of land-user behaviour and alternative public policies;

- application of economic assessment methods to establish policy priorities; and

- arriving at recommendations for action.

Careful judgement is always required in applying economic techniques to public policy. Certain guidelines must be observed, and in the case of dryland management a number of special difficulties must be addressed.

In evaluating policies, programmes and projects, a comparison of alternatives is necessary - one "with" the proposed plan of action and one "without". Only benefits and costs resulting from the action should be considered. Costs avoided should be included as a benefit. Costs already incurred or benefits already realized should be excluded.

\section{Techniques of economic analysis}

A number of economic analytic techniques are potentially applicable to the evaluation of dryland problems. The choice of the most appropriate technique for a certain type of project will depend on several factors. First, the information available and the data that can be feasibly gathered will determine whether a given technique can be employed. Some techniques require a great deal of information, while others are more modest in their data requirements. Second, the time and resources available to the analyst may limit the choice of technique. Finally, the type of result required will affect the 
choice of technique, since different techniques answer different kinds of questions.

All of the economic evaluation techniques described in this book are based on the observed actions of individuals. This is true whether the farmer is part of the market economy or the subsistence economy.

It is often important to make a correct financial analysis of a proposed project. Financial analyses are handled somewhat differently than a social welfare economic analysis. Details of financial and social benefit - cost analysis (SBCA) techniques are presented in Chapter 6 and are illustrated by the Lesotho case study (Chapter 11). There is also a set of analytical techniques that only use cost information and do not attempt to measure benefits. Costreffectiveness analysis (CEA) is discussed in Chapter 6, and other cost analysis techniques are covered in Chapter 7 . These techniques are particularly useful in assessing alternative projects or programmes for certain public services (for example, education and health care) where benefits are hard to value in monetary terms.

Decision analysis and computer simulation models can be used in conjunction with SBCA and CEA for more complex problems. For example, linear programming models and input - output models can be used for sectoral development planning and are especially useful in analysing broad development options and providing infrastructure and community services. Techniques based on decision theory can be used to deal with the problem of uncertainty, which is common in dryland management problems. These are discussed more fully in Chapters 8 and 9.

\section{References}

Dixon, J. A. and M. M. Hufschmidt (eds) (1986),

Economic Valuation Techniques for the Environment: A Case Study Workbook (Baltimore, Md: Johns Hopkins University Press).

Dixon, J. A., D. E. James and P.B. Sherman (eds) (1990),

Dryland Management: Economic Case Studies (London: Earthscan Publications).

Dixon, J. A., R. A. Carpenter, L. A. Fallon, P. B. Sherman and S. Manopimoke (1988),

Economic Analysis of the Environmental Impacts of Development Projects (London: Earthscan Publications).

Gittinger, J. P. (1982),

Economic Analysis of Agricultural Projects, 2nd edn (Baltimore, Md: Johns Hopkins University Press for the World Bank). 
Haveman, R. (1969),

"The opportunity cost of displaced private spending and the social discount rate", Water Resources Research, 5,pp.947 - 57.

Henry, C. (1974),

"Option values in the economics of irreplaceable assets", Review of . Economic Studies, Symposium of Exhaustible Resources, vol.41, pp.89 -104 .

Howe, C.W. (1979),

Natural Resource Economics (New York: Wiley).

Hufschmidt, M. M., D. E. James, A. D. Meister, B. T. Bower and J. A. Dixon (1983),

Environment, Natural Systems, and Development: An Economic Valuation Guide (Baltimore, Md: Johns Hopkins University Press).

Miller, J. R. and F. Lad (1984),

"Flexibility, learning and irreversibility in environmental decisions: a Bayesian approach", Joumal of Environmental Economics and Management, vol.11, no.2, pp.161-72.

Pearce, D. W. and C. A. Nash (1981),

The Social Appraisal of Projects: A Text in Cost -Benefit Analysis (London: Macmillan).

Wang, G. S., W. D. Wu and F. R. Li (1990),

"Economic evaluation of environmental effects of a land levelling plan in Weibei dry upland, Shaanxi, China", in Dixon, James and Sherman, op. cit. 


\section{Managing Drylands as Renewable Economic Resources}

This chapter examines drylands as a renewable economic resource. As discussed in previous chapters, dryland management involves a complex interplay of physical, climatic and human factors. Patterns of dryland use range from those of nomadic pastoralists to subsistence farmers to highly commercial farming or ranching operations. Each group will respond to management options and environmental stress differently. Even though drylands are potentially renewable economic resources, their fragility makes them more susceptible to over-exploitation and degradation. This chapter examines these issues within an economic framework and considers various options for improved land management practices.

\section{Renewable production systems in dryland areas}

\section{Sustainable production from dryland ecosystems}

From an economic viewpoint, dryland areas can be considered a capital stock, capable of yielding a stream of goods and services indefinitely if properly maintained and managed by those people dependent on the resource. The concept of sustained yields has been strongly advocated by the World Commission on Environment and Development (1987) as the basis for future economic development, especially in developing countries.

Dryland ecosystems typically have low productivity. Their performance is highly variable; damage to both the physical and social systems can easily occur if the resource base is over-exploited. Long recuperation times may be needed for damage to be repaired. In some cases damage is, for all practical purposes, irreversible.

Conway (1985) has explained the concepts of productivity, stability, sustainability and equitability in terms of agroecosystems (see Figure 5.1). Productivity is defined as the net increment in production per unit of input and is measured as annual yield, net income or gross margin. Stability is the degree to which productivity 
Figure 5.1: The system properties of agroecosystems

HIGH
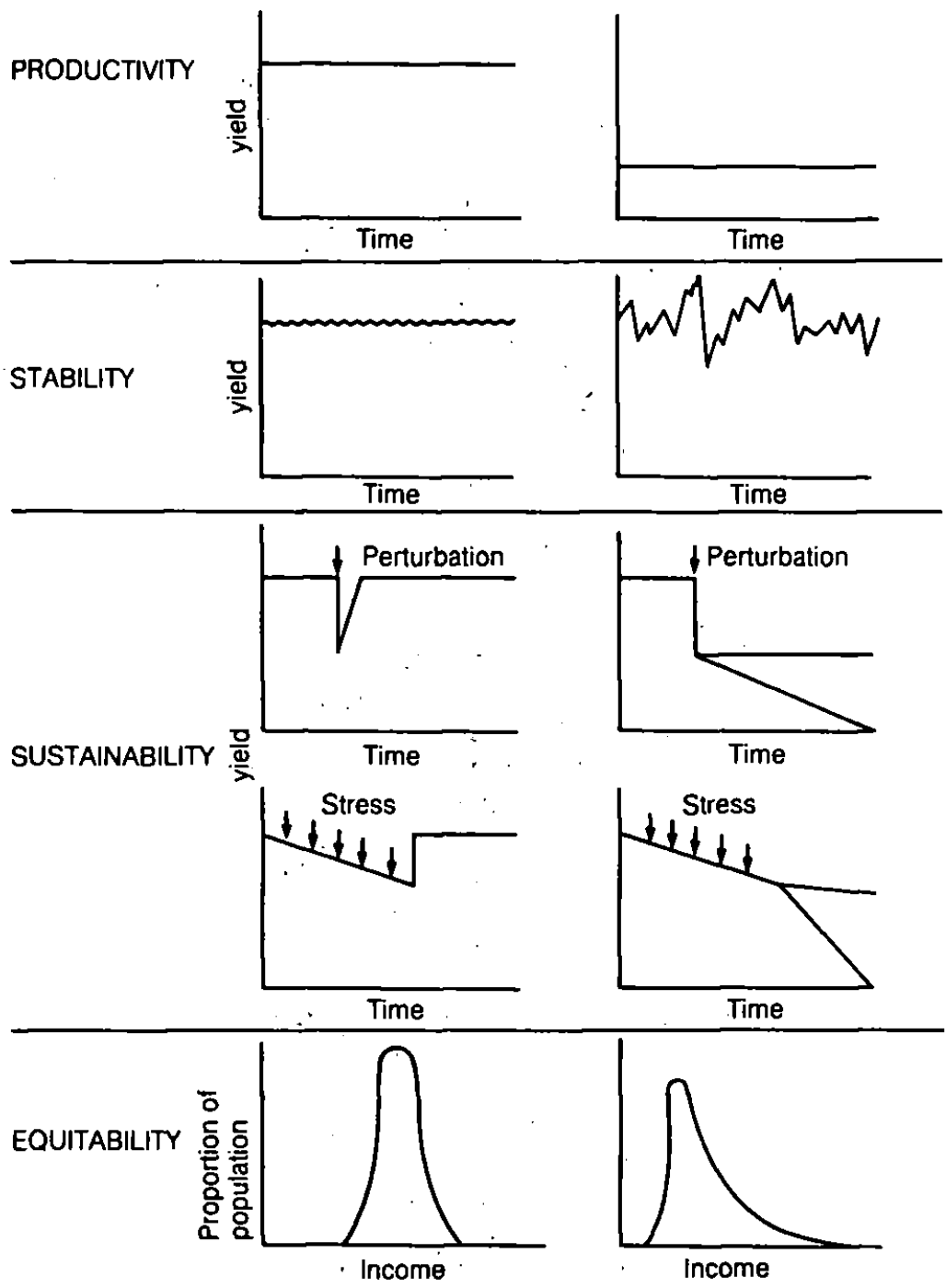

Source: Conway, 1985. Reprinted by permission of the publisher. 
remains constant, allowing for normal, small-scale fluctuations in environmental variables. Sustainability refers to the capacity of a system to maintain its productivity when subject to stress or perturbation. Equitability is a measure of the distribution of products among people.

Each of these four characteristics is important in understanding dryland management. Productivity and equitability are concerns of all production systems; drylands, however, are particularly sensitive to variations in weather and patterns of resource use. Stability, therefore, is a major concern of dryland inhabitants. Sustainability, the ability of a system to "bounce back" from a stress, is perhaps the most difficult factor to manage. Economic analysis of management alternatives, therefore, has to incorporate the risks associated with random events and the possibility that the dryland system may not be able to recover, at least in a reasonable period of time. Sustainability is also directly linked to carrying capacity, the ability of any system to support individuals or animals on a continuing basis. Carrying capacity is usually measured in terms of the number of animals (or people) per ha or $\mathrm{km}^{2}$. The poorer the quality of rangeland, for example, the lower is its carrying capacity for animals.

Another important concept in the management of dryland resources is that of maximum carrying capacity, which can be applied to both human and animal populations. Upper limits, consistent with sustained yields, depend on environmental characteristics, applied technology and management practices.

Limiting factors vary. For example, the availability of water may determine the maximum carrying capacity for grazing animals in some situations, whereas in others the availability of fodder may be the key constraint. Increasing the supply of the limiting factor will increase the carrying capacity of the land until another factor becomes limiting. For example, in some areas borehole development has changed the limiting factor from water to fodder; this has then resulted in overgrazing and consequent land degradation.

The ability to support human populations depends greatly on economic opportunities and social systems. According to Cossins (1986), subsistence pastoralism in Africa is sustainable only if at least four to five livestock units are available for each person. Given the low stocking rates of these areas, only a few people can be supported per $\mathrm{km}^{2}$. In areas where mixed farming is practised, the carrying capacity of the system may be much greater. Still higher population densities may be supported if agriculture and grazing 
are supplemented by economic activities such as mining and manufacturing.

The occurrence of drought, and the adaptation to drought, are important factors in determining maximum livestock carrying capacity. Domesticated animals may be slaughtered or left to die. Alternatively, they may be moved to other areas, sold or maintained through supplementary watering and feeding if such options are available. For many poor pastoralist groups, only death or sale of animals are possibilities. Quite different adaptive responses may occur for wild animal populations. Survival often depends on migration, changes in reproductive patterns and shifts in feeding habits.

\section{Products of dryland areas}

Several broad categories of products can be raised on a sustained yield basis in dryland areas. The first is rainfed crops, which are usually grown on an annual basis. Management decisions include the best species and varieties to use, the timing and intensities of sowing and optimal harvesting times. Availability of and variation in rain and other water sources are major concerns.

The second products category is irrigated crops, where water is not as limiting a factor as in rainfed areas. The timing of sowing and harvesting is less critical and more than one crop may be grown each year.

A third category is animal populations, both wild and domestic. This renewable resource has the potential for continuous yields. Management decisions are required concerning land-use and herd characteristics, such as herd size, age and species composition, and reproduction rates. A sustainable flow of products can be obtained from each individual animal (wool, milk, blood, dung) or from the whole herd, such as an offtake of live animals for meat:

A fourth category is dryland forest resources. In some cases, each tree is capable of yielding a continuous flow of products such as fuelwood (loppings or fallen branches), fruit, honey and fodder. In other situations, the trees must be cut to yield the products desired (sawn timber, poles, woodchips and fuelwood). Any forested area can be managed so that a continuous yield is obtained by proper rotation of cutting and replanting.

The preceding product categories are all potentially renewable; that is, they regenerate naturally, usually within a time frame of one to several years. Annual crops have the most rapid turnover time, followed by grazing systems. Even dryland forestry can 
frequently be managed on a sustainable, if fairly long-term, basis.

\section{Economic management objectives}

The primary goal of economic management of dryland resources is maintenance of or improvement in the welfare of the people who depend on them. In extreme circumstances, survival is the obvious aim. Where conditions are less severe, a more appropriate goal is the maximization of net economic benefits, that is, selecting a management strategy that yields the greatest economic benefits after all costs are deducted.

In economic terms, the preservation or maximization of economic welfare may mean continued maintenance of long-run, average steady-state conditions. This involves establishing a pattern of production each year, or for a succession of years, that maximizes the difference between total benefits and total costs. Provided the natural-resource base is preserved, this pattern may be repeated indefinitely. Certain traditional forms of dryland agriculture and grazing fit this pattern and have been carried out for thousands of years without the occurrence of resource degradation. New forms of conservation farming (for example, farming approaches using minimum tillage, recycling and other soil and nutrient conservation measures) should also be feasible on a long-term sustainable basis.

It may not always be possible to maintain a steady-state situation because of continually changing conditions, especially weather variations and changes in human or animal populations. If human needs do not impose severe constraints, variables such as stocking rates, harvest rates and revegetation rates can be controlled over time to maximize the present value of net benefits. The productivity of a renewable resource, such as a forest or herd of animals, is often closely dependent on the size of the standing stock. Economic considerations may call for a reduction in standing stocks, a switch to new activities or periods of nonproduction. (We realize that a very poor, subsistence-level farmer or pastoralist may not be able to use these options.)

To handle the stochastic conditions typical of dryland environments, special risk-management strategies may be required. In principle, the optimal economic approach will lead to a maximization of "average" net benefits. The difficulty here is that the term "average" has a number of different interpretations and measures. In addition, the attitudes towards risk on the part of land users and public decision-makers will partially determine what is 
"optimal" from an economic viewpoint. Management strategies may be deliberately designed to minimize exposure to risk and to deal with the effects of risk, while others may be designed to maximize anticipated economic returns, regardless of the risk involved. These matters are discussed more fully in Chapter 8.

\section{Degradation: causes and corrective actions}

\section{Perspective of the land user}

Many factors underlie the behaviour of land users: social systems and cultural values, market and non-market forces and land tenure among others. Human interaction with the land can depend on whether the land is leasehold, freehold or a common property resource. Use rights are a key factor, whether based on cultural traditions, legal provisions or government regulations.

An economic explanation of land degradation begins with observed land use. The land user often has a shorter time horizon than society at large, and may value present consumption much more highly than future benefits. When threatened with starvation, people will naturally attempt to extract whatever is possible from the resource, regardless of the effects on future productivity. (In economic jargon, the problem is one of high discount rates and short planning horizons.)

Long-term steady-state yields can be achieved in dryland areas, even where the resource or stock is potentially consumable, as in dryland forestry and grazing. Inappropriate management may lead, however, to inefficient or high-cost production (see Box 5.1 on fuelwood gathering).

\section{Box 5.1: Fuelwood gathering}

A simple conceptual model of fuelwood gathering from a dryland forest gives an economic explanation of how resource degradation can occur. In Figure 5.2(I) the growth of the forest over time is represented by a logistic curve. At first the trees grow rapidly, but eventually growth ceases, constrained by available water, space, sunlight and nutrients. In Figure 5.2(II) the sustainable yield of wood, measured as the net increase in biomass, is shown as a function of the standing stock. It is assumed that the net increase is harvested to maintain a steady state. The sustainable yield first increases with the size of the stock, reaches a point of maximum sustained yield (MSY) and declines again at higher stock sizes.

The average costs of harvesting are assumed to increase as the stock 
becomes smaller, since trees are more widely spaced or smaller in average size. In market economies these costs are monetary, but in subsistence communities average costs are reflected in the time and distance needed, usually by women and children, to gather twigs and branches. Figure 5.2(III) shows the average cost of sustained yields. Points $A^{\prime}, B^{\prime}$ and $M S Y^{\prime}$ on the average cost curve correspond to points $A, B$ and $M S Y$ on the yield curve of Figure 5.2(II). Each level of sustained yield will involve two possible levels of average cost. At very low stock sizes, average costs approach infinity. Over-exploitation of the resource will lead to depletion of the stock and generally high levels of average cost.

The aim of policy should be to allow the forest to regenerate, increase the availability of trees and encourage harvesting at lower levels of average cost. Although maximum physical yields occur at points MSY and $M S Y^{\prime}$, this may not represent the economic optimum. The point of maximum net economic benefits will depend on the trade-off between the social benefits of the yield and the costs incurred to obtain that yield.

A similar conceptual model is developed for extensive grazing management in the study by Wilcox and Thomas (1990) in Dryland Management: Economic Case Studies (Dixon, James and Sherman, 1990).

The dynamics of the resource and the time preference of land users can combine to cause over-exploitation and degradation. The actions of land users usually reflect a trade-off between current use and desire to preserve the resource, thus allowing it to grow to meet needs in the future. Harvesting (of trees or animals) generates an immediate economic return, but at the same time involves an opportunity cost which is equal to the present value of the future return that could have been earned by letting the stock grow to a larger size. This cost is known as a resource "user cost". If the rate at which people discount future benefits exceeds the natural growth rate of the resource, people will prefer to harvest the stock immediately. Discounting by itself will not necessarily result in resource degradation, but it does tend to lead to a lower stock size (Clark, 1976; Lecomber, 1979; Fisher, 1981).

The ability of land users to invest in land maintenance and improvement is often limited by income and wealth. Capital may not be available, interest rates may be too high, and loan repayment schedules may not allow for the fluctuations in income that typically occur in dryland areas. In some African countries, cattle are the traditional means of accumulating and storing wealth. Endeavours by cattle owners to increase their number of cattle (stock of capital) may simply lead, especially during drought, to 
Figure 5.2: Conceptual model of fuelwood gathering

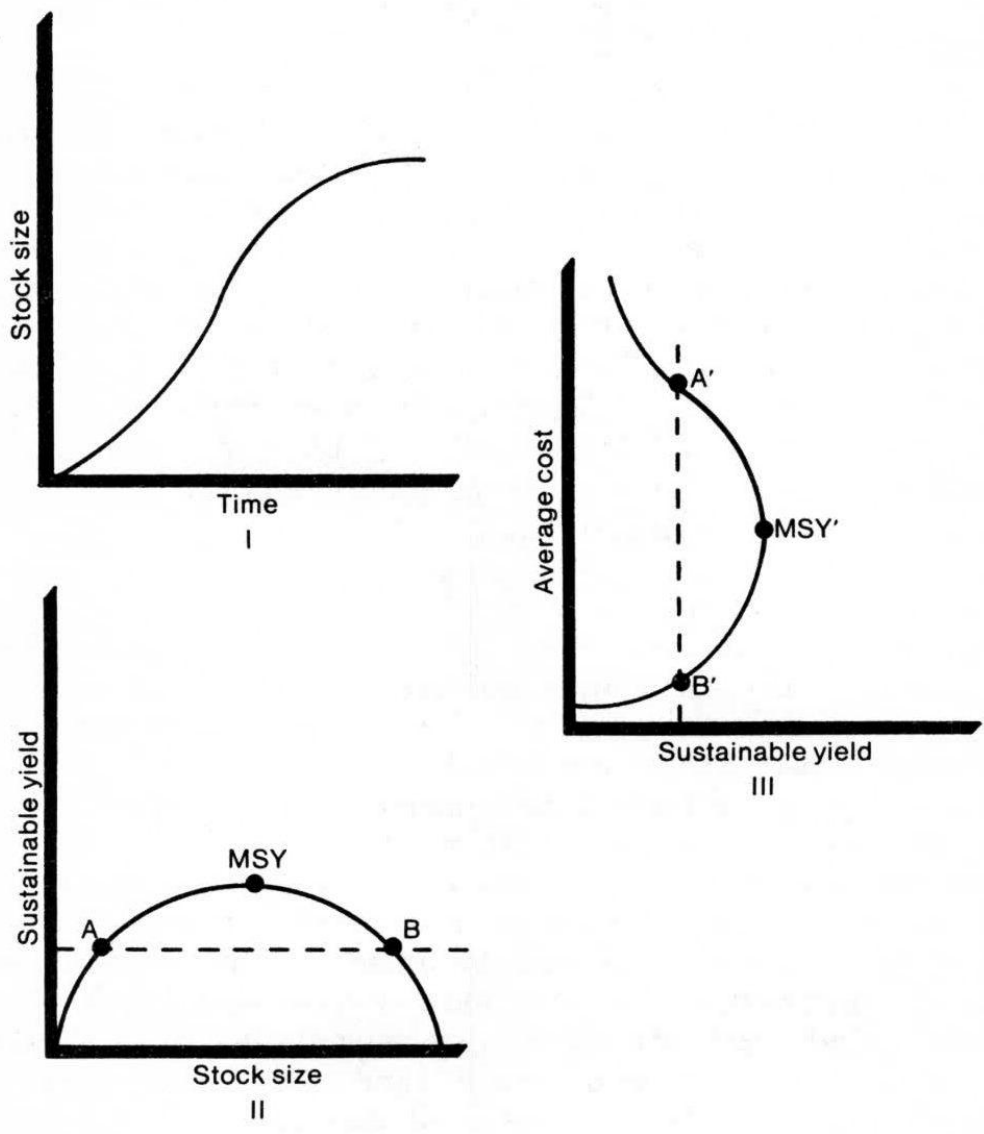

overstocking and degradation of the land resource. With low and variable incomes, people may try to maximize their current returns regardless of conditions, succeeding in the good seasons, but causing irreversible damage during drought because of overstocking, overcropping or deforestation.

Externalities and open-access common property resource effects

Resource degradation will be increased by off-site damage in the form of environmental externalities, and by improper use of common property resources. As explained in Chapter 4, off-site effects 
can result in serious land degradation. Productivity is rapidly reduced, and land users may attempt to reap as much as possible from the resource before it is completely destroyed, thereby accelerating the degradation process.

In the case of open-access common property resources, each user tries to maximize immediate returns, to the detriment of other users (in essence, they behave as if they have infinite discount rates). Harvest rates thus exceed the social economic optimum. In market-based economies, the average costs of production will increase, and market prices will be temporarily depressed because of high harvest rates. Ultimately, total costs of production will approach or even exceed total revenue, and net economic benefits will disappear. Severe degradation of the resource and destruction of resource stocks could easily follow. Public policies are clearly needed to deal with these problems and to introduce measures to prevent a decline in human welfare

\section{Corrective policies and strategies}

To reverse degradation, actions are needed to modify harvesting behaviour, encourage recuperation and restore the productivity of the land. Investment in specific programmes and projects may be required as part of this process.

From a policy viewpoint, the dynamics of adjustment - of moving from a situation involving degeneration of the resource base to one with environmental improvement - are of crucial importance. In maximizing the present value of net benefits, the behaviour of the human and natural systems, the impact of management actions and the distribution of benefits and costs over time must be carefully studied. The behaviour of the system must first be analysed in physical and economic terms; benefits and costs of alternative management actions and responses should be estimated, and strategies then evaluated on the basis of the present value of net benefits generated.

Figure 5.3 illustrates different natural system responses to a policy involving a fallow period (a period of temporary non-use) where yield (meat, fodder or fuelwood) is measured on the vertical axis and time on the horizontal axis. In Scenario 1 the land is used in a sustainable manner. In the absence of policy action, the land will normally remain in the current condition if present use levels remain constant and the land is not adversely affected by changes in environmental conditions. For all other scenarios, the land initially undergoes degradation. Under Scenario 2 the fallow 
Figure 5.3: Effects of fallowing on yields under different conditions

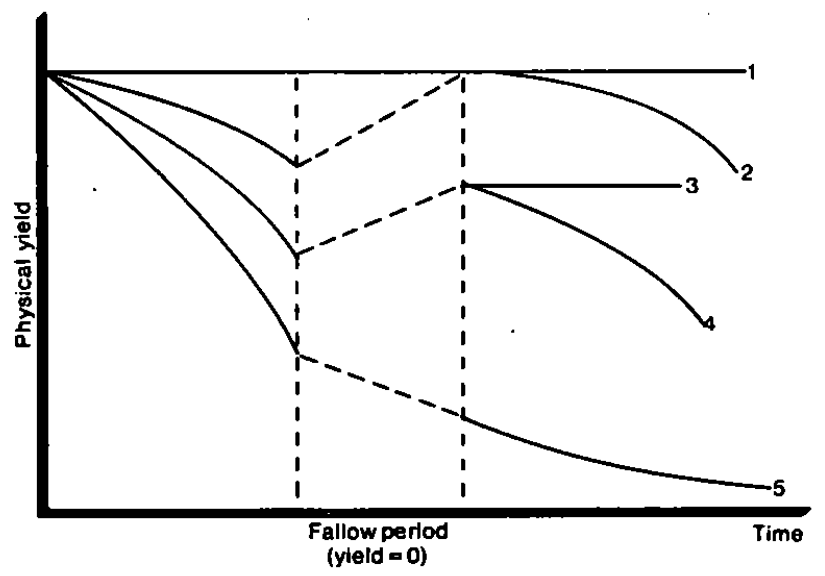

period allows the land to return to its original condition. It is assumed, however, that no subsequent corrective actions are taken, and the land begins to degenerate again. For some forms of production, this may be a perfectly acceptable strategy. The scenario accurately depicts fallowing in dryland farming in some semi-arid regions. During the fallow period, the land can store moisture within the soil and also replenish its store of nutrients and organic matter. Production can be considered sustainable in the long run if regular fallow periods are instituted.

Scenarios 3 and 4 illustrate the case where fallowing allows only partial recovery of the land, not a return to its original state. This can occur if the fallow period is not long enough or, especially in a grazing context, if certain desirable plant species have been eliminated and/or undesirable species have become established. In Scenario 3 the fallow period is followed by a change to a lower level of sustainable production, while in Scenario 4 no change in management practices occurs, and yields continue to fall. It should be recognized that, unlike Scenarios 1, 2 and 3, Scenario 4 will likely result in long-term degradation if no further management changes are instituted.

Scenario 5 depicts the situation where fallowing is ineffective in controlling degradation. In this case, the land has already degraded to a point where fallowing is not enough to stop degradation. Here, only active intervention such as the construction of erosion control structures or addition of inputs such as fertilizer can 
reverse the trend. An example of this might be severely overgrazed rangeland where erosion has resulted in small gullies before the fallow has begun. Even if the land is not used, the gullies continue to expand, eventually resulting in diminished yield.

Figure 5.4: Alternative investment programmes to improve land productivity

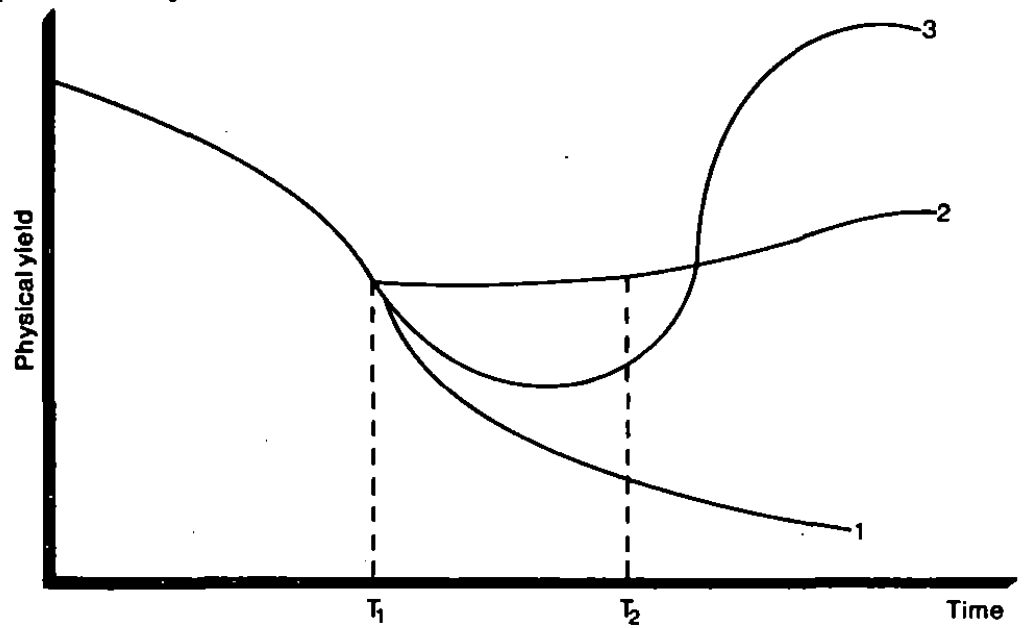

Figure 5.4 reflects two alternative paths to sustained yield where different types of investment in land improvement are introduced. The reference curve is Scenario 1, which shows the trend towards land degradation in the absence of corrective action. Investment is assumed to occur during the time period from $T_{1}$ to $T_{2}$. For the example shown, the duration of the investment phase is the same for the two alternatives. In general, this need not be the case, since investment programmes typically differ in their time requirements. Scenario 2 involves moderate-cost investment in a seeding programme combined with some land forming such as the construction of moisture ponds, which stabilizes yields and prevents further deterioration of the resource. Scenario 3 requires heavy investments in wells, fences and irrigation. The land productivity is temporarily impaired while the schemes are being introduced; but, once the improvements take effect, yields rise dramatically, surpassing those in the initial situation.

Physical effects can be converted into time streams of costs and benefits. In Figure 5.5, a comparison is made between two policy options (I and II) for rehabilitation. Over-exploitation and collapse 
Figure 5.5: Time streams of benefits, costs and net benefits for land improvement options
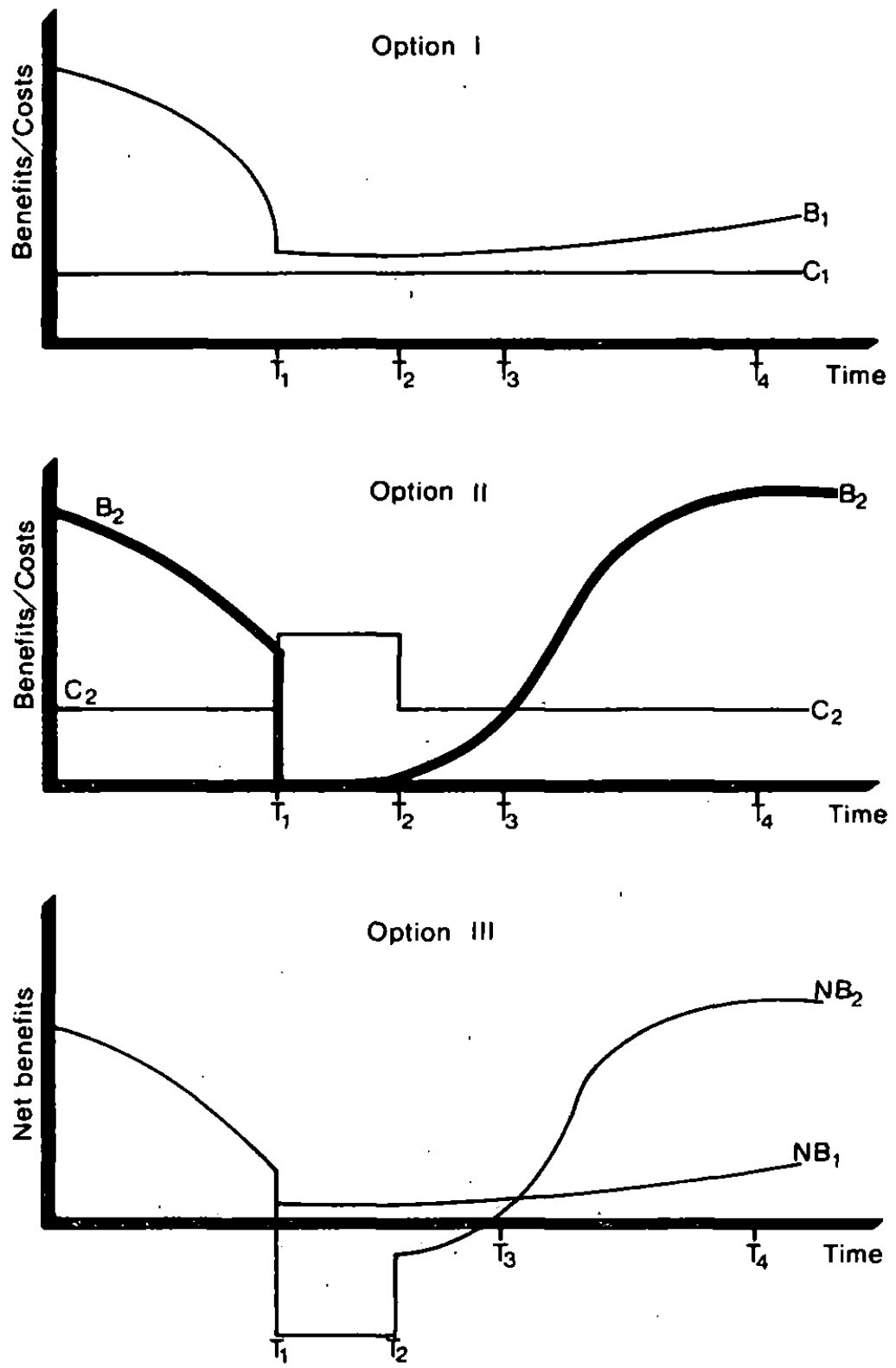
of the resources are common to both scenarios in the initial phase. Corrective strategies begin at point $T_{1}$ in time.

The first option, shown in Figure 5.5(I), involves a temporary reduction in land-use pressure, allowing the resource to recover naturally. A long recuperation time is assumed. Total costs $\left(C_{1}\right)$ remain constant. Total benefits $\left(B_{1}\right)$ initially fall, but gradually increase as productivity of the resource improves over time. The second option, shown in Figure 5.5(II), involves a rehabilitation investment programme in the period from $T_{1}$ to $T_{2}$. Total costs $\left(C_{2}\right)$ rise dramatically during this period, but are otherwise assumed to remain constant. Total benefits $\left(B_{2}\right)$ fall dramatically during the investment phase, but recover rapidly as a result of the corrective investment.

Net benefits for the two options are shown in Figure 5.5(III). In the short run, higher net benefits are earned under a policy of reduced pressure, but in the long run much higher net benefits are generated by the investment programme.

In comparing the two alternatives, much depends on the selection of a time horizon and discount rate. Policies should be ranked according to the present value of net benefits (see Chapter 6). If $T_{3}$ were the time horizon for policy assessment, reduced pressure (policy I) would clearly be the preferred policy on economic grounds. Between $T_{1}$ and $T_{3}$, this policy generates positive net benefits, whereas the investment programme has negative net benefits. Longer time horizons, such as $T_{4}$, would tend to favour the investment programme (policy II), but this ranking could be reversed by adoption of a high discount rate. Future net benefits from the investment programme might then, for all practical purposes, be largely ignored in terms of their present value.

\section{Dryland agriculture and forestry}

Much of the world's cereal crops come from dryland areas. Largescale commercial farming is widely practised, especially in Canada, the United States and Australia. Small-scale farming occurs predominantly in developing countries. Traditional forms of agriculture have survived for thousands of years in developing countries, but population pressure now threatens long-tern productivity. Degraded agricultural land is being taken over by grazing, and agriculture has been extended into marginal lands. More intensive use is being made of upland areas and slopes which are highly prone to soil erosion and loss of nutrients. Adverse environmental 
effects, which initially begin on specific sites, soon extend to a regional scale.

To reverse degradation trends in cropland and forestry areas, the benefits of different management strategies must be demonstrated. If part of the benefits does not go to farmers, there is no incentive for them to adopt improved agricultural techniques. Benefits from the correction of off-site damage may be important in convincing governments and funding agencies to support prevention and rehabilitation schemes. Economic methods of valuing on-site and off-site benefits of improvement programmes and projects are described in Chapter 7.

\section{Rainfed crop management}

For the production of annual crops such as cereals, unreliable rainfall is a pervasive problem. An optimal growing strategy can be based on the probability distribution for rainfall, provided historical data are available. The land manager may attempt to maximize net returns by selecting crops according to expected rainfall. One approach is to use the long-term mathematical mean. This may, however, place undue weight on the occasional extreme drought, and a more rational strategy might be to base production decisions on the most likely set of conditions (that is, the most typical year, rather than the average year). Costs associated with crop failure can be minimized by deferring some activities, such as watering and fertilizing, until the crop is actually established (World Bank, 1985).

An important requirement for a strategy of repeated annual sowings is sufficient monetary savings, food reserves or access to credit or insurance to cover losses in poor years. If the annual level of plantings is too high, or if sub-marginal lands are brought into production, resource degradation can occur during periods of drought, especially through wind erosion of exposed soils. It may be many years, if ever, before the productivity of the land recovers. (This has commonly occurred in the Mallee districts of New South Wales and Victoria in Australia.)

\section{Dryland forestry}

In many dryland communities, fuelwood is the major source of energy, and rapid depletion of dryland forests has occurred. The problem is most acute where open access prevails (Clarke and Shrestha, 1986). Degradation processes are accelerated when people turn to animal dung as a substitute, because nutrients are no longer returned to the soil. 
Afforestation is one solution to this problem. The main economic difficulty faced in afforestation schemes is the time lag between planting and harvesting. As a result of the lack of moisture, an extended period of watering and tending is usually required. A concerted effort involving the whole community may be needed for a successful reafforestation programme. Community schemes have produced excellent results in China. Success stories in India are reported in Dryland Management: Economic Case Studies (Dixon, James and Sherman, 1990). In some societies, landlords, retain their rights to tree products even when the land is rented out. Who plants and who harvests are important considerations in promoting afforestation (see Box 5.2).

\section{Box 5.2: The Tree Patta Scheme}

The tree-planting movement in India is gathering momentum. The Tree Patta Scheme, recently proposed by the Indian Government, will give poor people usufructory rights to trees on otherwise unproductive government and community lands. The tree patta will give them rights to harvest fuelwood, fruit, and fodder from the trees without granting rights to the land itself. Permits will be given to the woman of the family or jointly to husband and wife. Regulations will govern the planting and tending of trees and ensure they are replaced if cut down. Rights to the trees are transferable with official permission, ensuring continued interest in the scheme. People will be supported by the Government until they are able to reap an income from the trees.

(UNEP/Commonwealth of Australia, 1987 p.22)

Growth rates of trees in dryland areas are generally low. This problem can be overcome to some extent by planting species that are suited to dry conditions and have relatively high growth rates. Resistance to drought is also important. Appropriate trees include species of Acacia, Casuarina, Eucalyptus and Leucaena.

A flow of forest products can be established early by continuous cropping of twigs, branches, fruit and honey, rather than felling trees. In India, this strategy is being pursued under the Tree Patta Scheme administered by the Department of Agriculture (Box 5.2).

The economics of afforestation and managing wood fuel supplies in Africa are considered in several recent papers (Anderson, 1987a p.108, 1987b; Newcombe, 1987; Schramm, 1987). Using case studies 
from Nigeria, Ethiopia, Malawi and other African countries, these papers report promising results for afforestation and wood fuel programmes that are both economically justifiable and environmentally sound. All of the authors stress the importance of a broader economic analysis of forests as part of a resources management programme. As Anderson states (1987a, p.108), there is a

need to broaden the economic analysis of afforestation projects beyond the traditional focus on the benefits of tree products themselves. If afforestation products are analysed in terms of their capacity to produce wood and other tree products, their returns in arid and semi-arid areas are generally low. However, once their benefits in terms of stemming future declines in - and the actually enhancing - soil fertility are considered, the benefits may be appreciable.

In addition, these African studies point out the important role of the private sector and individual efforts, supported by appropriate pricing policies, in undertaking afforestation. Socioeconomic considerations, including landownership patterns, are also important determinants of success.

Irrigated forestry is also proving to be technically and economically feasible in some dryland areas. Methods of irrigation and silviculture are described by Armitage (1985). The major benefits stem from the production of fuelwood and fodder and the creation of shelterbelts. Land that is unsuitable for agriculture sometimes can be used for forestry. Irrigation can support trees such as Populus and Salix that would otherwise not survive dry conditions. Species that withstand saline water and interrupted irrigation also can be selected.

\section{Appropriate farm technology}

For small-scale farmers in developing countries, an ecological approach to agriculture (agroecology) may offer the greatest promise of sustained yields. As outlined by Dover and Talbot (1987), the conditions for sustainable agriculture include:

- replenishment of soil nutrients removed by crops;

- maintenance of the soil's physical condition;

- constant or increasing humus level in the soil;

- no built-up of weeds, pests or diseases;

- no increase in soil acidity or toxic elements; 
- control of soil erosion;

- minimization of off-farm contamination of the environment;

- maintenance of adequate habitat for wildlife; and

- conservation of genetic resources.

Adoption of an ecological approach to farming can be supported by farming systems research (FSR) which takes a holistic, systems view of farm management, including socioeconomic elements. Conservation farming is one application of these principles.

Mixed farming is commonly required to implement the concepts of agroecology. To meet the problem of fuelwood shortage and declining crop yields, agroforestry is an economic and ecological solution (Child et al., 1987). Agroforestry can also be combined with grazing activities.

In Dryland Management: Economic Case Studies (Dixon, James and Sherman, 1990), successful examples are given of conservation farming in upland areas of North Thailand and agroforestry in Kenya. Economic benefits accrue directly to farmers through increased crop yields and lower water and fertilizer costs, as well as to the wider community through a reduction in off-site damage from soil erosion.

\section{Soil and water conservation}

Soil and water conservation is a natural accompaniment to improved agricultural practices. Many different technologies are available to collect and conserve water in dryland environments. Collection methods include rainwater harvesting, wells, boreholes, reservoirs and microcatchments. Supplies can be extended by using saline water and re-using waste-water.

Water supplies can be conserved by reducing evaporation from storages and the soil, preventing seepage, installing trickle irrigation and reducing losses through percolation. Demands for irrigation water can be limited by planting water-efficient crops, constructing controlled environments and reducing rates of transpiration. Further details of these technologies appear in a publication by the US National Academy of Sciences (1981).

Soil conservation may involve structural changes in landforms. In China, as reported by Wang, Wu and $\mathrm{Li}(1990)$, land levelling in the loess plateau region has resulted in significant conservation of soil and water. Despite the large initial capital outlays, favourable benefit - cost ratios have been demonstrated.

The use of mulches can appreciably slow the rate of soil loss, as 
shown in a Korean upland study by Kim and Dixon (1986). Adoption of agroforestry on hillside slopes can lead to natural terracing, with soil and water conservation. A corn/Leucaena cropping system is shown in Figure 5.6.

\section{Figure 5.6: Corn/Leucaena system}

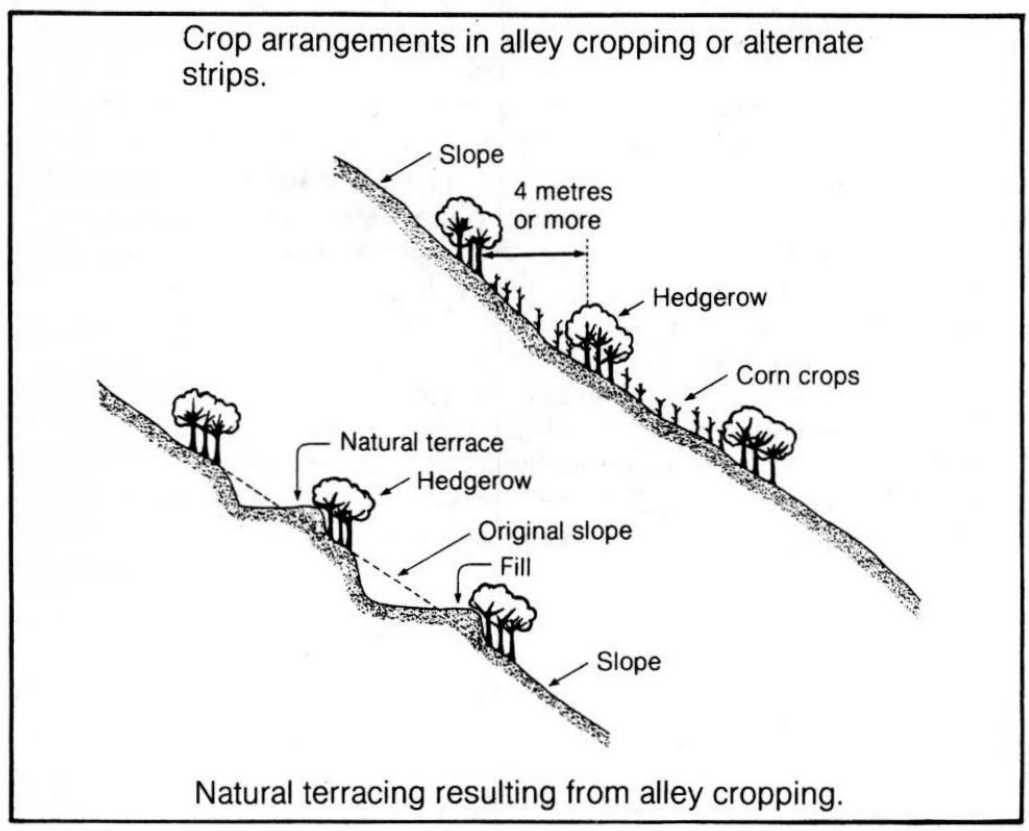

Source: Vergara, 1982.

On-site economic benefits of soil and water conservation programmes must be visible to farmers to gain widespread acceptance of new agricultural techniques. The results of such programmes, in the form of increased crop productivity and economic returns, are what matters, rather than soil conservation as an end in itself (Hudson, 1987). This change in focus from conservation to production is what Hudson calls "new ideals" (Box 5.3.).

The Lesotho case study in Chapter 11 presents an example of a soil |conservation programme that is financially attractive to farmers but economically doubtful to government because of oversubsidization of key inputs and extensive use of expatriate personnel. 


\section{Box 5.3: New ideals}

In effect a new philosophy is emerging in response to the new situation, and in many respects this is completely reversing the previous ideas. Soil conservation is no longer seen as an end in itself, an independent discipline to be undertaken by specialists who do nothing else. Soil erosion should be seen as the consequence of land use, not as the cause of soil degradation.

We should abandon the message "conserve the soil before you can get better crops" and substitute the objective "improve soil conditions for root growth and crop production, and in so doing achieve conservation of soil and water." In the new philosophy we shall not need separate conservation services, only conservation specialists within an Extension Service. The change will be helped if we drop the phrase "soil conservation" and substitute it by "land husbandry," something which should be helped through extension and research, with mechanical conservation works as something to be used only when necessary in support of biological soil conservation methods. Throughout this philosophy runs the thread that the required change can only be carried out by the farmers, so all plans and projects should be bottom-up, with full participation and support from the farmers.

(Hudson, 1987 p.22)

The study quantifies on-site and off-site benefits of the. soil conservation project.

\section{Grazing systems}

Key variables in grazing management

The main decision variables for economic management of grazing systems are stocking rates, take-off rates and composition of the herd. Other management options may include the provision of water, supplementary feed, fencing and pasture improvement. Grazing management in developing countries is discussed by Sandford (1983), among others.

Maximum carrying capacity is a key management variable. Different types of grazing animals have different needs, and the maximum carrying capacity depends on specific environmental conditions. The availability of particular kinds of vegetation, for example, may favour certain grazing animals over others. The possibilities for coexistence of domesticated and wild animals may also depend on the supply and species composition of vegetation. For 
example, in Australia, at low stock levels, kangaroos and sheep tend to be complementary feeders, whereas at high stock levels or during times of drought they can become competitive. Shifts in vegetation during different seasons can affect the carrying capacity for particular types of grazing animal (Cossins, 1986). The provision of supplementary feed (if affordable and available) can offset scarcities during droughts and dry seasons, raising the carrying capacity.

Stocking rates depend critically on the availability of water and type of animal. Camels and sheep are more efficient water users than cattle. Age is also an important factor. Young cattle and pregnant and lactating cows have much higher needs for water than mature cattle (Squires, 1981). Carrying capacity depends also on the supply and location of watering points and on the type of grazing animal. Camels, for example, can cover larger distances from watering points than other species, and thus have access to larger areas of feed.

The relationship between stocking rates and range condition is far from simple. Sustainable production of animals depends on the primary productivity of vegetation per unit area of land. If rangeland vegetation is allowed to approach a climax, net productivity will be low.

Cossins (1986) reports that on the Serengeti plains of Tanzania a quadrupling of the wild herbivore population was accompanied by an increase in primary productivity. The increased grazing pressure resulted in high compensatory growth in plants, leading to higher nutrient uptake by grazing animals. In the more common case, Cossins confirms that an increase in stocking rates can nevertheless cause degradation of the resource (for example, by increasing the proportion of unpalatable species). He also states that the timing of grazing in relation to the phenology of plant species (weatherrelated determinants of growth) may be more important than the stocking rate itself. Eventually, increasing stocking rates leads to an increase in the seasonal variability of rangeland productivity, a sharp drop in primary productivity and a major shift in plant species composition. Beyond a certain point, the process of rangeland degradation becomes irreversible.

Designing optimal offtake strategies should reflect the maximum carrying capacity of the range. There may be a trade-off between taking off a large number of animals with low liveweight per beast, or a smaller number of animals in better condition. In certain provinces of China the liveweight per beast is now only one-half that 
of the 1950s, following rangeland degradation. In addition, more stock are lost through mortality than are taken off to sell in local markets.

The age composition of the offtake should allow for reproduction and future regeneration of the herd. Management options may depend on whether stock can be readily bought and sold.

\section{Box 5.4: Conservatism and understocking}

As shown by Sandford (1982), if stocking rates are always geared to withstand drought conditions, opportunities for higher returns will be lost in better seasons. Such opportunities can be translated into "costs of conservatism and understocking". The relative magnitude of these costs depends on the degree of risk acceptance or aversion in selecting the conservative level of carrying capacity, as shown in Table 5.1. The table indicates the percentage loss of output by following a conservative rather than an opportunistic strategy. If opportunistic strategies are followed, supportive measures by governments, quite different from those normally carried out in development programmes, must be designed and implemented.

\section{Table 5.1: The costs of conservatism and understocking}

Variant of conservative strategy (expressed in terms of the risk1 in n years - of the level of carrying capacity selected proving too high)

1 in 5 years

1 in 10 years

1 in 20 years

1 in 50 years

1 in 100 years

1 in 200 years
Cost of variant where coefficient of variation of annual rainfall is:

$20 \%$
42

65

82

100

100

100

Source: Sandford, 1982. 
Handling stochastic conditions

Various management options exist to handle stochastic conditions, such as variability in rainfall. Sandford (1982) has examined the difference between the conservative approach to drought management, which sets a maximum stocking rate that can be sustained under a wide range of environmental conditions, and the opportunistic approach, which attempts to extract a higher return from the natural resource through adaptable management strategies (see Box 5.4). Sandford's analysis applies to more commercial livestock operations such as in Australia and not to smallscale subsistence-level pastoralists.

Fluctuations in production and income can be stabilized by controlling farm inputs, by regulating grazing activities themselves, by introducing insurance schemes and by improving marketing strategies.

The most difficult problems are faced during periods of drought. Animal populations respond dramatically to drought conditions. Figure 5.7 gives an historical record of drought and its effect on sheep and cattle populations in Australia from 1860 to 1970. Although the total numbers of sheep and cattle have increased over the 110-year period, drought has typically caused major short-term reductions in herd sizes.

An important farm input that can often be controlled is water supply. The provision of reservoirs or boreholes may be sufficient to counteract dry periods. The main decision is whether the increase in farm productivity warrants the necessary capital expenditure. Where water is supplied from publicly funded projects, special pricing and rationing policies may be needed to ensure that water is used efficiently and economically.

When fodder is a constraining factor, the use of fodder reserves is another mechanism for stabilizing production (Sturgess, 1979). This seems to be particularly successful in higher-rainfall areas where fodder can be grown on the farm, where severe droughts are less likely and where fodder can be purchased in local markets.

Controlling stocking rates is an alternative method of dealing with drought. In many commercial systems, stock may be sold, transported to other areas or allowed to die. There is no clear-cut preference for any of these strategies. A combination of strategies may be warranted. The optimal solution depends on factors such as the expected duration of the drought, costs and revenue for stock disposal, replacement costs for new stock and the dynamics of herd regeneration. The availability of drought 
assistance and loans may affect cash flow conditions and impose further constraints on management options.

Stabilization through markets can be achieved in various ways. An effective strategy is the development of new markets, possibly in other countries, as a ready outlet for the disposal of surplus stock during drought conditions. Processing and frozen storage of meat may help to match fluctuations in production to market demand. A switch to non-perishable dryland products, such as wool and hides, is another possibility.

In many subsistence-level systems, such as those commonly found in Africa, fewer options are available. Pastoralists may not have other resources to fall back on in time of drought, markets for excess livestock may not exist, and alternative occupations may not be available. During droughts, large numbers of animals frequently die, and available rangeland is further degraded by overgrazing.

Computer simulation modelling of dryland grazing systems

General understanding of the dynamic properties of dryland

\section{Figure 5.7: Australian sheep and cattle populations since 1860}

On scales in the ration $8: 1$, representing relative consumption of pasture. Droughts are indicated by the solid bars.

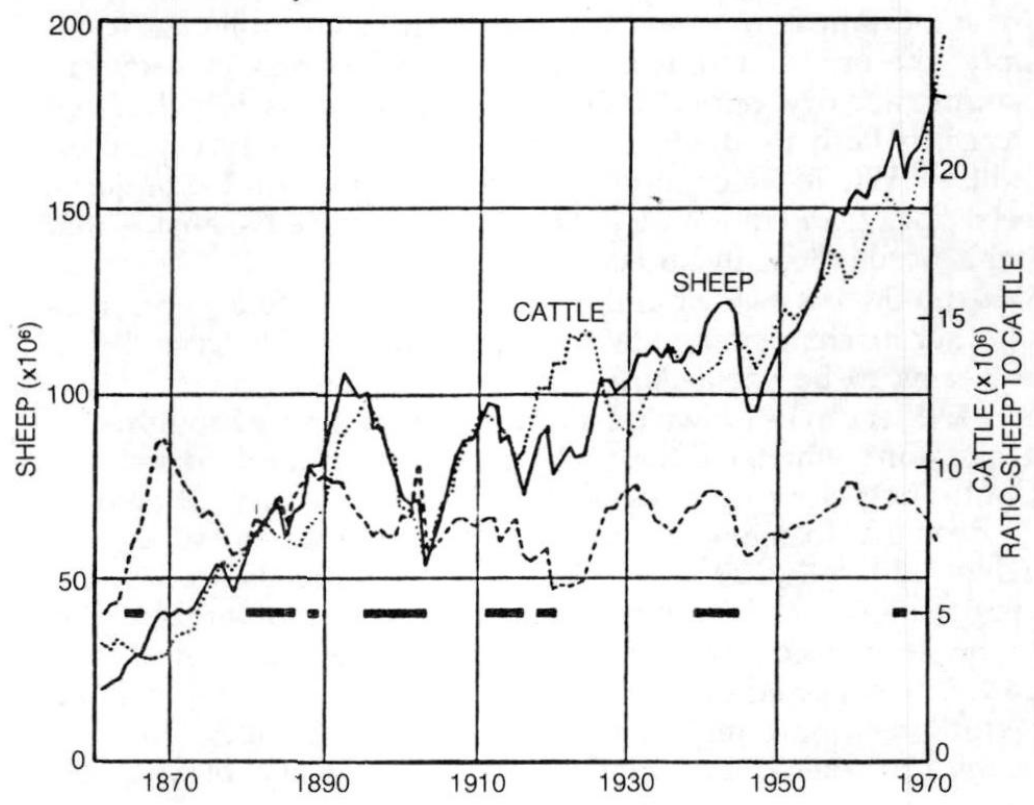

Source: Ferguson, 1979. 
grazing systems and the effects of management actions can be obtained from mathematical models, especially optimal control theory (Clark, 1976; Howe, 1979; Lecomber, 1979; Dasgupta, 1982). However, for realistic analyses, computer simulation modelling is more appropriate. One such model is described by Freeman and Benyon (1983).

The application of simulation modelling to the management of a dryland resource is demonstrated using a model for the management of livestock, rangeland and wildlife in Botswana. A more detailed model of grazing in Botswana by. Braat and Opschoor (1990) is presented in Dryland Management: Economic Case Studies (Dixon, James and Sherman, 1990). Here, the modelling methodology is briefly explained.

The specific aims of applying the model are to provide insight into the structure, risks and long-term impacts of range, nature conservation and livestock management problems, and to provide preliminary assessments of feasible alternative economic and ecological management strategies. The model concentrates on the relationships between rainfall, range area and quality, cattle herd development and socioeconomic aspects of cattle raising. (Other factors, such as small stock, competition between cattle and wildlife and alternative investment opportunities do not currently appear in the model, but could be incorporated with further effort.)

Simulation modelling involves the construction of scenarios. In general, a scenario examines the risks and effectiveness of alternative range, wildlife and livestock management strategies. Uncertainty enters via ecological factors such as rainfall and socioeconomic factors such as population growth and economic development. The outcomes of the scenarios deal with the effects on range and wildlife, livestock herds and socioeconomic welfare.

Specific management actions that are simulated in the model consist of the following:

- population growth;

- borehole development;

- range improvement;

- banning cattle from the wildlife management areas;

- controlling offtake; and

- socioeconomic policies.

There are basically two ways to use computer simulations. The first explores long-term future impacts of choices made now. The 
computer is instructed with input data representing the scenario selected, and subsequently calculates the future values for the model variables. Results are then given in the form of tables, graphs or maps offering the user a view of the future resulting from present knowledge, assumptions and choices.

The second involves a continuing process of evaluation and selection. After a preselected period of simulated time (such as three years), the user asks for a statement of the situation. Again, this is presented in the form of data tables, maps and/or graphs. The situation is evaluated, and decisions are made whether to change policies or to continue the present policies, after which the simulation proceeds for another selected period of time. In both cases the results may be printed to facilitate comparison with other scenarios.

Simulation modelling has the advantage of estimating a wide range of future "states" which reflect changes in certain key assumptions. When there are extensive interactive components, as in a dryland grazing system, the simulations are better predictors of future variations than simpler, steady-state assumptions or linear projections of past trends.

\section{References}

Anderson, D. (1987a),

"Economic aspects of afforestation and soil conservation projects", Annals of Regional Science, vol.21, no.3 (November) pp.100 - 10.

Anderson, D. (1987b),

The Economics of Afforestation: A Case Study in Africa (Baltimore Md: Johns Hopkins University Press for the World Bank).

Armitage, F. B. (1985),

Irrigated Forestry in Arid and Semi-Arid Lands: A Synthesis (Ottawa: International Development Research Centre).

Braat, L. C. and J. B. Opschoor, (1990),

"Risks in the Botswana range-cattle system" in Dixon, James and Sherman, op.cit.

Child, R. D., H. F. Heady, R. A. Peterson, R. D. Pieper and C. E. Poulton (1987),

Arid and Semi-Arid Rangelands: Guidelines for Development (Morrilton, Ark.: Winrock International).

Clark, C. W. (1976),

Mathematical Bioeconomics: The Optimal Management of Renewable Resources (New York: Wiley).

Clarke, H. R. and R. M. Shrestha (1986),

"Open access forestry and energy planning in developing countries", 
paper presented to the Eighth International Conference of the International Association of Energy Economists, Tokyo.

Conway, G. R. (1985),

"Agricultural ecology and farming systems research", in J. V. Remenyi (ed.), Agricultural Systems Research for Developing Countries (Canberra: Australian Centre for International Agricultural Research).

Cossins, N. J. (1986),

"The management of water and land resources in the traditional pastoral areas of East Africa", paper prepared for the Seminar on Water and Land Resources Management, Economic Development Institute of the World Bank, Washington, DC.

Dasgupta, P. (1982),

The Control of Resources (Oxford: Blackwell).

Dixon, J. A., D. E. James and P. B. Sherman (eds) (1990),

Dryland Management: Economic Case Studies (London: Earthscan Publications).

Dover, M. J. and L. M. Talbot (1987),

To Feed the Earth: Agro-Ecology for Sustainable Development (Washington, DC: World Resources Institute).

Ferguson, K. A. (1979),

"Future prospects for the pastoral industries", in G. Alexander and O. B. Williams (eds), The Pastoral Industries of Australia (Sydney: Sydney University Press).

Fisher, A. C. (1981),

Resource and Environmental Economics (Cambridge: Cambridge University Press).

Freeman, T. G. and P. R. Benyon (1983),

Pastoral and Social Problems in a Semi-Arid Environment: A Simulation Model (Canberra: CSIRO Computing Research).

Howe, C. W. (1979),

Natural Resource Economics: Issues, Analysis and Policy (New York: Wiley).

Hudson, N. (1987),

"Soil conservation strategies for the future", Splash, vol.3, no.3, pp.4, 22-3.

Kim, S. H. and J. A. Dixon (1986),

"Economic valuation of environmental quality aspects of upland agricultural projects in Korea", in J. A. Dixon and M. M. Hufschmidt (eds), Economic Valuation Techniques for the Environment: A Case Study Workbook (Baltimore, Md: Johns Hopkins University Press).

Lecomber, R. (1979),

The Economics of Natural Resources (London: Macmillan).

Newcombe, K. (1987),

"An economic justification for rural afforestation: the case of Ethiopia", Annals of Regional Science, vol.21, no.3, (November) pp.80 - 99.

Sandford, S. (1982), 
"Pastoral strategies and desertification: opportunism and conservatism in drylands", in B. Spooner and H. S. Mann (eds), Desertification and Development: Dryland Ecology in Social Perspective (London: Academic Press).

Sandford, S. (1983),

Management of Pastoral Development in the Third World (New York: Wiley).

Schramm, G. (1987),

"Managing urban/industrial wood fuel supply and demand in Africa", Annals of Regional Science, vol.21, no.3 (November), pp.60-79.

Squires, V. R. (1981),

Livestock Management in the Arid Zone (Melbourne: Inkata Press).

Sturgess, N. H. (1979),

"Management economies in the pastoral industries", in G. Alexander and O. B. Williams (eds), The Pastoral Industries of Australia (Sydney: Sydney University Press).

UNEP/Commonwealth of Australia (1987),

Drylands Dilemma: A Solution to the Problem (Canberra: Australian Government Publishing Service).

US National Academy of Sciences (1981),

More Water for Arid Lands: Promising Technologies and Research Opportunities (Washington, DC: National Academy of Sciences).

Vergara, N. T., (ed.) (1982),

New Directions in Agroforestry: The Potential of Tropical Legume Trees (Honolulu: East - West Center).

Wang, G. S., W. D. Wu and F. R. Li (1990),

"Economic evaluation of environmental effects of a land levelling plan in Weibei dry upland, Shaanxi, China", in Dixon, James and Sherman, op.cit.

Wilcox, D. G., and J. F. Thomas (1990),

"The Fitzroy Valley Regeneration Project in Western Australia", in Dixon, James and Sherman, op.cit.

World Bank, (1985),

Desertification in the Sahelian and Sudanian Zones of West Africa (Washington, DC: World Bank).

World Commission on Environment and Development (1987),

Our Common Future (Oxford: Oxford University Press). 


\section{Economic Appraisal of Investments in Dryland Programmes and Projects}

In many cases, countering the declining conditions in dryland areas, increasing production and improving living standards will require some form of capital investment. This investment takes various forms: investments in basic infrastructure such as roads or dams; development of marketing schemes and processing facilities; control of off-site effects of degradation such as siltation and migrating sand dunes; development of education, research and training programmes; and industrialization projects to provide alternate forms of employment. Regardless of the type of investment, some consistent form of analysis should be applied to identify desirable or feasible projects, and then to choose from among them, since it is usually not possible to fund all desirable projects.

This chapter focuses on these investment decisions. The point of reference may be the individual farmer deciding how to manage his or her own land, a group deciding how to manage communal land or a national government evaluating an investment programme composed of numerous individual projects.

Chapter 5 described the physical systems of different land uses in dryland areas. The production functions inherent in these systems and their implications for sustainable resource use are basic components of the projects analysed here. Even though political, social or cultural factors will also be important in deciding what is finally done, a correct economic analysis should be carried out to point out the economic implications of decisions.

Investment funding generally comes from one of three sectors: the private sector; the government sector or through nongovernmental organizations (NGOs). Private-sector funding may come from individuals or corporations, while governmental support may come from various levels (national, provincial, local), from a foreign government or from international organizations such as regional development banks. NGOs have been extremely successful in developing local and district-level programmes and projects, often in concert with community groups and local 
governments. The studies from India in Dryland Management: Economic Case Studies (Dixon, James and Sherman, 1990) illustrate the role of NGOs in dryland management. Collaborative efforts between corporations and governments are another possibility.

Evaluation of the expected returns to investments plays a crucial role in determining which projects receive the limited funds normally available. The type of evaluation employed, however, will differ according to the goals of the funding agency. A private individual or a corporation, for example, normally examines the rate of return and level of profits of various alternatives and chooses the project that offers the highest financial return. A national government may have a different primary objective, such as alleviating poverty in its poorest regions or increasing domestic food production, and will select projects based on these criteria.

When the objectives of the lenders or the private investors coincide with those of the national government and the people directly affected, all parties gain by co-operating to implement the proposed projects. This will not always be the case. Maximizing corporate profits is not always synonymous with maximizing the economic well-being of the community (what economists refer to as social welfare). When a potential investment is being evaluated by a government, international agency or NGO, the analysis should include those off-site or non-monetary effects that are usually ignored in the private financial analysis. On the other hand, some projects pursued by governments to achieve desirable social effects may not be attractive to potential lenders or to individuals whose actions are required to implement the programme successfully.

This chapter examines various analytic techniques that can be used to evaluate potential programmes and projects. It emphasizes the different perspectives of the private and public sectors, and how these differences affect what factors are included in the analysis and how they are valued. The chapter also discusses the various decision criteria commonly used to select projects.

\section{Financial analysis}

Suppose a farmer is considering whether to adopt a new cultivation technique proposed by an agricultural extension agent. The decision will be based in large part on expectations of the 
profitability and the risk associated with the new technique as compared to the present pattern of production. The potential benefits to the farmer can be examined by means of a financial analysis.

In a market economy, a financial analysis of a proposed project focuses on the monetary returns that a private individual, corporation or government can expect to receive from its investment. From an individual's or a company's point of view, it provides information on the profitability of a given investment compared to other alternative investments. In a non-market, subsistence economy, a different approach may be required. Since financial analysis relies on market prices to analyse benefits and costs, it is less useful in cases when most goods are traded by barter or used for subsistence purposes. In this case other techniques are required to analyse the potential benefits to individual farmers or pastoralists. Costeffectiveness analysis or an optimization approach may be useful, for example, to analyse returns to labour or minimization of the costs of inputs.

Financial analysis can also be of value to a government. It indicates whether its own proposed projects or programmes will be self-sufficient or, if not, how much additional financial support will be required. It also shows if the project or programme will be attractive to the intended recipients. This information can give an indication of what adjustments or incentives may be necessary to increase participation rates and increase the chances for successful implementation.

For example, a project to introduce a recommended package of conservation farming techniques may produce large social benefits. The project, however, will fail if individual farmers do not adopt these practices. By undertaking a financial analysis of the project, the government can foresee whether the project is profitable from the farmers' point of view and thereby design an appropriate incentive scheme if necessary to ensure that the programme is attractive to farmers. Several of the studies in Dryland Management: Economic Case Studies (Dixon, James and Sherman, 1990) present examples of financial analysis of farmer operations. Holmberg (1990) examines the financial benefits of soil conservation techniques practised by farmers in Kitui district, Kenya. Wang and Han (1990) examine both the private and social benefits of peanut growing in a dryland area using plastic mulch to retain soil moisture in China. Box 6.1 gives details of the Chinese study.

A financial analysis begins with a list of the expected costs and benefits which will occur year by year. If the company is providing 


\section{Box 6.1: Economic and financial benefits of peanut growing with plastic mulch}

Water and soil nutrients are valuable inputs to agricultural production in Shaanxi province, China. Experiments with peanut growing have been conducted by the North-west Agricultural University and the Science Commission of Qianxian county. The experiments involved the cultivation of peanuts with and without perforated plastic sheeting, used as a mulch.

On-site costs included those for fertilizers, seeds, agricultural chemicals, the use of tractors and draft animals, and labour inputs. Without the use of plastic sheet, total costs of production were estimated to be 60.93 yuan $/ \mathrm{mu}$ (US $\$ 1.00=3.7$ yuan; 1 hectare $=15 \mathrm{mu}$ ). Financial returns were $176.15 \mathrm{yuan} / \mathrm{mu}$, giving a net financial benefit of $115.22 \mathrm{yuan} / \mathrm{mu}$. When plastic mulch is used, the cost of production increases to $89.41 \mathrm{yuan} / \mathrm{mu}$. The yield, however, is increased by 55 per cent, and financial returns are 273.15 yuan $/ \mathrm{mu}$. The net financial benefit is 183.74 yuan $/ \mathrm{mu}$, making the new technique highly attractive to farmers. Net financial returns are 68.52 yuan/mu higher if plastic mulch is used.

Additional benefits of plastic mulch included water savings through the conservation of soil moisture, and the preservation of soil nutrients through more effective nitrogen and phosphorus fixation. The irrigation costs of moisture replacement were estimated to be $55.6 \mathrm{yuan} / \mathrm{mu}$ without the use of plastic and 23.19 yuan/mu when plastic is used. Replacement costs for nitrogen and phosphorus were 14.93 yuan/mu in the "without" situation, and 9.98 yuan/mu in the "with" situation. When these adjustments are made, the costs of production become $131.49 \mathrm{yuan} / \mathrm{mu}$ without plastic and 122.58 yuan/mu with plastic.

The difference in net benefits between the two growing methods increases to 105.88 yuan/mu when the replacement costs of water and nutrients are taken into account. Wang and Han (1990) describe these experiments more fully.

its own capital, one approach will be to spread the capital costs over the life of the project (amortization). If the project is debt financed, the loan period is used as the length of time over which the costs are spread. Regardless of the source of financing, the full capital cost plus interest charges are included in the analysis.

The interest rate used in a financial analysis usually depends on the source of the investment funds. If the project is financed by outside loans, the interest rate at which the funds are loaned will be the appropriate rate. For internally financed projects, the interest rate 
employed reflects the income or production forgone by investing in this project rather than the next best opportunity available. This is known as the opportunity cost of capital, since it is based on the net benefits which could have been generated by using these funds in alternative ways. The actual yearly payments can be calculated by use of the annuity formula (Box 6.2).

\section{Box 6.2: Calculation of yearly payments}

A simple formula can be used to convert a lump sum spent today into a number of equal payments (or annuities) that will be made in the future. This represents the annual payments required to pay back a loan over a certain number of years at a given interest rate with compound interest paid on the remaining balance.

$$
A=P\left[r(1+r)^{n}\right] /\left[(1+r)^{n}-1\right]
$$

where $A=$ annuity value;

$P=$ principal to be repaid;

$r=$ interest rate;

$n=$ number of years over which loan is repaid (or project life if internally financed).

For example, to finance a $\$ 100$ million capital investment over five years at a 10 per cent annual interest rate, the annual payment would be:

$$
\begin{aligned}
A & =100\left[0.10(1+0.10)^{5}\right] /\left[(1+0.10)^{5}-1\right] \\
& =100[0.2638] \\
& =26.38 \text { million per annum. }
\end{aligned}
$$

In addition to the initial capital costs, annual operating and maintenance costs (O\&M) are also included in a financial analysis. These costs include expected inflation rates and should be entered as the actual dollar costs which will be incurred each year. (The simplifying assumption is made that all revenue and costs occur at the end of each year, not as a constant stream throughout the year. This assumption is reflected in the use of single yearly discount factors.)

A financial analysis of a hypothetical five-year public-sector project is presented in Tables 6.1 and 6.2. The project's initial capital costs equal $\$ 100$ million $(\mathrm{m})$. It is assumed that the general annual inflation rate is 2 per cent. Operating and maintenance costs $(O \& M)$ begin at $\$ 10 \mathrm{~m}$ and increase at the same rate as the general inflation rate over the life of the project. Sales revenue begins at $\$ 40 \mathrm{~m}$. The price of output is assumed to increase in relation to the general price index by 1 per cent per year; thus, including inflation, 
114 The Economics of Dryland Management

the product price increases by 3 per cent per year. The interest rate on borrowed funds is 10 per cent. This rate is also used to discount future costs and benefits to present values. The total present value of the discounted cash flow for the project is $\$ 24.83 \mathrm{~m}$.

Table 6.1: Financial analysis of a hypothetical project based on loans (\$m) (interest rate $10 \%$, inflation rate $2 \%$ )

\begin{tabular}{ccccccc}
\hline Year & $\begin{array}{c}\text { Capital } \\
\text { cost }\end{array}$ & $\begin{array}{c}\text { O\&M } \\
\text { cost }\end{array}$ & $\begin{array}{c}\text { Gross } \\
\text { revenue }\end{array}$ & $\begin{array}{c}\text { Net } \\
\text { revenue }\end{array}$ & $\begin{array}{c}\text { Discount } \\
\text { factor }\end{array}$ & $\begin{array}{c}\text { Net present } \\
\text { value }\end{array}$ \\
\hline 0 & - & - & - & - & - & - \\
1 & 26.38 & 10.20 & 41.20 & 4.62 & 0.9091 & 4.20 \\
2 & 26.38 & 10.40 & 42.44 & 5.66 & 0.8264 & 4.68 \\
3 & 26.38 & 10.61 & 43.71 & 6.72 & 0.7513 & 5.05 \\
4 & 26.38 & 10.82 & 45.02 & 7.82 & 0.6830 & 5.34 \\
5 & 26.38 & 11.04 & 46.37 & 8.95 & 0.6209 & 5.56 \\
Total & 131.90 & 53.07 & 218.74 & 33.77 & & 24.83 \\
& & & & & & \\
\hline
\end{tabular}

Table 6.2: Financial analysis of a hypothetical project funded from internal sources $(\$ \mathrm{~m})$ (opportunity cost of capital $10 \%$, inflation rate $2 \%$ )

\begin{tabular}{ccccccc}
\hline Year & $\begin{array}{c}\text { Capital } \\
\text { cost }\end{array}$ & $\begin{array}{c}\text { O\&M } \\
\text { cost }\end{array}$ & $\begin{array}{c}\text { Gross } \\
\text { revenue }\end{array}$ & $\begin{array}{c}\text { Net } \\
\text { revenue }\end{array}$ & $\begin{array}{c}\text { Discount } \\
\text { factor }\end{array}$ & $\begin{array}{c}\text { Netpresent } \\
\text { value }\end{array}$ \\
\hline 0 & 100 & - & - & $(100)$ & - & $(100)$ \\
1 & - & 10.20 & 41.20 & 31.00 & 0.9091 & 28.18 \\
2 & - & 10.40 & 42.44 & 32.04 & 0.8264 & 26.48 \\
3 & - & 10.61 & 43.71 & 33.10 & 0.7513 & 24.87 \\
4 & - & 10.82 & 45.02 & 34.20 & 0.6830 & 23.36 \\
5 & - & 11.04 & 46.37 & 35.33 & 0.6209 & 21.94 \\
Total & 100 & 53.07 & 218.74 & 65.67 & & 24.83 \\
& & & & & & \\
\hline
\end{tabular}


Two different methods of handling capital costs are shown in Tables 6.1 and 6.2. In Table 6.1, it is assumed that capital costs are covered by borrowing. The borrowing period is five years, and the loan is amortized by paying back $\$ 26.38 \mathrm{~m}$ each year, including principal and interest charges. In Table 6.2 capital is provided from internal sources. The opportunity cost of capital is also assumed to be 10 per cent. Note that both approaches yield the same result, a net present value over five years of some $\$ 24.8$ million. If the interest rate in Table 6.1 was not the same as the opportunity cost of capital used in Table 6.2, the calculated NPVs would not be the same.

If capital inputs used in a project still have some value at the end of the project, this salvage value should also be included in the analysis. In the example given, it is assumed that the salvage value was zero; therefore, it was not included in the financial analysis.

An actual example of a financial analysis for a public-sector investment is given in Box 6.3. This example gives the net present value (NPV) and the internal rate of return (IRR) for a wasteland development project in India.

When a private company decides to implement a proposed project, it may need to convince the local government that the project will create substantial economic benefits for the community. Arguments used by companies often include some of the following issues:

- There will be profits of $\$ X$ of which a substantial portion will be spent in the community. This will create more jobs and generate more income.

- The project will directly employ $X$ workers who will be paid $\$ Y$ per year.

- The project will generate corporate income tax payments to the government.

- Half of the output will be exported, generating $\$ X$ in foreign exchange.

Although each of these statements may be true, from a broader social economic viewpoint most of these points are either irrelevant or misleading, and other socially important factors are ignored. (These points are discussed further under the heading "secondary impacts" in the following section.) It is now appropriate to turn to the type of analysis which should be employed to evaluate the economic effects of a project on society as a whole, that is, to evaluate the 


\section{Box 6.3: Financial analysis of a land development project in India}

Cash flow calculations are presented here for a 200 ha project in the wasteland of the Mehsana district of Gujarat (India), typical of projects undertaken by the Gujarat State Rural Development Corporation. This land was classified as barren and uncultivable in village records. The land was moderately saline, with EC ranging from 1 to 10 milimhos $/ \mathrm{cm}^{2}$. A tubewell was dug for getting water at a depth of $200 \mathrm{~m}$. The following steps were involved in the reclamation of wasteland.

(1) Bunding for harvesting rainwater.

(2) 100 ha of wasteland was used for planting trees and cultivating fodder. The breakdown of this 100 ha is as follows:

20 ha - high-density plantations of subabool (Leucaena leucocephala) at a spacing of $1 \mathrm{~m} \times 1 \mathrm{~m}$;

$60 \mathrm{ha}$ - mixed plantations of subabool, planted at a spacing of $4 \mathrm{~m} \times 1$ $\mathrm{m}$ along with cultivated fodder;

20 ha - for cultivation of improved fodder varieties.

(3) Creating irrigation resources by constructing a tubewell for ensuring continuous supply of green fodder throughout the year.

(4) Growing suitable grain and cash crops after the land has been sufficiently reclaimed for a period of three to five years.

Income comes from leaves, timber and seeds. Leaves yield fodder, and the seeds are used in tree nurseries. Output signifies the marketable output, although the actual production is much higher in the case of leaves and seeds.

Income from fodder (cultivated) has been estimated from $\mathbf{4 0}$ ha of sorghum during the kharif (monsoon) season and 20 ha of alfalfa during the rabi (winter) season.

Capital costs are incurred for constructing irrigation facilities and drainage systems; land reclamation by pada bunding and levelling operations; live hedge and trench fencing; and purchase of agricultural implements and equipment - a tractor, bullocks and bullock carts. Expenditures are also incurred for plantation of trees, including planting costs and costs for maintenance of the plantation, and for the growing of cultivated fodder and other crops during various seasons.

A financial economic analysis of the project has been made, calculating the net present value with discount rates of 20 per cent and 30 per cent. Table 6.3 gives the returns and NPV for the fifteen-year time frame. 
Table 6.3

\begin{tabular}{|c|c|c|c|c|c|}
\hline Year & $\begin{array}{c}\text { Net benefit } \\
\text { ( } x 1,000 \text { rupees) }\end{array}$ & $\begin{array}{c}\text { Discount } \\
\text { factor at } \\
20 \%\end{array}$ & $\begin{array}{c}\text { NPV at } \\
20 \%\end{array}$ & $\begin{array}{c}\text { Discount } \\
\text { factor at } \\
30 \%\end{array}$ & $\begin{array}{c}\text { NPV at } \\
30 \%\end{array}$ \\
\hline 1 & -832 & 0.833 & -693 & 0.769 & -640 \\
\hline 2 & -183 & 0.694 & -127 & 0.592 & -108 \\
\hline 3 & +151 & 0.579 & +87 & 0.455 & +69 \\
\hline 4 & +147 & 0.482 & +71 & 0.350 & +51 \\
\hline 5 & $+2,158$ & 0.402 & +867 & 0.269 & +581 \\
\hline 6 & +910 & 0.335 & +305 & 0.207 & +188 \\
\hline 7 & +119 & 0.279 & +33 & 0.159 & +19 \\
\hline 8 & $+1,519$ & 0.232 & +352 & 0.122 & +185 \\
\hline 9 & +716 & 0.194 & +139 & 0.094 & +67 \\
\hline 10 & +91 & 0.161 & +15 & 0.073 & +7 \\
\hline 11 & $+1,643$ & 0.134 & +220 & 0.056 & +92 \\
\hline 12 & +743 & 0.112 & +83 & 0.043 & +32 \\
\hline 13 & +91 & 0.093 & +8 & 0.033 & +3 \\
\hline 14 & $+1,650$ & 0.078 & +129 & 0.025 & +41 \\
\hline 15 & +757 & 0.065 & +49 & 0.020 & +15 \\
\hline Total & $+9,680$ & & $+1,538$ & & +602 \\
\hline
\end{tabular}

At both 20 per cent and 30 per cent discount rates, the project has a positive NPV; it is clearly attractive from a financial viewpoint. Given the net cash flow shown above, the IRR is 46 per cent, an extremely high number. The one constraint to adoption of the project might be credit availability for the initial investment. Sensitivity analysis should also be made on expected yields and prices for project outputs.

Source: Society for Promotion of Wastelands Development, 1984.

social economic welfare implications of projects undertaken by either the public or the private sector.

\section{Social benefit - cost analysis}

A social benefit - cost analysis ( $\mathrm{SBCA}$ ) takes a wider view than simply estimating net monetary returns. In SBCA, the focus is on the 
project's effects on the well-being of the community, also referred to as social welfare. Two of the major differences between a financial analysis and SBCA are the prices used in the analysis and the costs and benefits that are included.

A financial analysis uses the actual prices at which inputs are purchased and outputs are sold. Estimates of net returns also include the effects of inflation, subsidies, taxes and other transfer payments as well as allowable depreciation as defined by the relevant tax laws.

In SBCA, on the other hand, economic efficiency prices which remove any distortions are employed. Transfer payments, including interest payments, taxes and subsidies, are not entered into the analysis since they represent a transfer between members of a society rather than real resource commitments. A tax, for example, represents a transfer of a claim on resources (goods and services) from the taxpayer to the government. The decrease in the taxpayer's claim is equal to the increase for the government; thus, the resource cost to the national economy is zero. Transfers may increase total social welfare if they go from richer to poorer groups; equity concerns will be dealt with later in a different fashion.

SBCA also looks at a wider set of effects than a financial analysis. Some of them, such as off-site environmental impacts, affect social welfare even though they are often not valued in monetary terms. A financial analysis omits these environmental impacts, since they do not involve any actual monetary transfers. However, they should be included in SBCA since they will have an impact on social welfare. Bojö gives an assessment of the economic effects of off-site soil erosion in Lesotho in Chapter 11 of this volume. In Dryland Management: Economic Case Studies (Dixon, James and Sherman, 1990) several case studies deal with off-site effects. For example, Attaviroj (1990) provides an economic analysis of the benefits of conservation farming in Thailand, a farming technique that reduces off-site sedimentation and downstream damage. Deriving prices for non-marketed and environmental effects is covered in Chapter 7.

The following sections highlight the differences between financial analysis and SBCA.

\section{Project costs}

The financial costs of a project are relatively straightforward and include costs of capital and other materials, labour and O\&M. The true economic costs, however, often differ from the financial costs. 
From a social viewpoint, the real measure of the economic cost of using a resource is its opportunity cost (that is, its value in the next best alternative use).

For a variety of reasons, actual market prices may differ from the "correct" economic price which measures the true value of a resource to society. In such cases, shadow prices should be employed to convert the market price to a socially efficient price. Shadow prices are discussed later in this chapter.

In SBCA, costs are entered into an analysis at the time when the resources are actually used. This implies that the amortization schedules explained in the financial analysis section are not appropriate in SBCA. Instead, capital costs should be charged in the period in which they are actually incurred, as they were in the second example in the financial analysis section (Table 6.2).

Another difference between the two types of analysis is the treatment of interest payments. Though interest payments are a financial cost to the investing agency, they are more accurately described as a transfer payment from the investing agency to the lender. Therefore, they are not included in SBCA. (If interest payments go to an overseas bank, they are no longer a transfer payment within the country and become a cost. The national economy is poorer.)

Depreciation is another category of financial costs that is not included in SBCA. Allowances for depreciation are an accounting concept which are used for tax purposes and to provide a means of allowing for replacement of capital inputs as they wear out. They are normally included in a financial income statement, but are excluded from financial and economic cash flow statements. In SBCA, costs are only entered as they are incurred; if replacement capital is required, these costs will be entered at the time when the capital is actually replaced.

Domestic government subsidies and taxes are normally built into a financial analysis. Again, these are not true economic costs; rather, they are transfer payments between the government and the investing agency. Some taxes take the form of import tariffs; this topic will be discussed again in the section on shadow prices.

Table 6.4 lists the main differences between a financial analysis and SBCA. The key distinction is that a financial analysis represents the interests of the individual resource user or firm, and it relies on actual prices paid and cash flows. In contrast, a SBCA is carried out on behalf of a wider group - the community at large - and attempts to remove various price distortions that are included in the financial analysis. 


\section{Table 6.4: A comparison of financial and social benefit - cost analysis}

\begin{tabular}{ll}
\hline & Financial \\
\hline Focus & $\begin{array}{l}\text { Net returns to equity capital or } \\
\text { to private group or individual } \\
\text { Indication of incentive to } \\
\text { adopt or implement }\end{array}$ \\
Prices & $\begin{array}{l}\text { Market or administered } \\
\text { (may assume that markets are } \\
\text { perfect or that administered } \\
\text { prices have compensated } \\
\text { for imperfections) }\end{array}$
\end{tabular}

$S B C A$

Taxes Cost of production

Determine if government investment is justified on economic efficiency basis

May require "shadow prices" (e.g., adjustments for monopoly in markets, external effects, unemployed or underemployed factors, overvalued currency)

Transfer payments to governments-deducted from costs of project inputs and outputs

Subsidies Source of revenue

Transfer payments from governments - value of subsidies added to project costs of inputs and outputs

Loans Increase capital resources available

$\begin{array}{ll}\begin{array}{l}\text { Interest or } \\ \text { loan repay- } \\ \text { ment }\end{array} & \begin{array}{l}\text { A financial cost; decreases } \\ \text { capital resources available }\end{array} \\ \begin{array}{l}\text { Discount } \\ \text { rate }\end{array} & \begin{array}{l}\text { Marginal cost of money; } \\ \text { market borrowing rate }\end{array} \\ \begin{array}{l}\text { Income } \\ \text { distribution }\end{array} & \begin{array}{l}\text { Can be measured by net } \\ \text { returns to individual factors } \\ \text { of production such as land, } \\ \text { labour and capital }\end{array}\end{array}$

A transfer payment; transfers a claim to resource flow

A transfer payment

Opportunity cost of capital; social time preference rate

Is not considered in standard economic efficiency analysis; can be done as separate such analysis or as weighted efficiency analysis

Source: adapted from Hitzhusen, 1982. 
Physical boundaries of analysis

As mentioned previously, some economic costs are not included in a financial analysis because either they are not financial costs or they lie outside of narrowly defined project limits. In dryland projects environmental effects, either positive or negative, often result from the implementation of projects and programmes. Such costs to society, even though they are not financial costs and may occur outside of project boundaries, should be included in SBCA since they still affect social welfare, regardless of where they occur.

Two separate issues are involved here. The first issue is the question of the correct spatial limits of the analysis and is covered here; the second issue concerns the valuation of these effects and the possible impacts of a project on general price levels. The latter issue is a complex one and will be the subject of Chapter 7 .

Chapter 4 introduced the concept of externalities. External effects, though directly or indirectly attributable to the implementation of a project or programme, are routinely left out of a financial analysis. In SBCA, however, the physical boundaries of analysis should be large enough to incorporate all the effects which can be directly traced back to the project. Exactly how large such boundaries should be depends on the type and scope of the individual project. The appropriate time horizon must also be considered. This topic was discussed in Chapter 4.

An industrial project may generate large amounts of airborne pollutants and/or may discharge water pollutants that affect downstream users. Irrigation and agriculture projects may increase fertilizer and pesticide runoff which can contaminate local water supplies. A major water resource project including a multi-purpose dam can have far-reaching effects on people who live on the land which will be inundated and on downstream residents, and can even lead to significant effects upstream. In all cases, the analyst must consider the wider effects of the project, not only the effects on the project site. (Box 6.4 gives an example using a salinity control analysis for the Murray River catchment in Western Australia.)

Box 6.4: Salinity control in the Murray River catchment, Western Australia

A linear programming model was used by the Australian Commonwealth Scientific and Industrial Research Organisation, the Western Australia 


\section{2}

Forests Department and the Western Australia Department of Agriculture to analyse the off-site environmental impacts of different land uses in the Murray River catchment. The main problem addressed was river salinity. Downstream resources threatened by salinity damage consisted of dieback of natural forests and reduced productivity of agriculture. In addition to potentially affecting financial returns from forestry and agriculture, the damage associated with salinity was also predicted to lead to large imputed costs through a loss of recreational opportunity.

To carry out the analysis, the catchment was divided into zones, and all probable land uses were considered for each zone. Land uses simulated in the model included Eucalyptus forestry, agroforestry, agriculture, streamside plantations, national parks, fauna and flora reserves and bauxite mining. Each of these land uses has a particular effect on salinity levels. Other measures specifically designed to control salinity were also assessed, such as sealing the land surface to reduce percolation, water storage schemes and desalinization plants.

The economic value of different land-use options was determined from the sum of the costs and benefits of land use itself and the effects on recreation, water quality and water quantity.

A flow diagram of the model is shown in Figure 6.1. The study is described in greater detail by Thomas (1990) in Dryland Management: Economic Case Studies (Dixon, James and Sherman, 1990).

Effects outside the project site can also be positive in nature and should be included as project benefits. A reclamation project which also reduces siltation downstream is one such case. Other projects have off-site benefits as their primary goal - sand dune stabilization projects would fit in this category.

Some impacts may occur over longer distances or be more difficult to identify. There is no standard rule which can be employed to delimit project boundaries correctly. The analyst must consider the type of project, the area in question and all potential effects before arriving at a decision on where boundaries should be placed.

One rule of thumb is to include all major first-order effects, especially when there is an effect on welfare. A livestock development, for example, may change the quality or quantity of water runoff and thus affect people downstream. The impacts on these downstream areas should be included in the analysis.

\section{Shadow prices}

When market prices do not accurately reflect social costs or social values, prices must be adjusted to represent their true costs to 


\section{Figure 6.1: Flow diagram of salinity control model}

\section{STUDY}

COMPONENT OF

COMPUTER PROGRAMME

Economic criteria for catchment land use planning (max B-C)

Physical criteria for catchment land use planning (max clearing, min salinity etc.)

Precipitation, landforms and vegetation

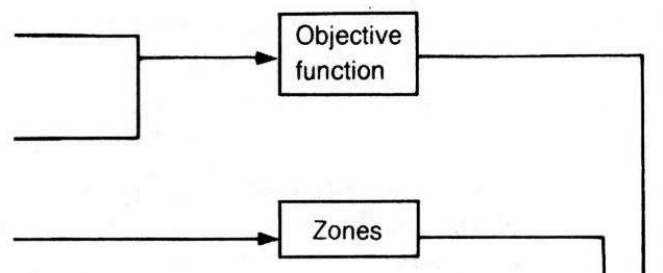

Physical products from allocating a unit of land in zone $z$ to activity $i$.

- Timber, wheat, sheep

- Recreation hours

- Salt

- Water

Economic values from flows over time in production/consumption of physical products

- Producer surplus (via land use budgets)

- Recreation consumer surplus

- Damages incurred by consumers of salty water

- Consumer/producer surplus from water development

- Fixed/variable costs of water resource infrastructure

\section{Constraints}

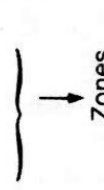

Activities

- Flora and fauna reserves

- Bauxite refining capacity

- River salinity (optional)

- Water storages

Linear programme
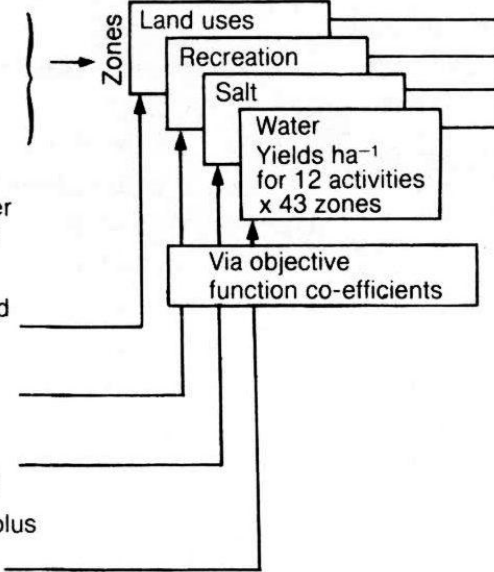

Output

- Alternative catchment land use plans, water yield, salinity, recreation, net present value, sensitivity studies.

Source: Thomas, 1990. 
society. Such adjusted prices are known as shadow prices.

One area where shadow prices are used is to counteract the effects of distortions in the market caused by government interventions. Such interventions take a variety of forms, including fixed exchange rates, price ceilings or floors, import quotas, tariffs and subsidies. Although governments may create price distortions to promote a goal they feel is socially desirable, these distortions do have a cost to society in terms of decreased efficiency, and this needs to be taken into account. For example, many governments subsidize chemical fertilizers and pesticides in order to promote agricultural production. A financial analysis would use the subsidized price, while the SBCA would use a shadow price that removes the subsidy. In the Lesotho study in Chapter 11, a 30 per cent additional charge is added to fertilizer costs to account for government subsidies.

Another reason for shadow pricing is to correct market imperfections such as externalities (see Chapter 4). Since market prices will not reflect total social costs or social values in some instances, economically efficient prices must be developed through shadow pricing. For example, the social cost of harvesting timber should include the value of off-site impacts created by the harvesting operation (such as soil erosion and sedimentation). These externalities are ignored in the financial analysis but should be included in the SBCA, either as a separate cost item or by shadow pricing a composite "harvesting cost" price.

One final category of costs that often requires the use of shadow prices is non-tradable goods and services. Among such items, the most important one is probably labour. Valuing the true opportunity cost of labour is a complex process and is described in detail in other sources (see, for example, Squire and van der Tak, 1975; Gittinger, 1982); however, some of the important points are worth noting here.

The correct valuation of labour rests on the same principle as that of other shadow prices (that is, the correct price should reflect the opportunity cost of the resource). If there is chronic unemployment in the project area, the additional demand for the labour needed by the project will be met by reducing unemployment rather than causing a loss of output elsewhere in the economy. In such cases, the correct shadow price will be lower than the prevailing market wage.

Though the opportunity costs in terms of forgone output for a previously unemployed worker may be zero, this does not imply a 
zero shadow price. For the worker involved, there is a "reservation" wage below which he/she is unwilling to work. This will reflect his/her personal opportunity cost of lost leisure time or time for other non-wage activities. As a result, shadow pricing for wages should accurately reflect the price which would be necessary to attract sufficient numbers of workers.

Normally in SBCA, workers are divided into three categories of skill level: skilled, semi-skilled and unskilled. For each of these categories, a separate labour shadow price will be necessary. Skilled labour is often in short supply, and market prices will often be a good indication of the value of output forgone. Semi-skilled and unskilled labour is usually in greater supply, and correct shadow prices will often be lower than the market wage.

Other factors which will affect shadow wage rates include differential demands for labour in different seasons, regional differences and differences between urban and rural demand for labour.

When to use shadow prices is subject to judgement; the following guidelines are offered. Adjustments to market prices to derive shadow or economic prices for goods and labour should be considered when the following situations exist:

- There exist sizeable tax or subsidy elements in market prices. Exactly how much is "sizeable" will vary, but one guideline is that a tax or subsidy of 30 to 50 per cent or more is sizeable, and one that is 10 per cent or less may be ignored. Of course, to make a completely accurate SBCA would require removal of all transfer payments like taxes or subsidies, but this may not always be possible or even necessary. An element of judgement as to what should be included or excluded is required. (Tariffs are commonly used as a form of import tax and should be treated as a tax.)

- Labour markets do not clear at the offered wage. Skilled technical labour may be in short supply and need to have a premium (a shadow price) placed on it; manual labour for the same project may be abundant at the official wage rate and not require a shadow price. If excess labour is available at the official wage rate, it means that the wage is too high, and the correct shadow price would be lower.

In the Lesotho study described in Chapter 11, skilled and semiskilled workers were priced at their financial wages, since labour 
markets for these workers were competitive. For unskilled workers, cash payments were considered a transfer from the project to the labourers, and in-kind payments were costed at their opportunity cost, since there were few or no alternative employment opportunities for unskilled workers.

When foreign exchange rates are distorted and are not allowed to fluctuate freely, it may also be necessary to use a shadow rate for foreign exchange if project inputs are imported from abroad or would have been exported, or project outputs replace imports or are exported themselves.

Distortions are commonly signalled by the existence of government exchange controls or the existence of a black market. Some minor differences between official and black-market or kerb rates are normal. If the differences are more than 5 per cent, however, there probably are distortions that need to be taken into account by means of a shadow exchange rate (SER). (See Box 6.5 for a discussion of calculating a SER.)

The Lesotho study in Chapter 11 discusses the problem of valuing foreign exchange in Lesotho. Two complications arise: the Lesotho currency is tied to the South African rand, which is subject to a number of political influences; and Lesotho is part of the Southern African Customs Union, which has substantial trade barriers. (See the discussion in Chapter 11 on how such problems can be approached.)

When the project uses imported goods or produces goods which would have been imported in the absence of the project, the appropriate border price is the cost-insurance-freight price (CIF). This price reflects all the costs necessary to get the good to the country's border. It is this price which is then converted via the SER to arrive at the foreign exchange value of the good in question. The last step is to add the transportation costs to move the goods from the country's border to the project boundary for an imported input, or to subtract the domestic transportation cost for any import substitutes produced by the project.

This procedure was used in the Lesotho study in Chapter 11. The main outputs of the project were maize and sorghum, which would otherwise have been imported. Therefore, the prices used were the CIF price plus handling, transport and distribution costs.

When the project uses inputs which would have been exported in the absence of the project, or when the project will produce an output for export, the correct border price is the free-on-board (FOB) price. This is the price which includes the cost of moving the 


\section{Box 6.5: Shadow exchange rates}

The shadow exchange rate (SER) is used as a replacement for the official exchange rate (OER) to convert prices of foreign goods to economically efficient domestic price equivalents.

One indicator of the SER is the rate which is used in "black markets" for foreign exchange. In this market, buyers are usually willing to pay higher rates than the OER, giving an indication of how foreign exchange is valued in this market. However, since black markets are illegal, the rates of exchange will include a risk premium which may result in an overestimation of the SER.

Another possibility for determining the foreign exchange premium is to ask the government central planning agency. Many governments, however, will not have this information or are unwilling to state what this premium is.

One method of calculating the foreign exchange premium is to take the ratio of domestic prices for traded goods to the border prices (see main text) of these goods, that is:

$$
\underset{\text { premium }}{\text { foreign exchange }}=\frac{\text { domestic prices }}{\text { bonder prices }}
$$

Normally these statistics can be found in volumes of trade statistics. The sum for all traded goods over a year is the normal amount used. The OER can then be converted to the SER by multiplying the OER by the foreign exchange premium:

OER $\times$ foreign exchange premium $=$ SER.

It is the SER which is then used to convert border prices to domestic prices.

One limitation of this method of determining the SER is that it may not be accurate for countries where strict import quotas or import bans are used rather than a tariff system. In such cases, other types of observation including informal currency markets should also be used to help determine a likely range of values. In situations where much uncertainty still exists, sensitivity analysis with a range of values should be used.

good to the country's border, but not the costs of getting it to its foreign destination. This price is then converted to the shadow foreign exchange value through the SER. For an exported output, this price is adjusted to the project boundary value by subtracting the transportation cost from the country's border to the project boundary. When diverted exports are used as project inputs, the 
analyst must also consider any change in domestic transportation costs.

Certain very large projects may be significant enough to affect the world price of a certain commodity. In this case, the marginal revenue from exporting the commodity is the correct pricing mechanism.

\section{Dealing with inflation}

A financial analysis normally uses actual prices and builds expected price increases due to inflation into the analysis. SBCA, on the other hand, relies on what economists refer to as "real" prices (that is, inflation-free prices). Prices that include an inflation component are called "nominal prices".

In SBCA, price changes in future years should only reflect relative price changes (that is, changes where a good or service becomes cheaper or more expensive compared to the general rate of price change). For example, if pesticide costs are expected to increase at the same rate as the general price level, the price will stay constant in "real" terms. On the other hand, if pesticide costs are expected to increase at 10 per cent per year while the general price level rises 6 per cent per year, there will be a "real" increase in cost of 4 per cent per year.

Another aspect of project costs affected by inflation is the interest rate. Interest rates in a financial analysis normally are some form of commercial rate. These rates include a component which allows for the expected rate of inflation, thus:

Market interest rate $=$ real interest rate + expected inflation rate.

As explained earlier, interest payments are not included in SBCA. Therefore, the discount rate used in SBCA should also be inflation-free to reflect real returns, as opposed to nominal returns. This issue becomes relevant when examining SBCA returns of projects and comparing them to rates of return in a financial analysis (which usually include a component for inflation).

\section{Secondary impacts}

Near the end of the section on financial analysis was a list of economic "benefits" which companies often use to promote their projects. A closer examination of these claims shows that many are not truly additional benefits; they are a combination of transfer payments, cost items and ot $\{$.er forms of double counting.

The profits generated by the project, as shown by the financial analysis, have little to do with benefits to the community. The claim 
that these profits will create further benefit in the community through creation of more jobs or reinvestment should also be examined closely. Additional income and expenditures are natural results of a new project. However, such secondary effects should not be compared to just the existing situation; they should be compared to what might be expected to occur if the funds were used in an alternative manner. If another project of the same magnitude were implemented, we might expect similar secondary benefits to be generated. Alternatively, if this project were developed elsewhere in the country, similar secondary impacts would also be expected to occur.

The correct accounting of secondary benefits, therefore, depends on the without-project situation. If no other investment would be made in the absence of the proposed project, then secondary benefits are an appropriate component of a SBCA. If other investments would have been undertaken, however, then the correct contribution of the project is the additional secondary benefits generated by investment in one project rather than in an alternative one. Therefore, if all possible investments yield the same secondary benefits, then all of the alternatives would contain the same value and would not become a factor in deciding between alternative investment opportunities.

From a regional or local viewpoint, however, the distribution of secondary benefits might be very different. For the national economy as a whole, there may be little reason to expect that the overall impacts would be very different except for distributional impacts among regions. These distributional impacts may be important, but they should be addressed in a different fashion, as discussed later in this chapter. The incidence of the economic impacts, both within and across regions, can be studied by means of multisectoral economic models, which are described in Chapter 9.

The claim of increased employment generated should be viewed in a similar manner (that is, it should be evaluated against other potential investments rather than against no investment). Even so, it should be recognized that wages are a cost of production, not a benefit. Value to society is determined by the value of output, not the amount of wages paid to workers.

If increased employment (job creation) is a primary goal of a government, one method of evaluating projects is the number of jobs created per unit of investment. This information can be evaluated qualitatively along with other information contained in the SBCA. 
In such cases, it is important to remember that it is the number of previously unemployed workers who are now able to work that is relevant; projects that require skilled workers already in short supply are not likely to reduce the unemployment rolls significantly and may reduce output from other parts of the economy.

Increased taxes generated by projects are another type of "benefit" claimed by project proponents. Taxes, however, are transfer payments from the private sector to governments, not economic benefits. Like profits and employment, taxes, if considered at all, should be considered in the context of alternative investments rather than against the status quo.

Finally, the effect of a project in terms of net foreign exchange earnings is often claimed as a benefit. As many developing countries are concerned with foreign exchange earnings, this issue is a valid one. Once again, however, it is the foreign exchange impacts of a project compared with other projects which could have been developed using the same scarce resources that is the relevant comparison, not a comparison with no project.

Calculation of net social benefits

A social benefit - cost calculation for the five-year project described in Tables 6.1 and 6.2 is presented in Table 6.5.

Table 6.5: Social benefit - cost analysis of a hypothetical project (\$m) discount rate $8 \%$

Capital OEM Gross Envir. Net
Year cost cost benefit costs benefit

\begin{tabular}{cccccccc}
\hline 0 & 120 & - & - & - & $(120)$ & & $(120)$ \\
1 & - & 11 & 40.40 & 2 & 27.40 & 0.9259 & 25.37 \\
2 & - & 11 & 40.80 & 2 & 27.80 & 0.8573 & 23.83 \\
3 & - & 11 & 41.21 & 2 & 28.21 & 0.7938 & 22.39 \\
4 & - & 11 & 41.62 & 2 & 28.62 & 0.7350 & 21.04 \\
5 & - & 11 & 42.04 & 2 & 29.04 & 0.6806 & 19.76 \\
Total & 120 & 55 & 206.07 & 10 & 21.07 & & $(7.61)$
\end{tabular}


Capital costs are incurred at the beginning of the project. It is discovered that a sizeable component of the capital cost consists of expenditure on imported equipment. Foreign currency is scarce, and, after correcting for the exchange rate, the real economic cost of capital is estimated to be $\$ 120 \mathrm{~m}$. An adjustment is also made to O\&M costs, as subsidies of $\$ 1 \mathrm{~m}$ a year are found to be paid by the government on inputs to the project. Inflation has been removed from all the estimates. O\&M costs in the benefit - cost analysis are $\$ 11 \mathrm{~m}$ each year. The value of output begins at $\$ 40 \mathrm{~m}$ but increases in real terms by 1 per cent per year. The real discount rate is 8 per cent, derived by subtracting the annual inflation rate ( 2 per cent) from the opportunity cost of capital (10 per cent). Environmental damage costs are estimated at $\$ 2 \mathrm{~m}$ per year, measured in constant prices. The present value of real net benefits is estimated to be $-\$ 7.61 \mathrm{~m}$. Although the project is feasible in financial terms, it does not represent an efficient economic use of community resources. On economic efficiency grounds, it should be rejected.

\section{Income distribution}

In a traditional economic analysis, the objective is efficiency (that is, maximizing the difference between total social benefits and total social costs, regardless of to whom they accrue). In SBCA, however, in addition to the absolute magnitude of the net benefits of a project, the distribution of the benefits is an important issue. As many of the countries most seriously affected by dryland degradation are among the world's poorest, the effects of changes in policy or management on the already disadvantaged must be given attention. By including income distribution effects in the analysis, either qualitatively or through the use of some type of weighting criteria, governments have a means of incorporating these concerns.

One method of providing such information to policy-makers is to estimate net benefits by either income class, group or region. The decision on how to use this information is then left up to the policymaker. An alternative is to take the distributional analysis one step further and assign specific weights to the net benefits received by different groups. Assigning weights is clearly a subjective decision and is more the job of a policy-maker than of an economic analyst.

Different schemes of weighting are discussed in Ray.(1984), Squire and van der Tak (1975) and UNIDO (1972). In general, the idea is to weigh benefits received (or costs borne) by a specific group of people more heavily than those received by another group. For example, benefits to farmers below a certain income 
level may be given more weight than those which accrue to wealthier farmers. This is an explicit recognition that the poorer farmer receives larger benefits per dollar earned than a wealthier person. In economic terms, the poor farmer's marginal utility of income is larger than that for a richer person.

Setting constraints on allowable distribution of benefits is yet another approach. This involves setting targets which establish a minimum acceptable distribution of benefits among a designated low-income class or group. This might involve considering only those projects where a certain per cent of benefits accrue to people whose income is below a certain level. Only projects that pass such a test are then evaluated further.

\section{Decision criteria}

When faced with funding or other constraints, consistent criteria for project selection are required.

Decision criteria can be used for both financial analysis and SBCA. In most cases a cash flow (or value flow) table is developed that lists benefits and costs, year by year over the period of analysis (the time horizon). Two assumptions are used here when discussing cash flows:

- The initial year of any project should be designated as either year 0 or year 1 . Which one is chosen does not really matter, but the base year should be clearly stated. When comparing between alternatives, the same base year should be used.

- For ease of calculation, all cash flows (both costs and benefits) are assumed to occur at the end of the year. This implies that, for example, a cost (benefit) incurred (received) at any point during year 3 is assumed to occur at the end of year 3 and is discounted for a full three years to arrive at its present value equivalent. This will create slight errors but is a normal practice since the simplification of the calculations outweighs the slight degree of error involved. Of course, if desired, all costs and benefits can be discounted from the exact time at which they occur.

As discussed in Chapter 5, alternative projects have different streams of costs and benefits over time. The three most common decision criteria used for comparison are net present value (NPV), internal rate of return (IRR) and the benefit - cost ratio ( $B / C$ ratio). Formulas for these criteria are discussed in Box 6.6. 


\section{Box 6.6: Formulas for decision criteria}

The following symbols will be used throughout this box:
$r=$ the interest rate or discount rate, expressed as a decimal;
$n=$ the number of years used in the analysis (that is, the time horizon);
$t=$ the relevant project year, going from $1,2,3 \ldots n$;
$B_{t}=$ total benefits in year $t$;
$C_{t}=$ total costs in year $t$;
$\Sigma=$ sigma, a summation sign over the period of time.

The net present value (NPV) of a project is found by using either of the following formulas:

or

$$
N P V=\sum_{t=1}^{n} \frac{B_{t}-C_{t}}{(1+r)^{t}}
$$

$$
\mathrm{NPV}=\sum_{i=1}^{n} \frac{B_{t}}{(1+r)^{l}}-\sum_{t=1}^{n} \frac{C_{t}}{(1+r)^{l}} .
$$

The two formulas are equivalent. Both measure the present value of total benefits minus the present value of total costs.

The internal rate of retum is found by means of the following formulas:

or

$$
\sum_{t=1}^{n}=\frac{B_{t}-C_{t}}{(1+r)^{t}}=0
$$

$$
\sum_{t=1}^{n} \frac{B_{t}}{(1+r)^{r}}=\sum_{t=1}^{n} \frac{C_{t}}{(1+r)^{r}} \text {. }
$$

The $r$ which solves the above equations is the discount rate which would yield a zero net present value for a project.

The formula for the benefit-cost ratio is a simple modification of the second NPV formula given earlier:

$$
\mathrm{B} / \mathrm{C} \text { ratio }=\frac{\sum_{t=1}^{n} \frac{B_{t}}{(1+r)^{t}}}{\sum_{t=1}^{n} \frac{C_{t}}{(1+r)^{t}}} .
$$

The net present value is one of the most widely used formulas in project analysis. The NPV formula determines the present value of net benefits (that is, total benefits minus total costs) by discounting the streams of costs and benefits back to the beginning of the base year. The internal rate of return is defined as the discount rate at 
which the present value of costs would be exactly equal to the present value of benefits (that is, where NPV is equal to zero). It is calculated through an iterative process.

One advantage of the IRR is that there is no need to preselect a discount rate; however, the IRR must be compared to some other discount rate or interest rate to determine whether the project is desirable. For example, if the IRR is 10 per cent and the preselected cut-off rate is 6 per cent, then the project will be attractive. However, if the preselected cut-off rate is 12 per cent, the project will not be desirable, since the IRR is less than this rate.

The IRR is routinely used by financial institutions including the regional development banks. Its usefulness and its problems will be discussed in the following section.

The third widely used criterion is the benefit - cost ratio. The $B / C$ ratio compares discounted benefits to discounted costs. If the $B / C$ ratio is greater than 1 , then the discounted benefits outweigh the discounted costs, and the project will generate net benefits over its lifetime. A B/C ratio exactly equal to 1 implies that discounted benefits exactly equal discounted costs, and over its lifetime the project will produce zero net benefits.

\section{Choosing a decision criterion}

The three measures described in the previous section are different ways of viewing the present value of a stream of costs and benefits. They rely on the same data concerning benefits, costs and time. The criteria relate to each other as follows:

If $\mathrm{NPV}=0$, then $\mathrm{B} / \mathrm{C}$ ratio $=1$, and $\mathrm{IRR}=r$.

If $N P V>0$, then $B / C$ ratio $>1$, and $I R R>r$.

If $N P V<0$, then $B / C$ ratio $<1$, and $I R R<r$.

Though it may initially appear that it makes no difference which criterion is chosen, this is not the case. Analysing the same set of projects using all three criteria can result in different rankings of the projects depending on which criterion is used. Table 6.6 shows a comparative analysis of the various measures under different circumstances.

As shown in the table, two important issues in choosing a decision criterion are whether a funding constraint exists and whether projects are independent or mutually exclusive.

No cost constraint. In the absence of funding constraints, the 
Table 6.6: Comparison of the three measures of present value for ranking projects

Net present value Intermal rate of return Benefit-cost ratio

Selection or

ranking rule

for:

Independ-

ent projects

No con-

select all projects with NPV >0; project ranking not required

costs

Constraint Not suitable for on costs
Select all projects with IRR greater than cut-off rate of return; project ranking not required

Ranking all projects by IRR may give incorrect ranking

$\begin{array}{lll}\begin{array}{l}\text { Mutually } \\ \text { exclusive }\end{array} & \begin{array}{l}\text { Select alternative } \\ \text { with largest }\end{array} & \begin{array}{l}\text { Selection of } \\ \text { alternative with } \\ \text { projects }\end{array} \\ \text { NPV } & \text { highest IRR may give } \\ \text { (all cases) } & & \text { incorrect result }\end{array}$

Discount rate
Appropriate discount rate must be adopted
No discount rate required, but cut-off rate of return must be adopted
Select all projects with $B / C>1$; project ranking not required

Ranking all projects by $B / C$ ratio where $C$ is defined as constrained cost will always give correct ranking

Selection of alternative with highest $B / C$ ratio may give incorrect result

\section{Appropriate} discount rate must be adopted

Source: adapted from Gittinger, 1982, as presented in Dixon and Hufschmidt, 1986.

choice of decision criteria will not affect selection among independent projects. All projects which show positive net benefits (either NPV $>0$ or $B / C$ ratio $>1$ ) or a rate of return greater than the cut-off rate of interest should be chosen. 
If there is no funding constraint but the projects are mutually exclusive (for example, two alternative projects for the same site), the project with the highest NPV should be chosen to maximize the benefits of using that site. An exception to this policy may occur if the project with a lower (but still positive) NPV can only be built on the given site, while the alternative project could also be profitably built on a different site. In these cases, total benefits from the two projects will be greatest by undertaking both projects.

Cost constraint. In cases where not all profitable projects can be undertaken due to funding constraints, project selections should be determined by the overall impacts on social well-being or social welfare. For independent projects, social welfare will be maximized by choosing those projects with the highest net present value (NPV) per unit of constrained costs. This is done by using an altered version of the $B / C$ ratio where the constraint (for example, capital costs, O\&M costs or a combination of the two) is placed in the denominator, and the numerator is formed by subtracting the remaining costs from the total benefits.

For example, if only capital costs are in short supply, the numerator will be benefits minus all costs except capital costs, and the denominator will be capital costs. Alternatively, if capital is freely available from international donors, but ongoing costs must be supplied by a local or national government with a limited amount of funds, the numerator will be gross benefits minus capital costs, and the denominator will include only ongoing costs. In this manner, the best use can be made of constrained funds.

However, use of this constrained cost method may result in the selection of projects which, though most beneficial to the entity performing the calculation, are not truly the most efficient projects in an economic sense. For example, a project with large capital costs donated by an outside agency may appear extremely attractive to a country which only considers ongoing costs. In reality, a standard NPV analysis might show that, when all costs are included, the project is not an efficient use of funds for the donating agency.

For mutually exclusive projects with a cost constraint (perhaps the most common situation), selection of the project with the largest NPV will give the correct answer. This criterion will ensure that social welfare is maximized.

Potential problems. The ability to alter the components of the $B / C$ ratio makes it valuable for cases such as those previously mentioned where something other than total costs is the constraint. 
However, it also points out one of the problems of using the $B / C$ ratio - changing the manner in which costs are defined will change the resulting $\mathrm{B} / \mathrm{C}$ ratio. This can lead to incorrect results and different rankings, depending on how costs are defined.

The use of IRR can also cause problems. In some cases, there will be more than one internal rate of return, $r$, which will solve the equation which yields the IRR. This can occur if annual net cash flows change signs more than once (that is, if net returns are negative, then positive, then negative again). Some forestry projects fall into this category - cash flows are negative in early years, positive during years when harvesting or commercial thinning occurs, then negative again during years with little or no harvest. It is possible for such types of projects to yield two or more r's, all of which are technically correct. This phenomenon has rarely been observed in practice. A more common problem has been the use of IRRs to rank projects. Since the IRR only reflects the rate at which net benefits are generated, not their actual magnitude, this can lead to incorrect project ranking if used by itself.

Nevertheless, one advantage of IRR is that it eliminates the need to choose a discount rate (of course, choosing a cut-off rate must be done instead). IRR also has the advantage of providing lenders with a standard means of comparison between projects and is widely used by the World Bank and regional development banks.

\section{Cost-effectiveness analysis}

Though SBCA is often the first choice of technique to analyse a project or programme, it will not always be possible to perform a full SBCA. A number of factors may force the analyst to consider other analytic techniques.

A comprehensive SBCA is a serious undertaking - the need for a quick decision on whether or not to implement a project may preclude a full SBCA. Similarly, there may not be enough funds available, or the necessary data may be lacking. Research skills and trained analysts may be in short supply and needed elsewhere.

In other cases it may be difficult or impossible to estimate the value of the benefits associated with a new programme or project. There may be insufficient knowledge or a lack of data to move from a given level of environmental damage to its associated effects on human health or welfare. This occurs if the effects of a project on some physical or biological parameter are unknown; or, even if the effects are known, it may not be possible to ascertain how these 
effects will translate into changes in human health and welfare. In famine situations where widespread human suffering occurs, or in situations of extreme poverty, meeting basic needs of survival or of a minimum real income are obvious policy targets, regardless of attempts to measure the economic benefits.

When benefits are not easily quantified, cost-effectiveness analysis (CEA) provides an alternative means of analysis. In a costeffectiveness analysis, no attempt is made explicitly to value benefits; instead, a target is chosen, and the analyst concentrates on finding the most effective means of reaching that target. The target might be a maximum acceptable level of soil erosion per hectare per year, or a certain per cent increase in crop production, or a desired level of carrying capacity for grazing animals.

The initial step in the analysis is choosing a realistic target. The analyst must consider the trade-offs involved in achieving different standards. Normally, we would want to consider different targets and look at the costs and benefits associated with the alternatives. However, when benefits cannot be quantified, a qualitative judgement considering the costs of reaching different alternatives must be employed.

In many cases, technology may dictate the alternatives available. If there are a limited number of alternative control technologies, the choice is reduced.

Cost-effectiveness analysis is also useful when for political, social or other reasons it is necessary to deal with an ongoing problem in some manner. In such situations, the problem is not choosing a goal but, instead, deciding how to achieve the goal.

Examples of this approach include preventing sand dune encroachment on an important town, railroad or other feature; a family health programme; or provision of potable water. In Morocco, for example, the government decided to stop sand dune encroachment in the southern part of the country. A variety of means were evaluated, including sand-shaping and sand-stabilization approaches. The final CEA focused on two alternatives: erection of fibrocement barriers to arrest sand dune movement, and use of a vegetative "quadrillage," reinforced by use of barriers constructed from local palm fronds and wood. Economic analysis showed that the cost of the vegetative stabilization approach was only half that of the fibrocement barriers. In addition, a much larger share of the expenditures was retained in the project region. This was an important income distribution bonus for this poor area. 
The Moroccan case is a good example of the use of cost-effectiveness analysis to meet a predetermined goal. In general, each study will require that a series of alternatives be studied to ensure that the least-cost solution is found. Some analyses will involve estimating the capital and operating costs of the various control technologies. In other projects, management practices may be the decision variable subject to change. However, the basic goal remains the same finding the most effective way of meeting the target.

Some analyses may show that even the most cost-effective means of reaching a target is still too expensive. Of course, this will depend on how much the society is willing and able to pay. If this is the case, the choices then are either to lower the standard or to do nothing. Sometimes lowering the standard will enable the society to have at least a partial solution which may be preferable to totally ignoring the problem.

Cost-effectiveness analysis, sensibly used, can be extremely helpful in making decisions that other techniques, such as SBCA, cannot solve. By replacing monetary benefits with a specific goal, we avoid the need to arrive at a specific dollar estimate of benefits and instead concentrate on the most effective way of meeting the goal.

\section{References}

Attaviroj, P. (1990),

"Soil erosion and land degradation in the Northern Thai uplands: an economic study" in Dixon, James and Sherman, op.cit.

Dixon, J. A. and M. M. Hufschmidt (eds) (1986),

Economic Valuation Techniques for the Environment: A Case Study Workbook (Baltimore, Md: Johns Hopkins University Press).

Dixon, J. A., D. E. James and P. B. Sherman (eds) (1990),

Dryland Management: Economic Case Studies (London: Earthscan Publications).

Gittinger, J. P. (1982),

Economic Analysis of Agricultural Projects, 2nd edn (Baltimore, Md: Johns Hopkins University Press for the World Bank).

Hitzhusen, J. F. (1982),

"The economics of biomass for energy: towards clarification for noneconomists", mimeo (Ohio State University).

Holmberg, G. (1990),

"An economic evaluation of soil conservation in Kitui District, Kenya" in Dixon, James and Sherman, op.cit. 
Ray, A. (1984),

Cost - Benefit Analysis: Issues and Methodologies (Baltimore, Md: Johns Hopkins University Press for the World Bank).

Society for Promotion of Wastelands Development (1984),

Economics of Wastelands Development (New Delhi: Society for Promotion of Wastelands Development).

Squire, L. and H. G. van der Tak (1975),

Economic Analysis of Projects (Baltimore, Md: Johns Hopkins University Press for the World Bank).

Thomas, J. F. (1990),

"Regional land use planning: The Murray River catchment of Western Australia" in Dixon, James and Sherman, op.cit.

UNIDO (United Nations Industrial Development Organization) (1972), Guidelines for Project Evaluation (New York: United Nations).

Wang, G. and L. Han (1990),

"Economic evaluation of dryland peanut growing with perforated plastic mulch", in Dixon, James and Sherman, op.cit. 


\section{Valuation of On-Site and Off-Site Effects}

An economic analysis depends on quantitative, monetary estimates of the benefits and costs that are connected with an activity. This is true of both financial analysis and social benefit - cost analysis (SBCA). Chapter 6 discussed many of the differences between financial analysis and SBCA - what is included and what is excluded, and how to handle certain complications such as the correct pricing of foreign exchange and the use of shadow prices. Nevertheless, a major task is the determination of monetary values for project benefits and costs.

Any project will have internal costs and benefits. There may also be external costs and benefits, including those associated with environmental goods and services. Environmental goods consist of material products such as fuelwood and water, while environmental services include such things as changes in water quality, changes in air quality (for example, reduced sand or dust in the air) and recreational, cultural or aesthetic effects. Some components of "services" are physical, others are less so. The important characteristic, however, is that the presence or absence of goods and services has an effect on social welfare. As such it needs to be included in the social analysis, SBCA.

This chapter is divided into two major sections: valuation of goods or services that can be measured by changes in productivity, both on-site and off-site, and valuation of other effects. Little attention is given to valuation of the direct project costs (inputs such as capital and labour and others), since these are fairly easy to identify and value. A considerable literature has developed on valuation techniques; recent works with extensive developing-country examples include Hufschmidt et al. (1983), Dixon and Hufschmidt (1986) and Dixon et al. (1988).

\section{Valuation of productivity changes}

The goal of many dryland management activities is to increase production (for example, to increase the yield of a crop or allow a larger 
number of animals to be carried on a pasture). A financial analysis looks at the project costs and compares them with the market value of project outputs (increased yields or more livestock). The SBCA includes these factors and, in addition, considers any other important effect, either within or outside the project boundaries. Social prices may be used in place of market prices, if necessary. Both analyses, however, rely on changes in physical production as a starting-point.

Consider a pasture development project. The project is designed to increase the quantity and quality of biomass production of the pasture in order either to carry more aniznals per unit area or to maintain a given number but with an improvement in their quality or food security. These changes in animal number, weight and quality can be measured and valued. A number of case studies in Dryland Management: Economic Case Studies (Dixon, James and Sherman, 1990) examine this sort of project (see, for example, the discussion of benefits from collective fencing in Botswana). There may also be changes in other factors that might be called "environmental services". Water quantity and quality are one example; airborne dust levels are another; soil erosion is a third.

The economic analysis of any project has to begin with the physical interactions that are taking place. Chapter 2 presented an overview of this dimension and indicated the likely cause-and-effect relationships. These interactions are the basic units that the analyses are built upon and therefore are fundamental to carrying out a correct analysis - financial as well as SBCA. Changes in production can occur both on-site and off-site.

\section{On-site productivity changes}

The usual place to begin is with those changes in production of goods and services, and the associated project costs, that take place within the project boundary. The term "project" is used here to indicate a self-contained activity (for example, rangeland development, irrigation or sand dune stabilization). Of course, the actual geographic extent varies greatly and may be very large in some cases. A "programme" may encompass an entire region or a whole country with many component projects. In either case, the principles of analysis remain the same.

As mentioned earlier, for a financial analysis, the "boundary of analysis" is quite narrowly defined. For a SBCA, however, a wide boundary of analysis is adopted, one that includes both the project 
site and all other areas affected by the project. These off-site effects are discussed later.

With-and-without-project analysis. The with-and-without-project approach is used to correctly measure changes over time attributable to a project. Simply stated, this approach requires that the analyst examine the situation with the project and compare this to the situation, over time, without the project. Note that this is not a before-and-after analysis; such an analysis is frequently wrong because of the implicit assumption that there are no changes in productivity without the project.

For example, consider a pasture development project. The correct measure of changes attributable to the project is the difference in biomass production (or animal production) at each point in time under two scenarios: with the project and, if no action is taken, the without-project case.

As seen in Figure 7.1, the actual change in production due to the project is directly dependent on the underlying production trends. Figure 7.1(a) presents the more usual result where a project leads to an increase in the level of production over time. Nevertheless, one can also obtain the seemingly counter-intuitive result that, even with a project, productivity may fall and yet the project may still be economically justifiable (Figure 7.1(b)). This can happen, of course, if the trend without the project is a very rapid decline in productivity and if the project benefits (correctly measured) are greater than the project costs.

The same with-and-without principle must be applied to all components of the system in order to identify correctly the project effects (both benefits and costs) and carry out a correct financial analysis or SBCA. In the Lesotho case study in Chapter 11, the assumption made is similar to Figure 7.1(a): with the project, there is a fixed increase over the initial yield; without the project, there is an annual decline of 2 per cent per year due to soil erosion, poor management and continuous monocropping.

Market versus shadow prices. As discussed in Chapters 4 and 6, a decision must be made on what prices to use to value changes in the production of goods and services. For financial analysis, the answer is fairly simple - since a financial analysis represents the actual conditions faced by an individual or an investor, market prices (and official exchange rates) are used in almost all cases.

For SBCA, however, the correct prices to use are "economic" prices which reflect the real resource costs of the item in question. 
144 The Economics of Dryland Management

\section{Figure 7.1: With-and-without-project analysis of a pasture improvement project}

(a)
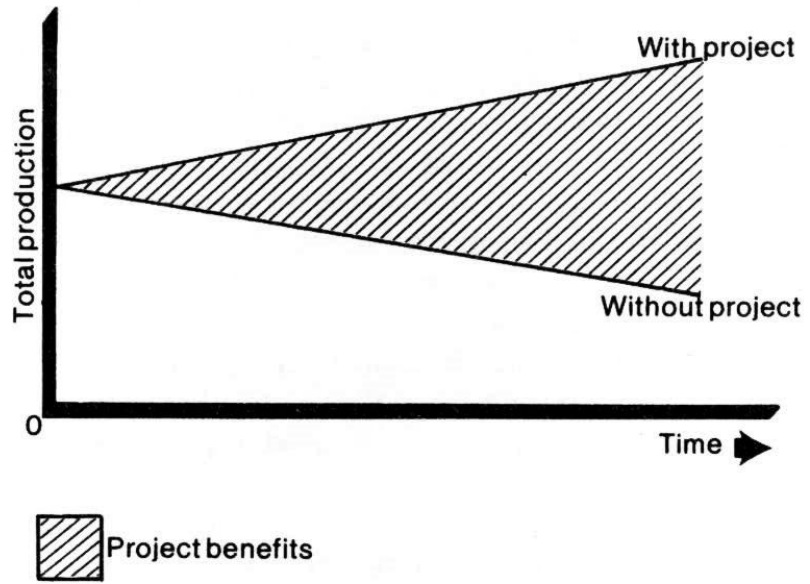

(b)

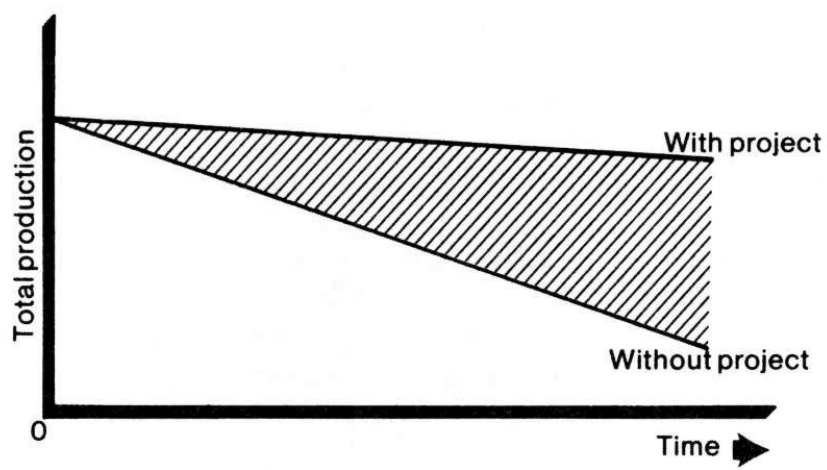

When major distortions (for example, government-imposed fixed exchange rates, sizeable taxes or subsidies or government-mandated labour rates) are known to exist, it may be necessary to use shadow prices.

In the Lesotho case study, it was determined that fertilizer prices contained a subsidy of 30 per cent. The subsidized market price was used in the financial analysis, while the higher, subsidyadjusted "shadow price" was used in the SBCA. Similarly, although there is no black market in foreign exchange, trade barriers exist for the Customs Union to which Lesotho belongs, and 
these affect import prices. Prices of imported goods are higher than they would be without the Customs Union. The value of imported items was therefore reduced by 20 per cent when going from financial to "economic" prices for the SBCA. In this case the price adjustments went both ways: the SBCA used higher fertilizer prices and lower imported good prices than the financial analysis.

In many cases, however, market prices can be used for SBCA as well as for financial analysis. A general rule of thumb is to use market prices whenever possible and to ignore minor distortions between market prices and "economic prices".

\section{Off-site productivity changes}

The valuation of off-site productivity changes is essentially the same as for on-site changes. Examples include changes in crop production, fishery production and air or water quality or quantity. Because they occur off-site, the values of such changes are usually not included in the financial analysis.

A financial analysis may take off-site effects into account if forced to do so by regulation (such as the payment of compensation to those adversely affected). SBCA, however, should always take offsite productivity effects into account as part of the analysis. Economic prices should be used to place values on these effects. How to determine these prices has already been discussed in Chapter 6.

The most difficult question is deciding which productivity changes need to be included. Since these productivity changes occur off-site, they are physically separated from the project. Establishing a precise cause-and-effect link may be difficult. Air pollution and water pollution are good examples: the larger the boundary of analysis, the larger the number of potential contributors to pollution.

The easiest procedure for identifying such changes is to begin with the most direct, most obvious off-site effects and slowly expand the analysis to the extent knowledge, time and resources permit. Frequently, the more distant the off-site effect, the more difficult it is to value even if the effect is very important.

One example of off-site productivity changes involves airborne or waterborne dirt or sand, perhaps from a degraded rangeland. The eroded material is deposited on fields, in water bodies and in irrigation canals. It may result in decreased production or other, indirect environmental costs. A rangeland management project involving pasture improvement and stock management is 
designed to improve the rangeland and increase animal production. The main benefit of the project, when measured in a financial analysis, is increased animal production. There may well be off-site productivity effects, however, and in this case they are largely benefits. By stabilizing the range and increasing plant cover, the amount of airborne and waterborne erosion is reduced. Adjacent fields experience a reduction in deposition of eroded soil and reduced damage by airborne particles, and this will tend to increase average yields. Yield changes are fairly easy to identify and monetize. In the case of more distant fields, however, the reduction in soil deposition may be minor; it is hard (impossible?) to say how much is due to the project under consideration and how much is due to other factors.

The following guidelines, therefore, may be of use in identifying, valuing and including off-site productivity effects:

- Start with the nearest, most visible and economically most important effects. Beginning literally at the project gate or fence, the analyst looks beyond to identify productivity changes that have a clear cause-and-effect linkage with the project. These changes may be either positive or negative. Their inclusion can help increase the economic attractiveness of a project as easily as they can increase the costs.

- Include more distant effects to the extent that one can reasonably establish a cause-and-effect link with the project. Changes in water quantity or quality may be one example. Changes in downstream or near-shore fishery production are another possible effect. - When great uncertainty exists, the potential effect still can be included in the analysis in a qualitative, not a monetary, manner. This has the benefit of making the decision-maker aware of the potential impact and yet does not require an attempt to monetize an interaction that is very difficult to prove conclusively.

An example of the calculation of on-site and off-site effects is given in the Thai study in Dryland Management: Economic Case Studies (Dixon, James and Sherman, 1990). Box 7.1 presents some of the points raised in that study.

Effects of production changes on prices, factor markets and consumer's and producer's surplus

Both financial and economic analyses must take into account possible changes in prices due to the project. The competitive market 
("small country") assumption is commonly used - that is, changes in production as a result of the project will not be large enough to influence the market prices of either the goods and services produced, or those goods and services used as inputs in the production process.

\section{Box 7.1: On-site and off-site effects in Thailand}

Upland areas in northern Thailand are used for rainfed agricultural production. Due to population pressure, the intensity of land use is increasing and has resulted in a growing problem with land degradation. In a study by Pitsanu Attaviroj (1990) in Dryland Management: Economic Case Studies, three alternative land management systems are examined and compared: exploitative monocropping, land development by itself and conservation farming.

The economic analysis examined the on-site and off-site impacts of the various alternatives and, where possible, placed monetary values on them.

The main on-site costs are the costs of agricultural production and the costs of soil conservation measures (construction of access tracks, land forming, ongoing maintenance of tracks and conservation banks). The direct farm input costs vary, with conservation farming requiring more inputs. Soil conservation measures averaged $1250 \mathrm{baht} / \mathrm{rai}$ (about $\$ 300$ ha), and annual maintenance averaged $125 \mathrm{baht} / \mathrm{rai}(\$ 30 / \mathrm{ha})$. The principal on-site benefits are the crops grown - com, mung beans, peanuts and rice. Details of benefits and costs are given in Attaviroj (1990).

Off-site benefits from land development and conservation farming were also considered. The major off-site benefits are from reduced forest encroachment and reduced soil erosion and downstream sedimentation. Of the 1.4 million rai $(224,000 \mathrm{ha})$ of forest lost each year in northern Thailand, about one-thind is used as additional farmland. It was assumed that about half of this was used to replace degraded lands, and the value of lost timber from this area was estimated to be 330 million baht per year (about $\$ 12.7$ million). The impact of soil erosion and sedimentation was estimated by considering decreased irrigated crop production resulting from lost storage capacity in major reservoirs. Similarly, lost storage capacity also imposes a cost in terms of reduced hydropower generation. Further downstream, silt loads lead to dredging expenses to keep the lower Chao Phraya River open to shipping as far as Bangkok.

The analysis then considered all three land management alternatives and the benefits and costs, on-site and off-site, associated with each. Exploitative monocropping produces positive net benefits for five years and negative net benefits thereafter. Land development alone is fairly unattractive because of large capital costs in the first year. Conservation farming is very attractive - both without and with land 
development. It increases yields and decreases off-site costs. Table 7.1 presents summary data on undiscounted net benefits over a fifteen-year period for the various alternatives.

Table 7.1: Net benefits from land-use alternatives in northern Thailand upland region (millions of baht)

\begin{tabular}{rrrrr}
\hline Year Exploitative & $\begin{array}{c}\text { Land } \\
\text { monocrop }\end{array}$ & $\begin{array}{c}\text { Conseroation } \\
\text { development } \\
\text { alone }\end{array}$ & $\begin{array}{c}\text { farming } \\
\text { alone }\end{array}$ & $\begin{array}{c}\text { Conseroation } \\
\text { farming plus land } \\
\text { development }\end{array}$ \\
\hline 1 & 3,367 & $-5,394$ & 2,851 & $-8,272$ \\
2 & 2,374 & 4,151 & 4,790 & 4,838 \\
3 & 1,608 & 2,975 & 4,788 & 4,836 \\
4 & 948 & 2,014 & 4,785 & 4,835 \\
5 & 357 & 86 & 4,783 & 3,730 \\
6 & -184 & 463 & 4,781 & 4,832 \\
7 & $-1,042$ & -895 & 4,779 & 4,831 \\
8 & $-1,427$ & $-1,308$ & 4,777 & 4,829 \\
9 & $-1,800$ & $-1,695$ & 4,775 & 4,828 \\
10 & $-2,096$ & $-3,033$ & 4,772 & 3,723 \\
11 & $-2,451$ & $-2,282$ & 4,770 & 4,825 \\
12 & $-1,129$ & 705 & 4,768 & 4,823 \\
13 & $-1,956$ & -585 & 4,766 & 4,822 \\
14 & $-2,587$ & $-1,487$ & 4,764 & 4,820 \\
15 & $-2,549$ & $-2,145$ & 4,761 & 3,715 \\
. & & & & \\
\hline & & & & \\
\hline
\end{tabular}

For most projects, this is a reasonable assumption. Increased livestock production from an individual pasture management project is unlikely to produce enough extra meat and livestock products markedly to reduce the market price. The same will be true for a small irrigation scheme designed to increase yields or permit double cropping. Similarly, a single project normally will not be large enough to increase the price of an input, such as fertilizer or seed.

In some cases, however, the size of the individual project may be so large or the market for the commodity so small that the project can be expected to influence the price level. (A programme that combines several small projects can have the same effect.) These changes must be taken into account in both the financial and 
economic analyses. For example, consider an agricultural project that will produce fresh vegetables. The market for these vegetables will depend on how far they can be transported and still be competitive with other producers of vegetables. The analyst must determine what this market is and then look at the relative increase in supply the project will create.

If a village is very isolated and the output is very perishable, then it is likely that the village will be the only relevant market. In this case, even a relatively small project in absolute terms might have a large impact on the market price. If the project area is on a major trade route and the product can be transported economically to a wide area, it is much less likely that it will affect the price of the output.

If the project is designed to use internationally traded inputs, it is unlikely that it will affect the world price of the good. Similarly, few projects whose output is exported will be likely to change the world price, though this may occur when the output is only produced in a few places. Again, it is the ratio of the additional output to the size of the market which will be the most important factor.

When it appears that the project will have an effect on either factor or output markets, this should be included in the analysis. Box 7.2 provides more detail on how this is done.

\section{Box 7.2: Calculation of production-induced price effects}

Figure 7.2 shows an example of a project which will increase output enough to lower the market price. The initial pre-project situation is at point 1 where the price is $P_{1}$ and the quantity demanded is $Q_{1}$. After the project is completed, the supply curve shifts from $S_{1}$ to $S_{2}$ and the new equilibrium point is at point 2 with a new price of $P_{2}$ and a corresponding demand of $Q_{2}$. Gross benefits (total willingness to pay) in the initial situation are measured by the sum of the areas $A_{1}, A_{2}$ and $A_{3}$. In the new situation, gross benefits increase by the areas $B_{1}$ and $B_{2}$. This change in area represents the gross benefits of the project.

The net benefits of the project consist of the overall change in consumer's surplus (areas $A_{2}$ plus $B_{2}$ ) plus the overall change in producer's surplus.

Three situations may be encountered:

(1) If domestic producers originally supplied the quantity $0 Q_{1}$ to the domestic market, their income will decline from $0 P_{1} \times 0 Q_{1}$ to $0 P_{2} \times 0 Q_{1}$ as a result of the project, that is, by an amount equivalent to the area $A_{2}$. This represents a transfer of income from producers to consumers, so the 
effect on net benefits, over the output range $0 Q_{1}$, is zero. The net effect of the project is thus confined to the change in consumer's surplus over the change in output $\left(0 Q_{2}-0 Q_{1}\right)$ represented by the area $B_{2}$ plus any producer's surplus earned in the project itself. The area $B_{2}$ can be calculated by multiplying the change in quantity by one-half of the change in price, that is:

$1 / 2\left(O P_{1}-O P_{2}\right) \times\left(O Q_{2}-0 Q_{1}\right)$.

(2) If the pre-project supply of the good was imported, then the reduction in producer's surplus (area $A_{2}$ ) will not be felt domestically. In this case, area $A_{2}$ would be added to area $B_{2}$ as a benefit, since domestic consumer's surplus would be increased by this amount with no corresponding decrease in producer's surplus. Area $A_{2}$ would be calculated as

$0 Q_{1}\left(0 P_{1}-0 P_{2}\right)$.

(3) If the good was produced domestically and exported, it would be overseas consumers who received the increased consumer's surplus, while domestic producers suffered the loss in producer's surplus. In this case, neither area $A_{2}$ nor $B_{2}$ should be included in the project benefits.

When a project affects the market price of an input, a similar analysis is used. In these cases, however, both the factor market and the output markets must be considered. The total change in welfare will depend on a number of variables including whether the factor is produced domestically or imported, whether the output will be consumed domestically or exported, the degree of substitutability of the factor and whether the factor is used in other domestic production processes. Because of the multitude of cases possible, combined with the rarity that factor (that is, input) markets will be affected to any large degree, these cases will not be discussed further. More information can be found in Mishan (1982) or Ray (1984).

\section{Valuation of other effects}

The first half of this chapter focused on valuation of direct productivity changes which result from a project or activity. These changes are the most easily identified (and valued) components of a financial or economic analysis. This part considers the valuation of other effects which are frequently left out or ignored because they are harder to identify, measure or value. Nevertheless, some fairly simple techniques to include such effects are available and much can be done to incorporate these effects in the analysis.

This part is divided into four sections. The first two sections - 
concerning damage to property and materials, and effects on human life and health - are examples of direct effects on social welfare. The last two sections deal with more difficult topics: the impact of projects on people via population dislocation, and the measurement of intangibles and non-quantifiables.

Figure 7.2: Change in social welfare from a price decrease, due to increased output

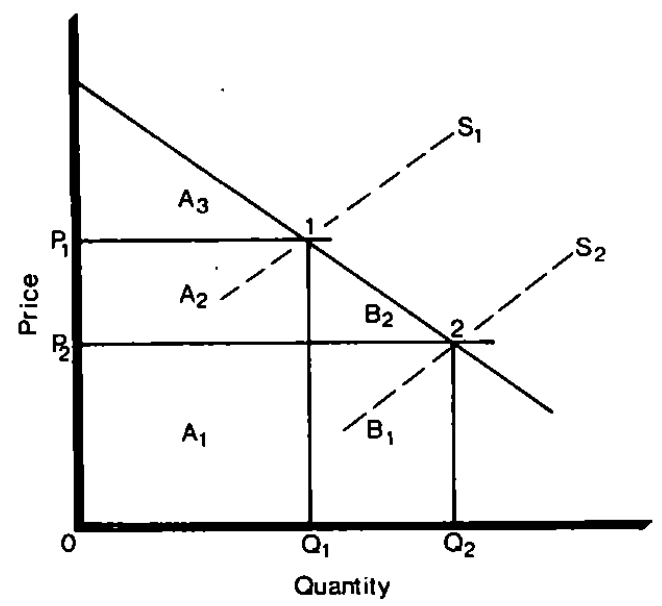

Damage to property and materials

Sometimes a project or activity will produce, as an unintended side-effect, damage to property or materials. These damages may occur on-site or, more frequently, off-site, at some distance from the project. A common example is a factory smokestack releasing soot that soils laundry, houses or other property some distance from the factory. Undoubtedly physical damage occurs with an associated cost - dirty laundry must be washed again, dirty houses or windows require increased maintenance. These damage costs are not included in the financial analysis but should be part of the SBCA.

In the dryland context, the agents causing damage will usually be dirt, dust or sand which may be either airborne or carried by water. Flooding may also be a problem in some areas. If area sources are widely dispersed, and if considerable distances are 
involved, it can become difficult to establish a meaningful causeand-effect relationship. According to residents of New Delhi, for example, airborne dust is transported from the deserts of Rajasthan, several hundred kilometres away. Although this is no doubt partly true, and the dust imposes considerable costs, it is almost impossible to prove that a range management programme, even one covering a considerable area, would have a direct effect on dust levels in New Delhi.

If a cause-and-effect link can be established, damage to property and materials can then be valued using market prices (for a financial analysis) or "economic" prices (for a SBCA). When measures are taken to prevent damage from occurring, they can be analysed using the cost analysis techniques presented in the last part of this chapter.

\section{Human life and health}

Environmental effects on human health can be considered a variant of the change-in-productivity approach (though this approach is mostly acceptable only to economists). In this case, the production unit in question is a human being, and productivity is affected by sickness or death. Monetary costs are incurred, both from lost production as well as from medical care expenses. In addition there are psychic costs from pain and suffering.

The valuation of effects on human life and health follows a similar process as outlined for damage to property. A cause-and-effect link must be established and measurement made in a with-andwithout-project context:

Actual valuation, however, is complicated because humans, not inanimate pieces of capital, are involved. In addition, there are major differences between valuation of morbidity (sickness) and of mortality (death).

Disease is common in many dryland areas. Income and nutritional levels are low, water may be in short supply and polluted, medical care may be hard to obtain. The most common health problems are associated with water shortages: contaminated water and poor sanitation. Respiratory diseases caused by airborne dirt and dust may also be common. All of these health effects are costs that may be reduced by some projects, and thereby become a measure of benefits.

Health problems also may be created by a project. For example, an irrigation or livestock watering project may create a new ecosystem suitable for certain disease vectors. Bilharzia (schistosomiasis), 
malaria, river-blindness and other diseases are possible results of otherwise very useful development projects. If these diseases are spread by the project, their costs are correctly counted as part of the project costs.

One useful typology for categorizing health benefits is given in Warner and Luce (1982):

- Personal health benefits relate to decreased morbidity, mortality or disability. Reduced pain and suffering are also personal benefits but are hard to measure and value.

- Health care resource benefits are potential savings from reduced medical care, both now and in the future.

- Direct economic benefit from increased productivity is another directly measurable benefit.

Although the correct measurement and valuation of health benefits associated with projects are not discussed in detail, some general guidance can be provided:

- Direct productivity changes of individuals can be used as a partial measure of health benefits from reduced illness if they can be measured in a with-and-without-project framework. This requires quantification of an individual's output (productivity) and its correct valuation.

- Health care costs avoided (doctors, facilities, staff, medicine) are another measurable benefit. If no health care is available, the withand-without analysis will not reveal any "benefits". Similarly, new health care costs created as a result of the project need to be counted as a project cost.

- The value of human life when death is involved also needs to be considered. The value of life is clearly large, but not infinite. Numerous techniques have been developed to place a monetary value on life, but none is entirely satisfactory. Human capital approaches usually rely on calculation of the net present value of earnings. Willingness-to-pay approaches have been proposed as a broader measure of the value individuals place on reducing risks of death and illness (see Mishan, 1982).

In general, great care should be taken in directly valuing human life; in most cases it should be included qualitatively rather than quantitatively. Actual health care costs avoided as a result of reductions in mortality should, of course, be counted as benefits just as 
they are in the case of changes in morbidity. These approaches focus on direct costs and changes in production. They ignore the very real physical and psychic costs associated with illness and death and are therefore minimum estimates of the effects being measured.

Although these guidelines are only suggestive, they do reflect the overall theme of this guide: start with those effects that have a direct impact on production and human welfare; use changes in productivity first (especially for those goods and services that have markets and market prices associated with them) and then proceed to less tangible effects; use market prices to the extent possible. The valuation of human life is one of the most difficult, controversial and value-laden topics. Unless clear guidelines have been established by government or another responsible agency, the analyst may be well advised to avoid this aspect of project valuation. For a more extensive treatment of this topic, see Jones-Lee (1976) and Mooney (1977).

\section{Population dislocation}

Population dislocation is the movement of people from one area to another in order to accommodate a project. Some projects, such as dam and reservoir developments, may involve moving tens of thousands of people. Such involuntary resettlement involves major social and economic costs.

The costs involved with population resettlement include some or all of the following:

- moving people, animals, household goods and non-fixed capital assets to a new location;

- preparing an appropriate new site, with associated construction and infrastructure costs;

- providing new income-generating opportunities (farms, industry, others) in the receiving areas and providing training when necessary;

- taking appropriate measures to minimize the impacts from increased population pressure and crowding in the receiving area; and

- incurring psychic and other societal costs involved in the move.

To the extent that a project involves population dislocation, the first three categories of costs (and sometimes the fourth) can be calculated and included in the project costs. The last category, psychic 
and societal costs, although potentially large, is much more difficult to value and is usually included only in a qualitative fashion. (In some cases dislocated people are given money in lieu of land. This approach raises a host of complicated issues but is not discussed here.)

The actual provision of facilities for dislocated people varies greatly from country to country and project to project. The World Bank, for example, has extensive requirements for involuntary resettlement built into its projects. (For a discussion of the World Bank's approach to resettlement and its economic implications, see Cernea, 1988.) These costs can be very large, and the ultimate decision of what should be done is largely political. The economist can help in determining the costs involved.

\section{Dealing with intangibles and non-quantifiables}

This chapter has progressed from concrete and more easily valued effects to those that are both less tangible and much more difficult to value. Nevertheless, to the extent that social welfare is affected, these latter effects need to be identified, quantified, valued (where possible) and entered into the SBCA. When it is impossible (or imprudent) to place monetary values on these effects, they can still be included in a non-monetary manner in the analysis.

Intangibles and non-quantifiables include a wide range of goods and services, frequently of an environmental nature. They include such things as biological diversity, cultural or historic sites, aesthetic considerations and even the knowledge that unseen or unused flora or fauna continue to exist. Many of these effects can be quantified in physical, if non-monetary, terms.

Ecologists and environmentalists are frequently concerned about preservation of natural ecosystems and functioning environments. Tropical rain forests, mangrove swamps and desert ecosystems are all examples of areas that have been targeted for development and whose loss would impose unquantified (and sometimes unknown) losses on society (see Oldfield, 1984; Peterson and Randall, 1984). These losses arise from loss of genetic material and genetic resources that could have economic value in the future (for example, new plant varieties, new drugs and substitutes for other plants or animals).

One way to address this problem quantitatively is by use of the opportunity cost approach, discussed in the next section. This approach is commonly used for siting decisions: the location of a factory, pier, dam or reservoir, the routing of a road, the 
development of a new irrigation command area. Under this approach, if a unique or potentially valuable resource would be destroyed by the project, the analyst examines alternative sites that could be used. Assuming that these alternative sites both are higher cost and do not have the same unique resource attributes, the economist calculates how much more it would cost to use the alternative site rather than the originally proposed site. This additional amount is the opportunity cost of using the alternative site. It expresses in monetary terms the extra costs involved in protecting or preserving some intangible or non-quantifiable effect.

This estimate does not place a value on these effects; it merely gives a monetary cost for preserving them intact. This information is then presented to the decision-maker, who must decide if preservation benefits are at least as large as this additional cost.

In some cases the opportunity cost of preservation may be very high and the alternative site rejected; in other cases the cost is fairly modest and may lead to adoption of the alternative site.

\section{Cost analysis techniques}

When benefits are hard to measure, it is sometimes possible to use information on actual expenditures to gain insights into the size of potential benefits. For example, one can examine the costs involved in making polluted water potable (for example, by boiling, filters or bottled water) to derive an estimate of the value placed on clean water. Cost analysis techniques rely on such surrogate markets to estimate values. These techniques are commonly used when air or water pollution is a problem. The assumption is that preventive expenditures express a minimum valuation of cleaner air or water. If the cleaner air or water were not considered valuable, the individual would not pay the costs associated with obtaining them.

For new projects that may have measurable environmental costs, cost analysis techniques assist in the design process. The analyst can examine whether it is better to use one project design, create certain environmental costs and take mitigative measures, or alter the project design to avoid the environmental problem occurring. The altered design will probably be more expensive initially but will avoid other expenditures later. (Note that costs may be cash expenditures or may be losses in welfare.) The question is whether to pay costs up front (for prevention) or later (for clean-up). 


\section{Preventive expenditures}

One method of valuing the damages of a new or ongoing problem is to examine the cost of defensive measures taken by individuals. Such measures indicate a minimum amount of how these people value the impacts to themselves or to their environment. This amount is considered a minimum estimate for two reasons. First, actual expenditures may be limited by income constraints (that is, the individuals might have spent even more money to avoid the damage but are limited by available income). Second, the cost of the defensive measures taken may be less than the damage they prevent (that is, if preventive measures cost more than the damages avoided, they should not be adopted).

Consider an individual reacting to sand dune encroachment or deteriorating water quality. We can model such behaviour in the following manner. An individual would be willing to make preventive expenditures if:

$D>D^{\prime}+E$

where $D=$ original level of damages;

$D^{\prime}=$ reduced level of damages after action is taken;

$E=$ expenditures made to reduce damages.

This can also be looked at in a slightly different fashion: action will be taken if the cost of reducing the damage (by either prevention or rehabilitation) is less than the benefits received by reducing the damage. Using the same notation as above, an individual is willing to take action if:

$E<D-D^{\prime}$.

In addition, the individual will continue to reduce or prevent the damage until the point where the cost of reducing or preventing the damage further is just equal to the benefits of the new level, that is:

$$
E=D-D
$$

This willingness to accept the cost of reducing or preventing damages can be interpreted as the individual's minimum valuation of the benefits from avoiding the resource damage. This amount, however, is only a minimum estimate, since the actions taken will probably be constrained by the individual's ability to pay, especially in poor dryland areas.

Another example of the use of this approach is a study of the environmental-quality aspects of upland agricultural projects in Korea (Kim and Dixon, 1986). The study showed that lowland paddy farmers often incurred costs by building water diversion dikes to prevent siltation damages caused by eroded soil from the 
upland areas. By examining these costs, it was possible to establish at least a minimum value of the damage caused by siltation as viewed by the farmer. (If the eroded soil enriched the lowland fields, any productivity gains should be counted as benefits.)

As yet another example of how this method might be used, consider crop damages caused by wildlife and/or domestic animals. One could look at farmers' expenditures on fencing to estimate a minimum value of the loss in agricultural revenue.

In some cases, though damages may be severe, an individual cannot afford to take any action. This may limit the opportunities to use this approach in low-income areas.

\section{Replacement cost}

In the replacement-cost approach, environmental damages are evaluated according to the costs which would be involved in replacing the environmental services that would be lost because of the project. The rationale behind this technique is similar to the preventive-expenditures approach, except that here the actual costs of replacing the good or service in question are used, and income constraints are no longer a factor.

By using the replacement-cost approach, better decisions can be made about what should be done concerning damages associated with a project. For example, the analysis may show that the damages in question can be prevented at a lower cost than the cost of replacing those services which would be destroyed. This would indicate that is is more efficient to prevent the damage than to allow it to occur and then repair it. In other cases, replacement costs may be low, indicating that the best alternative is to allow the project to proceed and then repair or replace the damages. In addition, the replacement costs must be calculable and be less than the value of the productive resources destroyed (or else it would not be efficient to make the replacement).

In the Korean case mentioned earlier (Kim and Dixon, 1986), the replacement-cost approach was also used to study the effect of soil erosion on crop productivity. The costs of replacing lost nutrients, and thereby maintaining productivity, were compared to the expected costs of allowing soil erosion to continue. These latter costs included both reduced productivity on-site as well as off-site costs imposed on others. The off-site costs were estimated by means of the preventive-expenditure approach just described.

Another example of the use of the replacement-cost technique is the case study on plastic mulch for peanuts in China, reported by 
Wang and Han (1990) in Dryland Management: Economic Case Studies (Dixon, James and Sherman, 1990).

This study showed that incurring the costs of plastic mulch would be offset by reduced replacement costs for moisture and nutrients. The study of land levelling in China, also included in Dryland Management: Economic Case Studies, provides an additional example. This study looks at different land-levelling techniques which can be undertaken as an adjunct to irrigation projects. The reduced cost of erosion associated with different land-levelling techniques was estimated by looking at the cost of replacing the soil and nutrients that would be lost under the various alternatives.

A variation of the replacement-cost technique is the relocationcost method. In some situations, rather than having to replace the services damaged by a project, it may be necessary to relocate an existing physical facility because of environmental changes associated with the proposed project. Here, the costs of relocating the existing facility are used to measure the benefits of preventing the damage (via pollution control or relocation of the project) or, alternatively, the costs of allowing the damage to occur.

For example, development of an industrial facility may result in a discharge of pollutants into a nearby river. As a result of these discharges, it may be necessary to relocate irrigation channels or water supply intakes. These costs would have to be included in project costs. If the costs are too high, one may have to consider relocation of the factory itself or installation of appropriate pollution control measures.

Another example would be a mining project requiring a large supply of water in an area where water is already scarce and no new sources are available. One alternative might be relocation of nearby farms to areas where more water is available. The costs of relocation would have to be considered as part of the total costs of the new mine and compared to the expected social benefits of the mine project.

When a project requires relocation of people, however, the actual physical costs of relocating them may be only a small portion of the true costs. Uprooting people from ancestral lands or moving them into unfamiliar areas is extremely distressing. Theoretically, the correct economic valuation criterion would be their willingness to accept compensation (WTAC) for such a move. This would be the amount of money that would make them indifferent between staying where they are or moving to the new area. In practice, however, 
this concept is extremely difficult to implement.

Both the replacement-cost approach and the relocation-cost approach are examples of how to measure environmental damages by the costs of offsetting the damages. It should be mentioned, however, that if the relocation or replacement does not completely compensate for the damage, then the cost estimates are not true upper bounds of the actual costs.

\section{Opportunity-cost approach}

The opportunity-cost approach differs somewhat from the other cost-side approaches discussed in this section. It is used to estimate the cost to society of preserving an area rather than implementing a development project. Essentially, it examines the additional cost that society must pay to preserve one site and develop an alternative, higher-cost site. This approach does not attempt to measure the benefits of preserving the area, which is often extremely difficult; rather it looks at the opportunity cost of preserving the area.

This approach is often used when deciding on the location for a project. In some cases the site initially chosen may have important environmental or historical characteristics. In cases where alternative locations are available, the approach quantifies how much more it would cost to choose an environmentally preferred but more expensive site. Once this information is gathered, it is up to the policy-makers to decide whether preserving the resource warrants the additional costs involved.

One potential area where this approach might be useful is for agricultural or grazing projects which will affect areas used by wildlife (for example, in Eastern or Southern Africa). Quantifying the benefits of such areas as wildlife preserves, especially if they are still undeveloped for tourism or other activities, can be very difficult. Rather than attempting to measure the benefits, one can examine a number of alternative sites for development along with their probable effects on wildlife. The opportunity-cost approach highlights the additional project costs associated with preserving the wildlife area.

\section{Travel-cost approach}

A last major cost analysis technique is the travel-cost approach. Originally developed to determine values for outdoor recreation sites such as public parks, this approach relies on survey data of actual time and money expenditures of those using a recreational 
area. This information is in turn used to derive demand curves and estimate consumer's surplus for park users. As such, it is an example of valuation of a non-priced good. The value consists almost entirely of consumer's surplus. Details of this technique are not presented here; they can be found in Hufschmidt et al. (1983) and in a case study in Dixon and Hufschmidt (1986). Where appropriate, the benefits of preserving recreational, tourism and cultural sites in dryland areas could be examined using this approach. It should be noted that this approach is usually applied in more affluent countries that have extensive recreational tourism.

\section{References}

Attaviroj, P. (1990),

"Soil erosion and land degradation in the Northern Thai uplands: an economic study" in Dixon, James and Sherman, op.cit.

Cernea, M. M. (1988),

Involuntary Resettlement in Development Projects, World Bank Technical Paper No. 80 (Washington, DC: World Bank).

Dixon J. A. and M. M. Hufschmidt (eds) (1986),

Economic Valuation Techniques for the Environment: A Case Study Workbook (Baltimore, Md: Johns Hopkins University Press).

Dixon, J. A., D.E., James and P. B. Sherman (eds) (1990),

Dryland Management: Economic Case Studies (London: Earthscan Publications).

Dixon, J. A., R. A. Carpenter, L. A. Fallon, P. B. Sherman and S. Manopimoke (1988),

Economic Analysis of the Environmental Impacts of Development Projects (London: Earthscan Publications).

Hufschmidt, M. M., D. E. James, A. D. Meister, B. T. Bower and J. A. Dixon (1983),

Enoironment, Natural Systems, and Development: An Economic Valuation Guide (Baltimore, Md: Johns Hopkins University Press).

Jones-Lee, M. W. (1976),

The Value of Life: An Economic Analysis (London: Martin Robertson).

Kim, S. and J. A. Dixon (1986),

"Economic valuation of environmental quality aspects of upland agricultural projects in Korea", in Dixon and Hufschmidt, op.cit.

Mishan, E. J. (1982),

Cost - Benefit Analysis, 3rd edn (London: Allen \& Unwin).

Mooney, G. H. (1977),

The Valuation of Human Life (London: Macmillan)

Oldfield, M. L. (1984)

The Value of Conserving Genetic Resources (Washington, DC: US Department of the Interior, National Park Service) 
162 The Economics of Dryland Management

Peterson, G. L. and A. Randall (eds) (1984),

Valuation of Wildland Resource Benefits (Boulder, Colo: Westview Press). Ray, A. (1984),

Cost. - Benefit Analysis: Issues and Methodologies (Baltimore, Md: John Hopkins University Press).

Wang, G. and L. Han (1990),

"Economic evaluation of dryland peanut growing with perforated plastic mulch" in Dixon, James and Sherman, op. cit.

Warner, K. E. and B. Luce (1982),

Cost - Benefit and Cost-Effectiveness Analysis in Health Care: Principles, Practice and Potential (Ann Arbor, Mich.: Health Administration Press). 


\section{Risk and Uncertainty in Dryland Development and Management}

\section{Handling risk and uncertainty}

Risk and uncertainty are unavoidable aspects of decisions concerning the development and management of dryland areas. Questions that need to be answered in addressing the problem of risk and uncertainty include:

- How can risk and uncertainty be defined and measured?

- How should the land user evaluate risk and uncertainty in managing resources at his/her disposal and balance the prospect of production failure against the need to produce physical or economic returns? - In benefit - cost assessments of public policies, programmes and projects, how should the analyst take risk and uncertainty into account and present meaningful information to public decision-makers?

- How should public decision-makers, acting in the best interest of the community, deal with the problem of risk and uncertainty in formulating and implementing improvement policies, programmes and projects?

Decisions on dryland development schemes and land management practices typically involve both the private and the public sector. Private decision-makers can be expected to deal with the problem of risk and uncertainty to maximize their own economic welfare. The "best" options for private decision-makers will be influenced by their perceptions of and attitudes towards risk and uncertainty. Public decision-makers must accept responsibility for dealing with risk and uncertainty on behalf of society as a whole. There may be major divergencies between private and social valuations of risk.

In many benefit - cost analyses, the problem of risk and uncertainty is ignored. The "best estimate" of net benefits is usually the one that the assessment team regards as being most appropriate. It is compiled from the "best estimates" of all the components of the analysis. In practice, a decision-maker often has no way of knowing how the assess- 
ment team arrived at its "best estimate". Any subjective combination of the level of net benefits and probability may have been used.

Where the distribution of values for any variable or for net benefits is known, the most commonly used "best estimate" is the mean value or arithmetic average of the distribution, also known as the expected value. It is unfortunately only a single figure and reveals very little about risk. "Best estimates" of the net benefits of policies, programmes and projects give no indication of the likelihood of success or failure.

Several courses of action are available to a decision-maker, private or public, forced to consider the results of an economic analysis presenting only "best estimates" of net benefits, with no information on the significance of risk and uncertainty:

(1) The decision-maker may make an ad hoc decision based on the available information. Subjective judgements by the decision-maker him-/herself are inevitable if this approach is adopted. Threshold values may be prescribed, such as a minimum level of net benefits or minimum internal rate of return, to allow for risk and uncertainty.

(2) The information base and underlying analysis can be improved to facilitate a decision. Such improvement may be carried out to varying degrees (Mar et al., 1987). A decision may be reached with considerable uncertainties remaining in the information base. Better information may be obtained through such methods as sensitivity analysis, scenario construction, reliance on expert opinion and the use of decision-analysis techniques.

(3) The analysis can be carried through to a full risk assessment. Risk assessment involves a number of separate steps. The first is identification of the nature and sources of risk. In economic terms, this would refer to factors possibly leading to low net benefits or major losses. Second is the measurement of risk. To carry out this step, the pathways and processes creating risk must be identified. Probability distributions for stochastic factors are needed. Values for other inputs to the analysis must be specified. Through appropriate computational or modelling procedures, the probability distribution for net benefits can be derived. Finally, an evaluation of risk must be undertaken. Actions can then be formulated based on risk assessment. Such strategies can be described as risk management (Whyte and Burton, 1980).

(4) The decision-maker may decide to abandon the original proposal and proceed on an entirely different basis. A possible approach is adaptive environmental assessment and management 
(AEAM), under which the decision-maker deliberately attempts to keep management options open as development proceeds, generating information from the experience gained as a guide to subsequent action. Other defensive strategies, specifically designed to cope with risk and uncertainty, might also be tried. An important strategy, aimed especially at the problem of critical zones and irreversibility, is the safe minimum standard (SMS).

\section{Sources of risk and uncertainty in dryland decision-making}

Changes in dryland environments are typically difficult to predict. The economic effects of existing land-use practices, the introduction of new practices and the application of investment funds to land improvements cannot be readily determined. In any economic analysis of management options, a range of possible values for benefits and costs is often obtained.

There are many sources of risk and uncertainty in the dryland context. Consider a dryland production system such as a communal farm or grazing plot, as shown in Figure 8.1. General social, economic and political factors can influence the decisions and behaviour of land users and the general community. Land tenure and financial conditions may be poorly defined.

Natural events affecting production include rainfall, drought, windstorms, floods, fire, lightning, hail, frost and freezing. Animal and plant diseases, plagues and pests are common. Other environmental processes may also be important such as erosion, salinization and devegetation.

Changes in physical yields, damages to property and shifts in the productivity of the resource base are some of the on-site effects that can be expected. Another class of effects is off-site environmental impacts imposed on other producers and members of the community. Pathways linking all these activities may not be known or clearly specified.

As explained in previous chapters, methods are available to value on-site and off-site effects. Such methods, however, are often subject to error. In addition, the prices selected to value inputs to production, outputs and environmental impacts are often uncertain or subject to wide fluctuation.

The dryland production system example is an appropriate vehicle for classifying all variables into three separate categories for analysis. Some variables may be known with complete certainty. A good example is a predetermined stocking rate. Other inputs might be known only in probabilistic terms, such as rainfall or the occurrence of insect plagues. Finally, in some situations, events may be 
Figure 8.1: Dryland production system

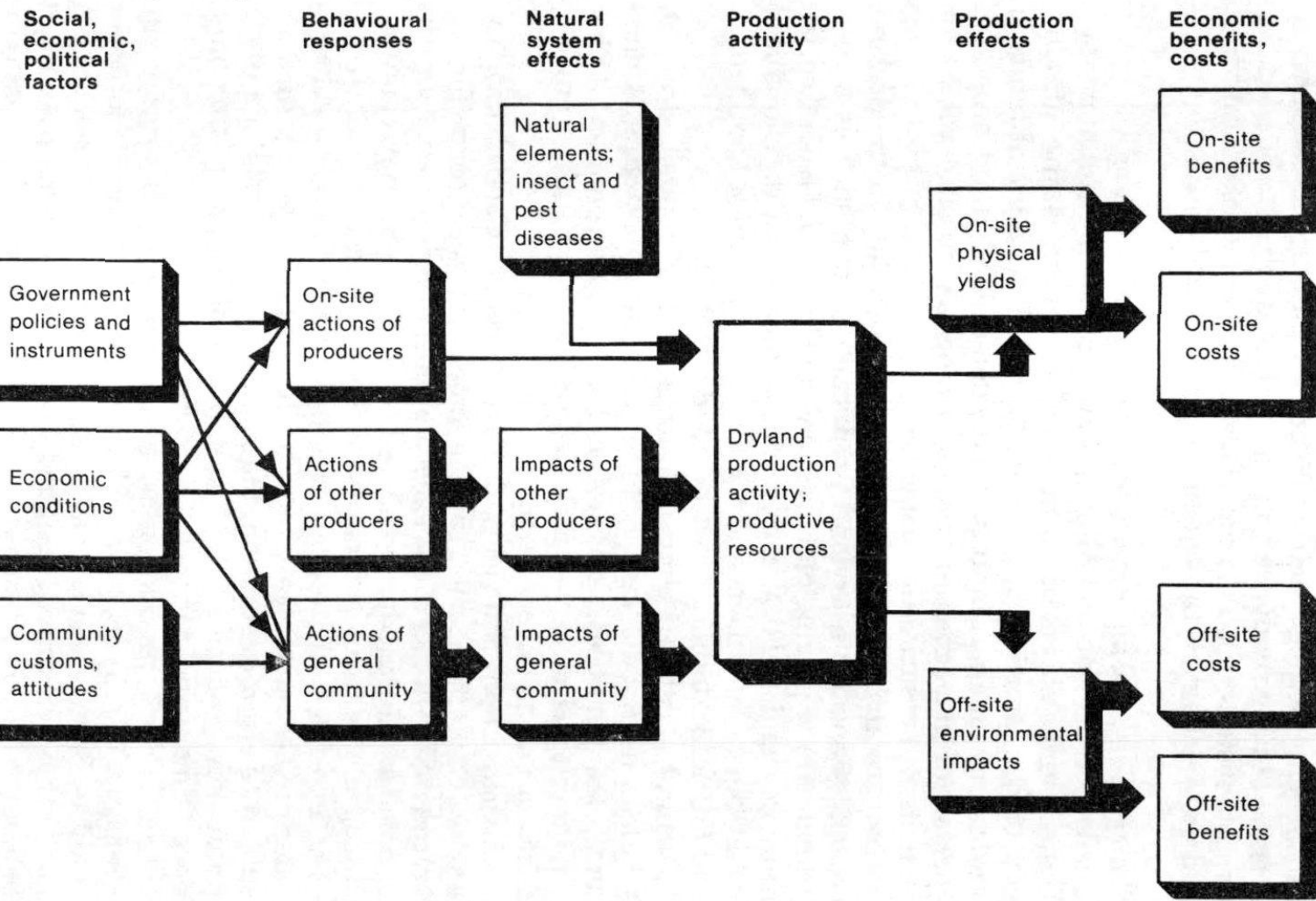


totally unpredictable (for example, social upheaval or natural disasters). Variables that are known with certainty can be described as deterministic. Randomly occurring variables are stochastic. The techniques used to handle these different types of variable in an economic analysis rely heavily on mathematical and statistical methods. The main concepts are presented in this chapter. Further details can be found in the recommended references.

\section{Definitions of risk and uncertainty}

The terms "risk" and "uncertainty" are commonly used interchangeably, but a distinction is drawn for economic analysis. With risk, the probability distributions for the variables are known. (A probability distribution reflects the probability associated with each possible value of the variable.) With uncertainty, the probability distributions are not known.

Probability distributions for stochastic (random)variables such as precipitation can be obtained from historical data, either directly as relative frequency distributions, or as fitted theoretical distributions (see Box 8.1). Such distributions are said to be objectively derived. Alternatively, where data are scarce, probability distributions may be obtained from subjective judgements by experts, assessment teams or decision-makers themselves (see Box 8.2).

\section{Box 8.1: Objective probability distributions based on historical data}

A frequency distribution is a tabular arrangement of historical data in classes. The frequency distribution can be described in graphical form as a histogram or a frequency polygon. A frequency histogram consists of a set of rectangles with areas proportional to class frequencies. The total area of the histogram is the total number of frequencies multiplied by the width of the class intervals. A frequency polygon is obtained by connecting the mid-points of the tops of the rectangles in the histogram. The area under the polygon is equal to the area of the histogram. A frequency distribution for rainfall is showri in Figure 8.2 based on forty yearly values.

A relative frequency distribution is found by dividing the class frequencies by the total number of frequencies (number of data items). A relative frequency distribution can be described by a histogram or polygon. The sum of the relative frequencies is 1 . The total area of the histogram or area under the polygon is thus also equal to 1.

The normal or Gaussian distribution is a theoretical distribution which can be fitted to data sets with a large number of values - in practice, more than thirty. The graph of a normal distribution is shown in Figure 8.3. The 
normal distribution is symmetrical, and the mean, mode and median coincide. With any normal distribution, 68.27 per cent of the frequencies lie within + and -1 standard deviations on either side of the mean, and $\mathbf{9 5 . 4 5}$ per cent within + or -2 standard deviations.

The normal distribution is not always appropriate in dryland applications because of its isymmetry. In reality, the probability distributions best representing stochastic variables in dryland projects are often strongly skewed. Distributions allowing for skewness, such as the log-normal distribution, would generally be more appropriate.

Special theoretical distributions are available to predict the occurrence of rare events (Rowe, 1981). The most commonly used distributions are the binomial distribution and the Poisson distribution. The binomial and Poisson distributions have very similar properties. Both approach the form of a normal distribution as their means increase in size.

The techniques used to deal with risk and uncertainty also differ. Risk is handled through the techniques of risk assessment, risk benefit analysis, and risk management. Uncertainty requires the use of decision analysis techniques.

Risk. Risk is usually viewed as an adverse factor in economic decisions. Rowe (1981), for example, defines risk as the chance of harm. In other contexts, risk is conceived as a hazard or danger (Whyte and Burton, 1980). In economic analysis, risk is usually specified in terms of the probability of an adverse event and its magnitude. In monetary terms, it is measured as the product of the probability and the associated monetary value of the event.

To assess the risk associated with a particular policy, programme, project or resource management action, the probability distribution for net benefits must be specified. If the probability distribution is known, it will be possible to measure the likely occurrence of above-average net benefits, as well as low net benefits or serious losses. Whether the odds favour high or low values depends on the form of the relevant probability distribution.

Uncertainty. Uncertainty is said to exist when the probability distribution for net benefits is unknown. As is evident from even a simple case such as that shown by Figure 8.1, there are many reasons why the probability distribution might not be known, ranging from incomplete data to inadequate methods of prediction and analysis.

Decisions designed to overcome the problem of uncertainty by postulating arbitrary values or by using ad hoc predictive procedures are necessarily subjective. Measurement of risk is 
Risk and Uncertainty in Dryland Development and Management 169

Figure 8.2: Frequency distribution for annual rainfall (forty years of observations)

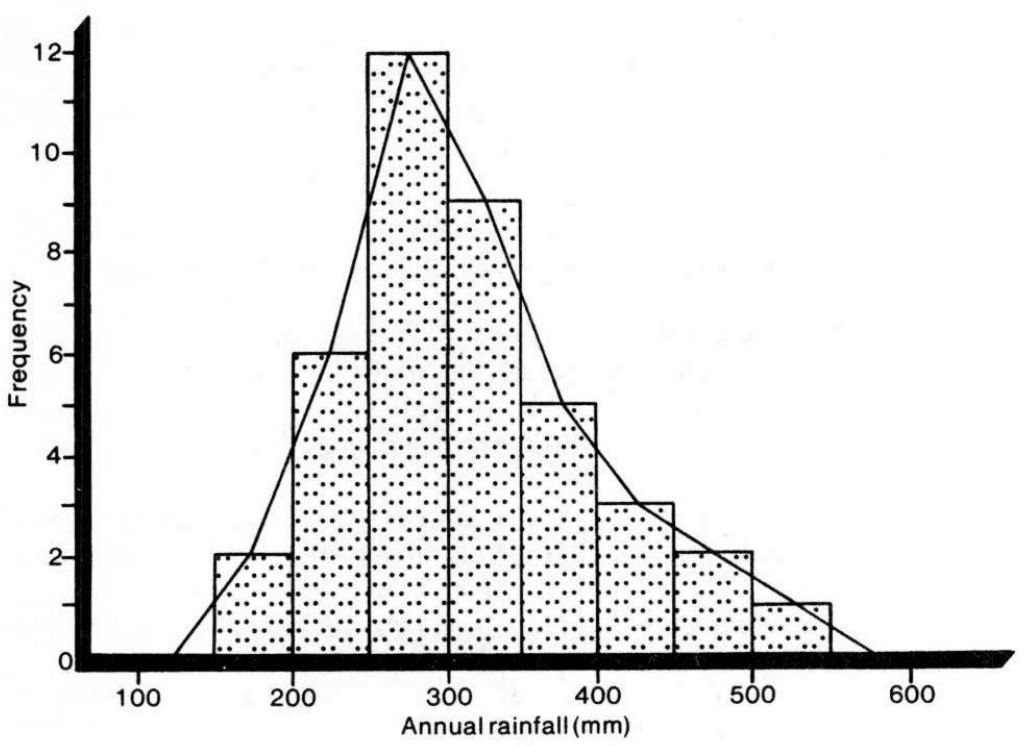

Figure 8.3: Normal distribution

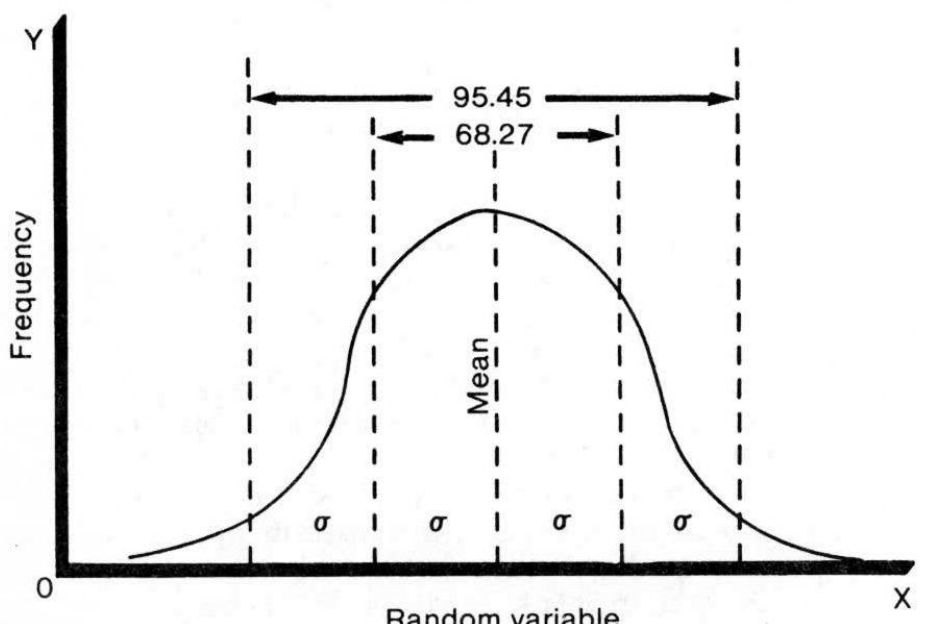

Random variable 
supposedly objective, since it is based on known probability distributions. For example, probabilities of rainfall are often based on historical records. However, subjectivity is still involved in measuring risks from such data, as certain assumptions must be made. These include the assumptions that the time period for the collection of data has been sufficiently long, that data have been properly collected and that the past is a reliable guide to the future.

\section{Box 8.2: Probability distributions based on subjective judgements}

As historical data are often not available to use in estimating probability distributions of variables in an economic analysis, subjective estimates may have to be used. These may be provided by the project appraisal team, where economic and scientific experts provide their best guess for the relevant probability distributions.

Alternatively, the project team may consult local farmers, independent experts or individuals with extensive field experience. In such a process, it is important for two criteria to be met. First, it should be possible to obtain the data without creating too much difficulty for those providing the information; otherwise, the process may become too complicated, time-consuming and subject to bias. Second, the form of the distribution chosen should, on theoretical grounds, match the kind of probability distribution that could be expected if proper historical data were in fact available.

The triangular distribution is very easy to use, as shown by North (1981). It requires subjective judgements on a lower limit (a), an upper limit $(b)$ and the mode $(m)$. One theoretical property of interest is that the distribution can be skewed, as often occurs with environmental variables in dryland situations. The graph of a triangular distribution for wheat prices is shown in Figure 8.4. In this case the distribution is positively skewed; that is, it has a larger number of observations to the right of the mode.

The step-rectangular distribution is described by Pouliquen (1970). To derive this distribution, experts are asked in a series of steps to divide the probabilities of various outcomes into successively smaller intervals. An example is shown in Figure 8.5, for the probability of crop yields in a dryland area.

Pouliquen claims several advantages for the step-rectangular distribution. The approach is based on the concept of preference ranking; the appraisal team is able to freely specify the size and number of class intervals; in practical use, the distribution has proved to be extremely reliable; and the technique gave much better results than attempts to arbitrarily fit theoretical probability distributions to limited data. Pouliquen also reported good results from the use of triangular distributions. 
Figure 8.4: Triangular distribution

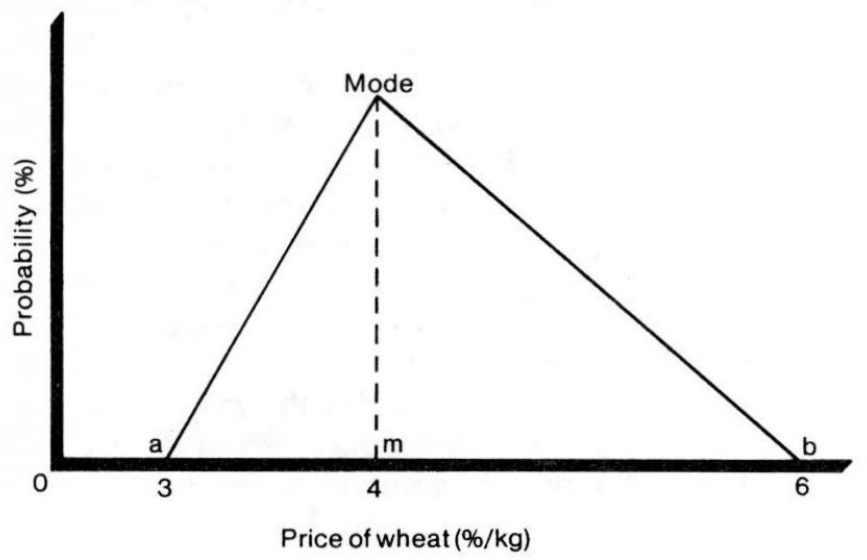

Figure 8.5: Step-rectangular probability distribution for crop yield

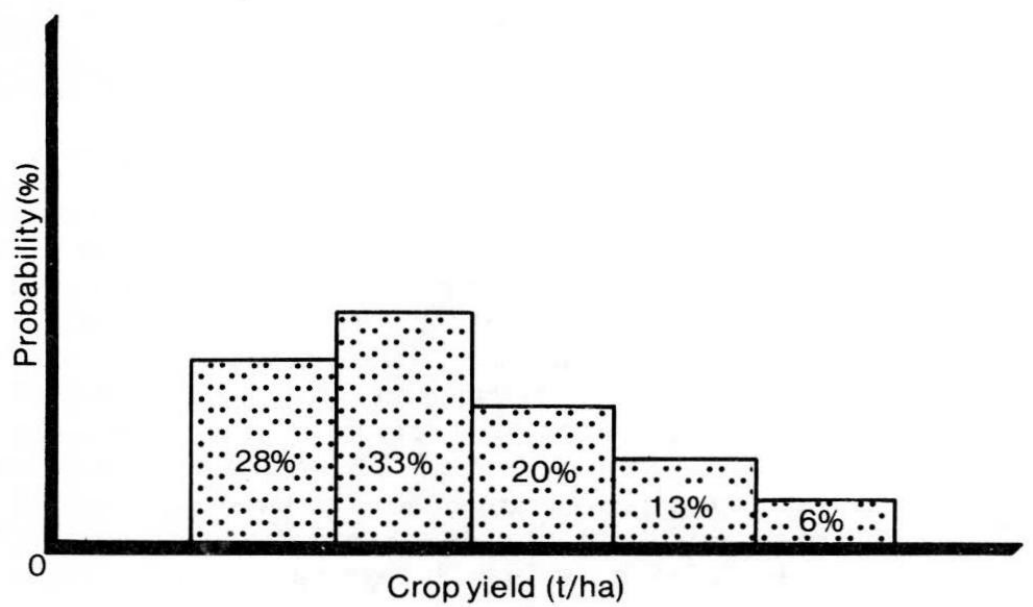

\section{Risk analysis}

Applications of risk analysis

Risk analysis forces the analyst to obtain more detailed information on the consequences of alternative actions and rigorously examine the different elements underlying final economic assessments. 
More specifically, the probabilistic properties of inputs to the analysis will be clearly defined, as well as the range of possible outcomes from each alternative, with some measure of the distribution of values. Whether inputs have been obtained from completely certain data, from probability distributions based on historical data or from subjective probability distributions must be clearly specified.

Given the results of a risk analysis, private decision-makers can assess potential pay-offs, the associated levels of risk and their willingness to accept risk or avoid it, and can formulate a specific plan of action. A good example of this is the risk analysis of stocking rates described in Chapter 5 (see Box 5.4), which shows the expected returns and costs associated with different risk management strategies. Information on the riskiness of particular alternatives should assist the private decision-maker in such matters as debt financing, crop selection and marketing strategies. Groups of private producers may institute special arrangements to offset risk, such as drought insurance or income stabilization schemes. Government assistance may also be appropriate, but some precautions may need to be observed (see Box 8.3).

\section{Box 8.3: Land use and drought relief}

While arid regions are characterized by low average rainfall resulting from their location in the high-pressure subtropical subsidence zones, drought is a temporary, irregular event which can occur anywhere, and is defined in different regions of the world according to land usage and expectations of water users. A part from rainfall, other variables which contribute to the different definitions of drought are temperature, precipitation at ground level, evaporation, effective evaporation (precipitation minus evaporation), runoff, sub-surface water storage and soil moisture. Often there is a confusion between drought and aridity which enables land users to redefine arid or semi-arid land as "drought stricken" for government relief schemes. This is facilitated in the Australian system of drought declaration, which is based not on rainfall data or soil moisture measures, but on percentage crop loss or percentage of animals to be moved or slaughtered.

In the public investment arena, Pouliquen (1970) has identified four important applications of risk analysis to project evaluations:

(1) The first is in marginal projects, where net benefits are just 
positive or where the internal rate of return is very close to the prescribed minimum level. An analysis of the riskiness of the project may determine whether to accept or reject the project.

(2) Another case is where there are unusual uncertainties, such that there is a strong possibility that the project will not earn a satisfactory rate of return. Many dryland development projects are of this nature.

(3) Risk analysis can assist in the design of projects, by isolating the main components and their probabilities influencing the rate of return. Changes in projects can be made in terms of scale, timing and design characteristics.

(4) Finally, in identifying new projects to be considered, risk analysis can increase the scope for action. Uncertain elements in the specification phase can be dealt with at an early stage, and inputs of time, effort and analysis can be minimized by an early rejection of projects with undesirable risk characteristics.

\section{A framework for risk analysis}

A general framework for risk analysis is described in Figure 8.6. When applied by land users, the aim of the analysis is to derive a probability distribution of the net benefits of a particular investment or land management strategy. The same procedure is applied to public decision-making to obtain a probability distribution of the net benefits of a policy, programme or project.

In the first step, raw data must be obtained. From the raw data, inputs to a predictive model or analytical framework are then prepared. Such inputs can be divided into three distinct categories: deterministic variables, which are known with certainty; stochastic variables with probability distributions obtained from historical data; and variables with probability distributions obtained from subjective judgements. These inputs are then introduced to a predictive model to determine the physical and social impacts of the proposed action. Economic values are placed on predicted effects to obtain estimates of benefits and costs. Finally, a probability distribution for net benefits is generated. This process can be carried out through explicit mathematical analysis or, more commonly, through computer-assisted methods such as Monte Carlo simulation (see Box 8.4).

Despite the difficulties introduced by incomplete knowledge and forecasting ability, it is important to be as objective as possible in the collection and analysis of information, and to present the results to decision-makers in the clearest and most meaningful 
way. Where subjective judgements have been made, these should be explicitly stated. An interpretation of the results of the analysis should be provided.

Figure 8.6: General framework for risk analysis

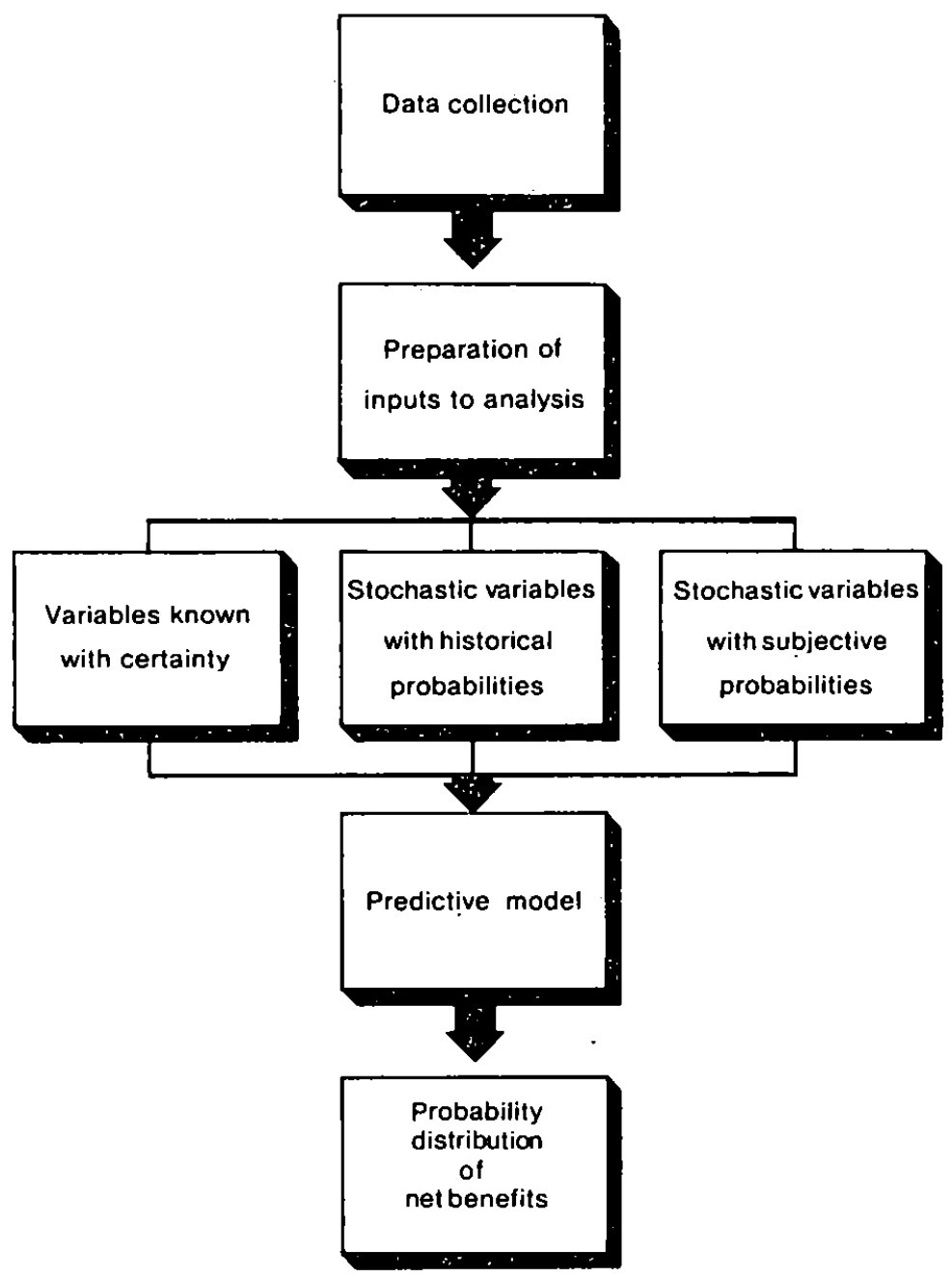

Interpretation of results of risk analysis

Properties of probability distributions. An example of a probability 
distribution for the net benefits of a dryland development project is given in Figure 8.8. The range of possible values for net benefits is measured on the horizontal axis, and the probability of each value occurring is measured on the vertical axis. The area under the curve is equal to 1 , reflecting the fact that the total probability of all possible net benefit values occurring in reality is 100 per cent. The expected value of the distribution is the mean value or arithmetic average of all the values.

\section{Box 8.4: Monte Carlo simulation}

The Monte Carlo technique involves computer simulation of the entire economic analysis. Inputs to the analysis, together with their probability distributions, are fed into the predictive model. Net benefits, with a corresponding probability distribution, are then generated for consideration by the decision-maker. The procedure is shown in diagrammatic form in Figure 8.7; for wheat production where production costs are known with certainty, annual rainfall depends on historical probabilities, and wheat prices are given in terms of subjective probabilities.

Monte Carlo simulation involves a large number of iterations, possibly several hundred. Before beginning the calculations, the probability distributions for rainfall and wheat prices are required in cumulative relative frequency or cumulative probability form. A random number selection procedure must also be established, with random numbers varying from 0 to 1 , representing cumulative probabilities for the stochastic variables in the analysis. This is easily achieved with a simple computer program.

To carry out a single iteration, values are randomly selected for each of the stochastic inputs and treated as if they were deterministic variables. The necessary calculations within the predictive model are then performed. A single value will be obtained for estimated net benefits.

The same process is repeated for a second iteration, giving a second estimate of net benefits. By carrying out a large number of iterations, a set of computed values will be obtained for the net benefits of wheat production. From the results, a frequency distribution can be derived. The information is then presented to the decision-maker for his or her evaluation of the relevant risks.

Monte Carlo simulation has a number of advantages (Environmental Resources Ltd, 1985). The technique is flexible and simple and can be understood by the non-expert or non-mathematician. It can be applied by people with limited training, as compared with the use of fitted theoretical distributions which require more highly skilled and costly staff. Any probability distribution can be used and may be specified to the degree of completeness required. Accuracy of the technique depends on the reliability of the predictive model and the number of iterations. It is particularly 
176 The Economics of Dryland Management

\section{Figure 8.7: Procedure for Monte Carlo simulation}

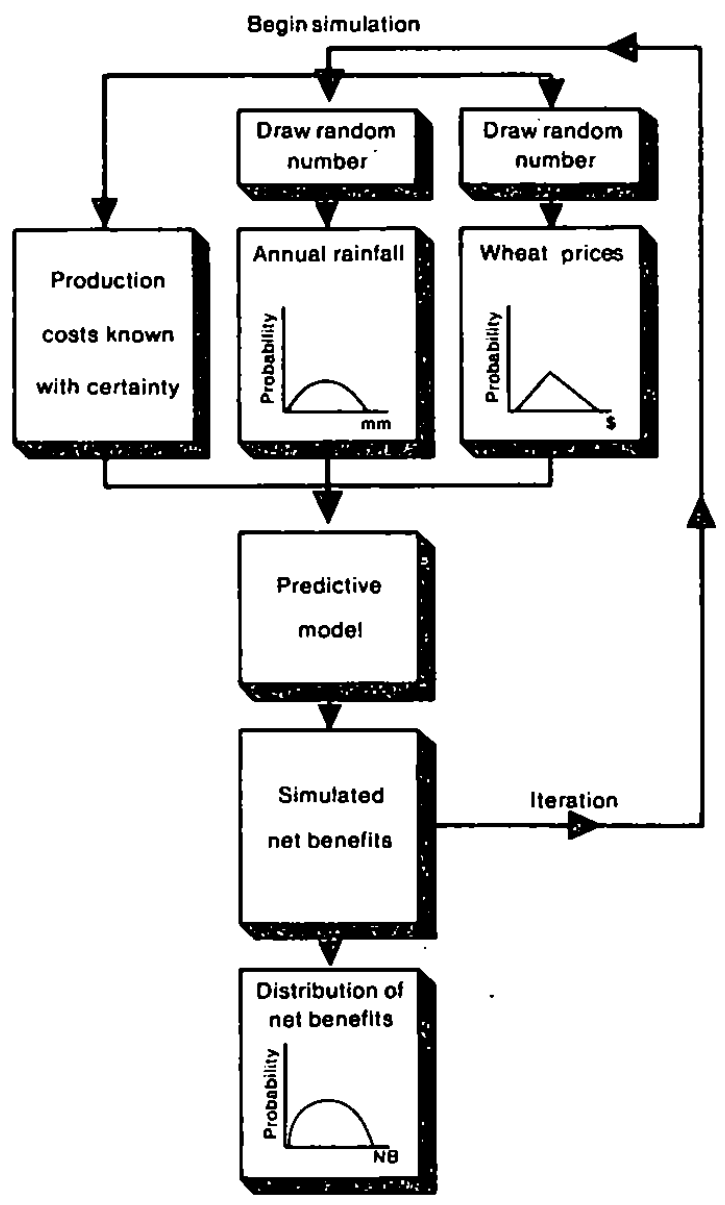

useful for non-linear models. One limitation of the technique is that it becomes much more complicated if the input variables are in any way correlated.

The main properties of a probability distribution of relevance to an analysis of risk are measures of central tendency, dispersion and 
skewness. The central tendency of a distribution is most commonly measured by the mean (or arithmetic average), the mode (the most commonly occurring or most likely value) or the median (the value above which and below which half of the probabilities lie). In a symmetrical distribution the mean, mode and median coincide; but if the distribution is skewed, the mean, mode and median have different values. In Figure 8.8 the distribution is positively skewed. For this particular distribution, rare events will tend to have a high rather than a low value. Various statistics are available to measure the dispersion of values in the distribution. In general, the greater the dispersion of net benefits, the riskier is the project.

In some applications of risk analysis, cumulative probability distributions are required. Cumulative probability indicates the total probability of all values less than or equal to a particular value. A cumulative probability distribution for rainfall is shown in Figure 8.9. It has the typical S-shape of an ogive.

Figure 8.8: Probability distribution for net benefits

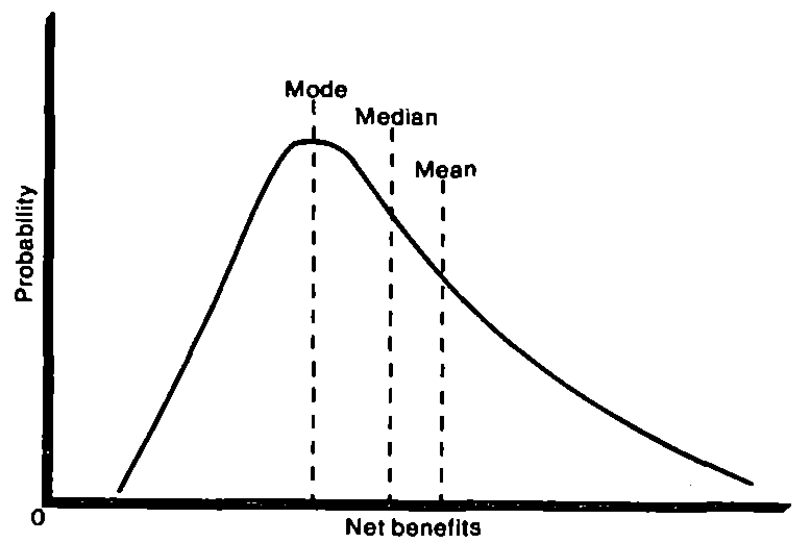

Attitudes towards risk. Individuals may be risk averters, risk takers or risk neutral. A simple example illustrates the difference. Consider a new dryland farming technique that is estimated to yield a net benefit of $\$ 1,000$ with a probability of 80 per cent, giving expected net benefits of $\$ 1,000 \times 0.8$ or $\$ 800$ (this implies a 20 per cent chance of complete failure with a net benefit of zero). A second technique has a yield of $\$ 4,000$ with a probability of 20 per cent, giving the same expected net benefits, calculated as $\$ 4,000 \times 0.2$ or 
Figure 8.9: Cumulative probability distribution for rainfall

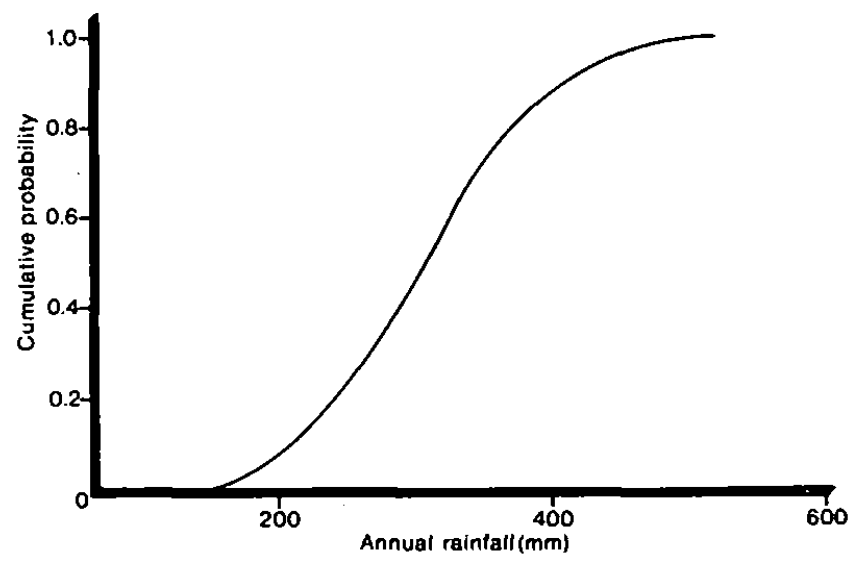

$\$ 800$ (this alternative has an 80 per cent chance of failure with net benefits equal to zero).

Farmers who regard the two alternatives as equally desirable (that is, who are indifferent between the two outcomes) because they both have expected net benefits of $\$ 800$ are said to be risk neut$\mathrm{ral}$. Those preferring the first technique and who would insist on a higher level of net benefits from the second before judging it equal are described as risk averse. Those who prefer the second technique because of its potentially higher pay-off are said to be risk takers.

A benchmark for assessing the welfare implications of risk is the certainty equivalent, which measures the guaranteed benefit that would make an individual as well off as a risky benefit. The individual's risk preference can be measured by the amount of benefit he/shelis willing to trade off to make him-/herself indifferent between a risky benefit and the certainty equivalent. If this amount is positive, he/she will be risk averse; if negative, he/she will be a risk taker; and if zero, he/she will be risk neutral (Norton, 1984).

Social valuation of risk. For formulating policies, programmes and projects, societal valuation of risk must be taken into account. Public decision-makers should be aware that their own perception of risk may influence their approach to the formulation of policies, programmes and projects. Community attitudes to risk, whether judged rational or irrational by public decision-makers, are important and can significantly affect the workability of improvement 
measures in dryland areas. Public decision-makers must nevertheless determine whether they will accept community preferences based on perceived risk, or whether to introduce policies specifically designed to change community attitudes and behaviour. For example, private land users in dryland areas may be reluctant to plant potentially high-yielding crops or adopt new productive technologies because of risk aversion. Through various kinds of economic incentives, land users may be encouraged to adopt improved production methods for the benefit of themselves and the whole community.

It can be generally presumed that, especially in dryland areas with widespread degradation and human suffering, people will be risk averse. In such situations, projects should be selected that minimize exposure to risk. As an example, consider two alternative development opportunities, $A$ and $B$. The distributions of net benefits for $A$ and $B$ are shown in Figure 8.10. Both distributions are symmetrical and have the same mean or expected value. Project $B$ is riskier in the sense that there is a greater chance that low net benefits might eventuate, although large net benefits might also accrue. Project $A$ is less risky, as the dispersion of values around the mean is smaller. A low value for net benefits is less likely to occur for project $A$. To minimize the probability of an adverse outcome, project $A$ should be selected.

To pursue socially risk-averse development strategies within the context of benefit - cost analysis, a risk premium should be

Figure 8.10: Alternative probability distributions for net benefits

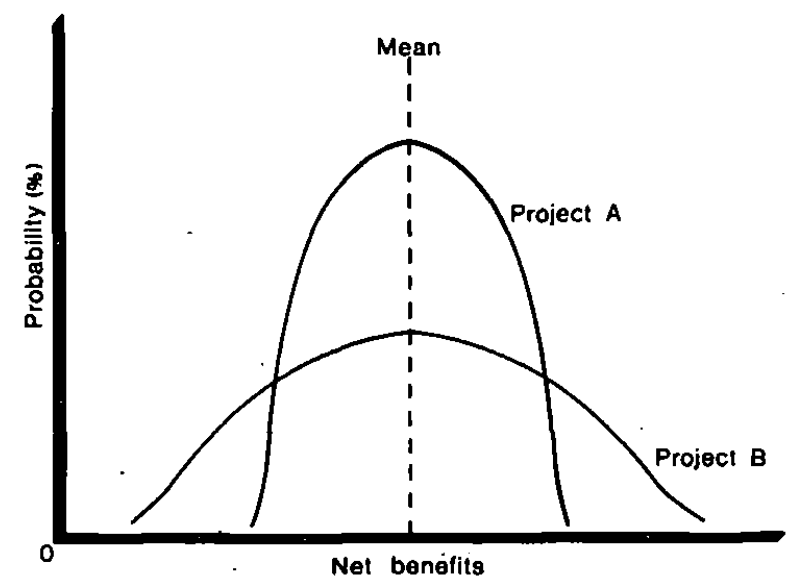


subtracted from expected values to derive estimates of the social value of risky benefits, and added in the case of risky costs. Empirical methods for obtaining measures of risk trade-offs appear to be lacking. It is possible to say only that the cost of risk bearing will be positive in policies and programmes affecting people that are risk averse. A conservative approach to risk bearing in resource management is accordingly suggested.

Voluntary and involuntary risk. An important consideration for policy purposes is the distinction between voluntary and involuntary risk. Most individuals insist on safer standards for goods and services provided by governments or large-scale enterprises than they apply to a substitute supplied by themselves. For example, farmers may willingly accept high levels of health risk by using pesticides, but insist on stringent pollution control measures for factories creating an environmental hazard.

New development projects such as the construction of new electric power-stations, intended to relieve pressure from fuelwood extraction in dryland areas, may not contribute significantly to general social welfare because of the community's resistance to the health risks associated with air pollution generated by the powerstations. Such risks are largely involuntarily borne. Even though the objectively estimated risks may be low and the investment shows a high expected rate of economic return;, the disutility associated with the perceived health risks may offset the apparent gains.

\section{Decision-making under conditions of uncertainty}

\section{Decisions based on available information}

The most direct way for a decision-maker to proceed in the absence of information on probabilities is to make an ad hoc decision based on available information. Paradoxically, there may be certain advantages, especially for public decision-makers, in this approach. As pointed out by North (1981), many public decision-makers will not accept probabilistic information because it may suggest weakness in the analysis. They may feel uncomfortable about making decisions involving a range of values, rather than a single figure.

Another political problem is associated with risk analysis. If public decision-makers know in advance that harm, however unlikely, can be expected from a particular policy or action, they may have to face a hostile community if an adverse event actually takes place. In some circumstances, ignorance may be preferred. 
If uncertainty prevails, one approach is to insist on a higher level of net benefits or higher internal rate of return from public investments in dryland programmes and projects. Some economists have advocated adding a risk premium to the rate of discount, giving a "risky discount rate". This procedure, however, is not advisable. Altering the discount rate is equivalent to deliberately distorting community time preference and capital productivity, which are quite distinct from community attitudes towards risk. The range of uncertainty typically varies for different components of a benefit cost analysis, and this cannot be properly measured by applying a risk-adjusted discount rate uniformly to all benefits and costs. Instead, the range of uncertainty applicable to different components of the analysis and the attitudes of the community or decision-maker to that uncertainty should be explicitly taken into account.

\section{Sensitivity analysis}

The information base can be improved through sensitivity analysis or the construction of scenarios. Arbitrary assumptions are made for key inputs to the analysis, generating net benefits ranging from the most optimistic to the most pessimistic values. This approach unfortunately does not indicate the probability of occurrence of the upper and lower estimates, or of values in between. Sensitivity analysis does have the advantage, however, of determining which variables have the most pronounced effect on benefits and costs and which are therefore the most critical in reaching a decision.

\section{Decision analysis techniques}

Applications of decision analysis. Decision analysis is a useful approach to the evaluation of alternative policies, programmes, projects and land-use practices under conditions of uncertainty. Decision analysis has been applied specifically to dryland management by Norton and Walker (1985). The approach assists a decisionmaker in making the best decision, but only after allowing for the decision-maker's own attitude towards uncertainty in defining acceptable planning and management strategies. Two :mportant tools of decision analysis are pay-off matrices and decision trees.

Pay-off matrices. Pay-off matrices are an extension of sensitivity analysis and can usefully be applied to the ranking of alternative strategies, actions or options which are mutually exclusive. Choice of one alternative automatically precludes choice of another. By conducting sensitivity analysis, the effects of different states of 
nature (for example, environmental factors or economic conditions) on the net benefits of each alternative can be assessed. The results can then be displayed in a matrix, with strategies as the rows, and different states of nature as the columns. Each element, $N B_{i j}$, indicates the estimated net benefit of the $i$ th strategy under the $j$ th set of conditions. Such a matrix is called a "pay-off matrix".

An example of a pay-off matrix in a drylands context is given in Table 8.1. It is assumed that a particular section of land may be used for wheat, cattle or sheep. One of these alternatives must be chosen. Net benefits are affected by rainfall which may be high, low or moderate. The net benefits predicted for each alternative under different rainfall conditions are displayed in the pay-off matrix. The problem is to determine which of the land uses is best.

Table 8.1: Pay-off matrix of net benefits $(\$ 000)$ under different land uses and rainfall conditions

\begin{tabular}{lccc}
\hline & \multicolumn{3}{c}{ Rainfall } \\
\cline { 4 - 4 } Strategy & High & Low & Moderate \\
\hline Wheat & 170 & 14 & 30 \\
Cattle & 100 & 10 & 70 \\
Sheep & 80 & 20 & 50 \\
\hline
\end{tabular}

If the probability of each net benefit value is known, conventional risk analysis can be applied. Objective probabilities are assigned to each outcome, and the best strategy is selected according to expected value, calculated as the net benefit multiplied by the corresponding objective probability (Norton, 1984).

For example, if the probabilities of high, low and moderate rainfall are $0.25,0.25$ and 0.5 , respectively, the expected pay-off for each land use can be calculated as

wheat: $0.25(170)+0.25(14)+0.5(30)=61.0$;

cattle: $0.25(100)+0.25(10)+0.5(70)=62.5$;

sheep: $0.25(80)+0.25(20)+0.5(50)=50.0$.

The cattle strategy has the highest level of expected net benefits and 
is the preferred alternative. The drawback with this approach, as previously explained, is that it assumes that the decision-maker is risk neutral. It does not allow for the effects of specific events on human welfare. In the preceding example, if any level of net benefits below 15 resulted in starvation, the outcomes might be evaluated quite differently.

Where probabilities are not known, arbitrary or subjective judgements must be made about the outcomes in the pay-off matrix. The "best" management strategy can be identified only when additional decision criteria are introduced (Pearce and Nash, 1981).

An acceptable trade-off between exploiting a dryland system and avoiding adverse consequences can be achieved by applying Wald's maximin criterion. This approach is based on caution. Wald advocates listing the worst pay-off for each strategy, then choosing the strategy with the highest of these minimum values. When the outcomes in the pay-off matrix are costs or losses rather than benefits, the Wald criterion leads to the minimization of the highest costs. Under these conditions, the Wald criterion is described as the minimax criterion. It is especially appropriate when a bad year would result in starvation or economic crisis and no defences, such as drought insurance, are available.

The lowest values for the pay-off matrix in Table 8.1 are 14 for wheat, 10 for cattle and 20 for sheep. The largest minimum value is 20 , indicating that sheep would be the best choice.

Decision trees. In complex resource management situations, outcomes of decisions can be studied by means of a decision tree (Norton, 1984). Decision trees describe the possibilities open to decision-makers and the implications of alternative decision sequences.

A simplified decision tree for the management of land suitable for wheat or sheep production is given in Figure 8.11. The net benefits from each sequence of decisions can be estimated to inform the decision-maker of the economic consequences of his/ her actions. In this respect, decision trees are similar to pay-off matrices. The advantage of decision trees is that they clearly describe the options available. They also indicate which options are foreclosed once a particular sequence of decisions has been commenced. Another virtue of decision trees is that they can show where further data collection and analysis are likely to be of value.

Uncertainty associated with irreversible damage to resources Concepts of irreversibility. The problem of irreversibility has already 


\section{Figure 8.11: Decision tree for dryland production}

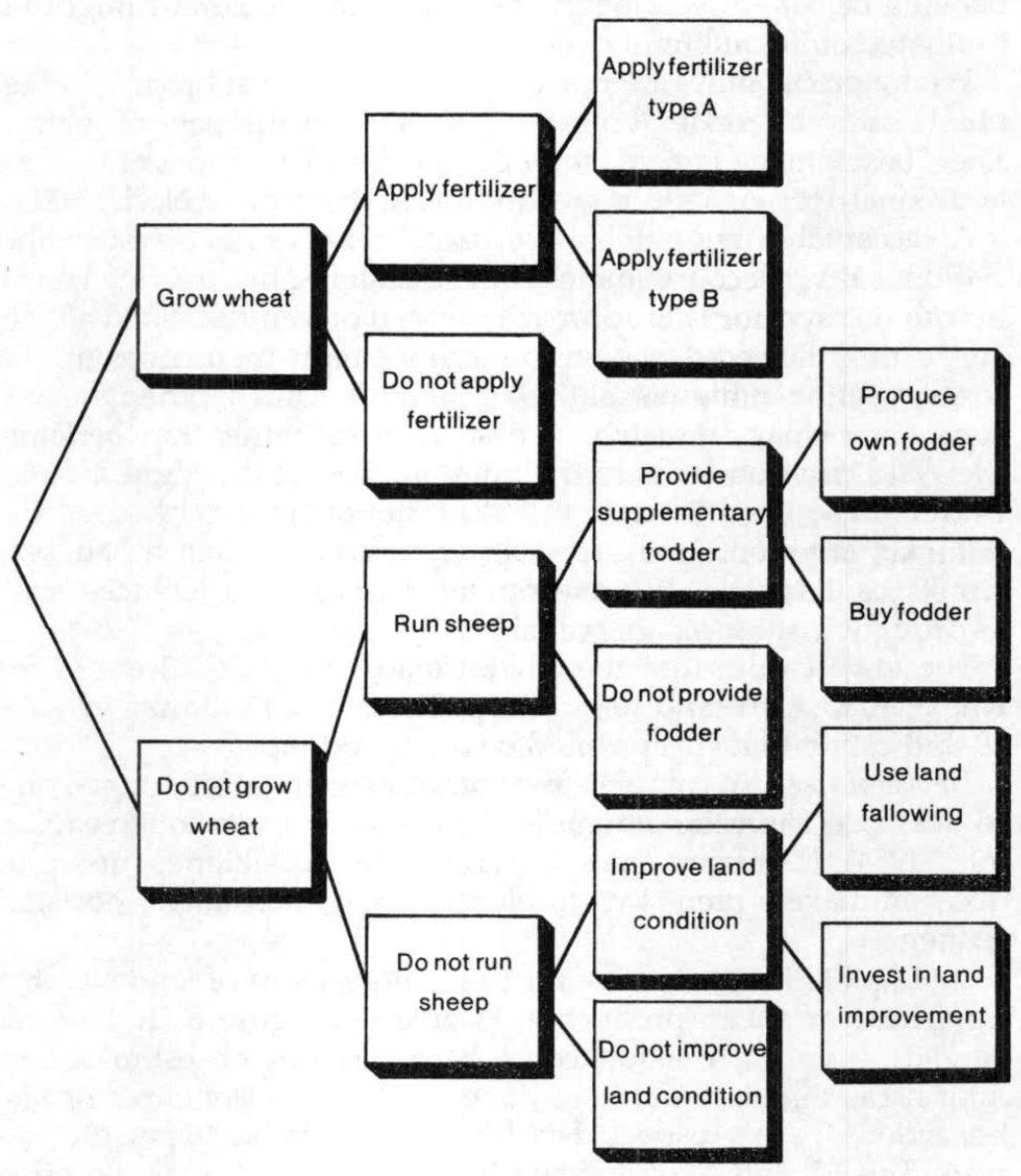


been raised in earlier chapters. In the dryland context, two important categories of response were delineated: First, fallowing or "passive repair" may be practised to reverse past damage. As the required time period must be extended, the more accurately the damage may be classified as permanent. In the second category, positive actions are taken, possibly involving significant investment, to restore the productivity of the resource. Again, as the cost of restoration increases, so can the degree of damage be described as irreversible.

Irreversibility can be viewed as a narrowing of options, and thus the effect of decisions with irreversible consequences is potentially to reduce future economic welfare. A constrained optimal decision cannot be superior to an unconstrained one. The welfare implications and the need for society to take a conservative approach to resource utilization where irreversible effects are imminent have been stressed by economists in the case of stock resources (Hotelling, 1931) for natural species (Ciriacy-Wantrup, 1952) and natural environments (Krutilla and Fisher, 1975).

Option value. Irreversibility can be appraised in terms of an "option value" which has been defined by Cicchetti and Freeman (1971) as the difference between an option price and the expected value of consumer's surplus for the use of a particular resource. The option price is the maximum price someone would be prepared to pay to preserve future choices in use of the resource. Alternatively, it may be conceived as the value, in addition to consumer's surplus, of retaining an option to a good or service for which the future demand is uncertain (Fisher and Krutilla, 1975). Option value is similar to a risk premium and would be positive for risk-averse people.

A related concept is "quasi-option value", which represents the benefits obtained by delaying a decision when one of the alternatives involves an irreversible choice and the benefits of other alternatives are uncertain. The policy implications of this concept are that it should be worthwhile reducing pressure on a resource and incurring a short-term reduction in economic benefits to offset uncertainty about future options. Quasi-option value can be associated with delaying a decision to generate better information (Conrad, 1980) and with management of development to reduce uncertainty and improve the information base. These applications are similar to those of adaptive environmental assessment and management (AEAM), which has its origins in ecology rather than economics. 
Problems of irreversibility in the drylands. The fragility of dryland environments makes them particularly vulnerable to irreversible degradation if improperly used, with serious implications for the welfare of dryland inhabitants. The issue of uncertainty revolves around the economic value of these lands in the future. As agricultural land is in relatively fixed supply, its value will tend to increase as populations grow and as other activities, such as industrialization and urban development, expand. If the opportunity cost of preserving land for agriculture is presently low, options should be preserved. Indeed, any delay in implementing resource protection or rehabilitation measures may simply result in the later generation of massive rectification costs.

\section{Defensive strategies to cope with risk and uncertainty}

\section{Overcoming the effects of risk}

Various approaches to the management of risk are available. Where risk itself cannot be reduced or avoided, policies can be implemented that mitigate the effects of risk (Little and Mirrlees, 1974). For example, the effects of drought can be mitigated by early warning systems (see Box 8.5), famine relief schemes, emergency cattle fodder reserves and flexible transport systems to move stock and people out of drought-affected areas. Some of these strategies have already been discussed in Chapter 5 . Financially, stochastic effects can be buffered through market stabilization schemes, flexible lending arrangements and farm insurance (Ray, 1981). Little and Mirrlees suggest that exposure to risk can be reduced by substituting less risky projects for risky ones.

\section{Box 8.5: Early warning systems}

The advent of drought requires immediate action to reduce the demand for animal feed (by moving or reducing animal numbers) and to find other sources of feed. An early response permits a more gradual transition and reduces the level of the crisis compared to that which occurs when action is delayed until the full force of the drought is felt.

The possibility of early warning rests on the fact that rainfall and forage growth follow somewhat regular patterns. Any marked departure during the early part of the pattern makes it more likely that the pattern as a whole will be affected.

If the data required for the early warning were used only to anticipate drought, gathering it might be too expensive relative to the 
benefits. However, knowing the state of range production is essential for management during all years, good or bad. In fact, the best possibilities of improving the range and optimizing production may occur only during the more favourable years. Therefore the good years should also be anticipated as early as possible in order to take maximum advantage of them.

An early warning system requires an adequate network for data gathering and sufficient long-term observations so that estimates of variability can be obtained. The network may pose problems of cost where there is a high rainfall variability because the greater the variability the more observation points are necessary. Nevertheless, such a system provides a rational approach to both grazing management and coping with drought.

Remote-sensing data from satellites can show rainfall distribution and vegetative cover. If correlated properly with ground data, this method could vastly increase the area sampled and would be much cheaper than full ground sampling. Indeed, this is a case where the most advanced technology is one that can do the job properly.

(Child et al., 1987 pp.162 - 3. Reprinted by permission of the publisher.)

Howe (1979) points out that risk can be handled by risk pooling and risk spreading. Pooling refers to the ability of a centralized agency to undertake a large number of independent projects and combine the total costs and benefits. The expected (mean) return of the pool rises faster than the variance as the number of independent projects increases. Risk spreading involves splitting the burden of risk from a given project among a large number of individuals. Such a policy can be pursued in countries which have diversified economic systems. Potential drought victims can be supported by other members of society. Where the drylands are dominant in the economy, however, the whole society may suffer from adverse outcomes, as is the case in much of the Sudanese - Sahelian region. Under these conditions, risk-averse strategies and development programmes should be followed.

\section{Investment in information}

As already explained, if excess pressure on dryland resources leads to effects that cannot easily be predicted, future options may be eliminated. Long-run economic benefits may be maximized by delaying development and investing in better information instead (Dasgupta, 1982).

Such investment may take the form of an opportunity cost (that is, the short-term benefits forgone by doing nothing). 
Information can be obtained by monitoring the behaviour of dryland ecosystems. Investment in information may also consist of directly sponsoring research programmes and field experiments.

\section{Use of expert systems}

Expert systems are computer programs that use expert knowledge to assist management decisions. Originating from research into artificial intelligence, expert systems have been widely used in mineral exploration, medicine and organic chemistry, and recently have been applied to natural resource and environmental management problems (Kessell, Good and Hopkins, 1984; Davis and Nanninga, 1985).

Expert systems are particularly useful in situations where decision-makers have only limited time and information to explore management strategies. The computer program is designed to function like an expert adviser and can be operated interactively by the decision-maker.

Unlike traditional simulation models that require detailed numerical data, expert systems focus on the main parameters and causal relations within a system. Moreover, they are more concerned with answering specific questions about the effects of particular environmental conditions and management options. "What if" scenarios are described mainly in terms of the kind of outcome that an expert would predict. Traditional simulation models frequently generate output that is irrelevant to specific management issues, in unnecessarily detailed numerical form. Expert systems are not designed to replace traditional simulation models and, in some situations, could be a valuable precursor to a traditional model-building exercise.

Expert systems are constructed by specialists with skills in computer programming and an ability to elicit and organize information from experts. Considerable time is needed to obtain the relevant bits of information and assemble the program. Special computer languages emphasizing relational operators are used. Once established, the main advantage of an expert system is its flexibility and ease of application. Most programs can be run on a portable personal computer.

Expert systems could greatly assist decision-making in the management of dryland resources. Possible applications include land-use practices, cropping techniques, stocking patterns and rehabilitation measures. They represent an effective way of transferring research results from one country or agency to another and 
of overcoming problems of deficient knowledge and management expertise in field situations.

\section{Adaptive environmental assessment and management}

Adaptive environmental assessment and management (AEAM) is an approach to natural-resource management originating in the Institute of Resource Ecology at the University of British Columbia, the Canadian Department of Environment and the International Institute for Applied Systems Analysis in Austria (Holling, 1978; Environment Canada, 1982; Walters, 1986).

AEAM is based on the assumption that uncertainty is an inevitable aspect of natural-resource management. Uncertainty cannot be eliminated, and any attempts to reduce uncertainty should be carefully scrutinized. Such attempts frequently involve significant economic costs. According to the proponents of AEAM, a superior approach is one that explicitly recognizes uncertainty and leads to more resilient strategies that create opportunities to benefit from ecological change. A wide range of alternative management strategies should be explored.

Ecological considerations should be incorporated at an early stage, rather than as an afterthought, so that management strategies can benefit from an enhancement of natural systems. The opportunity to benefit from change should be part of the design goal. Management plans should contain a trial-and-error component. In this way, information will be generated. Monitoring and remedial mechanisms should be part of the management approach. Holling (1978) argues that it is impossible to assess all possible impacts of development. Detailed surveys and descriptive studies are of only limited value, and scientific studies are useful only if focused through policy concerns.

A key feature of the AEAM process is the staging of professional workshops to formulate and explore management strategies. The workshops are led by a small core group of analysts with technical expertise and with skills in integrating information and co-ordinating people. Synthesis of information, specification of management alternatives and communication of results are accomplished through systems analysis modelling. An initial workshop is held with the core group and participating specialists. A crude model is developed reflecting expert opinion, available data and management alternatives. A consolidation phase follows, during which the model is refined. Subsequent workshops explore management options and the implications of uncertainty in greater detail. 
AEAM does not rely on any particular type of model. Applications of the method have been based on cross-impact (Leopold) matrices, qualitative simulation models (GSIM and KSIM) and numerical simulation models. Selection of a model depends on available time and data, the system under study and the management options. The technique has considerable potential for applications to the management of dryland resources.

\section{Critical zones and safe minimum standards}

The critical zone. The safe minimum standard (SMS) approach is based on the concept of a critical zone, which defines the limits within which the effects of depletion on the flow of renewable resources are economically reversible. It suggests a benchmark from which the economic desirability of further conservation practices can be gauged. The idea has been developed largely by Ciriacy-Wantrup (1952) and Bishop (1978).

Critical zone resources can be defined in terms of a sustainable flow of renewable products or services. The capacity of the resource is usually an operational measure based on conservation practices such as a permissible rate of soil erosion, maximum stocking rate or maximum harvesting rate. If the critical zone for a particular use has been passed, consideration of a standard for a "lower" use is encouraged. There is little point trying to implement a standard which has already been passed.

The economic rationale for the SMS. The basic assumption of the SMS is that the costs of maintaining the SMS are small in comparison with the possible losses accompanying irreversible depletion of land resources. The SMS is specified in physical terms to allow for uncertainty about the process of irreversibility.

As developed by Bishop (1978), the approach uses a pay-off matrix to assess whether the SMS is worthwhile in specific situations. Applied to dryland problems, the rows of the matrix would describe two basic options: adoption of the SMS, or allowing the land to continue to degrade. The columns of the matrix would reflect two possible states: sustainable use of the land, or loss of that option. The elements of the matrix would be social costs.

Wald's minimax rule is then applied to the pay-off matrix. According to the rule, the best option is that which minimizes the maximum cost. Unless the SMS leads to very high levels of social cost, it is preferable to the other alternative. The approach is, as previously explained, based on an attitude of caution towards resource management. 
It is important to note that the social costs of adopting a standard in one particular area may be vastly different from those associated with the same standard in some other area. Conclusions on an SMS cannot be transferred between regions or nations.

\section{References}

Bishop, R. C. (1978),

"Endangered species and uncertainty: the economics of a safe minimum standard", American loumal of Agricultural Economics, vol.60, no.1, pp.10-18.

Child, R. D., H. F. Heady, R. A. Peterson, R. D. Pieper and C. E. Poulton (1987),

Arid and Semi-Arid Rangelands: Guidelines for Development (Morrilton, Ark.: Winrock International).

Cicchetti, C. J. and A. M. Freeman III (1971),

"Option demand and consumer surplus: further comment", Quarterly Joumal of Economics, vol.85, no.3, pp.528 - 39 .

Ciriacy-Wantrup, S. V. (1952),

Resource Conservation (Berkeley, Calif.: University of California Press).

Conrad, J. (1980),

"Quasi-option value and the expected value of information", Quarterly Journal of Economics, vol.94, no.4, pp.813 - 20.

Dasgupta, P. (1982),

The Control of Resources (Oxford: Blackwell).

Davies, J. R. and P. M. Nanninga (1985),

"GEOMYCIN: towards a geographical expert system for resource management", Joumal of Environmental Management, vol.20, no.4, pp.37790.

Environment Canada (1982),

Review and Evaluation of Adaptive Environmental Assessment and Management (Ottawa: Environment Canada).

Environmental Resources Ltd (1985),

Handling Uncertainty in Environmental lmpact Assessment (The Hague: Netherlands Ministry of Public Housing, Physical Planning and Environmental Protection).

Fisher, A. C. and J. V. Krutilla (1975),

"Resource conservation, environmental preservation, and the rate of discount", Quarterly Joumal of Economics, vol.89, no.3, pp.358-70.

Holling, C. S. (1978),

Adaptive Environmental Assessment and Management (New York: Wiley).

Hotelling, H. (1931),

"The economics of exhaustible resources", loumal of Political Economy, vol.39, no.2, pp.137 - 75 .

Howe, C. W. (1979),

Natural Resource Economics (New York: Wiley). 
Kessell, S. R., R. B. Good and A. J. M. Hopkins (1984),

"Implementation of two new resource management information systems in Australia", Environmental Management, vol.8, no.3, pp.251 69.

Krutilla, J. V. and A. C. Fisher (1975),

The Economics of Natural Environments (Baltimore, Md:Johns Hopkins University Press).

Little, I. M. D. and J. A. Mirrlees (1974),

Project Appraisal and Planning for Developing Countries (New York: Basic Books).

Mar, B. W., W. S. Mitter, R. N. Palmer and R. A. Carpenter (1987), Cost-Effective Data Acquisition, Workshop Report No.1 (Honolulu: East - West Environment and Policy Institute).

North, R. M. (1981),

"Risk analyses applicable to water resources program and project planning and evaluation", in Y. Y. Haimes (ed.) Risk Benefit Analysis in Water Resources Planning and Management (New York: Plenum Press).

Norton, G. A. (1984),

Resource Economics (London: Edward Arnold).

Norton, G. A. and B. H. Walker (1985),

"A decision analysis approach to savannah management", Journal of Environmental Manegement, vol.21, no.1, pp.15-31.

Pearce, D. W. and C. A. Nash (1981),

The Social Appraisal of Projects: A Text in Cost - Benefit Analysis (London: Macmillan).

Pouliquen, L. Y. (1970),

Risk Analysis in Project Appraisal (Baltimore, Md: Johns Hopkins University Press).

Ray, P. K. (1981),

Agricultural Insurance: Theory and Practice and Application to Developing Countries (Oxford: Pergamon).

Rowe, W. D. (1981),

"Methodology and myth", in Y. Y. Haimes (ed.), Risk Benefit Analysis in Water Resources Planning and Management (New York: Plenum Press).

Walters, C. (1986),

Adaptive Management of Renewable Resources (New York: Macmillan).

Whyte, A. V. and I. Burton (eds) (1980),

Environmental Risk Assessment, SCOPE Report No.15 (Chichester: Wiley). 


\section{Models for Dryland Development Planning}

\section{General policy issues in dryland development planning}

Despite all the research on dryland problems and the availability of techniques to assess the economic desirability of corrective programmes and projects, there may still be difficulties in formulating appropriate plans and policies. How should a donor agency, for example, best allocate funds to the alleviation of dryland problems? Projects can be evaluated and the best ones chosen, as discussed in preceding chapters, but the larger-scale economic and environmental implications need to be addressed. Project planning does not answer the question of whether an optimal mix of policies has been selected to achieve the most effective results.

Policy-makers often tend to focus only on programmes that deal directly with the land. Carrying out such programmes may not be the best or only way to allocate scarce resources to combat land degradation. Restoration itself may be insufficient. The fundamental mechanisms underlying degradation must be properly understood and dealt with.

One of the most difficult problems in formulating policies towards dryland development is achieving better living standards within the carrying capacity of dryland ecosystems. Especially in less developed countries, the rural sector of ten has large amounts of surplus labour (disguised unemployment) leading to low average wages and excessive pressure on natural resources. To the extent that an expansion of output is possible, new jobs may be created in the rural sector, thereby reducing the level of disguised unemployment and raising rural wages.

Frequently, because of the limited capacity of the land to yield higher levels of output, improvements must be assisted by the encouragement of non-agricultural activities. It is important to have an analytical framework with which to assess the possibilities of structural change within the economy and provide information to assist the formulation of effective development strategies. 
Especially at the regional or wider community level, analytical techniques are required that identify trade-offs among options and identify the best or most acceptable outcome. Methods are also needed that facilitate an analysis of policy options and predict their effects, both direct and indirect, on different sectors of the economy and on the environment itself. Box 9.1 describes a programme for integrated development in Egypt. Systems analysis models and other kinds of economic simulation model are usually required to tackle such problems. Such models can take many forms and can be applied at levels ranging from local communities to the whole globe. Attempts are also being made to assess the national implications of changes in the natural-resource base through the development of natural-resource accounts. Some of the main methodologies are discussed in this chapter.

\section{Box 9.1: Integrated development in Egypt}

The success of programmes aimed at developing drylands as a long-term renewable resource depends partly on the degree of integration of different sectors. Regional schemes which provide material, technical and training inputs may fall short of their goals if they fail to meet human needs such as employment opportunities, social infrastructure, reasonable standards of living and environmental amenity.

The Desert Development Demonstration and Training Program conducted by the American University in Cairo assumed a multisectorial approach from its inception in 1978. The project aimed to incorporate modern agricultural and renewable energy technologies which had evolved to suit the harsh environment, and also to develop communities which would provide an improved quality of life for attracting families from the over-populated villages and cities. The emphasis was on enhancing and protecting, rather than dissipating, natural systems of energy and water exchange, and on farmer responsibility for implementing the ideas developed by the experimental stations. During the design, these community concerns ranged from socioeconomics to the aesthetics of architecture.

Source: Bishay, 1984.

\section{Linear programming models}

General properties and applications of linear programming models The term "linear programming" derives from the general 
mathematical properties of the modelling approach, which puts the decision-maker's objective into a linear form and the constraints on attaining that objective into linear equations or linear inequalities. To illustrate the use of linear programming models, a simple example is given here. The same principles apply to more complex problems.

A dryland community is assumed to possess 20,000 hectares of land and 100 workers with which to produce sheep or stonefruit. Output possibilities are limited by the supplies of land and labour and by the input requirements in both lines of production. Sheep and fruit can be sold in markets at fixed prices. The community is thus a price taker. To maximize its real income, the community should try to produce that combination of sheep and fruit which maximizes the value of its market sales. This revenue can then be spent on sheep and fruit or on other commodities purchased outside the region.

\section{Setting up a linear programming model}

Linear constraints. To show how constraints are established in a linear programming model, land and labour restrictions on the production of sheep and stonefruit can be taken as an example. Let the output of sheep, measured as the number of animals tumed off each year, be represented by $x_{1}$ and the output of stonefruit, in tonnes per year, by $x_{2}$. Assume that 4 sheep can be turned off per hectare each year. Inputs of land for sheep production are 0.25 ha per sheep. For stonefruit, each hectare produces 20 tonnes of fruit each year; thus land requirements per ton of fruit are 0.05 ha.

Now, suppose all the land available $-20,000$ ha - is used in the production of sheep and stonefruit. Maximum feasible outputs of sheep and fruit from the land can be described by the following equation:

$$
0.25 x_{1}+0.05 x_{2}=20,000 \text {. }
$$

It is more appropriate to assume that the total amount of land used in production is less than or equal to the available supply. Such a constraint can be written as the linear inequality

\section{$0.25 x_{1}+0.05 x_{2} \leqslant 20,000$}

Output combinations satisfying this constraint lie on and below a straight line, as shown in Figure 9.1. The line appears as $P C$. The way the inequality is written, the line $P C$ can be extended in both directions with negative values of $x_{1}$ and $x_{2}$ satisfying the constraints. It is clearly necessary to introduce additional constraints, since negative outputs are meaningless in an economic sense. 
Non-negativity constraints $x_{1}$ and $x_{2}$ are simply $x_{1} \geqslant 0, x_{2} \geqslant 0$.

Figure 9.1: Land constraint for dryland production

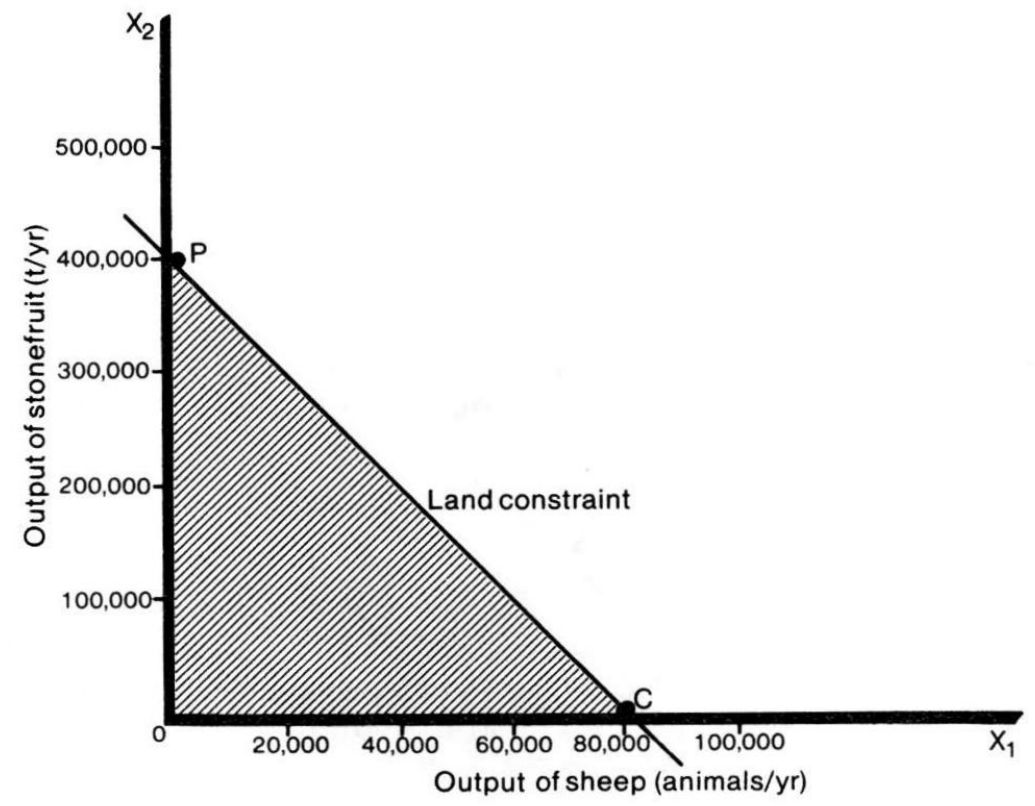

Figure 9.1: Land constraint for dryland production

Returning to Figure 9.1 and taking into account the non-negativity restrictions on $x_{1}$ and $x_{2}$, it can be seen that if all land were allocated to sheep production, the maximum output of sheep that could be produced from available land is $20,000 / 0.25$ or 80,000 animals per year. This output combination coincides with point $C$, where $x_{1}=80,000$ and $x_{2}=0$. At the other extreme, if all land were allocated to stonefruit production, the maximum amount of fruit that could be produced is $20,000 / 0.05$ or 400,000 tonnes per year. This output combination is represented by point $P$, where $x_{1}=0$ and $x_{2}=400,000$. By allocating land to both forms of production, output combinations between these two extremes are achievable, such as $x_{1}=40,000$ and $x_{2}=200,000$. Output combinations lying below the line $P C$ and on or above the axes of the diagram are also attainable but do not make full use of the land resource.

Restrictions on the use of labour can be handled in a similar way. 
The available supply of labour is 100 persons. On average, labour requirements in sheep production are 0.00083 person-years per animal. For stonefruit production, labour requirements are 0.0005 person-years per tonne. The labour constraint on outputs of sheep and fruit is thus

$0.00083 x_{1}+0.0005 x_{2} \leqslant 100$.

The labour constraint is shown in Figure 9.2. If all labour were allocated to sheep production, as at point $Q, 120,000$ sheep could be produced. At the other extreme, at point $A$ where all labour is allocated to fruit production, 200,000 tonnes of fruit could be produced. Combinations anywhere along or below the line $A Q$ are possible. Non-negativity constraints on $x_{1}$ and $x_{2}$ preclude combinations of $x_{1}$ and $x_{2}$ lying outside the axes of the diagram.

Figure 9.2: Labour constraint for dryland production

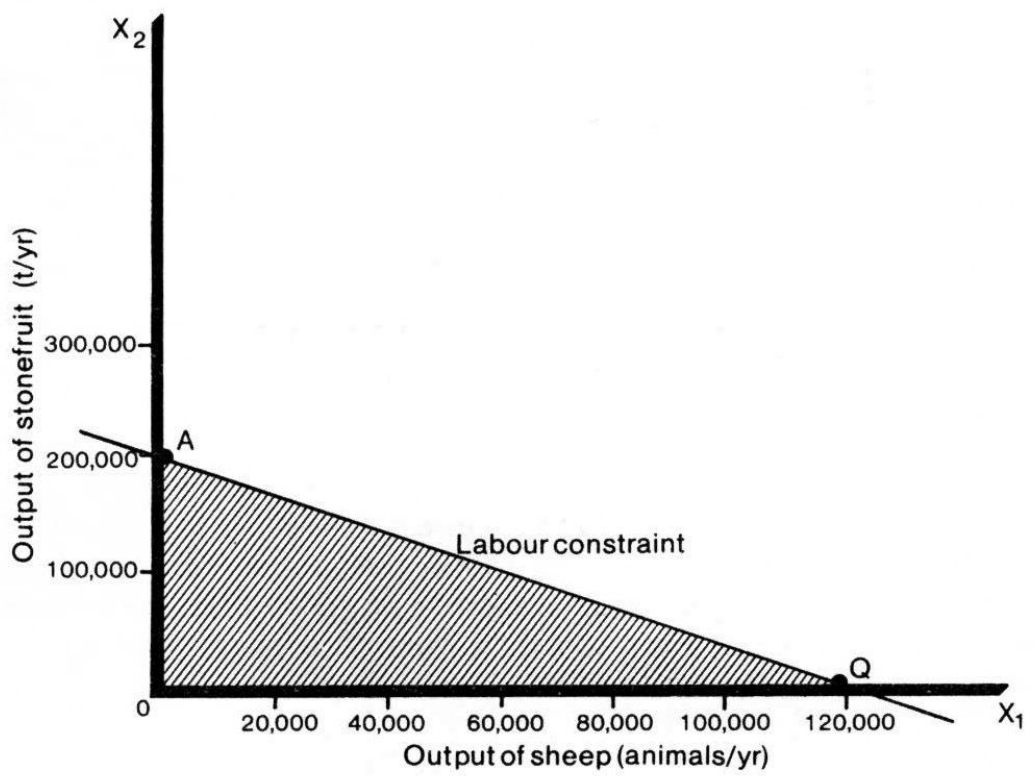

Taking all constraints together - restrictions imposed by land utilization, labour inputs and non-negativity conditions - the feasible region of outputs is as shown in Figure 9.3. Output combinations must lie on or inside the boundaries of the shaded region, 
formed by the lines connecting points $0, A, B$ and $C$. Such a region is described mathematically as a convex region, with extreme points at $0, A, B$ and $C$.

\section{Figure 9.3: Region of feasible output}

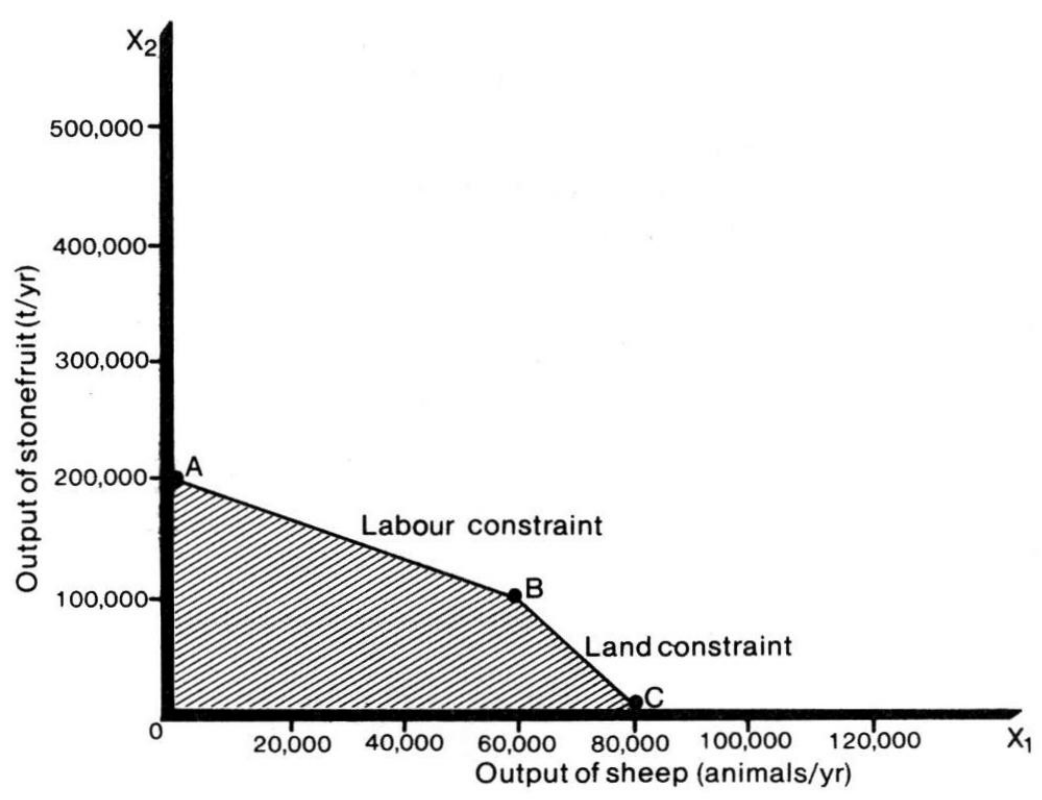

The objective function. If the community wishes to make best economic use of its resources, it will try to maximize the total revenue from sales of sheep and fruit. Suppose each sheep sold fetches $\$ 20$, and each ton of fruit $\$ 6$. For any given quantities of sheep and fruit, the total revenue received will be

$Z=20 x_{1}+6 x_{2}$

where $\mathrm{Z}$ is total revenue measured in dollars.

Total revenue lines for different quantities of $x_{1}$ and $x_{2}$ are shown in Figure 9.4. Each line indicates the combination of $x_{1}$ and $x_{2}$ that will yield a given level of revenue. For example, a total revenue of $\$ 2,000,000$ can be obtained by selling 100,000 sheep or 333,333 tonnes of fruit. Combinations in between such as 40,000 sheep and 200,000 tonnes of fruit (yielding $\$ 800,000$ and $\$ 1,200,000$ respectively) will also give total revenue of $\$ 2,000,000$. 


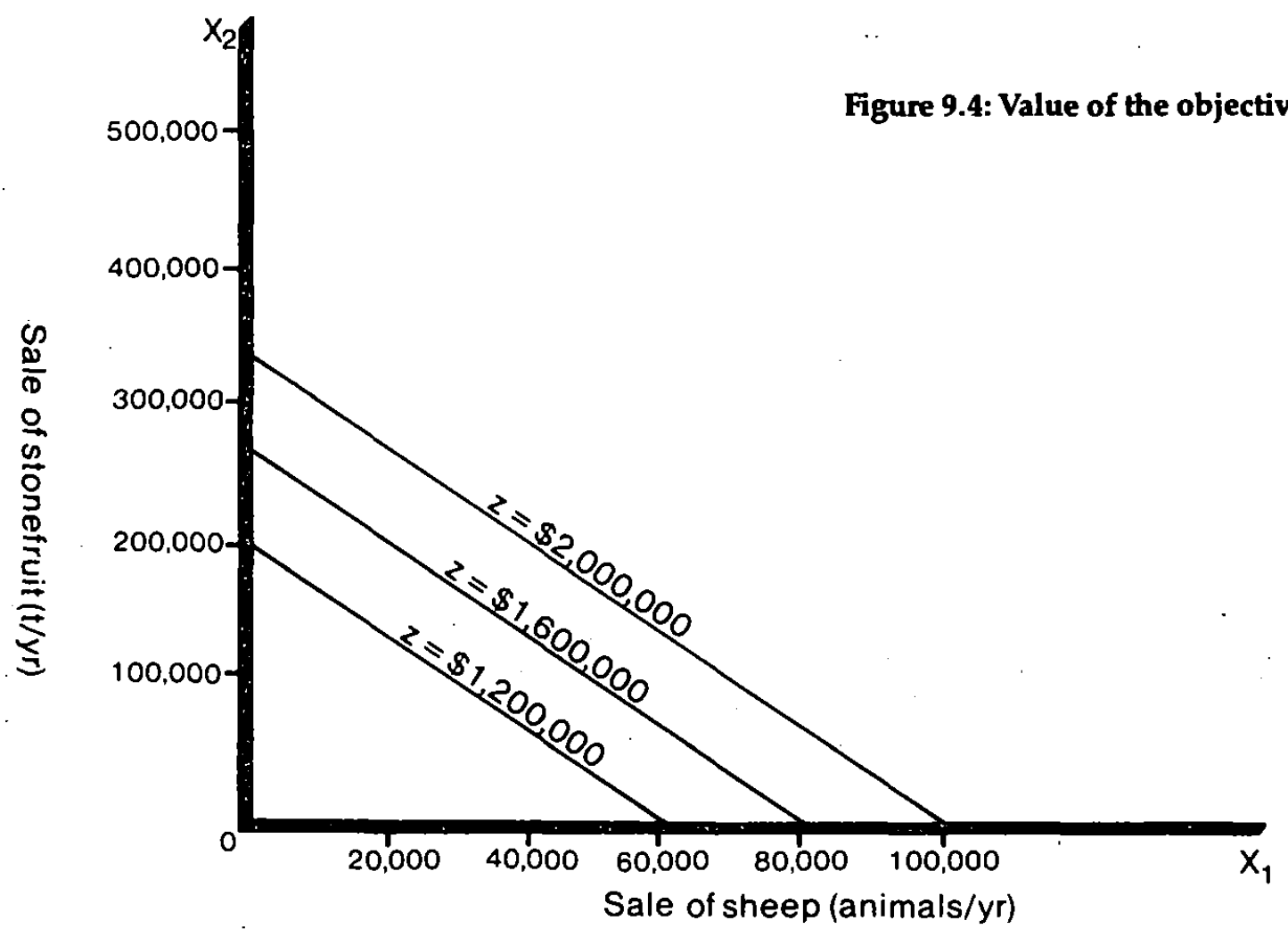


Smaller quantities of sheep and fruit yield lower levels of total revenue. Revenue lines are shown in Figure 9.4 for $Z=1,200,000$ and $Z=1,600,000$. The further away from the origin is the total revenue line, the higher will be the value of $Z$.

The objective function can be written as

maximize $Z=20 x_{1}+6 x_{2}$.

General specification of the model. The various components of the linear programming model can now be gathered. The problem takes the form

maximize $Z=20 x_{1}+6 x_{2}$

subject to

$0.25 x_{1}+0.05 x_{2} \leqslant 20,000$

$0.00083 x_{1}+0.0005 x_{2} \leqslant 100$

$x_{1}, x_{2} \geqslant 0$.

This version of the model, where the objective function is maximized subject to a set of constraints, is known as the primal problem. The model can alternatively be set up as the so-called dual problem, as explained in the standard texts (Hufschmidt et al., 1983).

\section{Finding the optimum solution}

The simplest method of solving the linear programming problem is by using graphs, as in Figure 9.5. The feasible region is $O A B C$. The aim is to find the revenue line, furthest from the origin, on the boundary of the feasible region. This clearly occurs at point $B$ where $x_{1}=60,000, x_{2}=100,000$, and $Z=\$ 1,800,000$.

Although the graphical method of finding the optimum solution is acceptable when there are only two basic variables in the model, more powerful approaches are required when dealing with large numbers of variables and constraints. An operational model might contain hundreds or even thousands of variables and constraints. In practice, especially for large problems, a computer pack is essential. Many standard packs are available, and program listings can be found in some computer texts (Bui, 1982).

Introducing an environmental externality

Effects of salinity. Linear programming models have been successfully used to analyse the problem of salinity in dryland regions. Specific examples appear in Dryland Management: Economic Case Studies (Dixon, James and Sherman, 1990). Thomas (1990) presents a case study on river salinity in Western Australia, and Dumsday and Oram (1990) describe a study of dryland salinity in Northern 


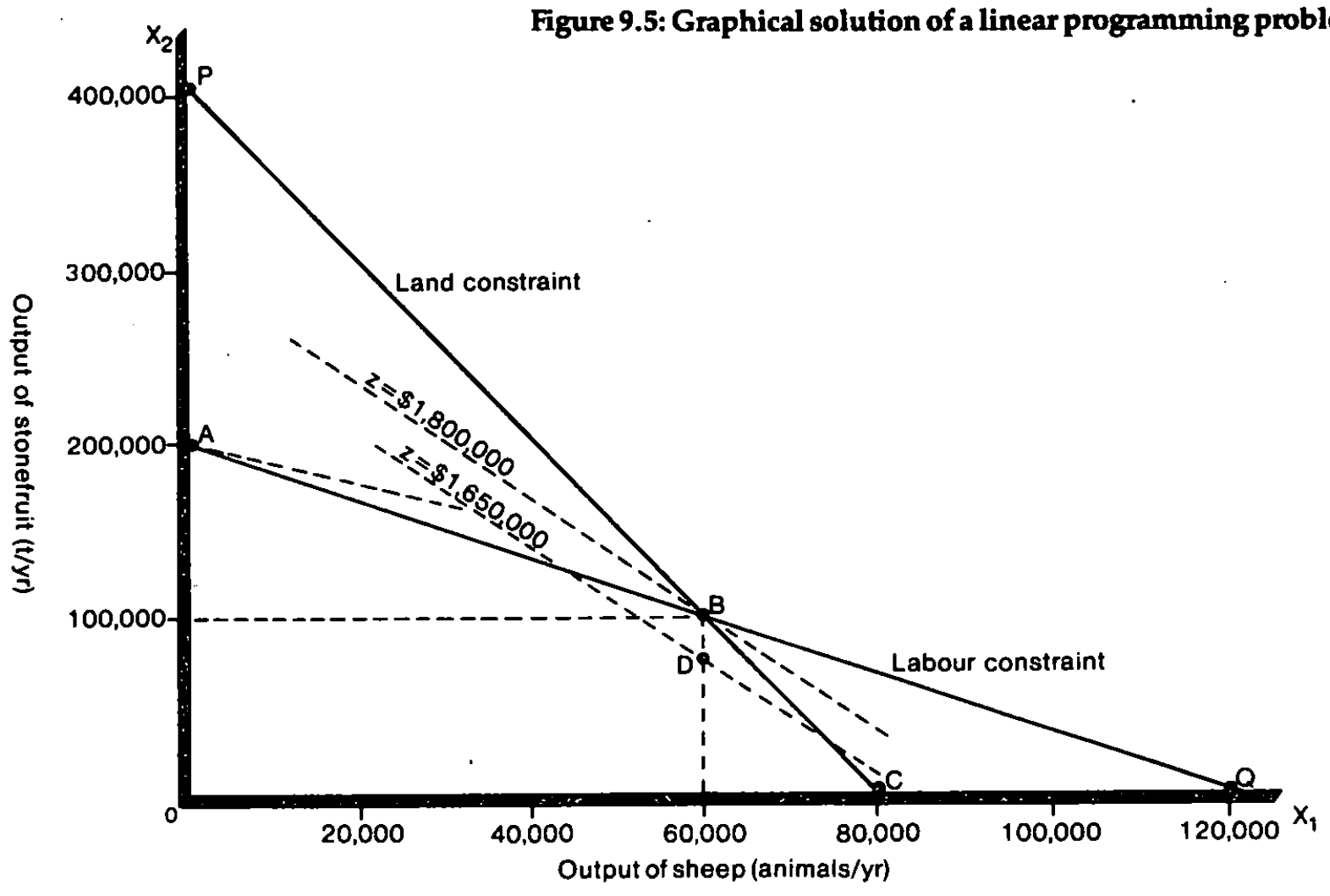


Victoria. A simple extension of the preceding model is given here as one approach to the problem.

Figure 9.6: Dose-response of fruit relative to salinity

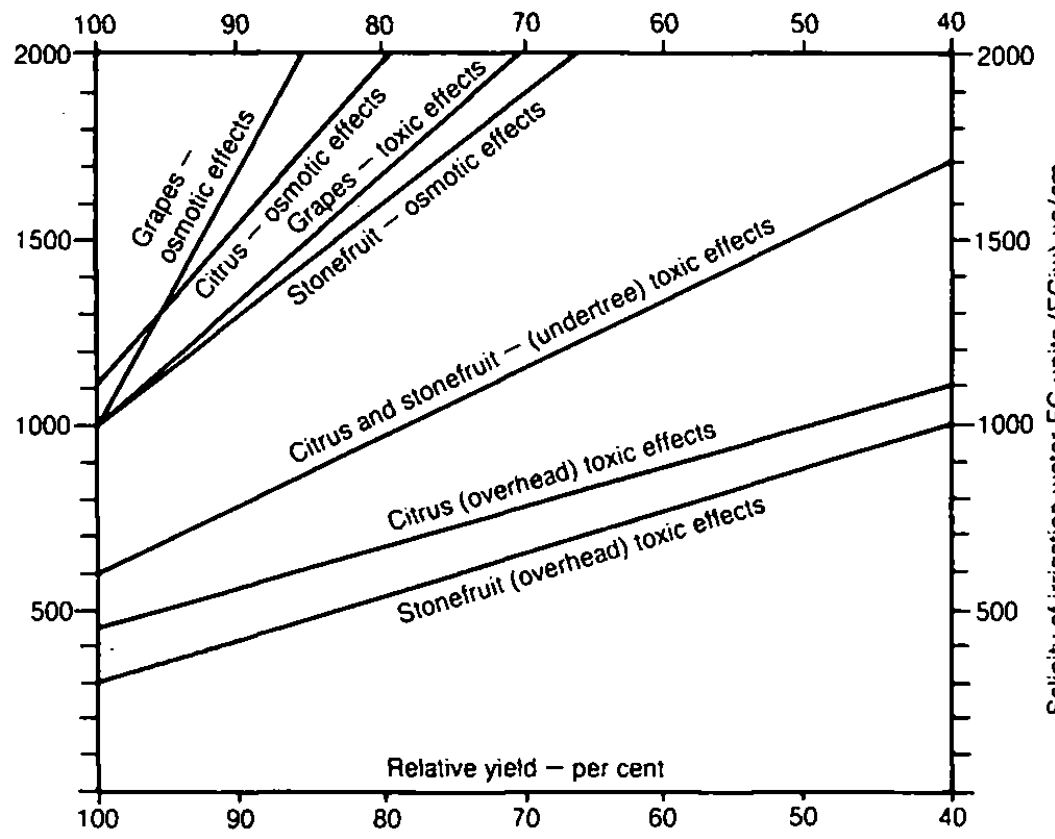

Source: River Murray Commission, 1984.

Stonefruit production is adversely affected by saline irrigation water, particularly when overhead sprinkler irrigation is used. Dose-response functions are shown in Figure 9.6, taken from a study of salinity in the River Murray basin in Australia. The level of salinity is measured on an electrical conductivity (EC) basis, in microsiemens $/ \mathrm{cm}$. For overhead sprinkler irrigation, a loss in productivity of about 25 per cent occurs when salinity reaches a level of $600 \mathrm{EC}$ units. When salinity is 800 EC units, the crop loss is approximately 43 per cent.

Modelling the effects of salinity. Sheep can contribute to salinity of irrigation water by reducing ground cover, raising the water table and causing saline runoff to streams that are subsequently used for irrigation purposes. Starting with the optimum solution calculated earlier, this mechanism can be analysed with the assistance of 
natural systems models. Suppose a salinity level of $600 \mathrm{EC}$ units is predicted by such an analysis, and the 60,000 sheep are causing a 25 per cent loss in stonefruit production ( 25,000 tons). The analysis thus reveals that, on average, 0.4167 tonne of stonefruit is lost for each sheep produced. (This is simply an arbitrary figure to show how the effect can be modelled. The actual figure would depend on such factors as sheep per ha, slope and hydrology.)

The effect of sheep production on stonefruit production could then be described mathematically as

$$
y=x_{2}-0.4167 x_{1}
$$

where $x_{2}$ is the quantity of fruit that would have been produced in the absence of salinity, $0.4167 x_{1}$ measures the loss of fruit inflicted by sheep production, and $y$ is the amount of fruit remaining to be sold.

In the objective function, as $y$ rather than $x_{2}$ is now sold to the market, the price of $x_{2}$ must be set at zero and the price of $y$ at $\$ 6$ per ton instead. The objective function is thus

maximize $Z=20 x_{1}+6\left(x_{2}-0.4167 x_{1}\right)=20 x_{1}+6 y$.

After rearranging the inequality involving $y_{1} x_{1}$ and $x_{2}$, the constraints on sheep and stonefruit production take the form

$$
\begin{aligned}
& 0.25 x_{1}+0.05 x_{2}+0.0 y \leqslant 20,000 \\
& 0.00083 x_{1}+0.0005 x_{2}+0.0 y \leqslant 100 \\
& x_{2}-0.4167 x_{1}-y=0 \\
& x_{1}, x_{2}, y \geqslant 0
\end{aligned}
$$

The result is shown in Figure 9.5 at point $D$ where $x_{1}=60,000$, $x_{2}=100,000, y=75,000$ and $Z=\$ 1,650,000$.

The damage to stonefruit caused by salinity results in a loss of revenue of $\$ 150,000(25,000$ tonne $\times \$ 6)$. It should be observed that, if the impacts of salinity were any more severe, the optimum production combination might shift to point $C$. In such circumstances, it would be more economic for the community to put all of its resources into sheep production and give up production of stonefruit altogether.

A shift in the relative prices of sheep and stonefruit might also result in a completely different optimum. For example, if the objective function had a slope such as that of the broken line passing through point $A$ in Figure 9.5, the community would be better off concentrating exclusively on fruit production and abandoning sheep production. A different outcome could be indicated by altering land-use practices or irrigation techniques to reduce damage to stonefruit. With low-level irrigation, as indicated in Figure 9.6, the crop damage is only about one-third of that caused by overhead 
sprinklers. To simulate such effects, coefficients in the model would need to be changed. The model of Dumsday and Oram (1990) uses linear programming to explore the relationships among alternative land uses, farm income and salinity levels. Some results are presented in Box 9.2.

\section{Box 9.2: Linear programming model of dryland salinity}

Figure 9.7 shows the results of a linear programming model applied at the farm level by Dumsday and Oram (1990). The curves indicate the cost (income forgone) of different land-use practices to counteract soil salinity by reducing deep percolation. The lower-case letters refer to land-use activities which include forestry (agroforestry), and the upper-case letters reflect cropping/vegetation systems that exclude forestry. The initial income/cost point is $0, A, a$. For some land uses, especially agroforestry, the change in cost is negative, indicating an increase in farm income accompanying the reduction in salinity. A genuine loss of income is predicted only for points $C$ through $H$.

\section{Limitations of the linear programming approach}

Practical limitations. Like most general equilibrium models, linear programming models require extensive data gathering, information processing and computing time. A decision must be made as to whether the problem is so complex that an elaborate model needs to be constructed.

Mathematical properties. The mathematical properties of linear programming models often lead to unrealistic solutions. One characteristic of such models is "flip-flop" changes in optimal solutions when prices in the objective function are changed. As noted above, a moderate increase in the relative price of stonefruit would induce a jump out of sheep production into fruit production exclusively; the optimum point would be $A$ rather than $B$ in Figure 9.5. This is an extreme result. In complex situations, major shifts in mixes of activities might be indicated. Introducing further constraints can overcome the problem, but in a large model it may be difficult to determine what kinds of constraints are required, and they may not be realistic in any case.

Problems with constraints. Another feature of linear programming is that the number of variables in the final solution can never exceed 
the number of constraints. If only a few constraints are specified, the optimal solution may be too simplistic. The addition of further arbitrary constraints may misrepresent true restrictions on the attainment of planning objectives.

Figure 9.7: Total private costs of reducing deep percolation in a grazing area (Axe Creek)

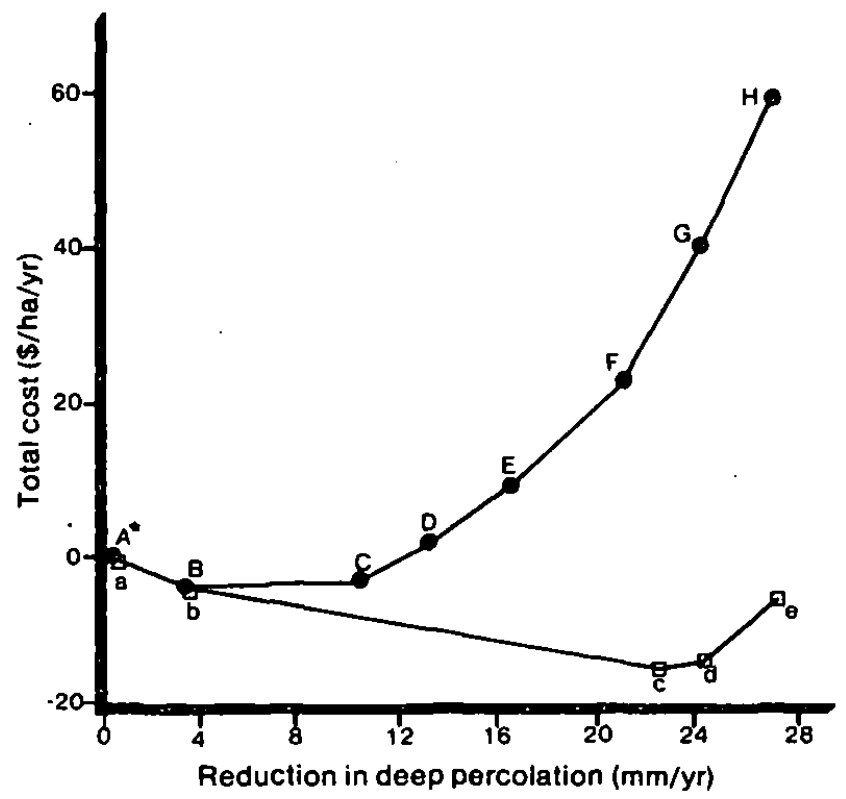

Handling non-linearities and dynamic conditions. The model discussed here is very simple and is based on the notion of steady-state conditions. As explained in earlier chapters, however, dryland ecosystems are characterized by complex dynamic ecological relationships. Dynamic optimization can, with some difficulty, be carried out within a linear programming framework. Restrictions on variables between time periods may be difficult to specify and will necessarily be in a linear form. Dynamic simulation may give a better understanding of the physical and economic properties of dryland systems and of the impacts of planning and management options.

Perhaps the most severe limitation of linear programming 
models is the fact that most natural-system responses are nonlinear. Linear approximations of non-linear relationships around a given set of values can be taken, but this necessarily restricts the predictive powers of the model for large changes in variables. As the main purpose of modelling is to explore planning and management options that diverge significantly from the existing situation, the suitability of linear models should be carefully assessed. Other mathematical programming methods are available to handle nonlinearities, but the computational requirements are usually. substantial.

\section{Sectoral planning models}

The 'most' widely' used loperational models for leconomic development planning are input - output models. Originally developed by Leontief in the 1930s, such models have been applied at regional, national and international levels (Leontief, 1966).

With the assistance of such models, economic policies towards the drylands can be assessed as part of national development planning. Such models can also be applied at the regional level (Richardson, 1972). The typical region might include agricultural areas threatened by land degradation and related economic activities such as general services, supply of agricultural materials and equipment and facilities for storage, processing, transportation and marketing of agricultural output. The techniques used to assess planning options are the same at national and regional levels.

Expansion of non-agricultural industries can be achieved by a variety of policy measures, ranging across direct government purchases of non-agricultural output, facilitation of new investment, creation of new domestic markets, export promotion schemes and import replacement programmes.

It is frequently not possible to achieve multiple planning objectives through single policy measures. Stimulation of a particular sector (an industry, group of industries or some other subset within the economy) may, for example, maximize employment but have a negligible effect on income. With other policies, all the gains may go to a particular group in the community, but not to others. The advantage of the input - output approach is that it takes into account the indirect impacts of policy, providing a better overall assessment of planning options than methods that concentrate on "obvious" avenues for economic development. 
The application of input - output analysis to dryland development planning is demonstrated here using a simple hypothetical model. In this way, the fundamental principles can be conveyed and the necessary mathematical manipulations kept at an elementary level. The model has only two producing sectors. In practice, twenty or thirty sectors would be a more realistic number.

\section{General properties of input - output models}

Conceptual framework. Input - output analysis is conceptually very simple. The economic system is divided into separate producing sectors, in this case agriculture and services. Each sector sells its output to other sectors and to final buyers such as consumers, governments and export buyers. Such demands are "final" in the sense that goods and services supplied to these categories pass out of the production system. They are not involved in current production and are regarded as having fulfilled their end uses.

At the same time, each sector buys goods and services from other producing sectors, as well as labour, land and capital inputs, to carry out production. In order to meet final demands for goods and services, sectors have to produce enough to supply inputs to other producers as well as satisfying the final demands themselves. An input - output model "predicts" the necessary production conditions to meet the specified final demands.

The flow or transactions table. The usual starting-point for the construction of an input - output model is a data set for a given base year, showing the financial transactions that occurred among the various producing sectors and final buyers within the region. These transactions are normally measured in monetary units.

It is also possible to construct models with flows specified in physical terms. Some models contain a mixture of monetary and physical units. Physical and monetary models are linked by the prices charged by each of the sectors, as shown by Dorfman, Samuelson and Solow (1958).

A hypothetical transactions table for a dryland region is shown in Table 9.1. The regional economy is assumed to consist of only two producing sectors - agriculture and services. All flows are measured in dollars. More realistically, the units of measurement would be thousands or millions of dollars, but the use of single dollars here helps to simplify the exposition.

Looking across the rows of the table or matrix, it can be seen that the agricultural sector sold $\$ 74$ of output to the services sector, $\$ 505$ to households and $\$ 500$ to government agencies, and exported 
$\$ 700$ to other regions or overseas. In total, the agricultural sector produced and sold $\$ 1,779$ worth of output. The services sector sold its output only to the agricultural sector and to households within the region. It did not sell anything to the government sector, nor was it able to export services outside the region. Total production and sales by the services sector amounted to $\$ 737$.

Table 9.1: Flow matrix for a hypothetical two-sector input - output model of a dryland region

\begin{tabular}{|c|c|c|c|c|c|c|}
\hline & $\frac{\text { 导 }}{\text { 导 }}$ & 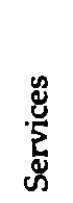 & 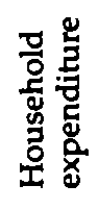 & 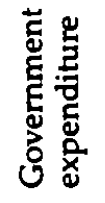 & 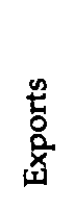 & 可市 \\
\hline Agriculture & & 74 & 505 & 500 & 700 & 1779 \\
\hline Services & 534 & & 203 & & & 737 \\
\hline Household income & 569 & 442 & & & & 1011 \\
\hline Other income & 142 & 147 & & & & 289 \\
\hline Imports & 534 & 74 & 101 & & & 709 \\
\hline Total outlays & 1779 & 737 & 809 & 500 & 700 & 4525 \\
\hline
\end{tabular}

Employment

133

74

207

Looking down the columns of the transactions table gives an account of the cost structure for each sector. The agricultural sector, for example, purchased $\$ 534$ worth of services as an input to production, paid $\$ 569$ to households for labour inputs, $\$ 142$ to other contributors to production, and also purchased $\$ 534$ of imported materials such as fertilizers, fuel and equipment required in production. The services sector purchased $\$ 74$ of agricultural products (such as foodstuffs and materials), \$442 of inputs from households, $\$ 147$ of inputs from other owners of factors of production and $\$ 74$ of imports. The total cost of production was $\$ 1,779$ for the agricultural sector and $\$ 737$ for the services sector. Total employment in the economy is 207 persons, 133 in agriculture and 74 in services. 
It can be seen that the row and column totals for each sector are equal. The total value of output or total sales revenue just covers the cost of inputs to production.

Direct requirements coefficients. To convert the data base in Table 9.1 to an operational input - output model, it is assumed that inputs are purchased by each sector in fixed proportions. These proportions are measured by "direct requirements" coefficients, which are obtained by dividing the column entries for each sector by the corresponding total output figure. For example, in the agricultural sector, each dollar's worth of output directly requires $\$ 0.30$ of inputs from the services sector $(534 / 1,779), \$ 0.32$ of inputs from households $(569 / 1,779), \$ .08$ of inputs from other contributors to production $(142 / 1,779)$ and $\$ 0.30$ of imported inputs $(534 / 1,779)$. By a similar process, direct requirements coefficients can be calculated for the services sector. Labour requirements are calculated in a similar manner -0.075 persons are required per dollar's output in agriculture and 0.100 person per dollar of services. The resulting matrix of coefficients is shown in Table 9.2. For each column of coefficients, the sum is 1 .

Table 9.2: Direct requirements coefficients of a hypothetical twosector model (inputs per \$; derived from Table 9.1)

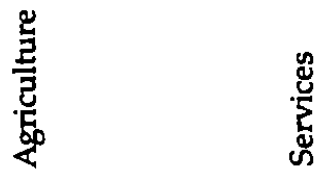

$\begin{array}{lll}\text { Agriculture } & & 0.10 \\ \text { Services } & 0.30 & \\ \text { Household income } & 0.32 & 0.60 \\ \text { Other income } & 0.08 & 0.20 \\ \text { Imports } & 0.30 & 0.10 \\ \text { Total outlays } & 1.00 & 1.00\end{array}$
Employment
0.075
0.100 
The direct requirements coefficients are assumed to remain constant at all levels of production. Production is thus characterized by constant returns to scale. Marginal and average input coefficients for any input remain equal. There is no input substitution in the model.

\section{Solving an input - output system}

Solving for equilibrium outputs. Consider what needs to occur when a given set of final demands has to be satisfied (for example, \$1,705 of agricultural commodities and $\$ 203$ worth of services as in the base year). Final demand is the combination of demand by households, by government and for exports, as shown in Table 9.1. In the first round of production, $\$ 1,705$ of agricultural output and $\$ 203$ of services must be produced. Agricultural production, however, requires inputs of services, so a second round of services production must take place. This in turn requires agricultural products, so another round of agricultural production must occur. A chain reaction of production within the regional economy will be stimulated by the initial set of final demands. Ultimately, the system will converge on an equilibrium, reflecting the sectoral outputs required directly and indirectly to satisfy the initial set of final demands.

Another way of looking at the process is to consider final demands as "driving" the regional economy. The producing sectors respond directly through the initial final demands, and indirectly through production linkages within the region. Final demands are said to be "exogenous" (determined outside the system), and sectoral outputs are "endogenous" (determined within the system).

Mathematically, the model can be represented as a set of simultaneous equations. The relevant equations are:

$$
\begin{aligned}
& x_{1}=0.00 x_{1}+0.10 x_{2}+1,705 \\
& x_{2}=0.30 x_{1}+0.00 x_{2}+203
\end{aligned}
$$

where $x_{1}$ and $x_{2}$ are sectoral output levels for agriculture and services, respectively. Solving the input - output model involves finding the values of $x_{1}$ and $x_{2}$ that satisfy the simultaneous equations. This can be done by simple substitution. For the model described here, the solution is $x_{1}=1,779$ and $x_{2}=737$, reconfirming the relationships in Table 9.1. The model accurately "predicts" baseyear outputs of 1,779 and 737 , given the base-year final demands of 1,705 and 203.

The total output levels for the two sectors far exceed the initial levels of final demand. The extra output required consists of 
indirect production or intermediate output sold to the producing sectors. Intermediate sales are $\mathbf{7 4}$ for the agricultural sector and 534 for the services sector.

From the direct requirements coefficients for the producing sectors, a set of special coefficients known as "Leontief-inverse" or "total-requirements" coefficients can be computed using matrix algebra; the results are shown in Table 9.3. By using total-requirements coefficients, sectoral outputs can be determined immediately from final demands. The calculations are performed as follows:

$$
\begin{aligned}
& x_{1}=1.0309(1,705)+0.1031(203) \\
& x_{2}=0.3093(1,705)+1.0309(203)
\end{aligned}
$$

The reader can verify that the result is $x_{1}=1,779$ and $x_{2}=737$, as previously obtained through simple substitution. As another exercise, the reader may care to prove that to satisfy final demands of $\$ 2,500$ for agricultural products and $\$ 1,000$ for services, the required outputs are $x_{1}=2,680$ and $x_{2}=1,804$.

Table 9.3: Leontief-inverse coefficients for a two-sector model (derived from Table 9.2)

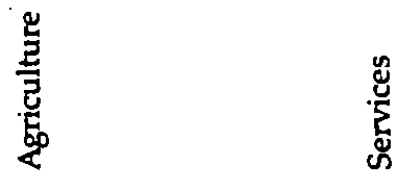
Agriculture
1.0309
0.1031
Services
0.3093
1.0309

When a full-scale model is used for planning, it is impractical, if not impossible, to solve the system by manual methods. A standard computing package is essential. Once the input - output data are fed into the computer program, the answer can be obtained in a matter of seconds. Simulating the effects of changes in final demand on the structure of the regional economy is a straightforward task.

Primary inputs. Information on primary inputs can be used to guide policies and programmes designed to relieve pressure on the land, raise income levels and improve living standards within the 


\section{2}

The Economics of Dryland Management

region. Once total outputs have been computed, it is relatively easy to determine the associated pattern of income, imports and employment.

\section{Simulating the effects of new production}

Expansion of existing industries. Assessing the effects of introducing new economic activity to a region can be carried out in several different ways using input - output analysis. The approach depends on the kind of expansion that is involved.

If development consists of new producers entering established industries using the same technology, the effects can be simulated with the existing input - output model. The same direct-requirements and total-requirements coefficients are applicable. In such cases, it is necessary to determine how'new activity can be accommodated. An expansion of output is possible only if final demands increase. Development planners must be certain that the new market opportunities exist, or that government purchases can be increased, before expecting that new production within existing industries can take place.

Primary inputs to production, such as labour and managerial expertise, must be available in sufficient quantities to permit economic expansion to occur. Required inputs can be estimated once final demand has been determined. Such requirements can then be compared with available supplies of inputs to see whether expansion is feasible or whether production bottlenecks are likely to occur.

New industries. A second development possibility is the introduction of a completely new sector. In dryland regions, such activities may consist of mining, energy production, tourism or manufacturing. To simulate the effects, an extra row and column representing the new industry must be added to the input - output model. Market opportunities and the availability of primary inputs should again be assessed-to determine whether introduction of a new industry is possible. In carrying out such an assessment, it is important correctly to identify production linkages between the new activity and existing sectors in the regional economy and to allow for direct and indirect effects on production and input requirements.

\section{Incorporating consumption expenditure}

Economic impacts known as "induced effects" occur in an input output model when consumption is treated as a set of endogenous 
variables dependent on household income. Household demands for sectoral outputs can be determined by the relative proportions of income spent on the different categories of goods and services supplied. The ratios of consumption expenditure to income are known as the "propensity to consume".

In mathematical terms, induced consumption effects are incorporated in the model by adding an extra column and row to the direct-requirements matrix. Households are treated as a new sector, with consumption coefficients appearing in the new column and household income coefficients in the new row. The new matrix so obtained is described as an "augmented matrix", and the model is said to be "closed". The construction of closed input - output models is described in standard texts (Dorfman, Samuelson and Solow, 1958; Robinson, 1972).

\section{Data sources and construction of input -output models}

Various methods are available for the collection of data and the compilation of input - output tables. The first method is by conducting an economic survey of the region to obtain basic data on intersectoral sales, final sales and imports. Direct surveys always involve a large amount of time and effort and therefore tend to be costly. The data may be out of date by the time the input - output table is compiled. It can be difficult to discover exactly what each particular producer buys from and sells to other producers.

To save time and effort, samples of the major producers may be taken. It is customary to focus on the kinds of commodity each producer buys, regardless of origin. By making various assumptions about regional production and imports, the intersectoral flow matrix can be approximated. Surveys can sometimes be designed to obtain "sales only" data (that is, information only on the rows of the matrix) to reduce the amount of work involved (Richardson, 1972).

An alternative approach is the non-survey method, which relies on modification of a national input - output table to obtain a regional table. Adjustment of the national direct-requirements coefficients is carried out, allowing for differences in the regional industrial structure and in regional trade flows. Although this method is less data intensive and less costly than direct survey methods, it can lead to errors in the regional model. The method also presupposes that a national input - output table is available.

Hybrid methods offer a compromise solution to the problems of cost and accuracy in constructing an input - output model. These 
use a combination of direct survey data and adjustment of national coefficients. Successful results have been achieved by the University of Queensland, which has developed a procedure called GRIT (Generation of Regional Input - Output Tables) to construct regional Itables / using hybrid methods Jenson, Mandeville and Karunaratne, 1979). A preliminary table is first compiled from the national table using arbitrary assumptions concerning regional production and trade. Key elements of the table are revised on the basis of direct surveys. The table is then adjusted to ensure that the usual input - output accounting identities are satisfied.

In dryland areas of developing countries, market and financial data often are not available, making it difficult to construct an input - output model based on monetary flows. It may be possible, however, to model structural relationships within the regional economy using physical flows, such as tons of grain, hours of services or cubic metres of timber.

For new industries or production activities, the relevant directrequirements coefficients can frequently be obtained from scientific or engineering data, such as the number of tonnes of fertilizer required per tonne of wheat output, or the number of kilograms of coal required per kilowatt hour of electricity generation. Such data can be very useful in forecasting the structure of the regional economy and are often used in conjunction with $e x$-ante methods of economic forecasting and planning.

Physical models have the advantage that they can be extended to assess secondary environmental impacts accompanying regional economic development, such as changes in air quality, water quality and utilization of natural resources (Hufschmidt et al., 1983; James, 1985; James and Chambers, 1986).

\section{Application of multipliers to dryland development planning}

Economic multipliers involve changes in economic variables around their equilibrium values. In general, an economic multiplier can be computed for each possible pairing of exogenous and endogenous variables. If an economic model has $m$ exogenous variables and $n$ endogenous variables, the number of multipliers will be $m \times n$. A multiplier measures the change in an endogenous variable caused by a change in some exogenous variable.

The concept of multipliers is usually demonstrated at the macroeconomic level using a simple Keynesian model, whereby any change in exogenous investment demand results in a multiplicative change in national income. Such models can be applied at 
regional level (McColl and Throsby, 1972).

Economic multipliers can also be derived from input - output models. The topic is fairly mathematical and is explained in standard texts. It suffices here to note that multiplier analysis can provide valuable guidelines on the formulation of development plans and programmes for dryland regions. Employment multipliers indicate which economic sectors should be encouraged to maximize the number of jobs. Effects on income can be assessed through the use of income multipliers.

\section{Natural-resource accounts}

To keep track of economic activity and the use of resources by the national economy, statistics are customarily compiled. The traditional approach to monitoring and measuring macroeconomic changes is use of the SNA (System of National Accounts), recommended by the United Nations. The aim of national income accounting is to provide an information framework suitable for analysing the performance of the economic system. To this end, the SNA incorporates major accounting concepts such as domestic production, national income, capital formation, consumption and savings. Since all entries are made in monetary terms, the SNA does not show the actual flow of environmental or natural resources. If a good or service does not have a market price or is not traded, it tends to be ignored under the SNA. Externalities are commonly ignored as well.

Depletion of resources, both renewables such as forestry and fisheries, and non-renewables such as minerals, is counted as a benefit in the SNA. Rapid deforestation, for example, has played a major role in the rapid economic growth of some countries. The production of logs and timber products is entered in the SNA as a benefit. The loss of timber resources, especially the growing margin of extraction over natural regeneration and replanting, tends to be ignored. As a result, rapid rates of economic growth are achieved through exploitation of the resource base without adequate consideration of the finite nature of that base.

In the drylands context, many natural resources may fall into this "overlooked" category. Land and water are two examples, especially when they are communal or public property. In response to this whole issue of valuing the contribution of natural resources and measuring the rate of change of resource stocks, a parallel 
approach to the SNA called natural-resource accounting (NRA) has evolved.

NRA is a methodology for the presentation of environmental and economic statistics. Its main feature is that the accounting framework facilitates the monitoring and illustration of trends in the production functions affecting natural-resource stocks and environmental services. Natural-resource accounting results in natural-resource accounts - a series of tables that present information in a consistent format and generate indicators to summarize trends in the patterns of resource use.

The ultimate goal of NRA is to improve economic management of natural resources by facilitating the integration of economic and environmental information, and providing an effective means for its presentation to decision-makers.

\section{Approaches to NRA}

NRA involves the daunting task of combining economics with ecological variables. A variety of approaches had been developed; these can be grouped as follows:

(1)purely economic, in which modifications to the regular national accounts and presentation of information in monetary forms are attempted;

(2)purely physical, in which alternative accounting systems are developed using only physical units such as tonnage or units of energy; and

(3)mixed, in which alternative accounting systems are developed using a mixture of physical and economic units.

Each of these general approaches has advantages and disadvantages. The framework presented here (as well as those developed in France and Norway) uses a mixture of units. Consequently, the same parameter may be presented more than once and in more than one unit. For example, a forest may be presented in terms of the area of land covered, its species composition, the number of trees or an estimated monetary value of the timber. Such a system attempts to present information in a form most valuable to the full range of users. Care must be taken, of course, to avoid double counting.

The expansion of the economic accounts to incorporate resource and environmental data can result in a clumsy system, especially 
when a mixture of units is included. A modular approach is generally adopted in which economic information is presented in "Economic Accounts", ecological information in "Ecological Accounts" and the economic - ecologic interface in "Resource User Accounts". However, linkage between these sets of accounts is needed, as well as the generation of appropriate indicators.

The Economic Accounts consist of a modified version of the National Accounts, capable of being subdivided into smaller spatial levels such as states or provinces. Three main modifications to the traditional SNA structure are foreseen: first, adjustment of sectors to facilitate linkage with the Resource User Accounts; second, more detailed and explicit specification of expenditures within resource-using sectors, particularly those associated with waste disposal and pollution control, investments, incentives and subsidies into resource and environmental systems, conservation and outdoor recreation; and third, a social-accounting framework which both modifies and expands the traditional accounting structure.

The Ecological and Resource User Accounts consist of sets of "subaccounts" which have the same basic structure. The Resource User Accounts provide a link between the Ecological Accounts and the Economic Accounts; they also provide additional social and demographic information. The following paragraphs describe this general structure briefly.

The central element of each account is the "summary table" in which information on a particular resource or resource user is presented for the nation, subdivided into geographic or administrative regions (see Figure 9.8). The characters are, in most but not necessarily all accounts, grouped broadly into inputs and outputs. Since no common unit is necessarily used, there is no formal mathematical link between these inputs and outputs. Rather, the characters have been selected so that the key variables in the production function are displayed. This summary table is disaggregated in three directions. In the vertical disaggregation, the list of characters in the summary table is repeated and the information is presented for one region or for a particular combination of regions.

In the horizontal direction, more detailed information is provided on each character from the summary table, again for the nation and for each region. If the character is an indicator, these tables will present all information used in its calculation. In this way all "inputs" and "outputs" are specified at both national and regional levels. 


\section{Figure 9.8: General structure of the Ecological and Resource User}

\section{Accounts}

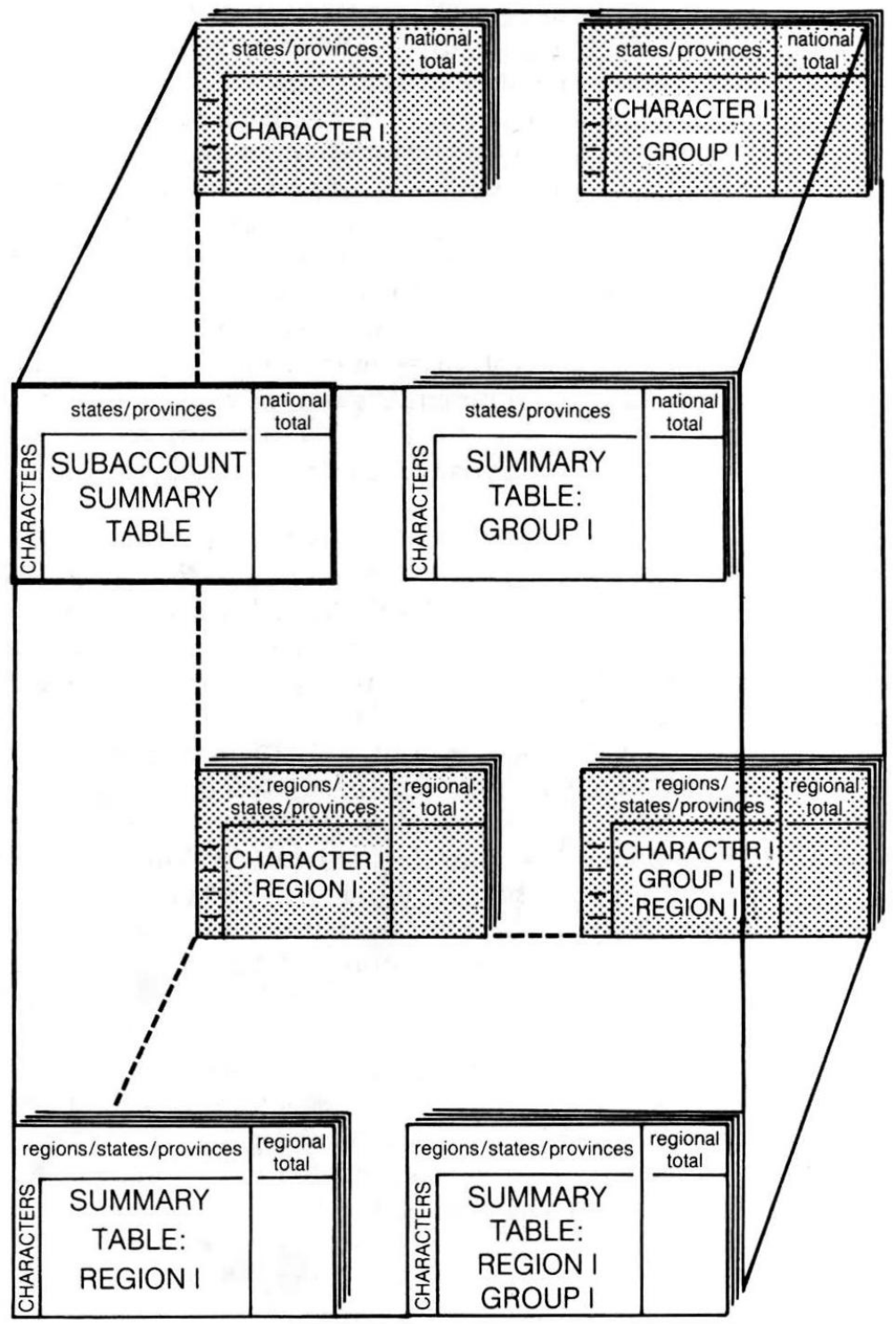


The third disaggregation is dependent on the particular subaccount. For example, if the resource user "livestock" is being presented, the first summary table will give information on all species combined. Disaggregation would permit a breakdown into individual species.

The whole area of NRA is new, and techniques are still being developed. Nevertheless, it holds considerable promise for bringing many dryland resources into a national accounting framework in a more meaningful way. Gilbert (1990) and Braat and Opschoor (1990) present a first examination of the use of NRA to examine livestock and range management in Botswana.

\section{Global models}

Global modelling methodology was introduced during the early 1970s with publication of The Limits to Growth (Meadows et al., 1972), a report commissioned by the Club of Rome which applied system dynamics to describe the interrelated behaviour of population, pollution, capital investment and the finite natural-resource base on which the planet depends. Since then, various models have been built at the global level. Some of the main models, especially those dealing with the environment and natural resources, are described in Box 9.3.

A global model can be an expression of economic and noneconomic linkages among sectors within a region, among regions within a country and among countries. Such a model typically consists of a large number of equations and variables, is installed and operated on a computer and is capable of simulating the effects of a wide range of policy options. Global modelling offers a unique contribution to the policy process because of its integrative nature. Policy-makers are forced to acknowledge the existence of interrelationships among seemingly unrelated problems. The environmental impacts of changes in economic variables can be traced through trade patterns, consumer and producer behaviour, labour supply and population growth.

Use of a global model to study dryland degradation is described in Dryland Management: Economic Case Studies. The model is a modified version of the SARUM/AREAM model sponsored by the Australian and UK governments for long-term strategic policy analysis and planning (Mula and Parker, 1979; Gigengack et al., 
Box 9.3: Global models

Global ecological/environmental research

\begin{tabular}{llll}
\hline Name & $\begin{array}{c}\text { World model } \\
\text { used }\end{array}$ & Main focus & $\begin{array}{l}\text { Enoironmental factors } \\
\text { considered }\end{array}$ \\
\hline $\begin{array}{l}\text { World 2; } \\
\text { World 3 }\end{array}$ & Yes & $\begin{array}{l}\text { Long-term carrying } \\
\text { capacity }\end{array}$ & $\begin{array}{l}\text { Pollution; population; } \\
\text { natural resources; } \\
\text { soil degradation }\end{array}$
\end{tabular}

\begin{tabular}{lccl}
\hline SARUM; & Yes & $\begin{array}{l}\text { Long-term OECD- } \\
\text { world relations }\end{array}$ & $\begin{array}{l}\text { Pollution; natural } \\
\text { resources }\end{array}$ \\
$\begin{array}{l}\text { INTER- } \\
\text { FUTURES }\end{array}$ & & &
\end{tabular}

\begin{tabular}{llll}
\hline $\begin{array}{l}\text { World } \\
\text { Integrated }\end{array}$ & Yes & $\begin{array}{l}\text { World regional } \\
\text { development and } \\
\text { podicy-making }\end{array}$ & $\begin{array}{l}\text { Natural resources; } \\
\text { climatic change }\end{array}$ \\
(WIM) & & & \\
\hline
\end{tabular}

\begin{tabular}{|c|c|c|c|}
\hline $\begin{array}{l}\text { Future of } \\
\text { the World } \\
\text { Economy/ }\end{array}$ & Yes & $\begin{array}{l}\text { United Nations } \\
\text { development } \\
\text { objectives }\end{array}$ & $\begin{array}{l}\text { Natural resources; } \\
\text { pollution }\end{array}$ \\
\hline
\end{tabular}

UN

\begin{tabular}{llll}
\hline FUGV & Yes & $\begin{array}{l}\text { North-South } \\
\text { relations }\end{array}$
\end{tabular}

\begin{tabular}{llll}
\hline $\begin{array}{l}\text { Global } \\
2000\end{array}$ & No & $\begin{array}{l}\text { Global development } \\
\text { projections }\end{array}$ & $\begin{array}{l}\text { Natural resources; } \\
\text { pollution; population; } \\
\text { climatic change }\end{array}$
\end{tabular}

\begin{tabular}{llll} 
AREAM & Yes & $\begin{array}{l}\text { Australian } \\
\text { environmental } \\
\text { development }\end{array}$ & $\begin{array}{l}\text { Natural resources; } \\
\text { pollution }\end{array}$ \\
\hline
\end{tabular}


Various types of global model have been constructed to study the relationship between changes in international policies and environmental conditions. The information in this table is based on papers published in Brudkmann (1982). The SARUM model has been used in a pilot project to analyse the problem of dryland degradation, as reported in Dryland Management: Economic Case Studies (Dixon, James and Sherman, 1990).

1985; Australian Department of Arts, Heritage and Environment, 1986). Information about the economic and demographic causes of degradation is incorporated in equations within the model. Some of the equations are linked with conventional economic variables such as production, investment and consumption, which in turn are the target for development assistance strategies. Implicit in the equations are assumptions about ecological conditions and regional government policies towards the land. Model parameters describe soil fertility, water availability and land degradation rates under different levels of environmental stress at the regional level. Each set of assumptions generates a particular scenario. Results of simulations are presented by Gigengack et al. (1990) in Dryland Management: Economic Case Studies.

Global models offer a promising methodology to analyse the implications of changes in international policies and economic conditions on natural resources, including dryland areas, in different countries of the world. Potential applications of global models include assessing the impacts of international trade on land use and land condition, providing indicative measures of economic losses resulting from land degradation and simulating the introduction of new technologies and land management practices.

\section{References}

Australian Department of Arts, Heritage and Environment (1986), AREA Model Handbook (Canberra: Australian Government Publishing Service).

Bishay, Adli (1984),

"An integrated approach to desert development", Ekistics, vol.51, no.304, pp.41-6.

Braat, L. C. and J. B. Opschoor, (1990),

"Risks in the Botswana range-cattle system" in Dixon, James and Sherman, op.cit.

Bruckmann, G. (ed.) (1982),

Environmental Aspects in Global Modelling, proceedings of the Seventh IIASA Symposium on Global Modelling (Laxenburg, Austria: International Institute for Applied Systems Analysis). 
Bui, X. T. (1982),

Executive Planning with BASIC (Berkeley, Calif: Sybex).

Dixon, J. A., D. E. James and P. B. Sherman (eds) (1990),

Dryland Management: Economic Case Studies (London: Earthscan Publications).

Dorfman, R., P. A. Samuelson and R. M. Solow (1958),

Linear Programming and Economic Analysis (New York: McGraw-Hill).

Dumsday, R. G.-and D. A. Oram (1990),

"Economics of dryland salinity control in the Murray River Basin, Northern Victoria, Australia" in Dixon, James and Sherman, op.cit.

Gigengack, A. R., C. J. Jepma, G. J. Lanjouw and C. Schweigman (eds) (1985),

The Use of a World Model for the Analysis of North - South Interdependence and Problems of Security and Development (Groningen, Netherlands: University of Gronigen),

Gigengack, A. R., et al. (1990),

"Global modelling of dryland degradations", in Dixon, James and Sherman, op. cit.

Gilbert, A. (1990),

"Natural resource accounting: a case study of Botswana" in Dixon, James and Sherman, op.cit.

Hufschmidt, M. M., D. E. James, A. D. Meister, B. T. Bower and J. A. Dixon (1983),

Environment, Natural Systems, and Development: An Economic Valuation Guide (Baltimore, Md: Johns Hopkins University Press).

James, D. E. (1985),

"Environmental economics, industrial process models and regionalresiduals management models", in A. V. Kneese and J. L. Sweeney (eds), Handbook of Natural Resource and Environmental Economics (Amsterdam: North-Holland).

James, D. E. and J. A. Chambers (1986),

"Managing environmental impacts of energy development: air quality in the Hunter region, New South Wales, Australia", Environmental Management, vol.10, no.3, pp.421 - 30.

Jensen, R. C., T. D. Mandeville and N. D. Karunaratne (1979), Regional Economic Planning: Generation of Regional Input - Output Tables (London: Croom Helm).

Leontief, W. (1966), Input - Output Economics (New York: Oxford University Press).

McColl, G. D. and C. D. Throsby (1972),

"Multiple objective benefit - cost analysis and regional development", Economic Record, vol.48, no.122, June,pp.201 - 19.

Meadows, D. H., D. L. Meadows, J. Randers and W. W. Behrens (1972), The Limits to Growth (New York: Universe Books for Potomac Associates).

Mula, J. M. and K. T. Parker (1979),

The Quantification of Stress Using the SARU/AREAM Global Model 
(Canberra: Australian Department of Arts, Heritage and Environment).

Richardson, H. W. (1972),

Input - Output and Regional Economics (London: Weidenfeld \& Nicolson).

River Murray Commission (1984), River Murray Water Quality Management Study, Working Papers E and F, Canberra.

Robinson, J. N. (1972),

Planning and Forecasting Techniques: An Introduction to Macroeconomic Applications (London: Weidenfeld \& Nicolson).

Thomas, J. F. (1990),

"Regional land use planning: The Murray River catchment of Western Australia" in Dixon, James and Sherman, op.cit. 


\section{Implementation of Policies, Programmes and Projects}

Improved management of drylands is the objective addressed by this book. Economic analysis is the underlying analytical approach employed, although the importance of a multidisciplinary perspective has been stressed throughout. Implementation of actual policies through programmes and projects is perhaps the greatest challenge and is also where many policies have failed.

The underlying reasons for project failure are diverse. Sometimes the technical analysis is flawed, and the wrong plant or animal species or an inappropriate agricultural technique has been recommended. Technical reasons, however, are usually not the sole cause of failure. More often, disappointing results can be traced back to social, institutional or economic factors, or to a combination of these. A major focus of this book has been the correct application of economic analysis to the challenging task of analysing dryland management options and anticipating the responses of dryland resource users. Merely getting the economics "right", however, is not enough. Successfully implementing the chosen policy, programme or project still requires careful planning and execution.

This chapter discusses some of the more important dimensions of the process of implementation. These range from such straightforward aspects as presenting the results of the analysis to decision-makers in such a way as to improve their understanding of problems and proposals, to the creation of appropriate incentives to help ensure acceptance and adoption of the desired course of action by land users. Social and cultural constraints may loom large when implementing a programme; again, the proper use of incentives may solve this problem. Policies on land tenure and use rights may be particularly important components of dryland management options. Finally, the overall management of programmes and projects requires special attention. 


\section{Presenting results to decision-makers}

\section{Characteristics of a useful economic analysis}

Once the economic analysis has been completed, the results must be organized into an appropriate format to allow the decision-makers to evaluate the proposed project or programme. Even the bestdesigned project may never proceed beyond the planning stage if the decision-maker is not convinced that the project is a sound one. This can happen for a number of reasons:

- The analysis is too long and remains unread.

- The analysis is too technical, full of "jargon" or simply unclear.

- The analysis contains obviously over-optimistic assumptions or ignores potential problems.

Analysts must realize that their evaluations will normally be directed towards busy decision-makers with neither the time nor the inclination to study a detailed, technical analysis. To ensure the highest likelihood of having the evaluation read and understood, the following guidelines should be kept in mind (adapted from Gregersen et al., 1987).

Structure of the report. In most cases, the analysis should consist of three parts: an executive summary; the main body of the report; and technical appendices.

In general, the most important part of the presentation will be the executive summary. Often, the policy-maker's decision will be based solely on the information contained in this section. The summary, which should be no longer than three or four pages, should include a description of the problem, the alternatives considered and the results of the analysis. If the analyst is expected to make recommendations, these should stand out from the text and be enumerated in a clear, concise manner.

The main body of the analysis will include the same items as the executive summary but in an expanded form. When possible, the text should be less than twenty-five pages. All additional information along with highly technical details should be relegated to technical appendices.

Level of presentation. Above all, the analysis must be comprehensible to the policy-maker. Though most dryland projects and programmes will be based on complex interactions of physical, biological, economic, social and other factors, the analysis should illustrate the essential points as clearly as possible. Liberal use of 
graphs and tables can aid in illustrating key points and help make the report easier to read and comprehend.

Important elements of an economic analysis

The presentation of the analysis should mirror the structure of the analytical process itself. The following briefly outlines the important sections of an economic analysis.

Definition of objectives. The first step of any analysis, and thus any report, is a description of the current situation and the impetus for the proposed programme or project. Before any project will be given serious consideration, there must be agreement that the project will either correct or prevent a serious problem or will, in some way, improve upon the current state of affairs.

Once the present situation is described, the objectives of the proposed project should be clearly enumerated. This section should highlight both the anticipated results of the project and why such results are worth working towards.

Identification of altermatives. Once the objectives of the programme or project have been defined, alternative means of achieving these objectives should be discussed. The initial discussion should include a wide array of potential measures of achieving the objectives. Alternatives which were eliminated at an early stage should at least be mentioned in general terms, while those options which merited closer consideration should be discussed in greater detail.

Even when only one potential project has been analysed, the two options of with-project and without-project should be included. Also, for a single project, alternatives need to be considered in decisions such as siting, optimal size and timing of implementation.

Identification and prediction of effects. Each project alternative will have a number of impacts - physical, biological, social or economic. An important step in analysing a project will be to assess correctly and predict these impacts in physical terms such as the number of hectares to be rehabilitated or expected increases in yield. Those effects which cannot be quantified in physical terms should be included in a qualitative fashion.

Some effects may be difficult to estimate due to various sources of uncertainty. In such cases, a realistic range of estimates should be used, along with an explicit outline of the assumptions employed in the analysis. As recommended in Chapters 6 and 7, the analyst should begin with the most direct, easily quantified 
effects. Negative as well as positive effects should be included.

Valuation of effects. Once the effects have been identified in physical terms, they must then be converted to economic terms. For the financial analysis, this means applying market prices to all changes in production and output. For the SBCA, a combination of market prices and shadow prices often will be necessary, as discussed in Chapter 7. Effects which cannot be converted to monetary terms should still be included in this section, although in a qualitative fashion.

Discussion of results. All of the information contained in the previous sections must be integrated to provide the decision-maker with some means of evaluating the project. Many governments or funding agencies will have and use a predetermined decision criterion (for example, internal rate of return or net present value). In other cases, or for analyses other than SBCA, approval will be more heavily dependent on factors such as income distribution, foreign exchange and qualitative effects.

A discussion of results should also include a sensitivity analysis to examine how these results will be affected by a change in key factors. Such considerations are especially important in dryland projects, which will often face variable conditions when implemented. Where warranted, contingency plans or other means of coping with adverse conditions (such as those discussed in Chapters 5 and 8) should be included in the evaluation.

\section{Creation of implementation incentives}

Incentives have an important role in the successful implementation of policies, programmes and projects aimed at protecting and improving the utilization of dryland resources. Their purpose is to motivate those persons responsible for management of the resources to undertake (or to forgo) particular land uses or land management practices. Consideration of incentives should be an integral part of policy selection and project design, rather than an add-on or an optional extra. Failure to incorporate a set of conditions which create positive motivation among participants may lead, at best, to inefficient or incomplete achievement of objectives or, at worst, to total failure of the project.

This section focuses on the potential for greater reliance on economic incentives in combating dryland degradation. The strengths and weaknesses of economic incentives are contrasted with other approaches, and some general criteria are suggested to 
aid decision-makers in their assessment of alternative policies. Figure 10.1 provides a schematic view of the basic strategies available to the policy-maker. A fundamental choice is whether to incur expenditure directly on a "physical" solution or to attempt to influence private behaviour via controls, moral suasion or economic incentives.

\section{Direct government expenditure}

Public funds may be directed to public works such as the restoration of environmentally degraded areas or the funding of preventive schemes such as flood mitigation. Also, public authorities may directly fund programmes of research, extension and education.

Direct expenditure is best suited to situations where land users are unable to secure a reasonable return from undertaking similar action or where it would not be feasible or economic to delegate responsibility to land users. This might be the case on governmentowned land; where the required level of investment is beyond the means of an individual land user; where there is a great deal of risk or uncertainty; or where non-contributors could not be excluded from the benefits derived from the expenditure.

The provision of information and the undertaking of public works are "direct" strategies inasmuch as they involve observable action and explicit products. However, they may have little direct effect on the processes of degradation. Supplementary incentives drawn from other approaches may be necessary if direct government expenditure is to be effective.

\section{Influencing private behaviour}

In contrast to direct government expenditure (which may influence individual behaviour only indirectly), there are three broad policy strategies whose major thrust is to influence individual behaviour: moral suasion; direct controls (that is, regulation and enforcement); and economic incentives (see Figure 10.1).

Moral suasion relies upon a land user's sense of social responsibility, attaching the labels "good" and "bad" to particular dryland management practices. The power of this approach depends on the psychological make-up of the targeted individuals, the cohesiveness of the society (peer pressure) and the strength of competing factors in the land user's mind. Moral suasion is most likely to be effective in combination with a regulatory approach or if supported by adequate expenditure on facilities or information. It will also tend to work better with land users who are better educated and 


\section{Figure 10.1: Instruments of environmental policy}

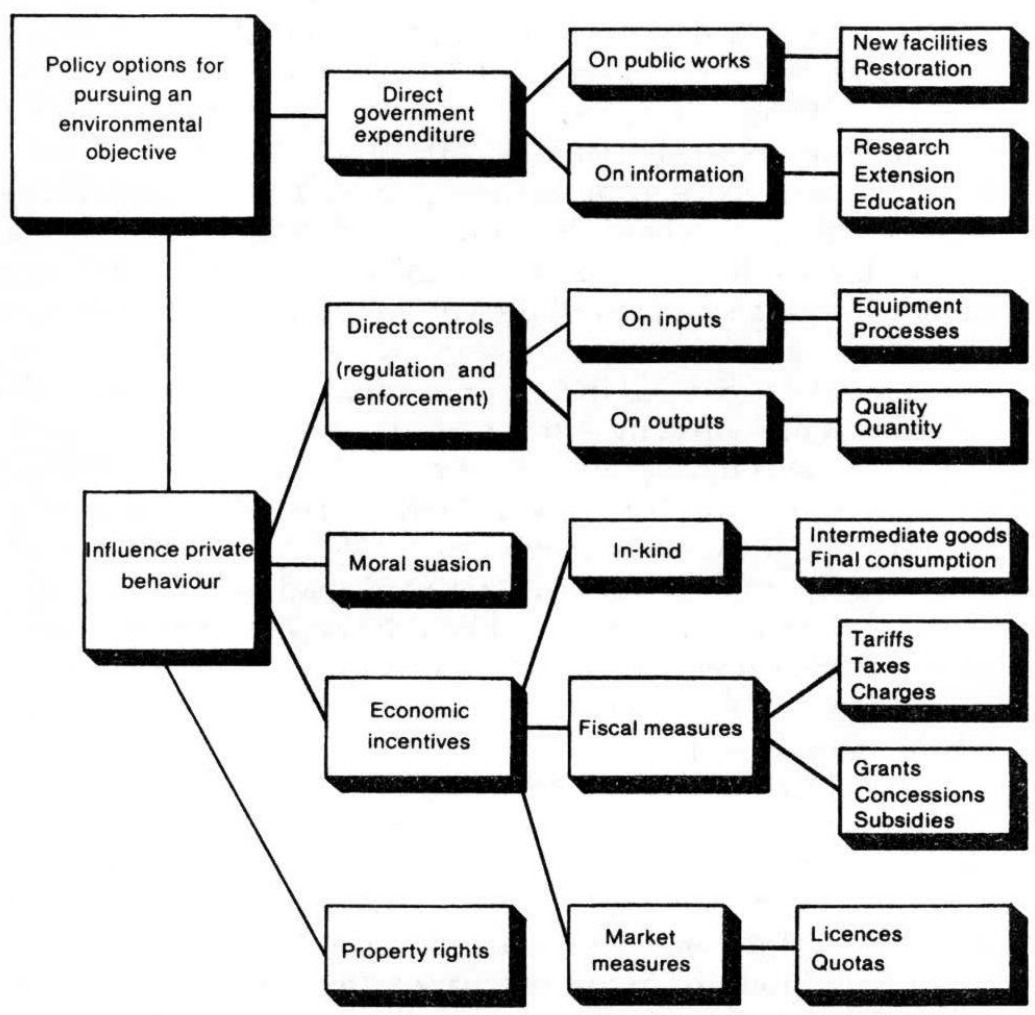


not suffering from extreme poverty.

The strategy of regulation and enforcement is universally popular among governments. Direct controls operate principally either on inputs, productive processes, or on outputs, by enforcing standards in regard to the products or by-products of economic activity. For instance, in the dryland context, direct controls on processes may involve specifying a particular crop rotation cycle or the periodic exclusion of livestock, or penalties for exceeding target maximum levels of soil loss from a particular area.

Economic incentives encompass a range of policy instruments distinguished by their reliance not on moral pressure, nor on the threat of legal sanctions, but on tangible economic rewards or penalties accruing to land users directly and automatically as a consequence of particular management decisions. Economic incentives may be presented in cash or in kind. In-kind incentives are of two basic types, affecting either inputs to the dryland production process or final consumption values of land users. In the former category would be the distribution of ferti' izer or improved seed to land users, and in the latter the provision of food, fuel or improved access to health care as "rewards" for participation in a given programme. In-kind incentives:are likely to be far more effective than! fiscal ! measures, where cash exchange ' markets are poorly developed, as is the case in many dryland areas.

Where more reliable markets exist, the public authority may choose instead to implement policies that provide a financial incentive to individual land users. These policies are often called fiscal measures because of their impact on government revenue or expenditure. Fiscal measures may result in additional government revenue, as in the case of taxes or selective tariffs on particular types of farm input, or from user charges (for example, for water from publicly funded irrigation schemes). Alternatively, fiscal measures may involve additional government expenditure, as with grants for special purposes or subsidies for farmers purchasing improved cultivars; or they may involve the treasury forgoing revenue it would otherwise receive, as with taxation concessions for land users retaining or replacing a proportion of "natural" vegetation on dryland properties.

Finally, a third category of economic incentive is linked with those policies that create new markets or substantially alter the parameters of existing markets through changes to the distribution of property rights. These so-called market measures may encourage the establishment of prices for previously unpriced goods or 
services, alter the number of participants in a market or change the ruling entry/exit conditions. The goal is to establish conditions where individuals face cost and revenue incentives to change their land-use patterns and promote improved management of dryland resources.

Characteristics of efficient incentives

A number of factors need to be assessed in evaluating implementation incentives. Baumol and Oates (1979) identify a series of characteristics generally useful in appraising environmental policies. Many of these are also relevant in the dryland context.

Dependability and permanence. These criteria refer to the reliability of the approach in achieving its objective. Direct controls and regulations characteristically treat environmentally damaging activities as illegal acts. Their effectiveness depends on their deterrent power, which in turn depends on the risk of discovery and successful prosecution, and the size of the penalty faced by offenders. Vigorous, systematic, enduring and frequently costly enforcement activities are generally required.

In contrast, economic approaches regard environmentally damaging activities as normal consequences of economic activity to be curtailed without resort to police powers. An appropriate economic incentive is able to provide routine, continuous, predictable and consequently effective enforcement. Direct government action is likely to be effective if carefully targeted. On the other hand, the effectiveness of moral suasion is likely to be highly unpredictable.

Adaptability to economic growth. This criterion recognizes that the pattern and pace of economic development and population growth may significantly affect a particular policy or programme. Inflation in particular may erode the effectiveness of an economic incentive while having relatively little impact on other approaches. Careful attention must therefore be paid to the design of economic incentives to ensure that they are flexible enough to cope with changes in broader economic parameters.

Equity. What is equitable or "fair" is a complex and sometimes contentious issue. Vertical equity refers to the notion that individuals should contribute to the common good in proportion to their means. Horizontal equity refers to the notion that persons of similar means should contribute equally to the achievement of objectives which benefit them in similar degree.

The question of who should pay the costs of protecting and 
rehabilitating drylands has no easy answer. Costs may be shared among the public treasury, beneficiaries of the programme and those causing the damage. In principle, the most effective and efficient approach is one in which the costs of environmental damage are paid by those causing the degradation. This may be possible in the more advanced economies, but elsewhere this is plainly an unrealistic expectation, even though land users most directly responsible for dryland degradation will also be the prime beneficiaries of improvement in the condition of the drylands.

Flexibility and incentive for effort. These criteria refer to the degree of freedom individual land users retain in determining their response to a particular policy or programme, and the strength of the inducement provided to them to pursue the environmental objectives of that policy or programme.

Direct controls that stipulate a particular management practice or standard of performance provide little or no freedom or incentive for individuals to do better than the regulated minimum. Economic incentives, particularly market measures, provide freedom for land users to devise innovative individual or co-operative responses which may result in a higher level of performance at no greater cost.

Economy. This criterion refers to the achievement of objectives at least cost to society, without excessive use of resources.

Consider, for example, a regional catchment plan to reduce soil loss and protect water quality. Direct policy options include equal target reductions in soil loss per hectare for all land users in the catchment or the universal use of particular management practices. Economic incentives include penalizing (taxing) land users for each tonne of soil lost from their property or rewarding land users for each tonne of soil "saved" (that is, reductions in soil losses attributable to improved land management).

Assuming the level of tax or subsidy was set to induce the same aggregate response as the direct control option, these economic approaches would result in soil conservation activity being distributed among landholders to concentrate effort among those able to reduce soil loss most cheaply. The marginal cost of control would be approximately equated between individuals, whereas direct controls could result in the marginal cost incurred by one land user being several times that of a neighbour due to different land or enterprise characteristics. The result is that the same level of improvement can be achieved at a lower total cost through economic approaches. However, the distribution of total costs 
between landowners may be much more unequal as compared with direct controls.

\section{Selecting the appropriate incentives}

Having established a set of objectives for a proposed dryland policy, programme or project, there remains the task of settling on the appropriate mix of policy instruments to achieve those objectives. The broadly based evaluation criteria just discussed should provide a useful starting-point. Equally important will be the specific characteristics of a particular case.

Constraints on the use of economic incentives

Factors which may assume critical importance in a given situation include the risk of failure, uncertainty regarding future events and the absence of economic infrastructure.

Risk of failure. Where failure of a policy or project would have catastrophic consequences, and success is an "all-or-nothing" event, direct government action may be necessary. In such circumstances, moral suasion is not a realistic option. Economic incentives may play a supplementary role but are unlikely to be successful if relied upon alone.

Uncertainty regarding future conditions. Where outcomes are subject to the impact of uncertain, uncontrollable events, it may not be possible to design economic incentives which work efficiently in the face of such unpredictable variability.

Consider the example of user charges for water supplied to dryland irrigators. A charge high enough to ensure adequate supplies (or the least possible shortfall) in the event of the most severe drought would almost certainly impose excessive restraint on water use and inhibit the efficient use of water and other resources in more average years. Ideally a system of fees which varied according to water supply (rainfall, storage) and expected demand would be charged, but this may be administratively cumbersome and slow to respond to critical shortages as they emerge. A feasible solution may consist of a combination of economic incentives to encourage water conservation during periods of "normal scarcity" backed up by direct controls on water use in the event of serious shortfalls in supply.

Absence of economic infrastructure. Application of the more sophisticated economic approaches may be frustrated by the absence of necessary economic institutions. For example, fiscal 
measures originating from the central government require a reliable system of revenue collection and disbursement. This may not exist in the most severely affected dryland regions of many developing countries. In such circumstances, locally administered fiscal measures compatible with existing social infrastructure may be successful; however, the absence of an exchange economy severely limits the application of many economic approaches in some areas. In such situations direct intervention may be the most feasible alternative.

\section{A checklist of incentive characteristics}

The following checklist poses a series of questions specifically relating to the incentives contained in a dryland policy, programme or project. Adapted from Yapp and Upstill (1984), these questions focus on the practical aspects of programme implementation.

Point of application. At what stage of the production - marketing - consumption process is the incentive introduced?

Breadth of application. How extensive or selective is the incentive? Is it well targeted?

Beneficiaries. What social groups or classes of individuals gain (financially) from the incentive?

Losers. What social groups or classes of individuals are disadvantaged by the incentive?

Simplicity. Is administration relatively straightforward? Can target groups easily understand its operation and impact?

Public-sector impact. At what level of government is the incentive best administered? Does the incentive result in a net loss or gain to the public sector?

In summary, economic incentives constitute an important policy instrument for improved programme implementation in areas with market or semi-market economies. Their usefulness comes from their ability to target failures of the economic system where landuse decisions fail to take into account the full social costs of those decisions. Economic incentives can at least partially correct for these failures by motivating and supporting behaviour that closes the gap between self-interest and public interest.

\section{Social and cultural constraints to implementation}

Social and cultural factors were touched on briefly in Chapter 3. People use resources to meet their needs, and the patterns of resource use are frequently moulded by social and cultural factors. 
This may be especially true in dryland areas inhabited by populations characterized as being traditional and not well integrated into national markets.

Implementation, therefore, and the design of appropriate incentive systems must take into account the social and cultural factors. At the same time, since present patterns of land use and land degradation are the result of the existing situation, complete acceptance of the status quo may mean that no improvement is possible.

The chances of success are greatly improved if the people are asked about their ideas on problems and possible solutions. They can contribute valuable insights, and their involvement right from the start will help ensure easier implementation of projects as well as minimizing disruption of the community.

If local concerns are ignored, policy-makers are often unable to induce major shifts in traditional behaviour. Interventionist policies are likely to create public resentment and result in failures of planning and implementation.

It is important to avoid disturbing the cohesion of the community. The wrong kinds of policy can easily lead to disruption and depopulation. In most cases, high priority should be given to avoiding the dissolution of existing communities and to strengthening community feeling where it is weak. It is, however, recognized that in some situations current population levels may be considered excessive. Difficult policy decisions on whether some people should be encouraged to move may need to be made. Any movement away from the community should be monitored carefully.

It has become common practice in the development arena to include an evaluation or monitoring component in all project documents. However, such components generally focus on the material results of the project or related economic statistics (that is, on parameters that are readily amenable to measurement). The social and cultural dimension of the situation must also be monitored and taken into account.

One indicator of the success of a project and the welfare of the population may be seen in the time horizon of their thoughts about their own lives. A shortened time horizon generally indicates a loss of confidence in the community; a lengthening time horizon indicates strengthening of community feeling. These perspectives then feed back into the actions taken to manage dryland resources. A shortened time horizon favours intensified exploitation and 
degradation of the dryland resource; a longer time horizon favours a more sustainable development path.

\section{Policies on land tenure and use rights}

One of the key determinants of how land users react to potential change is the existing land tenure system and the obligations associated with it. Land tenure arrangements are complex manifestations of how individuals and groups interact with and manage their land resources. Programme implementation must take these factors into account.

Land tenure systems include the formal and informal, or customary, rules which prescribe individuals' opportunities and responsibilities with respect to the use, transfer and succession of land. These rules define what may be done as matters of private rights; which of the different uses of land may be alienated to different individuals and what claims people can make on collective, or common, resources; which are retained for community benefit; and what safeguards to individuals are provided against the actions of others. They have.the important economic function of allowing people to form expectations and plan ahead (Knetsch, 1983).

Tenure systems, and especially specific rules governing land use and transfer, vary widely from area to area depending on historic, cultural and economic factors. Different tenure systems have evolved to meet varied objectives. These objectives include access to land for subsistence purposes, security of minimal production of food in leaner times, protection of weaker members of the community, greater production to attain tradable surpluses and preservation of family or group lineage.

These varied objectives may provide inconsistent incentives. It is all too common, for example, for individual farmers to increase their herd sizes on open-access pasturelands to attain higher incomes and, in doing so, collectively to overstock and degrade their commonly owned resource. Other results are equally compromising: becoming dependent on submarginal lands during years of more abundant rains may lead to failures and severe disruptions in more normal years of limited rain; striving for maximum vegetative production may put the community at greater risk of crop failures in dryland areas, thereby decreasing its security; successive subdivision of land among heirs may lead to lack of viable holdings for family survival; and unlimited alienation and transfer of rights may result in lack of community control and 
inequitable distributions of returns.

The success of efforts to arrest degradation, rehabilitate degraded land and encourage sound management may depend on the tenure arrangements of the area in question. For example, if graziers are required individually to improve grazing capacity on open-access common property pasture lands, or if tenants are not assured of sufficiently long tenancy to realize the benefits from any productivity investments they make, they will be reluctant to undertake the desired actions. When efforts to improve matters are consistent with tenure rules, they are more likely to be effective. This would be the case when a technical change requiring an investment of labour would clearly result in the benefits of this effort being received by the tenants making the sacrifice. Alternatively, when a needed windbreak project requires the participation of many people to reach a worthwhile scale, there might be a need to prescribe sanctions for non-participation.

Modifications to tenure systems are often needed to respond to changing conditions and priorities and to overcome problems such as too little investment, too little concern with longer-run conservation of land resources and too little rehabilitation of land. The major challenge in this area is to design modifications of tenure rules that will encourage greater gains while protecting other objectives and taking account of limited administrative resources. Although greater efficiency in the use of resources is necessary to attain greater productivity, equity and fair distribution of benefits and costs are also important to people and can be expected to have a major impact on the acceptance of any proposed changes.

Economic analyses of tenure systems can be particularly useful for two purposes. First, they can provide insight into the economic impacts of specific tenure rules; and second, they can provide useful information for decision-makers to evaluate the gains and losses that might be expected with various alternative arrangements of entitlements.

\section{Systems and incentives}

Different forms of tenure often exist within a single country, especially between rural and urban areas, and between different rural areas of widely diverse characteristics. In some areas, notably in most of Europe, North America and Australia, private freehold or perpetual Crown or government leases dominate, especially in areas of most intensive economic interest. In other areas large numbers of people inhabit land or migrate over it with no recognized 
claim to the use of the land or to any of its benefits. Government ownership, with leases or rights of occupation to private individuals or groups, is another important system of tenure, especially in parts of Africa. Leaseholds from either government or private owners are a major form of tenure in both urban and rural areas in all parts of the world, while communal and other traditional forms of tenure dominate in Africa and parts of the South Pacific.

Tenure rights are not a single entitlement in any of these systems. The rights pertain instead to a variety of entitlements, sometimes referred to as a "bundle of rights", that may be allocated in different ways and to different groups and individuals. The specific rights may include entitlements to sell land or lease it to others; to trespass; to graze cattle; to harvest wildlife; to gather firewood; to grow and harvest crops, which may be limited to a season or may be effectively perpetual; rights to pass on to heirs; and rights to use surface waters. An individual may have one entitlement exclusively, share others with other members of a group and share still others with outsiders (Box 10.1).

\section{Box 10.1: Property rights and trees in India}

A search for better means of accommodating conflicting tenure goals should include examination of alternative ways of separating the various property interests within the "bundle of rights" associated with land parcels and allocating them in ways that will result in better use of the resource.

For example, an innovative scheme has been implemented in India that gives limited rights to local landless people to allow them to use certain public landholdings "for the purpose of planting of fuelwood or fruit trees or fodder", while clearly ensuring that the "planter shall have no ownership right whatsoever on the earmarked land on which the trees are planted and shall not transfer, sub-let or otherwise dispose of or create any interest, title, right, easement or liability on it". The separation and assignment of only limited rights to specific groups of people - in this case agricultural labourers, ex-service personnel and small and marginal farmers - permit and encourage more productive use while allowing the state to retain residual rights to the land. The interests of both the individuals gaining access to plant trees and the community are better served by this arrangement.

Source: Report to the Group Constituted to Evolve Guidelines for Grant of Tree Pattas. Government of India, Department of Rural Development, 1986 
Private property. The chief characteristics, and major advantages, of freehold, or its near equivalent of perpetual leases, are security of tenure and fewer restraints on the use and transfer of land. The security of private property has the principal economic advantage of the so-called "sowing and reaping" rationale (that is, an owner can invest in the seeding and growing of a crop or can make any other form of investment, secure in the knowledge that the benefits resulting from the investment will accrue to him /herself even if he/ she chooses to sell the land after making the investment). The value of the investment will still go to the seller, in this case because the market price of the land can be expected to reflect closely the future productivity and profitability of the land including investments that increase future yields. Similarly, if an owner chooses to lease the land to another individual, the rental value can be expected to reflect the potential productivity of the land.

The costs of any disinvestment, or permitted degradation of the land, will of course also accrue to the owner in the form of lower returns, lower sale price or decreased rental value. (The value of any government subsidy scheme will be capitalized and captured by the present landowner in much the same way; an annual grant to cover part of the costs of seed, fertilizer or other input, or marketing assistance, will have the effect of making the land more profitable and will escalate its price, and the value of all future payments will accrue to the present owner.)

A lack of restriction on the use of private property has the great efficiency advantage of allowing owners to change land uses quickly in response to changing conditions or demands. Since private property can be transferred, it encourages land to be used by people able to make the most beneficial use of it. If another person is able to work the land more productively than the present owner, a transfer at a mutually advantageous price - greater than the value that can be derived by the present owner, and less than that achievable by the buyer - will result in a socially advantageous change as a higher-value use replaces the lower-value use.

Private property can also be used as collateral (mortgages) to obtain credit on favourable terms. This overcomes an often important impediment to undertaking beneficial investment. (See Box 10.2 for an example from Thailand.)

There are, however, potential negative effects of private ownership. These include the following:

- A small group of individuals may accumulate large amounts of 


\section{Box 10.2: Availability of credit and incomes in Thailand}

A recent study of farmers in Thailand demonstrates the significant relationship between security of land tenure and access to credit on more favourable terms.

The incentive to undertake investments that would increase land productivity was related to the ability of farmers to secure credit. The supply of credit, especially from financial institutions rather than from highercost informal sources, was found to depend directly on the security of land interests.

The extent to which land arrangements were seen to provide desirable collateral for longer-term loans had a significant positive effect on farmers' incomes in the areas studied.

Source: Feder and Onchan, 1987.

property. Restrictions on property transfers can be imposed, but such restraints normally come at a cost of not only blunting some efficiency incentives but also increasing the administrative resources needed to implement, monitor and police the restrictions.

- Private individuals may have discount rates that are higher than social discount rates (as discussed in Chapter 4). Investments that are more socially desirable but take a longer time to yield benefits may not be undertaken in preference to ones with more immediate returns for the private investors.

- There may be a serious divergence between private returns that motivate the actions of landowners and social gains and losses that measure the impacts on the community, because some actions impose costs on others that are not borne by those responsible for them (negative externalities), or yield gains to others that are not paid for (positive externalities). (Chapters 4 and 5 give examples of such externalities.)

Many of the problems of divergent private and social interests can be corrected by altering land rights better to reflect gains and losses. Use rights can be adjusted to restrict socially costly practices: certain cropping practices can be restricted or prohibited; stocking levels can be controlled; and compensation can be paid for tree plantings that benefit others. But, again, implementation of 
such restrictions will involve costs.

Leaseholds. Another form of tenure frequently found in rural as well as urban areas is a leasehold interest involving tenants and owners. Leasehold involves an explicit sharing of the rights associated with the land and has many of the efficiency advantages of freeholds, such as flexibility to change land use in response to changing conditions.

Leasehold agreements, however, especially in rural areas, are often restricted by local custom and may not adequately reflect the contributions of the tenant and owner. A tenant with a fixed shortterm lease has little incentive to make improvements that will increase future productivity of the land, since this will only benefit the owner and future tenants. Similarly, a tenant may choose to exploit the land for short-term gains, thereby hurting the owner's interest. Most tenants prefer longer-term leases to recoup the gains from land improvements, while landowners may have an interest in the flexibility to change tenants provided by shorter-term leases.

A proportional sharing of crop revenues is a very common form of rental payment, and although this reconciles the major interests of both landowner and tenant in greater yields, splitting any added gain from added effort may result in inadequate compensation for a tenant's extra work or investment. Landowners sometimes encourage tenants to make worthwhile improvements by offering to compensate them for any unrealized gains at the end of the lease. This is, however, often difficult to implement in practice because of valuation and specification problems.

The lack of security may also make credit less available or more costly to tenants. Although potentially a major disadvantage, it is sometimes possible to arrange credit on the basis of the owner's interest.

Absence of recognized entitlement. In some areas, population pressures, lack of available resources and a variety of institutional and social circumstances give rise to large numbers of people inhabiting lands without any recognized rights of use or trespass. In other areas, nomadic groups have been denied their long-established customary entitlement to migrate across particular land areas, and consequently may also be left without recognized rights.

Lack of entitlements is usually associated with severe impoverishment, lack of security and social and economic deprivation. These conditions and the incentives they create give rise to further problems of land degradation and productivity loss.

Common lands are particularly susceptible to over-use by people 
desperate for means of survival. The consequences of their increasing use of grazing lands, forests and water resources are as predictable as they are understandable. Whatever the motive, overextension and exploitation with little or no attention to future needs invariably yield increasingly meagre returns.

State ownership. In many regions, vast areas of land are owned by the state as a result of interventions to take title "to be held in trust for the people of the country" (Read, 1975, p.128), as remainders of unclaimed land, as other vestiges of historic development or for a range of other reasons. The tenure arrangements for subsequent use also vary.

In many cases, especially in Africa, these lands continue to be occupied by indigenous inhabitants in accord with their customary rules. Usually such groups enjoy occupation rights granted by the state (McDowell, 1975). In other cases the state offers leasehold rights to individuals or groups. These may be for a variety of purposes and for varied lengths of time, with essentially perpetual leases not uncommon. Direct state operation and use of land and provision of agricultural products are also common and are typically carried out either by state enterprises or by contract arrangements with third parties.

In each instance the basic issue remains one of providing incentives that lead to socially desired activities and investments. Although operations of state enterprises and use of state lands normally reflect concerns with a variety of social and economic goals, the extent to which productivity gains are sacrificed for other benefits can often be explicitly demonstrated and decisions made on the basis of such information.

Communal and traditional tenure. Communal ownership or control and customary or traditional tenure systems are common in many dryland areas. Many evolved when there were fewer people, when a need existed for security against neighbouring groups and when there were fewer opportunities for trade of surplus production, little or no outside assistance from national governments, little possibility of enforcement of contracts and limited technical or economic change.

Largely as a consequence of these conditions, customary land laws tended to treat land less as a factor of production and more as a source of security and a centre of cultural values and obligations. Although they vary widely over areas and groups, customary laws are often largely concerned with assuring access to land for all members of the group and establishing reciprocal obligations 
between people within a group and among kinship groups.

With fewer pressures on land resources and a lack of outside insurance schemes, traditional patterns of land use and tenure may have been more appropriate. Early societies were often able to apply effective sanctions on herd sizes, and trek routes and pasture areas were strictly defined and divided among members of the groups (Franke and Chasin, 1980). Swidden agriculture, grazing on common pastures and cutting open forests for subsistence needs could often be accommodated with tolerable loss of productivity.

However, the effectiveness of such sanctions is often a function of the social cohesiveness of the group, the extent of the pressure on resources and the opportunities to exploit resources for gain. With increasing rural populations relative to land availability and greater opportunities for taking advantage of technological and market changes, some of the restrictions come at increasing costs.

Customary tenure often allows individual occupation and cultivation of communally owned land. It usually, however, provides insufficient security of tenure for individuals to be confident of appropriating all the benefits of land improvements, and such land interests can rarely be pledged as security for needed credit. Without assurance of return, the incentive to pursue a series of management options - adjusting inputs, grazing levels, selling of assets - to best cope with the changes in climatic conditions so characteristic of dryland areas is similarly blunted.

Rules of mutual obligations also impose restrictions on land-use changes, and the inhibitions on securing larger holdings restrict the ability to take advantage of scale economies. Group decisionmaking, often with unanimity requirements, can be a cumbersome and serious inhibition to timely change.

The common rules prohibiting or restricting transfer of land interests to individuals outside of the group may also impose costs of more efficient production. While promoting other important objectives, such as keeping the land in control of the community, such controls may inhibit the use of lands by individuals most capable of increasing production and protecting its productivity, reduce the ability to gain scale economies and diminish the ability to obtain gains of specialization.

Customary tenures may provide fewer controls on the use of common property resources. With fewer restraints, overgrazing of pasture, rapid deforestation and failure to maintain the productivity of the land are an all too frequent consequence. Such tenure systems are typically ill-suited to control the imposition of external 
costs on others, as in cases of long-term build-up of salinity and erosion resulting from loss of vegetation. However, where social cohesiveness has been maintained, customary tenures may actually work better than private property, since costs to neighbours are treated the same as costs to individuals themselves. (People working on soil and water conservation projects in Africa note that customary tenure may provide just as firm a right to land in the future as does "private" tenure. This may require increased sensitivity to these arrangements on the part of government administrators and appropriate support for the customary system.)

In the case of customary systems, as in others, tenure rules can be modified to encourage more appropriate activity and investment. Changes in tenure may reduce the adverse effects of inflexible use and transfer of land. However, such changes may also reduce the long-term security of the current users and result in short-lived gains at the expense of a future, and perhaps permanent, loss of rights.

Economic analyses can be of substantial aid in designing legal institutions that would better accommodate both security and development objectives. An example that might be profitably followed is the proposal to allow previously forbidden transactions by communal landowning groups in Papua New Guinea. The proposed partial remedy took the form of limited transfers of some of the rights to use land. Such dealings could be registered and security interests protected even without a land registration scheme. Even limited dealings would allow individual members of the communal groups to make better use of the land, secure capital by using certain rights as collateral without the usual dangers of possible complete loss to traditional owners, produce tradable surpluses and serve other development goals (Trebilcock, 1984).

\section{Accommodation and change}

Perhaps the most useful general principle of reform of tenure arrangements is that any change should clearly be directed to realigning incentives and restraints so that the rules motivate individuals in ways that are more consistent with longer-term goals and values of the wider community. Rules that inhibit investments in maintaining and increasing long-term land productivity, those that discourage individuals from making a quick accommodation to changing conditions and those that encourage uneconomic exploitation of land and water can be changed to benefit nearly all members of the community. 
It is also generally advisable to modify rather than replace existing systems. Replacement necessitates further uncertainty and administrative costs, with the possibility of larger losses imposed on minority groups, and a consequent smaller likelihood of being justified.

Change invariably imposes both gains and losses on different individuals. Most economic assessments of changes tend greatly to understate the costs. Resistance to change is generic to people in all parts of the world. In part this is because some people suffer losses that are not compensated by gains. However, it is also due to an asymmetric weighting of gains and losses. Studies in North America, Australia and Europe have concluded that people weigh losses much more heavily than gains and will favour or oppose changes accordingly. There is little reason to expect people affected by changes in dryland tenure systems to react any differently than others in this regard. Institutional design can be expected to be more successful to the extent that it takes account of this valuation asymmetry (Krietsch, 1984).

Many communal or traditional land systems operate without any form of registration of individual or even group interests. This leads to uncertainty of entitlements, difficulty in resolving disputes and inhibitions to the transfer of interests and the granting of credit - all of which can be expected to be major obstacles to development and beneficial change. Although the lack of clear title is the major disadvantage of such systems, the most useful reform is usually not a complete registration system of all current interests, with the enormous costs that this would entail. Instead, it is often one of essentially registering only current land dealings. Such administrative activities would substantially reduce transaction costs of completing mutually desirable arrangements, yield greater security of entitlements, provide opportunities for greater assurance of provision for security interests of groups and individuals, give a more secure basis for grants of credit and generally encourage the search for and implementation of productive activities (Knetsch and Trebilcock, 1981).

The range of potential specific changes is wide, and it is important to weigh the advantages and disadvantages of each. Economic analyses can provide assessments that are useful for such exercises. Although an explicit/accounting of gains and losses of each alternative is most useful, even partial assessments can prove to be of great value. 


\section{Management of programmes and projects}

Just as the technical and economic design of programmes and projects in dryland areas requires special attention, management also needs to be explicitly considered. Given the great diversity of social, cultural, economic and political structures in countries confronted with dryland degradation, it is impossible to prescribe a preferred management structure. One could say that the best structure is that which gets the job done. Such truisms, however, are not very helpful. Rather, a series of points and guidelines will be offered. Some of these are obvious, and most rely on common sense. They may help, however, to devise that "ideal" programme or project-implementation plan that meets four target goals - technically correct, socially acceptable, economically efficient and, most important, capable of being successfully implemented and put into practice with the acceptance and support of the people affected.

A list of guidelines and points for successful programme or project management would include the following.

\section{Technical management}

- Any technical component shouid be field-tested and proved appropriate for the project site.

- Any required equipment and trained personnel should be available.

- Provisions for operating and maintenance (O\&M) should be planned for.

- Insights of local participants should be incorporated in the project.

- Flexibility should be maintained to cope with any change in circumstances.

Financial management

- Both the private individual benefits and the social benefits of the project should exceed gross costs.

- Provisions for credit, if necessary, should be taken care of before implementation begins.

- The connection between sources of revenues (and which body receives them) and expenditures for the project needs to be clear.

- Responsibilities should be assigned for raising and expending funds and for financial monitoring and control.

- Financial incentives should be designed to resolve potential con- 
flicts between public and private economic interests.

\section{Social management}

- Local participation is essential for problem identification, project design and implementation.

- Social and cultural factors must be taken into account in the design and implementation of any actions.

- Population dislocations need to be carefully considered and handled.

- Steps must be taken to provide any needed social services.

- The functions of NGOs and extension workers should be clearly specified, especially in relation to social and cultural values.

\section{Administrative management}

- Responsibility for project implementation must be clearly defined and agreement reached on each unit's duties.

- Co-ordination of both provision of services and provision of technical support needs to be worked out.

- Financial obligations of all parties must be clarified.

- Sanctions for non-compliance should be established.

- A monitoring and review function should be organized and the results incorporated.

In guidelines suggested for the design of projects within the Soil and Water Conservation and Land Utilization programme of the SADCC (Southern African Development Co-ordination Conference), for example, the following points were highlighted for particular emphasis (SADCC, 1987):

- regional impact of project and consistency with the overall strategy for the sector;

- relevance to the sector and possible co-ordination with other sectors;

- clearly stated problems and project objectives;

- budgeting of main costs;

- benefit quantification and valuation to the extent possible;

- relation to government's development objectives, administrative structure and available human and financial resources;

- realism in approach and likely popular participation; and

- dissemination of information and experiences.

The frequency of review is another policy variable. Benefits are 
expected to increase with more frequent and more detailed monitoring and review. These reviews impose costs, however, and the analyst needs to consider the net benefits of review. As one author has pointed out (Staffurth, 1980):

If there is no review, the benefit [of the review] will be zero. For a review halfway through the project, the benefit could be substantial. Reviewing the project four times will increase the benefits as unfavorable trends will be detected earlier. But as the review period is shortened, the additional benefits approach zero.

As usual, the benefits of increased effort devoted to an activity have to be weighed against the costs of the additional effort. The ability to retain flexibility in project design and implementation has frequently been mentioned as a key variable in allowing project managers to derive maximum benefit from the results of the review process.

The problems addressed in this book are essentially those resulting from a divergence between private benefits and social benefits, private costs and social costs. The "drylands dilemma" is also the "drylands challenge". But the challenge will not be met without imaginative, flexible and cost-effective programmes that help lead to a convergence of private and social benefits and an improved and more sustainable use of the world's dryland resources.

\section{References}

Baumol, W. J. and W. E. Oates, (1979),

Economics, Environmental Policy and the Quality of Life (Englewood Cliffs, NJ: Prentice-Hall).

Feder, G. and T. Onchan (1987),

"Land ownership security and farm investment in Thailand", American Journal of Agricultural Economics, vol.69 no.2, pp.311 - 20.

Franke, R. W. and B. H. Chasin (1980),

Seeds of Famine (Totowa, N]: Allanheld, Osmum).

Gregersen, H. M., K. N. Brooks, J. A. Dixon and L. S. Hamilton (1987), Guidelines for Economic Appraisal of Watershed Management Projects, FAO Conservation Guide No. 16 (Rome: FAO).

Knetsch, J. L. (1983),

Property Rights and Compensation (Toronto: Butterworths). 
Knetsch, J. L. (1984),

"Legal rules and the basis for evaluating economic losses", International Reoiew of Law and Economics, vol.4, no.1, pp.5 - 13.

Knetsch, J. L. and M. J. Trebilcock (1981),

Land Policy and Economic Deoelopment in Papua New Guinea (Port Moresby, Papua New Guinea: Institute of National Affairs).

McDowell, C. M. (1975),

"Compensation for compulsory acquisition of land in Nigeria", in J. F. Gamer (ed.), Compensation for Compulsory Purchase (London: UK National Committee of Comparative Law):

Read, J. S. (1975),

"Aspects of the East African experience", in J. F. Garner (ed.), Compensation for Compulsory Purchase (London: UK National Committee of Comparative Law).

SADCC (1987),

Workshop on Conservation Project Design, Southern African Development Co-ordination Conference Report no.7 (Maseru, Lesotho: SADCC).

Staffurth, C. (ed.) (1980),

Project Cost Control, 2nd edn (London: Heinemann).

Trebilcock, M. J. (1984),

"Communal property rights: The Papua New Guinea experience", University of Toronto Law Joumal, vol.34, no.4, pp.377 - 420.

Yapp, T. P. and H. G. Upstill (1984),

Fiscal Measures and the Environment: Impacts and Potential, Environment Papers (Canberra: Australian Government Publishing Service). 


\title{
11. Case Study: Benefit - Cost Analysis of Soil Conservation in Maphutseng, Lesotho
}

\author{
by \\ Jan Bojö \\ Background
}

Lesotho covers an area of $30,000 \mathrm{~km}^{2}$ and is dominated by a mountainous landscape; it has a population of about 1.5 million people. Lesotho is entirely surrounded by the Republic of South Africa (see Figure 11.1) and is heavily dependent on South Africa, in part due to extensive migration of mine workers. The reliance on mine wages has made agriculture relatively unimportant in terms of GNP; agriculture's total share of GNP was only 10 per cent in 1984 (2.5 per cent when only crops were counted), and the trend is declining (Bureau of Statistics, 1987).

In accordance with ancient tradition, land is considered the property of the Basotho people, held in trust by the king and administered by him and his subordinate chiefs. In practice, the local chief is responsible for the allocation of land. Whereas residential and garden plots and cultivable fields are allocated to individuals, grazing land remains communal.

In theory, the Land Act of 1979 has introduced new tenure legislation, allowing for the grant of individual, registrable leases and inheritability of land. In practice, government lacks the capacity to implement this legislation, and very few leases have been registered so far. Instead, the number of "informal leases" by private agreement has increased (World Bank, 1986).

Erosion has been a concern of foreign visitors to Lesotho since well back into the last century, and a large-scale conservation programme was launched by the British colonial administration in the 1930s (Turner, 1975; Chakela and Cantor, 1986). Although initially successful in establishing physical soil conservation structures, farmers' participation was very limited. When external support was withdrawn, the structures began to deteriorate; remnants can 


\section{Figure 11.1: Project area}

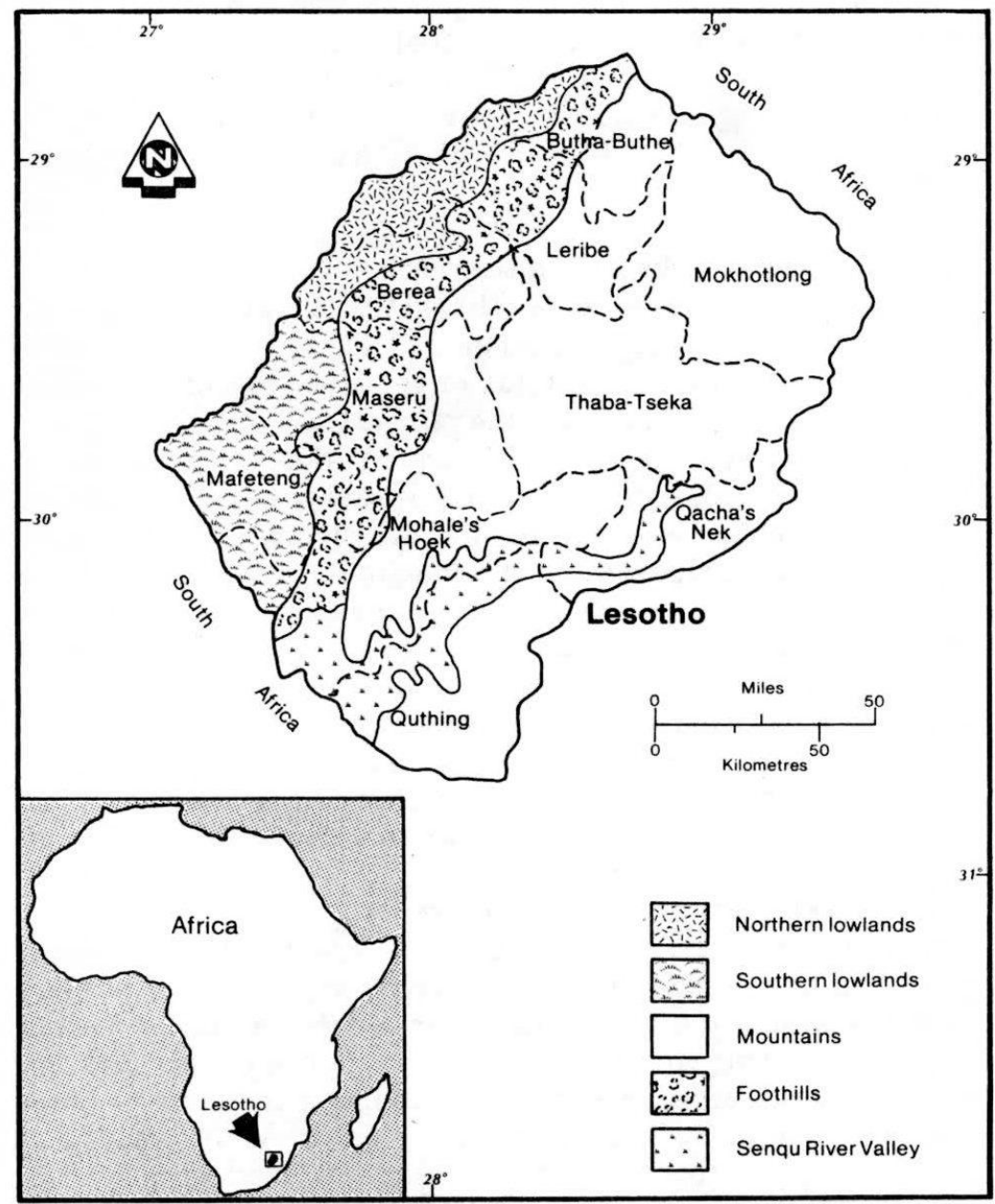

Source: Swallow et. al., 1987. 
still be found in large portions of the cultivated land.

Very little has been done to quantify erosion in Lesotho, although Chakela (1981) and Chakela, Lunden and Strömquist (1986) have carried out some research into this question. Even less has been done to evaluate the impact of erosion on crop yield and thereby on farm income and national agricultural income. Some (unconvincing) extrapolations from other countries are the basis of available estimates (see Ministry of Agriculture and Marketing, 1981).

The FISC project and the Maphutseng area

The FISC (Farm Improvement with Soil Conservation) project was initiated by the Swedish International Development Authority (SIDA) in 1981. After two rounds of consultant studies (Wenner, 1982; CPDO, 1982; Palin, 1983), the project was launched in 1985.

The first three-year phase of FISC has a budget of approximately 2 million maloti (M) (US\$1 million). It is said to be a pilot phase of a nationwide effort to combat erosion, which gives it further significance and has attracted more attention to the project than its size would seem to justify.

Contributing to the attention given to the project are its use of labour-intensive and simple technical methods, and its emphasis on popular participation and consultation at all stages. Farmers working on physical conservation structures on their "own" land are given incentive payments in the form of improved seed and fertilizer. People working on communal land are given cash payments.

The project operates through the district agricultural office in the district capital. Thus, it is designed to support the government's general efforts in extending its conservation message to farmers. There is also an important training component, in that both expatriates (one project manager/soil conservation engineer and one horticulturalist) are supposed to have counterparts. This ambition has been only partially fulfilled. There is also some training of extension agents, conservation assistants and "lead farmers".

The first pilot project area lies in the Maphutseng watershed about $5 \mathrm{~km}$ south of the district capital. This area comprises about 1,200 ha and contains five villages with a total population of about 870 people (not including some 75 long-term migrant workers). About half the households have landholdings, the usual size being 2 to 3 ha (DLUP, 1986). About half the households do not own any livestock, and only 12 per cent of households have more than four 
cattle (that is, the number needed for ploughing). The largest cattle owner has sixteen cattle (Dahlberg, 1987a).

The project has encouraged the establishment of a Village Conservation Committee (VCC) in Maphutseng. It is hoped that the VCC will assume a leading role in maintaining conservation works. Dahlberg (1987b) has made an extensive sociological study of local institutions in the area. Her findings cast severe doubts on the VCC's capability to assume this role, at least in the short run.

Land use in the Maphutseng area during the summer of 1985-6 is shown in Table 11.1. Note that most of the land is used for grazing. This includes a large percentage of marginal land, often intersected by dongas (gullies). In fact, the area used for grazing is rather nebulous, since some adjacent open areas belonging to other villagers are used during part of the year, and similar in-grazing by other villages occurs. In addition, cultivated land is opened for grazing between harvest and planting. Maize and sorghum take up together almost all of the actively cropped land. Winter cropping in the area is very limited; at most, half of the fallow land is taken up by wheat in the winter time.

Table 11.1: Summer land use in the Maphutseng area, 1985-6

Type of use

Area (ha)

Cultivated

area (\%)

Total area (\%)

$\begin{array}{lrrr}\text { Grazing } & 652 & - & 56 \\ \text { Maize } & 230 & 44 & 20 \\ \text { Fallow } & 116 & 22 & 10 \\ \text { Sorghum } & 108 & 21 & 9 \\ \text { Beans } & 14 & 3 & 1 \\ \text { Maize/beans } & 6 & 1 & 0.5 \\ \text { Eragrostis grass } & 6 & 2 & 0.5 \\ \text { Other } & 40 & 8 & 3 \\ \text { Total } & 1,172 & 100 & 100\end{array}$

Source: Institute of Land Use Planning, 1986. 
The project has rehabilitated old terrace structures, constructed new ones and added stone-paved waterways and cut-off drains. It has introduced improved maize, sorghum and grass seed, planted 9,000 pine seedlings and introduced rotational grazing on the higher mountainside where previously uncontrolled grazing was devastating the rangeland.

\section{The economic analysis}

\section{Choice of evaluation criteria}

This study is an ongoing evaluation and not an $e x$-ante appraisal. Its aim is not to optimize a given budget, but rather to estimate what surplus (if any) society could be expected to gain over the lifetime of the project's impact. The preferred criterion in such situations is the net present value (NPV).

Furthermore, it is useful to compare the yield of resources invested in the FISC project with alternative investment opportunities. This is done implicitly by using a discount rate based on the opportunity cost of capital, but it is also done more explicitly by calculating the internal rate of return (IRR). (See Chapter 6 for a review of these criteria.)

\section{Quantification of costs}

Not all costs will be readily assessable in monetary terms (for example, loss of soil from new, ungrassed terraces; "loss" of land to structures; and increased maintenance costs for roads due to greater use). However, these items are not likely to alter the calculations significantly, and no effort has been made to quantify them.

Monetary cost data were taken from project accounts and complemented by Swedforest data for costs paid by the donor agency (SIDA) directly to the consultant company. The cost data need to be adjusted to reflect that the project (1) is active in several areas and will gradually shift its emphasis from the Maphutseng area and (2) has made investments in buildings, vehicles and farm equipment which may have a residual value and which should be credited to the pilot project.

To adjust for point (1), it is assumed that 70 per cent of the costs in 1985 fell on the Maphutseng area. Corresponding figures for 1986 and $1987-90$ are 40 per cent and 20 per cent, respectively (FISC Team Leader, personal communication). The degree of resource utilization each year also affects the allocation of investments in buildings, vehicles and equipment, as explained further in the 
annex to this chapter (page 280).

To account for point (2), buildings have been written off at 3 per cent per year and vehicles at 33.3 per cent per year. This corresponds to rates used by the Central Bank of Lesotho (Mellander, 1987). Farm equipment has been written off at 20 per cent per year, providing a residual value to be credited to the Maphutseng project in 1991.

A further adjustment is that the nursery costs have been completely omitted because of considerations regarding the benefit estimation on this point (this is discussed later).

Tariffs, subsidies and shadow pricing will affect economic costs. Finally, current costs must be converted to constant (1986) prices.

All these calculations are discussed in detail in the annex. The final cost entries are shown in Table 11.2.

Table 11.2: Adjusted economic project costs for the Maphutseng area (000 maloti; constant 1986 prices)

1985
1986
1987
1988
1989
1990
Source: calculations shown in the annex.

Quantification of benefits
The following points should be made about the physical
characteristics of the various benefit categories:
Crop benefits. The physical quantity of this benefit depends on:
(1) the difference in yield between the with- and without-
project scenarios;
(2) the base level of average yield;
(3) the area affected by the project's improvements;
(4) each crop's share of this land; and
(5) to what extent project recommendations will be adopted
over time.


An illustration of calculations for $1985-6$ is provided here and shown in Table 11.3. The following notation is used:

$d Y=$ relative increase in yield (1985-6);

$A Y=$ average yield for the crop in the district (data for thirteen years are available);

$A W=$ area with the project recommended inputs package;

$C S=$ the crop's share of the cultivated project area;

$d Q=$ total increase in crop yield in the project area; and

$d Q=d Y \times A Y \times A W \times C S$.

Table 11.3: Physical crop data (1985 - 6)

$$
d Y(\%) \quad A Y(\mathrm{~kg} / \mathrm{ha}) \quad A W(\mathrm{ha}) \quad C S(\%) \quad d Q(\mathrm{t})
$$

\begin{tabular}{llllll}
\hline Maize & 81 & 694 & 254 & 68 & 97 \\
Sorghum & 95 & 816 & 254 & 32 & 63
\end{tabular}

The value of $d Y$ is from random crop samples taken in 1985-6 in the Maphutseng area (Bojö, Pettersson and Shone, 1987), and the $A Y$ from the Bureau of Statistics. The Figure for $A W$ has been derived from project statistics collected by Idris Mohammednur in May 1987. Crop shares are weighted to split the improved cropland between maize and sorghum in accordance with relative coverage as reflected in Table 11.1. Again, it should be emphasized that crop data reflect only one season.

What about the long-term picture? A major problem is that crop samples today can only give an indication of present-day differences in yield, whereas a dynamic scenario covering the entire period of analysis is needed. Lacking sufficient data, it is necessary to assume certain trends based on crop samples, local experts and literature studies. The assumptions made in this study are as follows.

First in the "with-project" scenario, we assume a constant yield above the historical average of the relative magnitude measured in our crop samples. In reality, a gradual improvement in yields is likely to take place as the effects of better management in all its 
aspects accumulate. Some farmers.are expected to "drop out" and new ones to join at a later stage. We will ignore this and assume a linear pattern, applied to a constant area from 1986-7 onwards.

Second, in the "without-project" scenario, yields are expected to decline gradually due to erosion, poor management and continuous monocropping. Eventually a point is reached where agriculture becomes financially meaningless even though yields are not zero. This point is not estimated here, because it depends so much on (1) the farmer's demand on return to labour and (2) subjective assessment of crop-level probability. A smooth declining function of 2 per cent per year will be assumed, but this will be subjected to sensitivity testing, since there is much uncertainty about this figure. These stylized assumptions are illustrated in Figure 11.2.

Figure 11.2: Two stylized yield scenarios

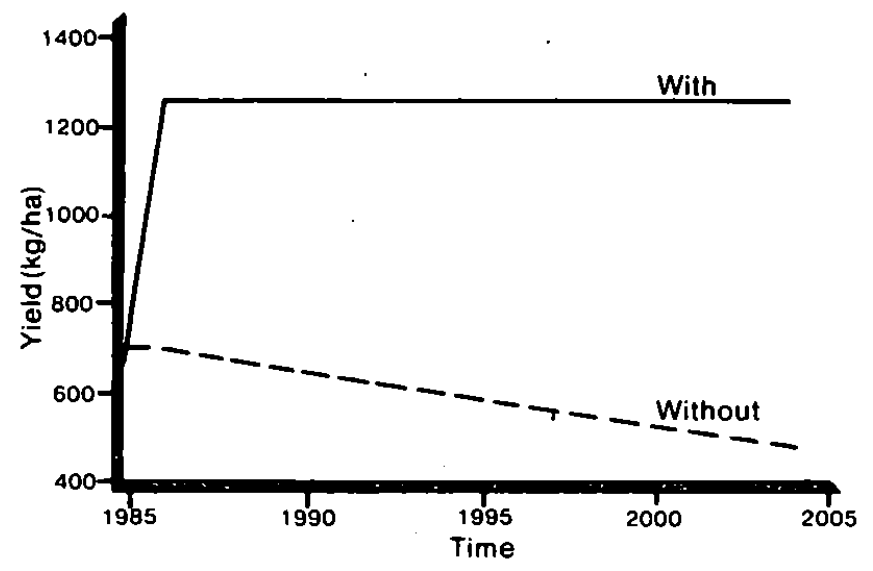

There is one further, very important qualification to make. It should not be automatically assumed that the entire difference in yield between the "with-" and "without-project" scenarios is caused by the project. Some farmers may have adopted the use of fertilizer and hybrid seed even without the project. It is necessary clearly to differentiate between (1) the effects of the use of fertilizer, hybrid seed and conservation structures and (2) the effect of the project on the use of such inputs. The first factor can be estimated by the crop sampling procedures used. The second factor is still uncertain.

Since no pre-project data on use of fertilizer and improved seed 
were available, one can only compare today's situation with a control area. One study (Yaxley, 1987) indicated that there is no significant difference in the number of farmers who have adopted improved seed in the Maphutseng as against the control area. However, there are no data on the exact seed types or quantities used. As for fertilizer, the comparison is blurred by the fact that many farmers in Maphutseng saved some of their "project" fertilizer from the first year. It is uncertain how many will continue to buy fertilizer with their own money.

A minimum alternative is to assume that there has been no change in adoption rates of agricultural inputs because of the project. A maximum alternative is to assume that the entire difference between the two scenarios has come about because of FISC. For the base case, we have chosen to attribute 50 per cent of the use of fertilizer and improved seed to the FISC project. The other alternatives will be examined during the sensitivity analysis.

It is fairly certain that no physical conservation works would be undertaken without the project's presence; traditionally, no maintenance work has been done in Maphutseng (B. Rydgren, personal communication).

Table 11.4 shows how the gross benefits from increased crop yields are calculated. $Q(W O)$ represents the expected maize yield without the project, based on average historical yield in the district and a 2 per cent annual decline from the base year 1986 . The entry for 1985 is nominal, only showing that there was no difference in the yield for the two scenarios that season. $Q(W)$ is the with-project level based on relative increase measured in crop samples (Bojö, Pettersson and Shone, 1987) and is equal to average yield (694) times relative increase $(1.81)=1,256$. The next column, $d Q$, is the difference between the two columns.

The "area" is the hectarage under improved maize management. Data from extensive field interviews by Idris Mohammednur in 1987 show that the total "with-project" area in Maphutseng was 96 ha in 1985 (it did not, however, affect that year's harvest and is therefore entered as 0), 254 ha in 1986 and 244 ha in 1987. Thereafter, stabilization is assumed. The "with-project" area is split between maize and sorghum in proportion to existing land distribution (see Table 11.1) - that is, 68 per cent and 32 per cent, respectively. The area is split in half in the base case to allow for the 50 per cent degree of project impact. This gives 0,86 and 83 ha for the respective time periods for maize.

The next column in Table $11.4(T d Q)$ is the resulting product in 
Table 11.4: Differential crop yield and gross crop benefits (maize)

\begin{tabular}{cccccccc}
\hline Year & $\begin{array}{c}Q(W O) \\
(\mathrm{kg} / \mathrm{ha})\end{array}$ & $\begin{array}{c}Q(W) \\
(\mathrm{kg} / \mathrm{ha})\end{array}$ & $\begin{array}{c}d Q \\
(\mathrm{~kg} / \mathrm{ha})\end{array}$ & $\begin{array}{c}\text { Area } \\
(\mathrm{ha})\end{array}$ & $\begin{array}{c}T d Q \\
(t)\end{array}$ & $\begin{array}{c}\text { Price } \\
(\mathrm{M} / \mathrm{t})\end{array}$ & $\begin{array}{c}\text { Gross benefits } \\
(\mathrm{M})\end{array}$ \\
\hline 1985 & 694 & 694 & 0 & 0 & 0 & 388 & 0 \\
1986 & 694 & 1,256 & 562 & 86 & 48 & 380 & 18,366 \\
1987 & 680 & 1,256 & 576 & 83 & 48 & 372 & 17,800 \\
1988 & 667 & 1,256 & 589 & 83 & 49 & 365 & 17,856 \\
1989 & 653 & 1,256 & 603 & 83 & 50 & 358 & 17,895 \\
1990 & 640 & 1,256 & 616 & 83 & 51 & 350 & 17,917 \\
1991 & 627 & 1,256 & 629 & 83 & 52 & 343 & 17,923 \\
1992 & 615 & 1,256 & 641 & 83 & 53 & 337 & 17,915 \\
1993 & 602 & 1,256 & 654 & 83 & 54 & 330 & 17,894 \\
1994 & 590 & 1,256 & 666 & 83 & 55 & 323 & 17,859 \\
1995 & 579 & 1,256 & 677 & 83 & 56 & 317 & 17,813 \\
1996 & 567 & 1,256 & 689 & 83 & 57 & 310 & 17,755 \\
1997 & 556 & 1,256 & 700 & 83 & 58 & 304 & 17,686 \\
1998 & 545 & 1,256 & 711 & 83 & 59 & 298 & 17,607 \\
1999 & 534 & 1,256 & 722 & 83 & 60 & 292 & 17,519 \\
2000 & 523 & 1,256 & 733 & 83 & 61 & 286 & 17,423 \\
2001 & 513 & 1,256 & 743 & 83 & 62 & 281 & 17,318 \\
2002 & 502 & 1,256 & 754 & 83 & 63 & 275 & 17,206 \\
2003 & 492 & 1,256 & 764 & 83 & 63 & 270 & 17,086 \\
2004 & 482 & 1,256 & 774 & 83 & 64 & 264 & 16,960 \\
& & & & & & & \\
\hline
\end{tabular}

terms of increased yields per year. This is multiplied by the sliding price column ( -2 per cent per year) to arrive at gross benefit for maize per year. (Prices are discuissed in a later section.) Note that increased variable costs have to be deducted from gross benefits to arrive at net benefits.

Table 11.5 shows the calculation of crop benefits for those parts of the Maphutseng area where farmers are assumed to use fertilizer and improved seed on their own initiative (that is, regardless of the project), but application of conservation methods is due to the project. This results in a gradual decline, $Q(W O)$ but from the higher $Q(W)$ level.

Fodder benefits. The area for fodder (Eragrostis) production in 1986 was only 6 ha. However, it is assumed that this area will expand at $3 \mathrm{ha} / \mathrm{yr}$ until it reaches a maximum of $24 \mathrm{ha}$ in 1994. The average yield is estimated to be 2 t/ha. 
Table 11.5: Benefits from conservation works only (maize)

\begin{tabular}{|c|c|c|c|c|c|c|c|}
\hline Year & $\begin{array}{l}\text { Q(WO) } \\
(\mathrm{kg} / \mathrm{ha})\end{array}$ & $\begin{array}{c}Q(W) \\
(\mathrm{kg} / \mathrm{ha})\end{array}$ & $\begin{array}{c}d Q \\
(\mathrm{~kg} / \mathrm{ha})\end{array}$ & $\begin{array}{l}\text { Area } \\
\text { (ha) }\end{array}$ & $\begin{array}{c}T d Q \\
(t)\end{array}$ & $\begin{array}{l}\text { Price } \\
(\mathrm{M} / \mathrm{t})\end{array}$ & $\begin{array}{c}\text { Gross benefits } \\
\text { (M) }\end{array}$ \\
\hline 1985 & 1,256 & 1,256 & 0 & 0 & 0 & 388 & 0 \\
\hline 1986 & 1,231 & 1,256 & 25 & 86 & 2 & 380 & 821 \\
\hline 1987 & 1,206 & 1,256 & 50 & 83 & 4 & 372 & 1,537 \\
\hline $\begin{array}{l}1988 \\
1989\end{array}$ & $\begin{array}{l}1,182 \\
1,158\end{array}$ & $\begin{array}{l}1,256 \\
1,256\end{array}$ & $\begin{array}{l}74 \\
98\end{array}$ & $\begin{array}{l}83 \\
83\end{array}$ & $\begin{array}{l}6 \\
8\end{array}$ & $\begin{array}{l}365 \\
358\end{array}$ & $\begin{array}{l}2,237 \\
2,894\end{array}$ \\
\hline 1990 & 1,135 & 1,256 & 121 & 83 & 10 & 350 & 3,511 \\
\hline 1991 & 1,113 & 1,256 & 143 & 83 & 12 & 343 & 4,088 \\
\hline $\begin{array}{l}1992 \\
1993\end{array}$ & $\begin{array}{l}1,090 \\
1,069\end{array}$ & $\begin{array}{l}1,256 \\
1,256\end{array}$ & $\begin{array}{l}166 \\
187\end{array}$ & $\begin{array}{l}83 \\
83\end{array}$ & $\begin{array}{l}14 \\
16\end{array}$ & $\begin{array}{l}337 \\
330\end{array}$ & $\begin{array}{l}4,628 \\
5,132\end{array}$ \\
\hline 1994 & 1,047 & 1,256 & 209 & 83 & 17 & 323 & 5,603 \\
\hline 1995 & 1,026 & 1,256 & 230 & 83 & 19 & 317 & 6,042 \\
\hline $\begin{array}{l}1996 \\
1997\end{array}$ & $\begin{array}{r}1,006 \\
986\end{array}$ & $\begin{array}{l}1,256 \\
1,256\end{array}$ & $\begin{array}{l}250 \\
270\end{array}$ & $\begin{array}{l}83 \\
83\end{array}$ & $\begin{array}{l}21 \\
22\end{array}$ & $\begin{array}{l}310 \\
304\end{array}$ & $\begin{array}{l}6,450 \\
6,829\end{array}$ \\
\hline 1998 & 966 & 1,256 & 290 & 83 & 24 & 298 & 7,180 \\
\hline 1999 & 947 & 1,256 & 309 & 83 & 26 & 292 & 7,505 \\
\hline 2000 & 928 & 1,256 & 328 & 83 & 27 & 286 & $\begin{array}{l}7,805 \\
8081\end{array}$ \\
\hline $\begin{array}{l}2001 \\
2002\end{array}$ & $\begin{array}{l}909 \\
891\end{array}$ & $\begin{array}{l}1,256 \\
1,256\end{array}$ & $\begin{array}{l}347 \\
365\end{array}$ & $\begin{array}{l}83 \\
83\end{array}$ & $\begin{array}{l}29 \\
30\end{array}$ & $\begin{array}{l}281 \\
275\end{array}$ & $\begin{array}{l}8,081 \\
8,335\end{array}$ \\
\hline 2003 & 873 & 1,256 & 383 & 83 & 32 & 270 & 8,566 \\
\hline 2004 & 856 & 1,256 & 400 & 83 & 33 & 264 & 8,778 \\
\hline
\end{tabular}

There is an opportunity cost to fodder growing, as cropland will then diminish. Since the land used for fodder production is of poor quality, it is estimated that crop yields on these lands are only about 75 per cent of the average yield for the area (Team Leader, personal communication). This translates into yields of about $521 \mathrm{~kg} / \mathrm{ha}$ if maize is the crop that would have been grown. This opportunity cost is charged against the income from growing fodder.

Afforestation benefits. Ten hectares were planted with 7,000 pine seedlings (Pinus radiata) in 1986. Of these, approximately 50 per cent died, and another 2,000 seedlings were planted in a second round. Local forestry experts have estimated the probable survival rate until maturity at about 50 per cent for this type of tree. Assuming that the first round of planting had an unusually high mortality rate in the early stages due to a temporary drought, it is assumed 
that 3,000 of the first planting will survive along with 50 per cent of the second planting, resulting in a total of 4,000 plants at fuelwood cutting age.

Harvesting is assumed to take place in year 12, at which time each tree is assumed to have an average volume of $0.15 \mathrm{~m}^{3}$. The total harvestable volume is therefore $600 \mathrm{~m}^{3}$ (M. May, Lesotho Woodlot Project, personal communication). In reality, the trees are likely to be harvested both before and after year 12, but more complicated modelling would not significantly affect the results.

The opportunity cost of lost grazing areas is insignificant in this case, because villagers can cut and carry grass while trees mature. When the trees are large enough to be safe from livestock, animals will be allowed to graze in the area. The spacing of the trees is very wide to minimize interference with range productivity.

Fruit trees and vegetables. The establishment of a nursery is a major component of the project. However, no significant distribution of seedlings to the Maphutseng area has taken place to date. The nursery is an investment with a very long gestation period. Lacking quantitative information about demand for fruit trees and vegetable plants or seeds, this activity will not be considered further in this analysis. This implies no value judgement as to the profitability of the nursery.

Other potential benefits. The extension agent, conservation assistant, lead farmers and members of village committees involved in project-related activities have received or will receive training. The first two of these will also be active in other areas outside Maphutseng. Training should be noted as an intangible benefit.

The introduction of improved communal management of grazing land has potential spin-off effects for areas not directly involved in the project. There is no basis for quantification at this stage, and these effects are merely noted as a potential intangible benefit.

There are no dams for hydropower and/or irrigation in the area, but some small dams are used for watering livestock. Their lifetime will be extended because of less siltation. Irrigation potential will be developed by the project, and communal gardens are encouraged, although there are currently no significant gardening activities in the Maphutseng area. Improved water quality will have an aesthetic value but will not affect washing facilities or drinking water.

Secondary community benefits (multiplier effects) are likely to arise as the level of consumption is raised through the increased 
agricultural incomes. Theoretically, a cash flow of about M20,000 in Maphutseng could lead to about sixteen person-years of employment, based on M5 per day and 250 working days per year. Lesotho, however, has an extremely import-dependent economy, and very little of this will be retained as local income and employment. There is almost no absorption capacity at all in Maphutseng for this demand. There is some in the district capital, Mohale's Hoek, but the import leakage to South Africa is rather immediate, and therefore multiplier effects will not be included in the study.

This review of potential benefits has found some of them significant, others less important. The main benefits will now have to be priced to arrive at a comparison between total costs and benefits for the project.

\section{Valuation of costs and benefits in economic prices}

Market prices are not always good reflections of social values; it is often necessary to adjust for "distortions" (see Chapter 6). On the cost side, shadow pricing of labour and agricultural inputs will be considered. On the benefit side, output prices and foreign exchange will be considered.

Price trends. It is standard practice in benefit - cost analysis (BCA) to use constant prices, even for long periods. There is nothing wrong about not accounting for inflation in this case - the calculations are made in real, not nominal, prices. However, it may be simplistic to assume that relative real prices will remain the same for, say, twenty years ahead.

The bulk of project inputs are confined to a short period at the beginning of the project. The best forecasts available are the budget projections that FISC management has made, after adjustment for the inflationary assumptions behind them. Project outputs in this case are subject to price changes over a much longer period, and it is therefore necessary to pay some attention to long-term price trends. In this study, it implies a look at how the main project outputs - maize and sorghum - are likely to be priced over time. This point will be discussed further shortly.

Labour costs. In spite of considerable and chronic imperfections in the Lesotho labour market, there are no official guidelines as to shadow pricing of labour. Attempts to establish such guidelines have been made (Taylor, 1985; Modiani, 1986) but have received no official recognition. The result is confusion and inconsistency between different BCAs, with shadow wage rates ranging from 0 to 100 per cent of the current wage rate. The best approach in this 
situation is to apply a rate that appears reasonable depending on local circumstances.

Skilled personnel involved in the project operate in an international, competitive market. The semi-skilled personnel have access to the large South African labour market which often drains Lesotho of valuable skills. These groups, including project management, extension agent, conservation assistant, secretary, driver and storekeeper, will be priced at their financial wage.

For the unskilled personnel, it is necessary to distinguish between payments in cash and in kind. Cash payments will be regarded as a pure transfer from the project to this group of labourers. This is based on subjective data of the local labour market that suggests a lack of alternative employment.

The project has never had any problems in recruiting unskilled labour at the rate offered. The in-kind payment for a day's work on an individual's own land is roughly equal to M2.5. For work on communal land, the rate is M2.5 in cash per "task". Normally one person can finish a task in one day, usually moving $2.5 \mathrm{~m}^{3}$ of earth. This is significantly lower than the official minimum wage of M5.09 per day (Taylor, 1985).

The project management has carefully adjusted communal activities so as not to interfere with own-farm activities. Thus the opportunity cost of communal labour has been minimized.

Setting a zero wage rate does not imply that leisure lost would be valueless, but that it is sufficiently close to zero to make that approximation in this case.

Payments in kind to unskilled labour will be costed at their opportunity cost.

Material input costs. The FISC project is so small that only marginal extra quantities of inputs will have to be produced. Thus, the marginal cost of this production is the true opportunity cost. This will be approximated with the market price (without tax).

The parastatal Co-op Lesotho dominates the market for agricultural inputs in Lesotho (for example, it holds 90 per cent of the fertilizer market). Prices to consumers for fertilizer contain a subsidy of 30 per cent. This will be added to the market price to arrive at the economic cost. The lower market price will be retained in the financial calculation.

Improved seed (PNR 473 for maize and PNR 8311 for sorghum) has been bought on the open market at $M 2.40 / 20 \mathrm{~kg}$ and M2.25/8 $\mathrm{kg}$, respectively, excluding tax, since the project is tax exempt. Likewise, agricultural tools have been bought on the open market 
without tax. Thus, for these items, no adjustments are necessary for social pricing.

Output prices. In the economic analysis, the relevant prices for increased output of crops are the economic value (to the economy) rather than the financial value (to the farmer). (The latter will be discussed in the section on financial analysis.) The economic value to Lesotho of one extra tonne of maize is the import cost saved. This includes the import price (CIF = cost-insurance-freight) plus landing at port, handling fees, transport to Lesotho and distribution in Lesotho. This has been calculated as M380 per tonne of maize in 1986 prices. For sorghum, the corresponding figure is M370 per tonne (IFAD, 1986).

The main output of the project is maize, a commodity which has undergone a substantial real price decrease in the past twenty-five years. An analysis of the price over time reveals an average downward trend of 2.3 per cent per year. Declining real world market prices will also affect the economic price for Lesotho. (The financial price may be affected by tariffs, quotas or taxes and is another matter.) Therefore, we assume a downward trend in the real price of maize of 2 per cent per year in the base case. The effect of this assumption will be tested by sensitivity analysis. Sorghum, being an imperfect substitute for maize, will be handled in the same way (that is, a 2 per cent annual decline).

Whereas increased maize and sorghum production in Maphutseng ultimately replaces imports, fodder is bought and sold only in the local market, and increased production should have a positive effect on local cattle. A fodder price was obtained from the project management: M4.50/20 kg bag for Eragrostis. Constant real prices will be assumed throughout for this commodity.

The economic value of fuelwood is another issue. It is reasonable to assume that locally produced fuelwood will, to some extent, replace alternative sources of energy: brushwood, dung and crop residues. There is not much replacement of imported coal and fuelwood in this particular area, so those fuels have been left out of the calculations.

The Central Planning and Development Office (CPDO) has recently produced estimates of substitution values for fuelwood. Table 11.6 shows how these calculations are performed. Consumption shares are based on national averages (CPDO, 1987) scaled up to 100 per cent for the three types of fuel considered here. One cubic metre of fuelwood is assumed to yield 8,800 MJ. Multiplying this value with the share of consumption gives the column 
containing fuelwood equivalents ("Equiv.") in MJ. This value is then transformed to weights by use of data on calorific values per fuel type: brushwood 16.0 , dung 12.9 and crop residues $14.0 \mathrm{MJ} / \mathrm{kg}$ (Energy Department, Lesotho). The economic costs per kilogram are from CPDO (1987). The last column is simply the substitute's weighted value per fuel type per cubic metre based on energy values. The total substitution value is M28.71. Constant real prices will be assumed in this case.

Table 11.6: Economic value of fuelwood (maloti/ $\mathbf{m}^{3}$ )

\begin{tabular}{lcccccc}
\hline Fuel & $\begin{array}{c}(1) \\
\%\end{array}$ & $\begin{array}{c}(2) \\
\mathrm{MJ} / \mathrm{m}^{3}\end{array}$ & $\begin{array}{c}(3) \\
\mathrm{Mj} / \mathrm{kg}\end{array}$ & $\begin{array}{c}(4) \\
\mathrm{kg} / \mathrm{m}^{3}\end{array}$ & $\begin{array}{c}(5) \\
\mathrm{M} / \mathrm{kg}\end{array}$ & $\begin{array}{c}(6) \\
\mathrm{M} / \mathrm{m}^{3}\end{array}$ \\
\hline Brushwood & 70 & 6,160 & 16.0 & 385 & 0.03 & 11.55 \\
$\begin{array}{l}\text { Dung } \\
\text { Crop }\end{array}$ & 24 & 2,112 & 12.9 & 164 & 0.10 & 16.40 \\
$\quad$ residues & 6 & 528 & 14.0 & 38 & 0.02 & 0.76
\end{tabular}

Total

1008,800

28.71

Source: Author's calculations, based on CPDO, 1987.

Note: Consumption shares are based on national averages scaled up to 100 per cent for the three types of fuel relevant here. One $\mathrm{m}^{3}$ of fuelwood is assumed to provide energy amounting to $8,800 \mathrm{MJ}$. Column (2) is derived by multiplying this with (1). Conversion to $\mathrm{kg}$ is done by dividing (2) by (3), which gives (4). Multiplying this by the appropriate price per $\mathrm{kg}$ (5) gives us (6), which is the value in maloti per $\mathrm{m}^{3}$ we are looking for.

Foreign exchange. Most developing countries have foreign currency markets characterized by severe imbalances and heavy government intervention. The existence of a black market for foreign currency is a clear sign that the consumer's willingness to pay differs from the official price. However, Lesotho does not have a currency black market.

The loti (pl. maloti) is fixed on a par with the internationally convertible rand of South Africa. The rand, however, is tied to some restrictions. There is also a two-tier market in that a financial rand is available for foreign investors at a discount, but all others have to buy the commercial rand. It could therefore be argued that the 
commercial rand is overvalued, and by implication therefore the loti is as well. On the other hand, it could be argued that the rand/ loti is undervalued for well-known political reasons. This is an area where the individual analyst should be careful in making assumptions. One should be able to get some guidance from financial authorities in the country (see the following paragraphs).

Trade barriers, usually tariffs and quotas, can also affect the relation between domestic market clearing prices and import prices. The existence of trade barriers puts a restraint on the demand for foreign goods (exchange) and therefore contributes to a lower price for foreign exchange than would be the case in a free market.

There are substantial trade barriers around the Southern African Customs Union (SACU), of which Lesotho, South Africa, Botswana and Swaziland are members. The price-raising effect of the SACU for Lesotho has been estimated to be 23 per cent (Kizilyalli, 1982).

Lesotho receives import duty not directly on its own imports, but through a complex revenue-sharing formula. It has been debated whether or not the actual payments compensate for the priceraising effect (as well as other negative aspects of the Customs Union). Kizilyalli finds that the actual compensation rate was about 17 to 22 per cent in $1974-81$.

In his study of fuelwood production in Lesotho, Matsaba (1985) calculates a standard conversion factor for foreign exchange as an average ratio of border prices to domestic prices for imports and exports. It appears that domestic market prices were derived by using compensation payments to Lesotho, rather than the actual price-raising effect created by the Customs Union. As noted, the match is not perfect. The result is a shadow price of R0.867 = M1.00.

Economists doing BCAs are sometimes asked to turn to the central planning office when in doubt (Gittinger, 1982). In the case of Lesotho there does not appear to be an official guideline, but a recent fuelwood programme appraisal produced by the Central Planning and Development Office (CPDO) uses a conversion factor of 0.86 on imports to adjust for "the average rate of duty on imports" (CPDO, 1987, p.11).

In summary, we are left with conflicting evidence concerning Lesotho's currency situation. If we were to adjust for a shadow price for foreign exchange, this would affect all items that enter, directly or indirectly, into international trade (that is, everything except labour inputs). In this analysis, the following approach will 
be taken:

(1) Imports from outside the SACU contain a tariff element that should be eliminated in the economic calculation. In this case, however, this element is so small that no adjustment will be made.

(2) Imports to Lesotho from other countries within the SACU contain an implicit tariff element (that is, producers have been able to demand a higher price because of the tariff protection). For nonLesotho producers, this producer's surplus does not benefit Lesotho and does not warrant any adjustment. However, there is a transfer of income to Lesotho based on the revenue-sharing formula of about 20 per cent of the import value. We therefore adjust the value of imported components by a factor of 0.80 when going from financial to economic prices.

(3) Apart from the adjustment mentioned, no general shadow price is assigned to the loti as against the rand or other currencies. This is consistent with other studies such as IFAD (1986). It implies that project output will be valued at import parity price including allowance for domestic transportation.

\section{Discounting}

Ideally, there should be a (reasonable) national discount rate available for consistent discounting in benefit - cost analyses carried out in Lesotho. However, there is none. Nor does the donor - SIDA have any guidelines as to the proper rate.

There is no domestic tradition of using BCA in Lesotho, and conservation projects are rarely organized to generate relevant empirical data (see, for example, Nobe and Seckler, 1979).

The largest project ever to be undertaken in Lesotho - the Highlands Water Project - was analysed using a 6 per cent discount rate. This was calculated as the real cost of borrowing and is not based on the opportunity-cost concept, because of the uniqueness and size of the project (LHC and OSC, 1986). A major road study (Louis Berger International Inc. and Lesotho Consulting Engineers (Pty) Ltd, 1986) used a 10 per cent rate based on the opinion of an economic adviser at the Central Planning and Development Office.

Interviews with banking officials point to the over-liquidity of the Lesotho banking system and the negative or low positive real interest rates charged to borrowers for many years. For the 1980s, the bank rate has averaged about 4.3 per cent. This implies that the opportunity cost of capital is low, perhaps about 5 per cent.

It may be thought that this issue can be avoided by simply using internal rates of return rather than NPVs. This is not correct. Both 
measures have their particular use, and an IRR must be interpreted in light of some reference point: the "acceptable" rate of return (or cut-off point).

In summary:

- There is a lack of clear policy from the recipient government and donor alike as to what discount rate is acceptable.

- There is very little empirical evidence of actual rates of return from projects in Lesotho.

- A low rate, such as 5 per cent, would appear sufficient to meet demands on capital placed elsewhere in the economy.

\section{Time horizon}

The FISC project may have long-lasting effects on the agricultural production in Maphutseng. The length of these effects will depend on factors such as:

- success in raising the production of maize, sorghum, fodder, fuelwood, fruit and vegetables; and

- how the local institutions manage to shoulder the project's role once the project team has left.

The intention is to monitor developments over the years, but, as of today, empirical evidence is scanty.

Given the dismal record of conservation maintenance in Lesotho, it is difficult to believe in a sudden turn-around at this particular stage. The physical structures installed have an expected effective lifetime of about 10 years without any maintenance. However, it is reasonable to assume that the project will be extended for at least another 10 years, and therefore some support (at additional cost) could be forthcoming should local initiative fail.

The further the time horizon is extended into the future, the less weight is given to additional costs and benefits if any positive discount rate is used. For example, at a 5 per cent discount rate, one US dollar received in 20 years is worth only 38 cents today. The corresponding figures for 30 and 50 years are 23 and 9 cents, respectively. Obviously, an extension beyond 50 years will have very little bearing on the final net present value result in this case.

It can be noted for comparison that other BCAs of conservation projects use time horizons of 10 to 50 years, with 20 years being rather common (Bojö, 1986a). A 20-year time horizon will be used 


\section{Table 11.7: Benefit summary (1986 maloti)}

\begin{tabular}{|c|c|c|c|c|c|c|c|c|}
\hline Year & Maize & Sorghum & Fodder & Fuel & Resid. & Cons.M & Cons.S & Sum \\
\hline 1985 & 0 & 0 & 0 & 0 & 0 & 0 & 0 & 0 \\
\hline 1986 & 18,366 & 11,757 & 2,700 & 0 & 0 & 821 & 483 & 34,127 \\
\hline 1987 & 17,800 & 11,190 & 4,050 & 0 & 0 & 1,537 & 891 & 35,469 \\
\hline 1988 & 17,856 & 11,188 & 5,400 & 0 & 0 & 2,237 & 1,297 & 37,978 \\
\hline 1989 & 17,895 & 11,177 & 6,750 & 0 & 0 & 2,894 & 1,677 & 40,394 \\
\hline 1990 & 17,917 & 11,158 & 8,100 & 0 & 0 & 3,511 & $2 ; 035$ & 42,720 \\
\hline 1991 & 17,923 & 11,131 & 9,450 & 0 & 23,006 & 4,088 & 2,369 & 67,968 \\
\hline 1992 & 17,915 & 11,097 & 10,800 & 0 & 0 & 4,628 & 2,682 & 47,123 \\
\hline 1993 & 17,894 & 11,056 & 10,800 & 0 & 0 & 5,132 & 2,974 & 47,857 \\
\hline 1994 & 17,859 & 11,009 & 10,800 & 0 & 0 & 5,603 & 3,247 & 48,519 \\
\hline 1995 & 17,813 & 10,956 & 10,800 & 0 & 0 & 6,042 & 3,501 & 49,112 \\
\hline 1996 & 17,755 & 10,897 & 10,800 & 0 & 0 & 6,450 & 3,738 & 49,640 \\
\hline 1997 & 17,686 & 10,834 & 10,800 & 0 & 0 & 6,829 & 3,958 & 50,106 \\
\hline 1998 & 17,607 & 10,765 & $-10,800$ & 17,400 & 0 & 7,180 & 4,161 & 67,914 \\
\hline 1999 & 17,519 & 10,692 & 10,800 & 0 & 0 & 7,505 & 4,350 & 50,866 \\
\hline 2000 & 17,423 & 10,614 & 10,800 & 0 & 0 & 7,805 & 4,523 & 51,165 \\
\hline 2001 & 17,318 & 10,533 & 10,800 & 0 & 0 & 8,081 & 4,683 & 51,415 \\
\hline 2002 & 17,206 & 10,448 & 10,800 & 0 & 0 & 8,335 & 4,830 & 51,619 \\
\hline 2003 & 17,086 & 10,360 & 10,800 & 0 & 0 & 8,566 & 4,965 & 51,778 \\
\hline 2004 & 16,960 & 10,269 & 10,800 & 0 & 0 & 8,778 & 5,087 & 51,895 \\
\hline
\end{tabular}

Note: This table shows benefits in terms of the increased production value of maize, sorghum, fodder and fuelwood. The next column shows the residual benefit of buildings. "Cons. M" signifies conservation benefits for maize, and "Cons. S" signifies those for sorghum.

in this case, and sensitivity analysis will be done using 10 and 50 years.

\section{Results}

Table 11.7 shows the breakdown of project benefits by category. Table 11.8 summarizes all the data and shows the yearly present value of net benefits. Overall, the NPV of the project is minus $\mathrm{M} 125,000$. This corresponds to an internal rate of return of approximately 1 per cent.

It has not been possible to quantify strictly all relevant variables. Remaining intangibles include:

- increased crop residue benefits suitable for animal feed;

- conservation benefits of up-slope tree planting; 
- training and demonstration benefits as spin-off effects into other areas;

- secondary benefits due to increased local purchasing power; - improved regional income distribution within Lesotho; and - increased employment and income in the Republic of South Africa (that may be considered a cost by the donor).

However, none of these intangibles is likely to affect seriously the overall outcome of the economic analysis.

\section{Table 11.8: Cost - benefit summary (1986 maloti)}

\begin{tabular}{rrrrrrr}
\hline Year & FISC & Inputs & Cropl. & Cost sum & Ben. sum & Net ben. \\
& & & & & & \\
\hline 1985 & 204,747 & 0 & 0 & 204,747 & 0 & $-204,747$ \\
1986 & 122,929 & 1,920 & 1,164 & 126,013 & 34,127 & $-91,886$ \\
1987 & 64,970 & 16,157 & 1,677 & 82,804 & 35,469 & $-\mathbf{4 7}, 335$ \\
1988 & 56,850 & 16,157 & 2,147 & 75,154 & 37,978 & $-37,176$ \\
1989 & 41,992 & 16,157 & 2,578 & 60,727 & 40,394 & $-20,333$ \\
1990 & 33,185 & 16,157 & 2,971 & 52,313 & 42,720 & $-9,593$ \\
1991 & 0 & 16,157 & 3,329 & 19,486 & 67,968 & 48,482 \\
1992 & 0 & 16,157 & 3,654 & 19,811 & 47,123 & 27,312 \\
1993 & 0 & 16,157 & 3,509 & 19,666 & 47,857 & 28.191 \\
1994 & 0 & 16,157 & 3,370 & 19.527 & 48,519 & 28,992 \\
1995 & 0 & 16,157 & 3,237 & 19,394 & 49,112 & 29,718 \\
1996 & 0 & 16,157 & 3,109 & 19,266 & 49,640 & 30,374 \\
1997 & 0 & 16,157 & 2,986 & 19,143 & 50,106 & 30,963 \\
1998 & 0 & 16,157 & 2,867 & 19,024 & 67,914 & 48,890 \\
1999 & 0 & 16,157 & 2,754 & 18,911 & 50,866 & 31,955 \\
2000 & 0 & 16,157 & 2,645 & 18,802 & 51,165 & 32,363 \\
2001 & 0 & 16,157 & 2,540 & 18,697 & 51,415 & 32,718 \\
2002 & 0 & 16,157 & 2,439 & 18,596 & 51,619 & 33,023 \\
2003 & 0 & 16,157 & 2,343 & 18,500 & 51,778 & 33,278 \\
2004 & 0 & 16,157 & 2,250 & 18,407 & 51,895 & 33,488 \\
& & & & & & \\
\hline
\end{tabular}

Note: The "FISC" column shows economically adjusted project costs. The next column shows economic input costs for the farmers in order to sustain the higher yields. The "Crop 1." column shows crops lost because of expanded fodder production. The next column is the sum of all the previous columns. The cost sum minus the benefit sum is the net benefit (last column).

Distributional effects

Distributional effects can be considered from both regional and individual perspectives. It is clear that distributional aspects have 
been a concern behind the location of the project. Among six reasons for this location, the following two are relevant here:

- "Agriculture in the south has been given less attention than in the north, where climate and soils are more favourable."

- "Incomes from family farms are even lower than in the north."

(Author's translation of SIDA, 1983 p.7)

The last statement is supported by the recently completed Household Budget Survey by the Bureau of Statistics. Provisional figures show that rural Mohale's Hoek district ranks eighth out of ten districts in terms of household income (cash and in-kind), with a mean income of M154, compared to the rural national average of M237 (Bureau of Statistics, 1987). As a result, increased rural incomes in Mohale's Hoek will contribute to the goal of a more even regional distribution. This is included as an intangible benefit.

There are also individual distributional effects. A project aimed only at landholding households would have left out the landless. However, this project (working through village institutions) has engaged many of the landless as labourers on communal land for cash payments. There is strong evidence that primarily women (about 80 to 85 per cent) have benefited from the labour opportunities (A. Bratt, personal communication). Thus the project has, to a large extent, reached a disadvantaged group.

The long-term inequality in land distribution is something the project cannot be expected to affect. The project has encouraged communal harvesting of hay in the afforested grazing area, under the guidance of the Village Conservation Committee, to be sold to animal owners. However, this scheme has generated considerable controversy and has not progressed; livestock owners object to "paying for something which is free". As noted earlier, about half of the Maphutseng households do not own any livestock at all and would therefore benefit from such a scheme. The handling of the so-called communal grazing land, which today actually benefits a relatively well-to-do minority, will be the real test of the project's distributional impacts.

\section{Uncertainty and sensitivity analysis}

Major uncertainties include yield patterns over time, FISC project impact, price trends over time, a suitable discount rate and the appropriate time horizon. Different assumptions on these issues will be tested here. Resulting changes in IRR and NPV are shown. 
Yield patterns. In the base case, the assumption was made that yields in the "without-project" situation would decline by 2 per cent per year as a result of continuous erosion. This assumption was tested by assuming a decline of only 0.5 per cent per year in one of the two "without-project" alternatives. The other extreme is to test the assumption of a 5 per cent annual decline. The resulting changes in NPV and IRR, shown in Table 11.9, indicate that, even at a 5 per cent annual decline, the NPV is still less than zero.

Table 11.9: Sensitivity for yield patterns

\begin{tabular}{crc}
\hline Decline $(\% / y r)$ & IRR $(\%)$ & NPV (M) at 5 \% discount \\
& & \\
\hline 0.5 & -3.2 & $-225,811$ \\
2.0 & 1.2 & $-124,615$ \\
5.0 & 4.5 & $-18,454$ \\
\hline
\end{tabular}

FISC project impact. In the base case, it was assumed that 50 per cent of the use of fertilizer and seed is a direct result of the project. This assumption is tested using 0 per cent as a minimum and 100 per cent as a maximum.

It should also be noted that in all cases there is a pure benefit from the conservation works. This has been accounted for by not including the benefits of increased yields from use of improved seed and fertilizer in any "with-project" area that is not fully

Table 11.10: Sensitivity of FISC project impact

\begin{tabular}{rrc}
\hline Impact factor (\%) & IRR $(\%)$ & NPV $(M)$ at $5 \%$ discount \\
\hline 0 & -4.2 & $-282,374$ \\
50 & 1.2 & $-124,615$ \\
100 & 3.1 & $-56,696$ \\
\hline
\end{tabular}


ascribed to the project. For those areas, only the sliding scale of erosion decline in yield ( -2 per cent per year) is applied.

The changes in IRR and NPV as a result of the different assumptions of project impact are shown in Table 11.10.

Price trends. The base case assumes that maize and sorghum prices would continue their decline according to the long-term trend (that is, about 2 per cent per year). This assumption is changed here to (1) constant real prices and (2) a price' increase of 2 per cent per year. The resulting changes in IRR and NPV are shown in Table 11.11. Note that, at a price increase of 2 per cent per year, the project shows a positive NPV.

Table 11.11: Sensitivity for price trends

Price change $(\% / y r) \quad \operatorname{IRR}(\%)$

NPV (M) at $5 \%$ discount

$\begin{array}{rrr}-2 & 1.2 & -124,615 \\ 0 & 3.6 & -53,151 \\ +2 & 5.9 & 36,025\end{array}$

Discount rates. In the base case a discount rate of 5 per cent was used to calculate the NPV of the project. This assumption is changed to (1) 0 per cent and (2) 10 per cent. The results are shown in Figure 11.3 and Table 11.12. Note that at a 0 per cent discount rate, the NPV is positive. (Of course, since the project has an IRR of 1 per cent, this result is not surprising.)

Table 11.12: Sensitivity to discount rates

Rate (\%) NPV (M)

$\begin{array}{rr}0 & 58,665 \\ 5 & -124,615 \\ 10 & -200,858\end{array}$


Figure 11.3: Different discount rates and NPVs

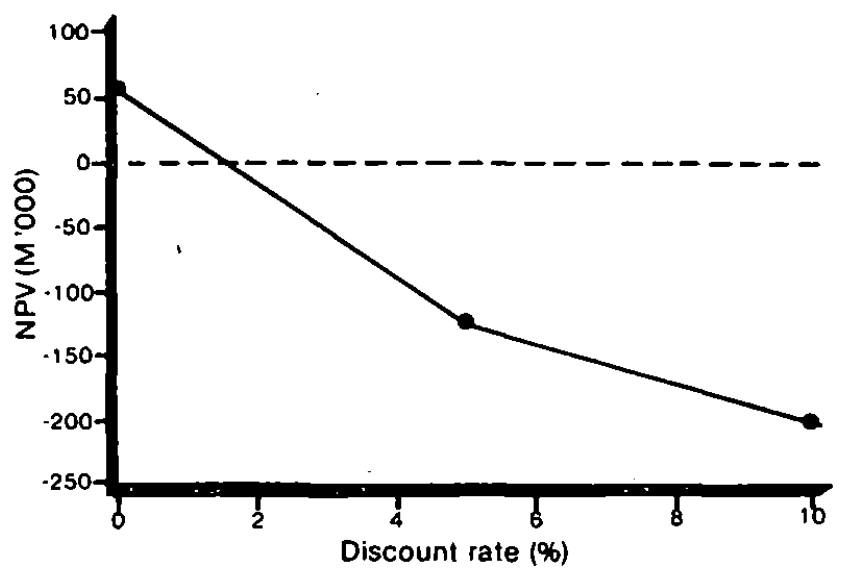

Time horizon. In the base case, a 20-year time horizon was incorporated into the analysis. It could be argued that the probable lack of. maintenance of structures and withdrawn institutional support from the project will result in a shorter time horizon, say 10 years. On the other hand, it could be argued that successful demonstrations and solid institution building will make the project last for 50 years. The resulting changes in IRR and NPV are shown in Table 11.13. Longer time horizons yield higher IRRs and NPVs, since most costs occur in the initial years.

Table 11.13: Sensitivity to time horizon

\begin{tabular}{rrr}
\hline Time horizon (years) & IRR (\%) & NPV (M) \\
\hline 10 & -16.7 & $-283,998$ \\
20 & 1.2 & $-124,615$ \\
50 & 6.1 & 79,302 \\
\hline
\end{tabular}

Summary of sensitivity analysis. Based on the sensitivity analysis, the discouraging results about the project's profitability appear 
rather robust. Reasonable assumptions regarding yield decline, level of project impact, price trends, discount rates and time horizon do not greatly affect this qualitative result, although they sometimes change the NPV from negative to positive. To make a stong case against the main thrust of the results, one would have to assume distinctly different, and fairly unlikely, developments.

Policy implications of the economic analysis

Although these results are tentative and based on a weak data base, they do have policy implications that are worth discussing.

The FISC project is led by highly competent and devoted personnel. It uses simple, labour-intensive techniques. It is based on consultation and people's participation. It therefore has several positive features associated with a successful conservation project - and is generally regarded to be so. The weak economic result was unexpected.

It appears that to make the project economically more attractive, the expensive but necessary expatriate personnel would need more domestic assistance to increase the area over which the project can be effective. By doing so, the substantial expatriate overhead costs can be "diluted".

Clear policy statements by the government of Lesotho regarding social discounting and shadow pricing of labour and foreign exchange would facilitate consistent evaluation of this and other projects. The donor could also supply performance criteria.

\section{The financial analysis}

\section{The farmer's viewpoint}

In order to evaluate the impact on the farmer of adopting the project's suggestions, we must calculate the net return per hectare for an average farmer and discuss the incentives for him/her to join in and continue with the project. To do this, consider performance in 1986.

Actual mean crop yields per hectare in Maphutseng for 1986 are taken from random crop samples (Bojö, Pettersson and Shone, 1987). This is straightforward, but these data represent only one season.

The correct price to use in the financial calculation is the price the farmer receives, or the price he/she would have paid for the crops (replacement cost). If the local market works well, the two prices 
should coincide. We know that the Maphutseng farmers sold their surplus locally or to people living in the mountains (Yaxley, 1987), but we do not have local price data. Project management judged that the local price is a few maloti above the official price, based on import parity prices. We will therefore use the economic prices (M380/t for maize and M370/t for sorghum) as a minimum estimate of the financial price.

Separate prices are not considered for the "with-project" and the "without-project" situations, because the increase in crop yield is unlikely to influence the price substantially. If local prices should fall, sellers would transport their produce to adjacent areas where the price is higher.

The net benefit calculated is the return to labour. Labour requirements after the initial investment in conservation structures are not expected to vary considerably between the two alternatives. Based on an estimated 75 working days per hectare (IFAD, 1986), the return per day increases from M4.23 to M6.27, or by 48 per cent. Alternatively, the farmer can work another 36 days on the same land and still receive the old return to labour. It is reasonable to assume that some extra labour days will be needed, but this will not exhaust the additional benefits in a year like 1986. (It should be added that yield figures for Maphutseng in 1985 - 6 were comparatively high. Normally, farmers in Lesotho cannot hope to receive such yields and rates of return.)

In addition to the cost of fertilizer and seed, the farmer will have additional requirements for weeding in the "with-project" case. Marginal additional costs may be incurred for transport of inputs and crops. On the other hand, stover yield will increase with the use of the project input package. There are no empirical data from Maphutseng on these points, and they will not be included here.

Is the return enough to provide an incentive to the farmer? Table 11.14 shows a net benefit in the "with-project" case of M470 for maize on an investment of M154, plus labour costs. The farmer is likely to look at his/her situation as one of investing an additional M126 (154 -28) in costs in order to obtain an additional gross benefit of M279 (624 - 345). This gives him/her a rate of return of 121 per cent, provided he/she can obtain the indicated yield and the necessary credit, which should be attractive enough to interest him/her in the programme. However, both provisos may present problems, which will be discussed here.

For sorghum, the corresponding financial figures are an increase in gross benefits of M370 for an additional investment of M105. 
Table 11.14: A farmer's comparison of 1 ha of maize "with" vs "without" FISC project (1985-6)

Without With

Yield (kg/ha)

Unit price

Gross benefit

Fertilizer cost

Bags

Seeds

Interest forgone

Total cost

Net benefit

\begin{tabular}{rr}
909 & 1,642 \\
0.38 & 0.38 \\
\hline 345 & 624
\end{tabular}

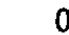

18

63

33

8

48

$\frac{2}{28}$

10

154

317

470

Sources: yield figures, Bojo, Pettersson and Shone, 1987; prices, FISC project management and Co-op Lesotho; interest rate, Central Bank of Lesotho, 1983, 1986.

This represents an IRR of 252 per cent (less additional unaccounted costs as mentioned).

The conclusions about the high profitability are borne out even more strongly by the fact that many farmers did not use all the recommended fertilizer but saved some for the next season (Yaxley, 1987). It is not known exactly how much they saved, but perhaps the fertilizer cost should be much lower.

Expectations of increased yields have in fact motivated 81 of the approximately 209 farm households to participate in 1985-6 (project management records). A major question is whether they will buy inputs when they can no longer get them as in-kind payments. Until further evidence is collected, one can only calculate on the basis of "rational expectations".

The long-run perspective

Assume that the farmer expects a certain average yield if he/she does not purchase inputs and maintains his/her conservation structures. Assume also that he/she has taken note of the relative 
increase in yield obtained in the area during the past season. $\mathrm{He} /$ she now has to buy the inputs for cash.

The farmer's expected net benefit is:

$E(N B)=(Y \times d Y \times P)-d v C$

where $Y=13$-year average yield in the district;

$d Y=$ relative increase in yield obtained in 1986 (per cent);

$P=$ market price of crop;

$d v C=$ (absolute) increase in variable input costs.

For maize, the calculation becomes:

$E(N B)=(694 \times 0.81 \times 0.38)-126=214-126=88$.

For sorghum, the corresponding figures are:

$E(N B)=(816 \times 0.95 \times 0.37)-105=287-105=182$.

The farmer's marginal returns on his investments now become 70 per cent (214/126) for maize and 173 per cent (287/105) for sorghum. These returns still appear convincing enough, but there are a couple of important qualifications: risk and credit.

The problem of risk. Crop yields are very unreliable in Lesotho. The farmers are quite aware of this and will (informally) calculate the chances of losing the little money they have available for investment. To calculate the break-even point, one must make an assumption about the implicit labour cost (that is, what the farmer demands in return for effort). Assume that he or she demands M2 per day (as recruitment at M2.5 has not been a problem). With the assumption that the farmer works 75 days, the imputed labour cost is M150. This value is added to the total input costs and compared to the yield that would be needed to have crop revenue (yield $x$ price) just equal to the total of labour and input costs. For maize, this is $800 \mathrm{~kg}(800 \times 0.38-150-154=0)$; for sorghum, it is $759 \mathrm{~kg}$ $(759 \times 0.37-150-131=0)$.

Available data show that maize yields have been less than the break-even amount in 7 of the last 13 years ( 54 per cent). The corresponding figure for sorghum is 8 out of 13 years (62 per cent). In over half of the years, therefore, yields would not meet the break-even criterion.

The farmer's perspective may also be influenced by perceptions of climatic cycles. This may alter the probabilities he or she attaches to the outcomes in a certain year. Lacking any empirical data on this, we use unweighted historical data.

Utilizing the project's input package certainly raises the mean yield above historical levels, but by how much is uncertain. The standard deviation of expected returns is still large. It is certainly rational to adopt a careful approach in the face of these risks. 
The problem of credit. If the farmer could rely on a perfect credit market, risks could be accommodated. Good years would outweigh bad years, and expected average yield within the personal time horizon would be the guiding variable. Real interest rates are low, but in the Maphutseng area there is no credit facility that extends credit to smallholder farmers. It can be assumed that the potential volume is too small to be interesting to the credit institutions and that there may be a problem with collateral. This is where the project may be able to extend assistance and thereby increase the chances for long-term survival of its ideas.

\section{Policy implications of the financial analysis}

The indication that the project represents a financially successful but economically doubtful package of measures suggests that this is a case of over-subsidization.

If farmers could be made aware of the financial benefits for themselves, they should be willing to invest out of self-interest. The main objections are risk and credit, but these could be addressed by government assistance through insurance and credit schemes.

Another aspect is that, although the full package may be financially worthwhile, the conservation aspect may not have such clear benefits. This becomes a "merit good" (that is, a value pursued quite apart from any economic significance) by the government and the donor. Option-value considerations may play a part here: there is a value in preventing irreversible losses of productive capacity, thus leaving more options open for the future. This becomes particularly important with the possibility of declining employment opportunities outside of Lesotho.

\section{Acknowledgements}

This case study was developed as a part of the SADCC Co-ordination Unit's sub-programme on the economics of conservation and is a continuation of two reports previously published by the same author (Bojö, 1986a, 1986b).

This paper establishes a framework for preliminary conclusions and further data gathering. It does not arrive at a definite judgement. The period of monitoring has been too short, and the paper represents work in progress. The current ambition is to continue monitoring the project for several more years. Comments on data collection or analysis are welcome; please address them to the 
author at Stockholm School of Economics, Box 6507, 113-83 Stockholm, Sweden.

Special thanks are due to Anna Bratt, Annika Dahlberg, Dennis Finlayson, Tim Greenhow, Lena Kulander, David Palin, Bernt Rydgren, Gedion Shone and Eric Yaxley, who have all given generously of their time to offer valuable comments and data. Tim Greenhow kindly provided computer facilities at the Institute of Land Use Planning and was a great help with the computer. Jan Clareus skilfully turned rough sketches into computer graphics. Lennart Annersten was very helpful in supplying and explaining financial data. Idris Mohammednur ambitiously collected vital data from the project area. Yvonne Eliasson kindly supplied financial information at short notice. I am also grateful to the large number of persons who have at one point or another contributed with pieces of information (see list of persons contacted), and to Rosinah Mabeleng, who typed substantial parts of this document.

However, the author alone accepts full responsibility for the views expressed, which are not necessarily those of the persons interviewed, the SADCC Co-ordination Unit, SIDA, the government of Lesotho or Swedforest.

\section{List of persons contacted in Lesotho}

Ms A. Bratt, FISC Project Horticulturist. Ms A. Dahlberg, Consultant, Social Anthropologist. Mr J. Eklof, Bureau of Statistics. Mr E. Karlsson, Governor of the Central Bank of Lesotho. Mr M. Masilo, Director, of Conservation and Forestry. Mr M. May, Forester, Lesotho Woodlot Project. Mr E. Modise, Chief Crops Officer. MrM. Phakoe, Marketing Manager, Co-op Lesotho. Mr Pomela, Agronomist, Agricultural Research Division. Mr B.Rydgren, Physical Geographer, Institute of Land Use Planning. Mr G. Shone, FISC Team Leader. Ms Takalimane, Price Office, Co-op Lesotho. Mr H. White, Central Planning and Development Office. Mr E. Yaxley, Senior Land Use Planner, Institute of Land Use Planning.

\section{Annex: cost calculations}

\section{Step 1: Elimination of nursery costs}

The establishment of a nursery is a major component of the project. However, no significant distribution of seedlings to the Maphutseng area has taken place to date. The nursery is an investment with a very long gestation period. Lacking quantitative information about demand for fruit trees and vegetable plants/seeds, we have 
Table 11A.1: Financial project costs (current maloti)

\begin{tabular}{lrrrrrr}
\hline & 1985 & 1986 & 1987 & 1988 & 1989 & 1990 \\
& & & & & & \\
\hline Buildings & 168,034 & 1,803 & 11,000 & 5,000 & 0 & $\vdots 0$ \\
Vehicles & 66,591 & 6,640 & 50,000 & 50,000 & 0 & $\vdots$ \\
Skilled pers. & 93,109 & 138,507 & 151,250 & 155,050 & 134,000 & 138,000 \\
Semi-sk. pers & 8,195 & 21,208 & 75,300 & 79,000 & 83,000 & 87,100 \\
Unsk. pers. & 29,583 & 62,633 & 57,000 & 60,000 & 60,000 & 50,000 \\
Incentives & 21,972 & 51,492 & 52,000 & 57,200 & 63,900 & 45,000 \\
Equipment & 7,562 & 25,585 & 0 & 32,000 & 0 & 0 \\
Nursery & 124,048 & 213,821 & 179,250 & 175,050 & 154,000 & 158,000 \\
Other & 66,332 & 102,315 & 56,000 & 50,000 & 50,000 & 30,000 \\
Total & 585,426 & 624,004 & 631,800 & 663,300 & 544,900 & 508,100
\end{tabular}

Sources: FISC monthly reports and Swedforest Lesotho office. Figures for 1985 and 1986 are actual expenditures; the remaining periods show budget estimates.

Note: The basic financial costs have to be modified in several ways to be useful for the economic calculations.

decided to separate this activity from the rest of the project. This implies no value judgement as to the profitability of this activity.

An additional adjustment is that the building investment in 1985 is split in half. Most of this sum refers to two staff houses, of which one is occupied by the horticulturist.

\section{Step 2: Allocation of investment costs}

The next consideration is the degree of utilization of an investment (INV) item for the Maphutseng area as against other project areas outside the scope of this analysis. The annual allocation factors, given by project management, are for 1985 (70 per cent), 1986 (40 per cent) and 1987 - 90 (20 per cent). These figures are used to derive an average utilization factor $(A V U T)$ for each class of investment; for example, an investment in 1985 will have the AVUT of $(0.7$ $+0.4+0.2(4)) \div 6=0.32$. The investment cost is multiplied with this factor to arrive at the appropriate cost share for Maphutseng (MAPSH) - Table 11A.2. 
Table 11A.2: Calculation of allocated building values

\begin{tabular}{lrcr}
\hline & INV & AVUT(\%) & MAPSH \\
\hline 1985 & & & \\
1986 & 84,017 & 32 & 26,885 \\
1987 & 1,803 & 24 & 433 \\
1988 & 11,000 & 20 & 2,200 \\
1989 & 5,000 & 20 & 1,000 \\
1990 & 0 & - & 0 \\
& 0 & - & 0 \\
\hline
\end{tabular}

The same exercise is now done for vehicles - Table 11A.3.

Table 11A.3: Calculation of allocated vehicle values

\begin{tabular}{lrcc}
\hline & INV & AVUT(\%) & MAPSH \\
\hline 1985 & & 32 & 21,309 \\
1986 & 66,591 & 24 & 1,594 \\
1987 & 6,640 & 20 & 10,000 \\
1988 & 50,000 & 20 & 10,000 \\
1989 & 50,000 & - & 0 \\
1990 & 0 & - & 0 \\
& 0 & & \\
\hline
\end{tabular}

As for equipment, the Team Leader informed us that the equipment bought in 1985 was used about 70 per cent in the Maphutseng area. No further purchases will be made for this area by the project. Thus, we register simply $0.7 \times$ M7,562 = M5,293 as allocated cost (in 1985).

We can now summarize the three items allocated - Table 11A.4. 
Table 11A.4: Summary of allocated capital costs

\begin{tabular}{lrrrrrr}
\hline & 1985 & 1986 & 1987 & 1988 & 1989 & 1990 \\
& & & & & & \\
\hline Buildings & 26,885 & 433 & 2,200 & 1,000 & 0 & 0 \\
Vehicles & 21,309 & 1,594 & 10,000 & 10,000 & 0 & 0 \\
Equipment & 5,293 & 0 & 0 & 0 & 0 & 0 \\
Total & 53,487 & 2,027 & 12,200 & 11,000 & 0 & 0 \\
& & & & & & \\
\hline
\end{tabular}

Step 3: Allocation of recurrent cost and shadow pricing of labour The foregoing adjustments have left us with the following costs to consider: personnel, incentives, and other costs. Unskilled personnel is shadow priced to zero. The remainder is taken from Table 11A.1 and summarized in the first line in Table 11A.5.

Table 11A.5: Allocation of recurrent costs

$\begin{array}{llllll}1985 & 1986 & 1987 & 1988 & 1989 & 1990\end{array}$

Total RC

Utilization

Allocated $\begin{array}{llllll}189,608 & 313,522 & 334,550 \quad 341,250 & 330,900 & 300,100\end{array}$

$0.7-0.4$

$132,725 \quad 125,409$

0.2

66,910
0.2

68,250

\section{Step 4: Calculation of duty revenue}

As discussed in the main text, Lesotho receives compensation for, inter alia, the price-raising effect of the common trade barriers around Southern African Customs Union (SACU). This compensation is paid for by Lesotho consumers and indirectly transferred to the government of Lesotho. To adjust for this, a flat rate of 20 per cent has been subtracted from import items. This is based on the average level of compensation payments during the past years (Kizilyalli, 1982). Since the compensation is not attached to any 
specific item, there is no point in trying to identify good specific tariffs. The adjustment affects buildings ( 80 per cent import content is assumed in accordance with CPDO, 1987), vehicles and agricultural inputs of all kinds - Table 11A.6.

Table 11A.6: Calculation of duty revenue

\begin{tabular}{lrrrrrr}
\hline Inputs & 1985 & 1986 & 1987 & 1988 & 1989 & 1990 \\
& & & & & & \\
\hline Bldg (80\%) & 21,509 & 346 & 1,760 & 800 & 0 & 0 \\
Vehicles & 21,309 & 1,594 & 10,000 & 10,000 & 0 & 0 \\
Equipment & 5,293 & 0 & 0 & 0 & 0 & 0 \\
Incentives & 15,380 & 20,596 & 10,400 & 11,440 & 12,780 & 9,000 \\
Total & 63,491 & 22,536 & 22,160 & 22,240 & 12,780 & 9,000 \\
Duty rebate & 12,698 & 4,507 & 4,432 & 4,448 & 2,556 & 1,800
\end{tabular}

Step 5: Transformation from current to constant prices and adjustment for duty revenue

We have so far considered values from different years without taking inflation into account. We now transfer all current values into 1986 prices. The inflation factors used are 18 per cent for $1985-6$ and 15 per cent for remaining years - Table 11A.7.

Step 6: Calculation of residual values

With the rate of depreciation chosen, there will be no residual values for vehicles and equipment by 1991 . However, the buildings will remain, and their residual value should be credited to the project. The building investments share for Maphutseng has been calculated and can now be converted into constant 1986 prices. Then the residual value (RES) is derived by multiplying $I N V$ by one, minus the depreciation ( 3 per cent) per year, times the number of years of utilization (DEPF) - Table 11A.8. 
Table 11A.7: Economic costs for Maphutseng in current and constant (1986) prices

\begin{tabular}{lrrrrrrr}
\hline & 1985 & 1986 & 1987 & 1988 & 1989 & 1990 \\
& & & & & & \\
\hline Investm. & 53,487 & 2,027 & 12,200 & 11,000 & 0 & 0 \\
Recurr. & 132,725 & 125,409 & 66,910 & 68,250 & 66,180 & 60,020 \\
Less duty & 12,698 & 4,507 & $\underline{4,432}$ & $\underline{4,448}$ & $\underline{2,556}$ & $\underline{1,800}$ \\
Current & 173,514 & 122,929 & 74,678 & 74,802 & 63,624 & 58,220 \\
Infl. factor & 1.18 & 1.0 & $\underline{0.87}$ & $\underline{0.76}$ & $\underline{0.66}$ & $\underline{0.57}$ \\
& & & & & & & \\
Constant & 204,747 & 122,929 & 64,970 & 56,850 & 41,992 & 33,185 \\
& & & & & & \\
\hline
\end{tabular}

Table 11A.8: Calculation of residual building values

\begin{tabular}{lrrrr}
\hline & INV(MAPSH $)$ & INFL & DEPF & \multicolumn{1}{c}{ RES } \\
& & & & \\
\hline 1985 & 26,885 & 1.18 & $1-6(0.03)$ & 26,014 \\
1986 & 433 & 1.00 & $1-5(0.03)$ & 368 \\
1987 & 2,200 & 0.87 & $1-4(0.03)$ & 1,684 \\
1988 & 1,000 & 0.76 & $1-3(0.03)$ & 692 \\
Total & & & & 28,758 \\
& & & & \\
\hline
\end{tabular}

Note: This residual value is further adjusted for duty rebate of 20 per cent; that is, 23,006 $(28,758 \times 0.8)$ is brought to the summary table (Table 11.7 for 1991, residual benefit of buildings). 


\section{References}

Bojō, J. (1986a),

A Reoiew of Cost - Benefit Studies of Soil and Water Conservation Project, SADCC Co-ordination Unit for Soil and Water Conservation and Land Utilization Report No.3 (Maseru, Lesotho: SADCC).

Bojō, J. (1986b),

An Introduction to Cost - Benefit Analysis of Soil and Water Conseroation Projects, SADCC Co-ordination Unit for Soil and Water Conservation and Land Utilization Report No.6 (Maseru, Lesotho: SADCC).

Bojö, J., K. Pettersson and G. Shone (1987),

"Crop sampling in the Maphutseng and Brakfontein areas", mimeo, (Maseru, Lesotho: SADCC).

' Bureau of Statistics, Lesotho (1987), unpublished data obtained directly from the bureau.

Central Bank of Lesotho (1983), Quarterly Review, March (Maseru, Lesotho).

Central Bank of Lesotho (1986), Quarterly Review, September (Maseru, Lesotho).

Chakela, Q. (1981),

Soil Erosion and Reserooir Sedimentation in Lesotho, (Uppsala, Sweden: Scandinavian Institute of African Studies).

Chakela, Q. and J. Cantor (1986),

History of Soil Conservation and Soil Conseroation Policy in Lesotho, report to the SADCC Co-ordination Unit, Maseru, Lesotho.

Chakela, Q., B. Lunden and L. Strömquist (eds) (1986),

Sediment Sources, Sediment Residence Time and Sediment Transfer-Case Studies of Soil Erosion in the Lesotho Lowlands, UNGI Report No.64 (Uppsala, Sweden: Department of Physical Geography, Uppsala University).

CPDO (Central Planning and Development Office) (1982),

"Financial assistance for labor intensive soil conservation project", mimeo (Maseru, Lesotho: CPDO).

CPDO (1987).

"Fuelwood and poles forestry sub-project: economic analysis", mimeo (Maseru, Lesotho: CPDO).

Dahlberg, A. (1987a),

"Livestock ownership in Maphutseng", mimeo (Maseru, Lesotho).

Dahlberg, A. (1987b),

"Local institutions - their role in soil conservation. A case study of the Maphutseng area, Lesotho", mimeo (Maseru, Lesotho).

DLUP (District Land Use Planner) (1986),

- "Proposed land use plan for Maphutseng watershed", mimeo (Mohale's Hoek, Lesotho).

FISC (Farm Improvement with Soil Conservation), monthly reports, mimeo (Mohale's Hoek, Lesotho). 
Gittinger, J. P. (1982),

Economic Analysis of Agricultural Projects, 2nd edn (Baltimore, Md, and London: Johns Hopkins University Press).

IFAD (International Fund for Agricultural Development), (1986), Appraisal Report. Lesotho Local Initiatives Support Project, Report No.0026-LE, Vols 1 and 2 (Rome IFAD).

Institute of Land Use Planning (1986),

"Maphutseng community land use plan", mimeo (Maseru, Lesotho).

Kizilyalli, H. (1982),

Options for the Lesotho Economy in the Year 2000: Perspective Plan Alternatives (Maseru, Lesotho: CPDO).

LHC and OSC (Lahmeyer MacDonald Consortium and Olivier Shoud Consortium) (1986),

Lesotho Highlands Water Project Feasibility Study, Supporting

$\because$ Report;Economic and Financial Analysis (Maseru, Lesotho: Ministry of Water Energy and Mining).

Louis Berger International Inc. and Lesotho Consulting Engineers Pty) Ltd. (1986),

Feasibility and engineering study. Feeder road network. Final report, vol.1, New York and Maseru.

Matsaba, T. G. K. (1985),

A Case for Fuelwood Production in the Kingdon of Lesotho (Bangor, UK: Department of Forestry and Wood Science, University College of North Wales).

Mellander, A. (1987),

Cost - benefit analysis of soil and water conseroation projects. A minor field study, (Stockholm: Stockholm School of Economics).

Ministry of Agriculture and Marketing (1981),

Soil Erosion and Crop Production in Lesotho (Maseru, Lesotho: Engineering Section Conservation Division).

Modiani, P. (1986),

"The shadow wage rate (SWR) in Lesotho", mimeo (Maseru, Lesotho: CPDO).

Nobe, K. C. and D. W. Seckler (1979),

An economic and policy analysis of soil -water problems in the kingdom of Lesotho, LASA Report No.3 (Maseru, Lesotho: Ministry of Agriculture and Department of Economics and Boulder, Colo: , Colorado State University.

Palin, D. (1983),

Farm Improvement with Soil Conservation in Lesotho. Report to SIDA Mission (Stockholm: Swedforest Consulting AB).

SIDA (Swedish International Development Authority), (1983),

"Insatspromemoria" [Terms of reference], mimeo, 11 October (Stockholm).

Swallow et al. (1987), A suroey of the production, utilization and marketing of livestock and livestock products in Lesotho, (Maseru, Lesotho: Ministry of Agriculture). 


\section{The Economics of Dryland Management}

Taylor, G. (1985),

"An appropriate shadow wage rate for LCU projects", mimeo (Maseru, Lesotho: Ministry of Works).

Turner, S. (1975),

"Soil conservation in Lesotho", mimeo (Cambridge: Downing College, Cambridge University).

Wenner, C. G. (1982),

"Soil conservation in Lesotho", draft discussion document 15 March (Maseru, Lesotho: SIDA).

World Bank (1986),

Lesotho Agricultural Sector Review, Report No.5866-LSO (Washington, DC: World Bank).

Yaxley, E. L. (1987),

Adoption of Fertilizer and Seed Recommendations by Farmers in Maphutseng, Lesotho (Maseru, Lesotho: Institute of Land Use Planning). 


\section{Index}

Figs in italic

Tables in bold

(b) after page no. refers to material in boxes

A

Acacia, 35, 96

accommodation and change (land tenure), 244-5

accountability, lack of in externalities, 66

adaptive environmental assessment and management (AEAM), 164-5, $185,189-90$

adjustment, dynamics of, 90

administrative management, 247

AEAM, see adaptive environmental assessment and management

afforestation, 96, 260-61

Africa

climatic changes, 12-21

economics of afforestation and managing wood fuel supplies, 96-7 state-owned lands, 242

agricultural land, concern over, 77-8

agricultural tools, Lesotho, 263-4

agriculture, 5

extension into marginal lands, 94

agroecology, 97

agroecosystems, 82-4

agroforestry, 34-5, 57, 98, 99

airborne dust levels, 142

amortization, 112, 115

animal populations, 24,85

response to drought, 103, 104

animals, domestication of, 5, 6-7

annual sowings, repeated, 95

annuity formula, 113(b)

appropriate technology, use of, 57-8

aquifers, confined, unconfined and

fractured, 22

arid lands, 1,18

marginal, and nomadic graziers, 28 artesian wells, 22

atmospheric circulation, global, affecting precipitation, 15

augmented matrix, 213
Australia

animal population response to drought, 103, 104

B effect of fall in beef prices, 40

barter, 31, 43.

benefit summary, Lesotho case study, 269

benefit-cost analysis problem of risk and uncertainty, 163-6 pursuit of socially risk-averse development, 179-80 soil conservation, Lesotho case study, 250-85

benefit-cost ratio, 132, 133, 134, 136 problems of, 137

benefits

gross, from increased crop yields, Lesotho, 258-9

potential, of public policies, 49-52

quantification of, Lesotho case study economic analysis, 255-62

risky, social value of, 180

benefits and costs, 79, 111-17

internal and external, 141

Lesotho case study, valuation of in economic prices, 262-7

measurement of, 64-79

benefits received, costs avoided, 52

best estimates, $163-4$

binomial distribution, 168

biological productivity, 23

birth control programmes, 44, 45

black markets, 126, 127

border prices, 126

boreholes, 84, 103

borrowing, cost of, 71-2

C

camels, 101

Canadian prairies, 19

capital 
opportunity cost of, $71,113,254$

real economic cost of, 131

capital borrowing, 115

capital costs, 116, 118, 119, 131

borrowed or from internal sources, 115

initial, 113

in short supply, 136

capital investment, 109

capital stock, dryland areas as, 82

carrying capacity, 29, 84-5, 101, 193

cash cropping, increasing in

developing countries, 32

cash flow calculations, 116

Casuarina, 96

catchments, off-site degradation

effects, 27

cattle, traditionally represent wealth, $40,88-9$

cereal crops, 30, 94

cereal-fallow systems, 6

certainty equivalent, 178

change, 245

China, 96

land-levelling study, 159

peanut growing with plastic mulch private and social benefits analysed, 111, 112(b)

replacement cost technique, 158-9

Weibei upland, Shaandi province, use of economic analysis, 63

cisterns, 21

climatic change, 19, 21

climatic cycles, 278

climatic fluctuation, 19, 21

climatic variation, 7

cold deserts, commencement of

growing season more reliable, 18-19

colonial rule, and breakdown of

traditional mechanisms, 75

commercial farming, drylands, 94

commercial livestock, 103, 103-4

commodity markets, 46

commodity price variations, 32

commodity prices, and livestock

population, 39-40

common lands, susceptible to

over-use, 241-2

communal property, 68-9, 75

community control of land, alienated,

236-7

community life, 59

community participation, dryland management, 55-6

community (social, mass) forestry, 34

community well-being, 118

companies, and creation of

community economic benefits, 115

competitive market (small country)

assumption, 146-9

computer simulation modelling, dryland grazing systems, 104-6

computer simulation models, 80 uses of, 105-6

conservation farming, 86, 98, 118 techniques package, financial analysis, 111

conservation maintenance, poor record of in Lesotho, 268

conservation programme, colonial administration in Lesotho, 250, 252

conservation projects, sometimes ineffective, 44-5

conservatism and understocking, 102(b)

constant prices, 255

consumer's surplus, $66,67-8(\mathrm{~b}), 69$, 161,185

consumption effects, induced, 213

consumption expenditure,

incorporation of, 212-13

com/Leucaena cropping system, 99

corporate profits, maximizing of, 110

corrective actions, factors to be taken

into account, 47

cost analysis techniques, 80, 156-61

cost calculations, Lesotho case study, 280-85

cost constraint, 136

cost-benefit summary, Lesotho case study, 270

cost-effectiveness analysis (CEA), 80 , $111,137-9$

cost-insurance-freight price (CIF), 126

costs

on-site, 44, 147

quantification of, Lesotho case study

economic analysis, 254-5

credit, 240, 246, 279

critical zone resources, 190

critical zones, 190

crop benefits, Lesotho case study, 255-9

crop failure, minimizing costs, 95

cropping

length of growing season, 18 
too frequent, results of, 32

on unsuitable land, 12

cropping practices, controlled, 240

cropping rights, 39

cropping systems, traditional, 25

cultivation, excessive, results of, 32

currency depreciation, results of, 45

currency situation, Lesotho, 266-7

customary land laws, 242-3

customary tenure

individual use of communal land, 243

D

rules can be modified, 244

decision analysis, 80, 181

decision analysis techniques, 164 , $181-3$

decision criteria, 132-7

formulas for, 133(b)

decision effects, internalized, 66-7

decision trees, 183, 184

decision-makers

and expert systems, 188-9

presentation of economic analysis

results to, 225-7

use of best estimates, 164-5

deep drainage, 17

deforestation, 5, 11, 215, 243

degradation effects, 64,65

degradation processes, 26-7

degradation trends, reversal of, 95

degraded land, rehabilitation of, 39

depreciation, not included in SBCA, 119

desertification, 1, 2, 25-6

classes of defined, 8

degree of, worldwide, 10

extent and pace of uncertain, 11

developed countries

land degradation, 29

ranch animal populations, 38

developing countries, 77

degradation worsening, 11

encroachment of dryland cropping

onto rangeland margins, 38

internal pricing policies, 40

lack of dryland data, 214

small-scale agriculture, 94, 97

development strategies, 47

direct controls, 230, 231, 232

direct intervention, 234

direct-requirements coefficients, 209-10, 213, 214

discount rate, $71-2(b), 71-3,94,137$, 240,254 and cost-benefit analyses, 73

Lesotho 273, 274

discounting, 70(b), $71-5,88,114$

Lesotho, 267-8

distributional effects, Lesotho case study, 270-71

domestic and international economy, interactions between, 45

drainage systems, adequate, 34

drought, 1, 19, 74, 85, 95

animal population response, 103, 104

conservative approach to

management of, 103

and controlled stocking rates, $103-4$

and irrigation, 33

and land degradation, 25

mitigation of, 186-7(b)

and nomadic subsistence, 28

drought management, conservative

and opportunistic approaches, 102, $103-4$

drought resistance, trees, 96

dry ecosystems, recovery slow, 24

dry farming, Near East, 6

dryland agriculture and forestry, 94-100

dryland agroforestry schemes, 34, 35

dryland cropping, encroachment onto rangeland margins, 38

dryland decision-making

interested institutions, 43

sources of risk and uncertainty in, 165-7

dryland degradation, 1

appears to be increasing, 65

biological/physical effects of, 64-5

can be slowed or arrested, 12

causes

basic, 24-5

and corrective actions, 87-94

identification of, 46

natural, 25-6

controlling action needed, 2

corrective policies/strategies, 90-94

costs, 9

extent of, 9, 46-7

and fallowing, 90-92

gradual physical phenomenon, 69

increased not alleviated, 58-9

irreversible, 77

and land tenure, 39

and land use, 24-37

and rehabilitation costs, 52-3, 54(b) 
resulting from

complex interacting factors, 2

the development of rich

countries, 40-41

human decision-making, 45

inappropriate land use and use

of inappropriate land, 32

individual usage, 64

overgrazing, 29-30

series of different circumstances, 74

social and institutional factors, 37-41

stopped or slowed, 47

studied via a global model, 219, 221

ungency of variable, 43-4

dryland development planning

application of input-output analysis, 207-15

general policy decisions in, 44-5

general policy issues, 193-4

multipliers, application of, 214-15

dryland ecosystems, 24, 26

monitoring of, 187-8

sustainable production from, $82-5$

dryland environments

fragility of, 77

variable conditions in, 86

water collection and conservation, 98

dryland management, 84

goal is increased production, 141-2

role of NGOs, 109-10

dryland plant communities, characteristics of, 23-4

dryland production, labour and land constraints, 195, 196-7

dryland production systems, risk and uncertainty in, 165-7

dryland projects, environmental effects affect social welfare, 121

dryland region, hypothetical transaction table, 207-9

dryland residents limited political influence of, 40, 49 and public assistance policies, 49

dryland resource management could assist in decision-making, 188-9 economic analysis of options, 62-3 dryland resources economic management objectives, 86-7

improved use of, 45-6

over-or inappropriate use of, 27 dryland salinity, linear programming model, 204(b)

dryland temperatures, stressful, 21

dryland usage, history and background, 5-7

dryland zones, characteristics of, 3

drylands, 1

agents causing damage, 151-2

apportionment of rehabilitation

costs, 231-2

benefits and costs, 64

climate of, 15-21

communal and traditional tenure,

242-4

current conditions in, 7-11

dimensions of the problem, 5-12

distribution of, 1

diversity of problems, 43-4

economic policies as part of national

development planning, 206

externalities in, 68-9

focus of public policy, 46

the future of, 11-12

growing season limited by lack of

moisture, 16

history and background, 5-7

irreversibility, 77-8

problems of, 186

natural vegetation, 23

new industries, 212

pay-off matrix, 182

physical and biological

characteristics, 15-24

policies towards, 43-9

populations, traditional, 235

position of basic resources, 76

products of, 85-7

rainfall, nature of, 19

renewable production systems, 82-7

as a renewable resource, 46

and risk aversion, 179

subjected to increasing pressure, 7

triage analogy, 54-5

dynamic optimization, 205

dynamic simulation, 205

E

early warning systems, 186-7(b)

ecological accounts, 217

ecological considerations, and AEAM,

189

ecological sustainability, 70

economic accounts, 217

economic analysis, 63, 64, 131, 224 
as an applied social science, 62 and changes of customary systems, 244

definition of objectives, 226 design of, 79 identification of alternatives, 226 important elements of, 226-7 Lesotho case study, 254-75 techniques of, 79-80

of tenure systems, 237

valuation of effects, 227 economic benefits, maximization of, 55 economic costs, 118-19, 255 economic efficiency prices, 118 economic externalities, $66-8$ economic growth, 215, 231 economic incentives, 227, 230-31, 232-4

economic infrastructure, absence of, 233-4 economic management objectives, dryland resources, 86-7 economic prices, 143, 145, 152, 276 economic rent, see producer's surplus economic surveys, 213 economic valuation techniques, 65 economic values, 173, 264 economic welfare, 63-4, 86 economics, 62

and the policy process, 46-9 economy, achievement of objectives at least cost to society, 232-3 ecosystems

fragile, robust, resilient, 26

natural, preservation of, 155 education, 44

Egypt, integrated development in, 194(b) employment increase claims, 129 entitlements, 241-2

uncertainty of, 245

environmental damage, 131, 158-60 environmental externalities, $89-90$ environmental goods and services, 141,142

environmental impact assessments, 46-7 environmental policy, instruments of, 228, 229

environmental quality, 46-7 environments, functioning, preservation of, 155 equitability, 84 equity, vertical and horizontal, 231

equity implications, alternative resource allocations, 64 eroded material, indirect environmental costs of, 145

erosion, 23, 32, 52, 244, 250 accelerated, 38

Eucalyptus, 96

evaluation criteria, choice of, Lesotho case study economic analysis, 254 evaporation, 15, 21 evapotranspiration, 16, 21 exchange controls, 126 exchange rates, distorted, 126

executive summary, economic analysis report, 225

expert systems, use of, 188-9

exports, diverted, as project inputs, $127-8$

external debt, 41

externalities, 68-9, 215 corrected by shadow pricing, 124 and open access common property F resource effects, 89-90

failure, risk of, 233

fallow(ing), 28, 31, 32, 77, 185, 253 effect of on yields, 90-92

famine situations, 138

farm technology, appropriate, 97

farmers, ignoring long-term effects, 74 farmer's perspective and viewpoint, Lesotho case study, 275-7, 277-9

farming, mechanized, capital-intensive, 32

farming systems research, 98

fertilizers, 31, 32, 257, 258

final demand, 210

financial analysis, 80, 110-17, 121, 142, 143,145 cf. social benefit-cost analysis, 120 expected costs and benefits, 111-17 land development project, India, 116-17(b)

Lesotho case study, 275-9

financial incentives, 230, 246-7

financial management, 246-7

financial price, 276

fire, effect on the environment, 5

FISC (Farm Improvement with Soil Conservation Project), Lesotho, 252-4, 272-3

fiscal measures, 230, 233-4 
flash floods, 21

flexibility and incentive for effort, 232

flip-flop changes, 204

flooding, dry river systems, 21

flow (renewable resources), 76

flow or transactions table, 207-9

fodder, 97, 116

availability of, 84

as a constraining factor, 103

Lesotho, 259-60, 264

Food and Agricultural Organization

(FAO), 1987 report on drylands, 9

food crops, drought resistant, 31

foreign exchange, Lesotho case study, 265-7

foreign exchange earnings, net, 130

foreign exchange premium, 127

forest products, flow of established, 96

forest resources, 85

forestry, 34-5, 95-7

irrigated, 97

free-on-board (FOB) price, 126-7

frequency distributions, 167-8

frost, 21

fruit trees and vegetables, Lesotho case study, 261

fuel demands, increased, and dryland degradation, 5

fuelwood, 35, 85, 95, 97, 261

collection, leading to forest cover

loss, 38

crops used for stabilization, 35

economic value of, Lesotho, 264-5

fuelwood gathering, 87-8(b), 89

funding agencies, evaluation of expected returns to investments, 110

funding constraints, 134-5

G

game parks/wildlife reserves, problems, 36

Gaussian (normal) distribution, 167-8, 169

genetic material/resources, loss of, 155 global modelling, integrative nature of, 219

global models, 219-21

goods, foreign exchange value of, 126

goods and services, 124-5, 155

government expenditure, direct, 228

government funding, 49, 109, 110

government interventions, use of

shadow prices, 124

governments borrowing for project finance, $71-2$

ownership of land, 238

value of financial analysis, 111

grass seed, 254

graziers, nomadic, using marginal arid lands, 28

grazing, 94

importance of timing of, 101

rotational, 254

grazing land, communal, Lesotho, 250

improved management, 261

grazing management, key variables, 100-104

grazing pressure, 29

grazing rights, 39

communally owned, 28

grazing systems, 100-106

computer simulation modelling of, 104-6

traditional, 25, 39

GRIT (Generation of Regional

Input-Output Tables), 214

groundwater, 21-2, 33, 34

group decision-making, inhibiting, 243

growing season, 16, 17, 18, 33

growing strategy, unreliable rainfall, 95

gullies (dongas), 253

gully erosion, 77

$\mathrm{H}$

harvesting, 88, 90

health benefits categorized, 153

health care costs avoided, 153-4

health care resource benefits, 153

health problems, project created, 152-3

herd composition, 28, 100

human factors in dryland degradation $37-9,59-60$

human life and health, valuation of, $152-4$

human suffering, relief of, 50

hunter-gatherers, 5

hybrid seed, 257

I

ignorance, 38-9

import bans, 127

import quotas, 127

import tariffs, 119

improved maize, 254, 255-9

improved seed, 263

improvement measures, maximizing net benefits of, 50,52

incentive characteristics, checklist, 234

incentive payments, Lesotho, 252 
incentive schemes/systems, 111 taking account of social and cultural patterns, 235

incentives, 47, 57, 111, 224, 227-33

appropriate, selection of, 233-4 efficient, characteristics of, 231-3 in-kind, 230

inconsistent, 236

income distribution, 131-2

income levels, 43, 46

India

financial analysis, land development project, 116-17(b)

property rights and trees, 238(b)

the tree patta scheme, 96(b)

village level forestry projects, 56

individuals, willingness to incur

preventive expenditure, 157-8

induced effects, 212-13

industries, existing and new, 212

infiltration, 16, 27

inflation, 113, 128, 131, 231

information

available, decisions based on, $180-81$

investment in, 187-8

infrastructure development, 44

inland areas, rainfall from re-evaporated soil moisture, 21

input costs, material, Lesotho case study, 263-4

input-output models, 206

conceptual framework, 207

containing mixture of physical and monetary units, 207

data sources and construction of, 213-14

direct requirements coefficients, 209-10

flow or transactions table, 207-9

hybrid methods, 213-14

input-output system

primary inputs, 211-12

solving for equilibrium outputs, 210-11

input-output table, modification of, 213 inputs

agricultural, Lesotho case study, 258,263

to control degradation, 91-2

institutional factors, 60

andpolitical factors, dryland

degradation, 39-41

intangibles and non-quantifiables, valuation of, $155-6$

interception (rain), 16

interest payments, SBCA, 119

interest rate, 114

in financial analysis, 112-13

financial (nominal), 71

internal rate of return (IRR), 115, 132,

$133-4,137,254,267-8$

investment costs, allocation of,

Lesotho case study, 281-2, 283

investment decisions, 109

investment finance, 47

investment funding, 109-10

Iraq, effects of soil salinization, 6

irreversibility, 76-8

concepts of, 183, 185

irreversible changes, 76-8

irreversible damage, evaluation of, 53

irrigated agriculture, 33-4, 85

irrigated crops, 85

irrigated forestry, 97

inigated land, 8, 12

large areas lost to salinity, 11

irrigation; 6, 203-4

irrigation potential, Lesotho, 261

irrigation reclamation schemes, 12

irrigation schemes, need for proper design, 33

irrigation water, poor-quality, results

J

$$
\text { of, } 34
$$

job creation, project evaluation, 129-30

K

Korea

replacement-cost approach to study of soil erosion effects, 158

use of cost analysis techniques in

L upland agriculture projects, 157-8

labour

costs, Lesotho case study, 262-3

opportunity cost of, 124-5

surplus, 193

labour constraints, 195, 197

land

communally owned, 28

current dealings, registration of, 245

inappropriate, $32,33,38$

subdivision of, 236

land husbandry, 100

land resources, under stress, 25

land restriction, 195, 196-7

land scarcity, 6 
land tenure arrangements/systems, 39 , 236

affecting success of rehabilitation programmes, 237

and incentives, 237-44

modifications needed, 237

reform directed to realignment of

incentives and restraints 244-5

and time horizons, $73-4$

land tenure and use rights policies, 224

land use

changes in with private property, 239

and drought relief, 172(b)

inappropriate, 12, 32

Lesotho, 253

more intensive, $2,7,12$

and tenure, traditional pattems of, 243

and transfer, 236

land users, limited investment in land

maintenance and improvement, 88-9

land-use pressure, reduction in, 94

land-use rights, 46

constrained by social and cultural

traditions, 43

land-users, perspective of, 87-9

landforms, structural change to aid soil conservation, 98

leasehold agreements, restricted by local custom, 241

leases

perpetual, 237

short-term, 241

least-cost solution, 139

leisure time lost, 125

Leontief-inverse coefficients, 211

Lesotho case study, 143, 250-85

fertilizer prices, $144-5$

pricing of workers, 125-6

soil conservation project, 74-5

valuing foreign exchange, 126

Lesotho currency, and the rand, 265-6

Leucaena, 35, 96

linear programming approach, limitations of, 204-6

linear programming models, 80 , 194-206

general properties and applications, 194-5

general specification of, 200

introducing an environmental externality, 200, 202

linear constraints, 195-8

most severe limitation, 205-6 the objective function, 198-200 problems with constraints, 204-5 salinity control, Murray River catchment, 121-2(b), 123

setting up, 195-8

livestock production, 27-30

livestock shade, 35

livestock watering, 261

M

maize

Lesotho, 264, 276-7

see also improved maize

management actions, simulated, 105

management, inappropriate, effects

of, $87-8,89$

management policies, conservative, 58

management strategies, adaptable,

102,103

managerial expertise, 47

Maphutseng, see Lesotho case study

marginal cost of control, 232-3

marginal land, 253

marginal utility

diminishing, law of, 64

of income, 132

market economies, 40, 43

financial analysis, 111

market failure, 65

market interest rate, 128

market measures, 230-31

market prices, 122, 125, 152, 262

os shadow prices, 143-5

market stabilization schemes, 186

maximum carrying capacity, 84, 85, 100-1

and optimal take-off strategies, 101-2

maximum stocking rate, 103

maximum sustained yield, 26

meat, processing and frozen storage, 104

mechanization, increase in and degradation, 12

mechanized farming, 58-9

medical and veterinary services,

results of improvement in, 37

Mesopotamia, salinity in, 6

methods and technologies, inadequate

field trials, 56

migration, animal, 24, 85

migration programmes, 44

mineworkers, migration of, Lesotho, 250

mining, 35-6

mining infrastructure, benefits of, 36

mixed farming, 84 
and agroecology, 98

moisture ponds, 92

monetary cost, illness or death, 152

monetary cost data, adjusted, Lesotho

case study economic analysis, 254-5

money, borrowing cost, 71-2

Monte Carlo simulation, 173, 175-6(b)

moral suasion, 228, 230, 231, 233

Morocco, prevention of sand dune

encroachment (CEA used), 138-9

motivation, by incentives, 227

mulches, use of to slow soil loss, 98

multiplier effects, Lesotho case study,

261-2

multipliers, application of to dryland

development planning, 214-15

mutual obligations, rules of, 243

$N$

national accounts system (SNA), 215

natural resources, "overlooked", 215-16

natural-resource accounting (NRA), approaches to, 216-19

natural-resource utilization and economic development, plans for, 45-6

natural-system responses, non-linear, 206

Near East, dry farming, 6

net present value (NPV), 73, 115, 132, $133,136,254$

"new ideals", 99, 100(b)

nomadic subsistence, 28

nomads, 7, 241

nominal prices, 128

non-agricultural activities, 193

non-agricultural industries, 206

non-compliance, sanctions for, 247

non-government organizations

(NGOs), 109-10

non-negativity constraints, 196, 197

non-priced goods, valuation of, 160-61

nursery costs, 255

nutrient loss, 94

O

objective function, 198-200, 203

objective probability distributions, $167-8(b)$

off-site benefits, $122,147-8$

off-site damage, $44,52,95$

off-site degradation, 27

off-site effects, 38, 89-90

off-site environmental effects, programmes require incentives, 57

off-site environmental impacts, 122, 165

in SBCA, 118

off-take, 101-2

on-site degradation, 27

on-site effects, 165

open-access common property

resources, 89-90

operating and maintenance costs

(O\&eM), annual, 113

opportunity-cost approach, estimates

costs to society of preservation, 160 optimism, 39

optimization, 111

option price, 185

option values, 185

options, trade-offs among, 194

output prices, Lesotho, 264-5

outputs, feasible region of, 197-8

over-exploitation, 44,88

overcultivation, $6,31-2$

overgrazing, $7,21,23,29-30,64,68,84$,

104,243

overstocking, 38, 88-9, 236

$\mathbf{P}$

palatable grasses and perennials,

replaced, 11, 29

Papua New Guinea, limited transfers

of some land use rights, 244

passive repair, see fallowing

pastoral communities, differing from

majority, 40

pastoralism, 104

subsistence, 84

pastoralists, wealth measured by

livestock owned, 40, 88-9

pasture deterioration, 25

pasture development projects, 142,

143, 144

paternalism, a fault, 56

pay-off matrices, $181-3,190$

peer pressure, 228

people

consultation with, 46, 235

and planning, 52

personal health benefits, 153

plans and policies

achieving better living standards, 193

difficulties in appropriate.

formulations, 193

plant communities, 23

plantation forestry, 34

plants 
adaption to dryland regions, 23 indigenous, 24

water extraction from the soil, 18

Poisson distribution, 168

policies

appropriate, design of, 49-59

to promote farmer-acceptance of rehabilitation schemes, 74

wrong, effects of, 235

policies, programmes and projects

best estimates, 164

desirable characteristics, 55-9

formulation of, $45-6$

implementation of, 47, 224-48

societal valuation of risk, 178-9

policy decisions, unielated, effects on dryland usage, 45

policy options

and alternatives, evaluation of, 47

means of analysis needed, 194

political failure, 65

population densities, related to carrying capacity, 84-5

population dislocation, 154-5, 247

population growth, 31, 46

population pressure, developing

countries, 94

population relocation, $159-60$

population resettlement costs, 154

population-resources ratio, changes in, 59-60

populations

human and animal, original

controls, 37

increased/increasing, 2, 7, 12, 38, 243

rural, affected by desertification, 8

Populus, 97

potential benefits, analysis of, 110-11

poverty, extreme, 138

power relationships, 59, 60

precipitation, 15, 18

preservation, monetary cost of, 156

preventive expenditures, $157-8$

price changes, relative, 128

price distortions, $65-6$

costs to society, 124

price effects, production-induced, calculation of, 149-50(b)

price trends, Lesotho, 262, 273

primary inputs, 211-12

primary productivity (by plants), 23-4

private behaviour, influences on, 228, 230-31 private costs os social benefits, 57

private decision-makers

and risk and uncertainty, 163

using result of risk analysis, 172

private freehold land, 237

private ownership, potential negative effects, 239-40

private property, 239-41

private-sector funding, 109

probability decisions, 170(b), 171

probability distributions, 168, 172

cumulative, 177,178

of net benefits, 173, 177

properties of, 174-7

stochastic variables, 167

problems, perceptions of by planners

and inhabitants, 56

producer's surplus, 67-8(b), 69

production, 25, 212

affected by natural events, 165

efficient, inhibited by restrictive land transfer rules, 243

production changes, effects of, 146-50

production-induced price effects, calculation of, 149-50(b)

productivity, 82, 84

arid lands, 18

improvement programmes, 92

increased, 99, 153

low in dryland ecosystems, 82

reduced, 90

of a renewable resource, 86

variable (drylands), 23

productivity changes

off-site, 145-6

on-site, 142-5

as partial measure of health benefits, 153

valuation of, $141-50$

programme, defined, 142

programmes, necessity for continuous monitoring and assessment, 49

programmes and projects

characteristics for success, 58

community-initiated, 56

management of, $246-8$

project costs, 118-19

project evaluations, important

application of risk analysis, 172-3

project failure, 224

project inputs and outputs, Lesotho, 262

projects

creating health problems, 152-3 
defined, 142

environmental costs and cost

analysis techniques, 156

ranking of, measures for, 135

social economic welfare

implications, 115, 117

wider effects of, 121-2

propensity to consume, 213

property and materials, valuation of damage to, 151-2

property rights, 75,238 (b)

property transfers, restrictions on, $\mathbf{2 4 0}$

Prosopis, 35

protection

appropriate level of, 53-5

costs os potential benefits, 52-3

public assistance, the case for, 44

public decision-makers

and community preferences, 178-9

and risk and uncertainty, 163

public lands, open to abuse, 69

public policies, risk and uncertainty in

benefit-cost assessments, 163

pulse production, 30

Q

quasi-option values, 185

$\mathbf{R}$

Rahad irrigation programme, Sudan, 56 rainfall, 15,19

from re-evaporated soil moisture, 21 long-term changes in amount and distribution, 25

partitioning of, 16, 26-7, 27

unreliable, 95

rainfall probabilities, 169,170

rainfall variability, sub-Saharan zones, 19-21(b)

rainfed crop management, 95

rainfed crop production, 30-33, 85, 95

traditional systems, 30-32

rainfed croplands, 8, 9

degradation increasing rapidly, 11-12

relationship, farmers and graziers, 28

temperate, problems decreasing, 12

rainy season, 30

ranching, 28-9

range condition, and stocking rates, 101

rangeland degradation, 101

rangeland developments, 50-51

rangeland management projects,

off-site productivity effects, 145-6

rangelands, 8, 11, 26 overgrazed, 91-2

reafforestation, community schemes, 96

recurrent costs, allocation of, Lesotho case study, 283

regulation and enforcement, 230

rehabilitation, $54,74,77$

costs, 52-53, 54(b)

relocation-cost method, measuring

environmental damage, 159

remedial action, economic issues in design of, 49-53

remote-sensing data, use of, 187

renewable resources, 75-6

rental payment, proportional share of crop revenue, 241

replacement costs, $158-60$

reservation wage, 125

reservoirs, 103

residual values, calculation of, Lesotho case study, 284, 285

resource allocation, alternative, equity implications of, 64

resource degradation, 65,95

fuelwood gathering, 30, 87-8(b), 89

increased, 89-90

regional scale, 44

resource depletion, a benefit in SNA, 215

resource management, 66,190

resource management systems, 75

resource user accounts, 217

resource user cost, 88 .

resource utilization, conservative approach needed, 185

resources, 47

access to restricted, 75

irreversible damage to, $76-8$

non-sustainable use of, 70

renewable and non-renewable, 75-6

scarce, efficient allocation of, 63

respiratory diseases, 152

restoration costs, and irreversibility, 185

risk, 78, 102, 168

assessing welfare implications of, 178 attitudes towards, 86-7, 177-8

importance of community attitudes,

178-9

overcoming the effects of, 186-7

problem of, Lesotho, 278

social valuation of, $178-80$

voluntary and involuntary, 180

risk analysis, 171-80, 182

applications of, 171-3

framework for, $173-4$ 
interpretations of results, 174-7 political problems, 180

risk assessment, 164,168

risk aversion/averters, 177-8, 179, 187

risk evaluation, 164

risk management, 86-7, 164, 168, 172

risk measurement, 168,170

risk neutral, 177-8

risk neutral probabilities, objective, 182

risk pooling, 187

risk spreading, 187

risk takers, $177-8$

risk and uncertainty, 78-9

defensive strategies to cope with,

186-91

definitions of, 167-70

handling of, 163-70

sources of in dryland

decision-making, 165-7

risk-benefit analysis, 168

risky discount rate, 181

river water, diversion of, 66

runoff, 16, 21, 32, 33

rural industries, 46

Russian steppes, 19

$\mathrm{S}$

safe minimum standard (SMS), 164-5,

190-91

safe stocking rate, 29

Sahel, 1

cash cropping declining, 32

desertification caused by human

activity, 25

sales only data, 213

sales revenue, 113

salinity, 122, 244

modelling the effects of, 202-4

salinization, $6,12,33,34,44,64$

Salix, 97

salvage value, capital inputs, 115

SBCA, see social benefit-cost analysis scarcity, 63

scenario construction, 164

scenarios, in computer simulation

modelling, 105

secondary benefits, 129

secondary impacts, 128-30

sectoral planning models, 206-15

security, lack of, with leasehold, 241

security of tenure, 239

sedimentation, 33, 52

seeding programmes, 92

semi-arid areas, 28 seasonal rainfall, 18

use of fallowing, 91

semi-arid tropics, defined, 8-9

sensitivity analysis, 164

Lesotho, summary of, 274-5

Serengeti Plains (Tanzania), increased primary production, 101

settlements in dryland regions, threats posed by, 36-7

shadow exchange rates, 126, 127(b)

shadow foreign exchange value, 127

shadow prices, 119, 122-8, 144

of agricultural inputs and labour, 262

guidelines to use of, 125

sheep, 101

shelterbelts, 35, 97

shifting cultivation, 5, 6

simulation models, traditional, 188

siting decisions, opportunity cost

approach, 155-6

skill levels, 125, 263

slash-and-burn techniques, 5

SNA, see national accounts system

social benefit-cost analysis (SBCA), 80, $117-32,142$

boundary of analysis, 142-3

and off-site productivity effects, 145

use of economic prices, 143

social benefits $50,52,57,111$

net, calculation of, 130-31

social cohesiveness, and customary tenures, 244

social costs, 124

social and cultural constraints, 224

social, cultural and institutional

factors, 59-60

social and cultural values, 46

social forestry, 34, 35

social management, 247

social prices, 142

social responsibility, user's sense of, 228

social welfare, $110,118,151$

soil conservation, 98-100, 147, 232-3

Lesotho case study, 74-5, 99-100

soil erosion, 32, 33, 44, 94, 98, 142

soil fertility, increased, 35

soil moisture, 32, 33

conservation of, 112

and plant growth, 16-19(b)

soil moisture store, 16,17

soil moisture-storage capacity, 33

soil nutrients, 97-8, 112

depletion of, 32 
soil root zone, water-holding capacity, 16 soil structure, breakdown of, 32

soil surface

exposure of, 29, 32-3

and partitioning of rainfall, 16

soil water storage

affecting inland rainfall, 21

winter-rainfall areas, 18

soils, 22, 26-7, 76

texture of, 16

wilting point of, 17

solar radiation, 21

sorghum, 254, 255-9, 264

South African Customs Union

(SACU), 126, 266, 283

sowing and reaping rationale, 239

springs, 22

stability, 82, 84

stabilization, through markets, 104

state enterprises, 242

state ownership, 242

stochastic conditions, handling of, 103-4

stock (non-renewable resources), 76

stocking levels, controlled, 240

stocking rates, 100, 101

controlled, 103-4

sub-humid tropics, and

desertification, 8

sub-Saharan zones, rainfall variability in, 19-21(b)

submarginal lands, dependence on, 236

subsidies, 124, 232-3

and taxes, 119

subsistence economy, analysis of potential benefits, 111

subsistence farming, 31, 43 expansion into marginal lands, 31

subsistence graziers, degrade land through short-term need, 38

subsistence grazing systems, traditional, in equilibrium with the environment, 37

subsistence-level systems, and drought, 104

subsoil, 22

Sudan, desertification, 11

Sudano-Sahelian region (Africa), 19, 187

summary tables, natural-resource accounting, 217-19

supplementary feed, 101

supply and demand, balancing of, 65-6

surface water resources, 21 sustainability, 58-9, 70, 75, 84

sustainable agriculture, conditions for, 97-8

sustainable development, 76

sustainable production, 47,101

sustainable use, 70

T

take-off rates, 100

targets, realistic, in CEA, 138

tariffs, 40-41

taxes, 232-3

as transfer payments, 130

technical expertise, lack of, 44

technical management, 246

technical methods, simple and labour intensive, 252

technology, 32, 138

and greater food production, 78

lack of familiarity an obstacle, 56-7

technology advances, and dryland degradation, 5

technology, new, 37, 59

tenure, 238, 242-4

tenure rights, pertaining to various entitlements, 238

Thailand

availability of credit and incomes, 240(b)

conservation farming, 118

on-site and off-site effects, 147-9(b)

threshold values, 164

time, effect of, 69-75

time horizons, 69-70, 73-4, 75, 94, 121

Lesotho case study, 268-9, 274

of people's own lives, 235-6

shorter for land users, 87

time perspective, short-term, 44

time preference, $71,72,88$

time streams, costs and benefits, 92-4

topography, 22

tourism, 36-7

trade barriers, 40-41

Lesotho, 266

training, Lesotho case study, 252, 270

trampling, and soil degradation, 30

transfer payments, SBCA, 118, 119

transhumance, 28,31

transpiration, 15, 16

transport and communications, 36-7

transportation costs, 126, 128

travel-cost technique, 160-61

treecrop plantations, 35

trees, for drylands, 96 
U

uncertainties

Lesotho case study, 271

unusual, 172-3

uncertainty, 78-9, 105, 168

and AEAM, 189

associated with irreversible damage

to resources, $183,185-6$

decision-making under conditions

of, $180-86$

regarding future conditions, 233

unemployment, 124

United Nations Conference on

Desertification 1977 (UNCOD)

assessment of status of arid areas, 7-8

Plan of Action to Combat

Desertification (PACD), 11

social and political inequalities

discussed, 40

United Nations Environment

Programme (UNEP), 1983 update,

desertification, 8

use rights, 68-9, 240-41

user-attractiveness, 56-7

users, constraints on, 57

V

variables, deterministic and stochastic, $165,167,173$

vegetation, $23-4,26,27$

particular, availability of, 100-101

vegetative cover, 27

Village Conservation Committees

W

(VCC), 253

W Australia, salinity control, Murray

River catchment, 121-2(b), 123,

$202-4$

wages, a production cost, 129

Wald's minimax rule, 183, 190

wasteland reclamation, India,

116-17(b)

water, 17

availability of, 84,85

pricing and rationing policies, 103

water conservation, 98, 99

water erosion, 32-3

water inputs and outputs, 16

water quality, improved, 261

water quantity and quality, 142, 146

water resources, 76

water savings, 112

water shortages and health problems,

152 water supply, a controllable input, 103 watering points, supply and location, 101

waterlogging, 12, 33, 34

weighting schemes, income

distribution, 131-2

wells, 22

"what if" scenarios, 188

wild grains, dietary importance, 6 willingness to accept compensation

(WTAC), 159-60

wind erosion, 32-3, 95

windbreaks, 35

winds, strong, 21

with-and-without-project analysis, 143

with-and-without-project scenarios

crop benefits, Lesotho case study, 255-9

woody shrubs and small trees,

unpalatable increase in, 29-30

World Bank, 71, 155

Y

yearly payments, calculation of, 113(b)

yield patterns, Lesotho case study, 272

yields

decreasing, 31

long-term, steady state, 87

lower, 25

sustained, 82, 85-6, 92

unreliable in Lesotho, 278 



\section{An Earthscan book}

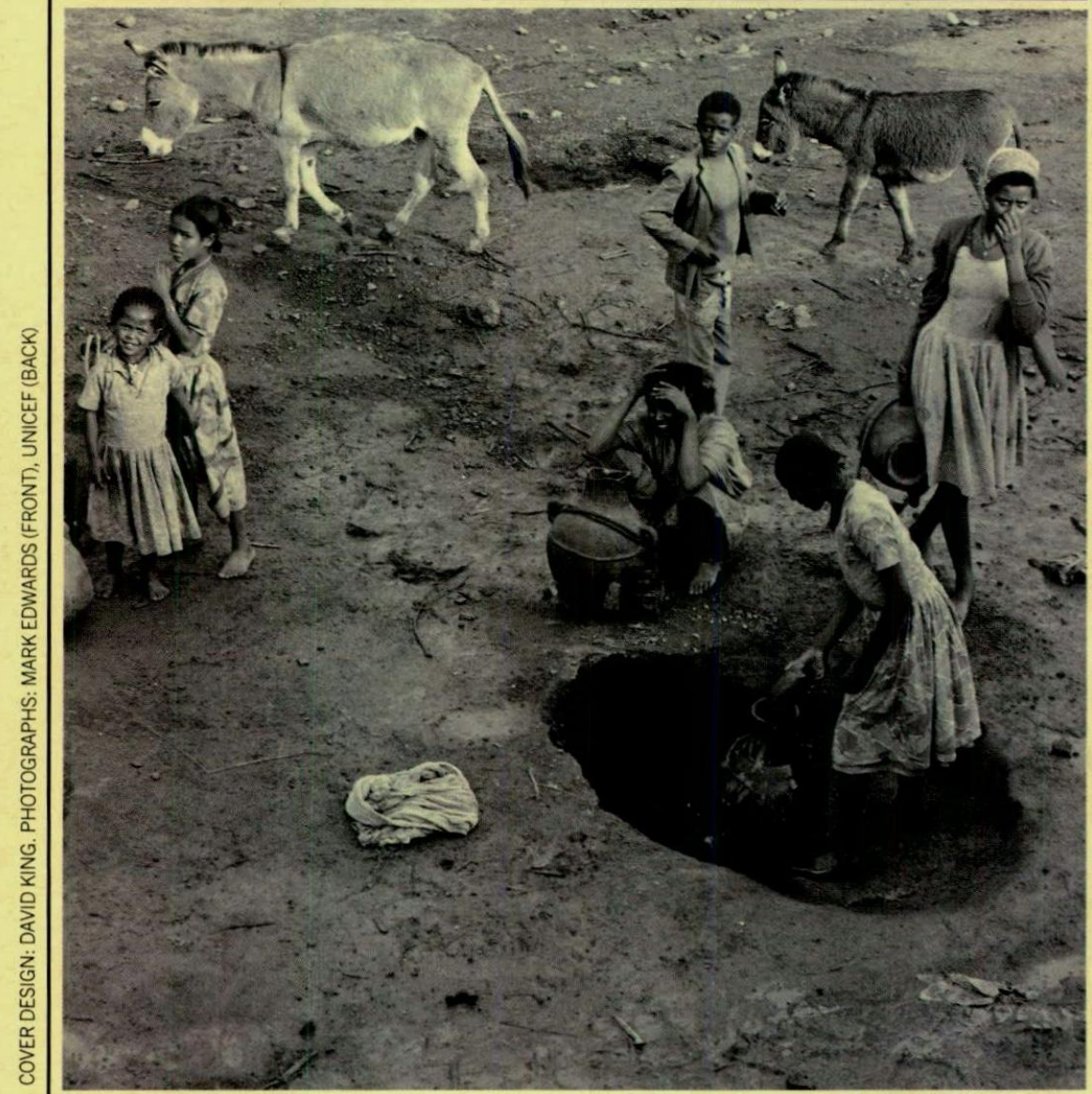

We have always had land in which the agricultural productivity is limited because there is not enough moisture. Systems of farming and burning often degrade dryland further until it is desert. Today, however, the problem is becoming much more serious. Over 20 per cent of the world's population lives in dryland areas, and unless action is taken drylands will increase dramatically.

This book focuses on the people who live and farm in the drylands, their use of land resources and the economic returns from their decisions.

In a clear and thorough economic appraisal, the authors show how it is still possible to arrest the problem. 